\title{
Developments of Advanced Cathodes and Stabilized Zinc Anodes for High-performance Aqueous Zinc-ion Batteries
}

\author{
Xiujuan Chen \\ West Virginia University, xc0001@mix.wvu.edu
}

Follow this and additional works at: https://researchrepository.wvu.edu/etd

Part of the Materials Science and Engineering Commons

\section{Recommended Citation}

Chen, Xiujuan, "Developments of Advanced Cathodes and Stabilized Zinc Anodes for High-performance Aqueous Zinc-ion Batteries" (2021). Graduate Theses, Dissertations, and Problem Reports. 10170. https://researchrepository.wvu.edu/etd/10170

This Dissertation is protected by copyright and/or related rights. It has been brought to you by the The Research Repository @ WVU with permission from the rights-holder(s). You are free to use this Dissertation in any way that is permitted by the copyright and related rights legislation that applies to your use. For other uses you must obtain permission from the rights-holder(s) directly, unless additional rights are indicated by a Creative Commons license in the record and/ or on the work itself. This Dissertation has been accepted for inclusion in WVU Graduate Theses, Dissertations, and Problem Reports collection by an authorized administrator of The Research Repository @ WVU.

For more information, please contact researchrepository@mail.wvu.edu. 


\title{
Developments of Advanced Cathodes and Stabilized Zinc Anodes for High-performance Aqueous Zinc-ion Batteries
}

\author{
Xiujuan Chen \\ Dissertation submitted to the \\ Benjamin M. Statler College of Engineering and Mineral Resources \\ at West Virginia University
}

in partial fulfillment of the requirements for the degree of

Doctor of Philosophy in

Material Science and Engineering

Xingbo Liu, Ph.D., Chair

Wei Li, Ph.D.

Xiaolin Li, Ph.D.

Terence Musho, Ph.D.

Konstantinos A. Sierros, Ph.D.

Wenyuan Li, Ph.D.

Department of Mechanical and Aerospace Engineering

\author{
Morgantown, West Virginia \\ 2021
}

Keywords: zinc ion batteries, manganese oxide, zinc anode, dendrite growth, electrochemical activation

Copyright 2021 Xiujuan Chen 


\section{ABSTRACT \\ Developments of Advanced Cathodes and Stabilized Zinc Anodes for High-performance Aqueous Zinc-ion Batteries}

Xiujuan Chen

Aqueous rechargeable zinc-ion batteries (ZIBs) have attracted considerable attention as one of the most promising energy storage systems for the grid-scale application owing to the natural merits of metallic Zn, including a high theoretical capacity, suitable redox potential, low cost, high safety, and eco-friendliness. However, the existing aqueous ZIBs are far from satisfying the requirements of practical applications. Significant challenges hindering the further development of ZIBs come from the low utilization and poor cycling stability of cathodes and limited reversibility of $\mathrm{Zn}$ anodes associated with dendrite growth, corrosion, and passivation. To date, enormous efforts have been devoted to developing high-performance cathode materials, reliable electrolytes, and stable $\mathrm{Zn}$ anodes to achieve ZIB with high energy and power densities and long cycle life. These progresses have been reviewed in this dissertation. Regarding the main issues of ZIBs, the dissertation covered both the cathode and anode to comprehensively improve the electrochemical performance of ZIBs. For the cathode, high-performance manganese oxide-based cathode materials have been developed by in-situ electrochemical activation of $\mathrm{MnS}$, and rational design of hierarchical core-shell $\mathrm{MnO}_{2} @$ carbon nanofiber structures. To further understand the underlying reasons for the enhanced electrochemical performance, the charge storage mechanisms of manganese oxide-based cathodes in ZIBs have been in-depth investigated. With respect to the $\mathrm{Zn}$ anode, a thin polyvinyl alcohol (PVA) coating layer on the $\mathrm{Zn}$ anode has enabled dendrite-free, long-life aqueous $\mathrm{Zn}$ batteries by effectively regulating the interfacial ion diffusion and inducing the homogeneous $\mathrm{Zn}$ nucleation and deposition of stacked plates with preferentially crystallographic orientation along $(002)_{\mathrm{Zn}}$ planes. This work is expected to provide facile and lowcost approaches for developing high-performance, cost-effective, and stable aqueous ZIBs and shed light on a new mechanistic understanding of manganese oxide-based cathodes. 


\section{Acknowledgements}

To begin with, I would like to express my heartiest gratitude to my supervisor, Prof. Xingbo Liu, for his constant support and kind guidance during my doctoral study. Prof. Xingbo Liu has been my supervisor since my master level study. Without his support and help, I would not have achieved so much. I would also like to take this opportunity to thank Dr. Wei Li for his tutoring during my Ph.D. study. His professional guidance in experimental design and paper writing greatly improved my research work. Both Prof. Liu and Dr. Li have provided very helpful advice and kind encouragement regarding my dissertation work.

I would like to thank Dr. Wenyuan Li, Dr. Konstantinos Sierros, Dr. Terence Musho for their time and constructive advice during my study. I would like to thank Dr. Xiaolin Li from Pacific Northwest National Lab (PNNL) for his kind help and valuable suggestions for my research paper. They have served as my committee members and offered great support.

I would like to thank Dr. Qiang Wang and Dr. Marcela Redigolo at the WVU shared facilities for helping with my sample characterization. Also, I would also like to thank Dr. Novruz Akhmedov from WVU department of chemistry for his kind assistance with NMR training and testing and Dr. Murugesan Velayutham and Dr. Valery V. Khramtsov from WVU school of medicine for their help in electron paramagnetic resonance measurements. I also want to thank Dr. David Reed, Dr. Yaobin Xu, Dr. Chongmin Wang and Dr. Vincent Sprenkle form PNNL and Dr. Frank Goodwin in International Zinc Association for their kind help and support for the dissertation work.

I would like to thank all my colleagues in Prof. Liu's group, including Dr. Shanshan Hu, Dr. Greg Collins, Dr. Liang Ma, Mr. Hanchen Tian, Mr. Lingfeng Zhou, Mr. Yi Wang, Ms. Bo Guan, Mr. Hector A. De Santiago, Mr. Artem Gavrilev, Ms. Angela M. Deibel, and Ms. Nhat Anh Thieu, and previous members include Dr. Zhipeng Zeng, Mr. Edwin Vega Hiraldo, Dr. Panpan Ren, Dr. Meng Yao, Dr. Nan Zhang, Dr, He Qi, Dr. Jianhua Yan for their kind help and support during my Ph.D. life.

Finally, I am grateful for having an understanding family. I would like to thank them all for being supportive during my study here. I also want to thank all the people who have helped me during my stay at West Virginia University. 


\section{Table of Contents}

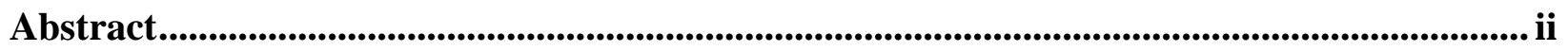

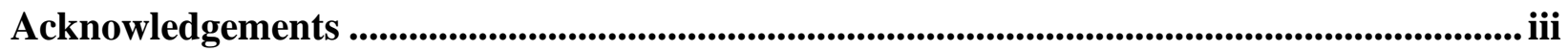

List of Figures.................................................................................................................................. vi

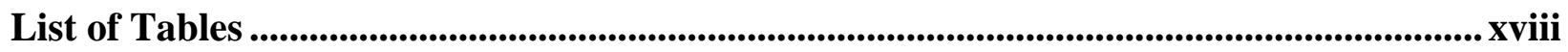

Chapter 1: Recent Progress in Aqueous Rechargeable ZIBs .................................................. 1

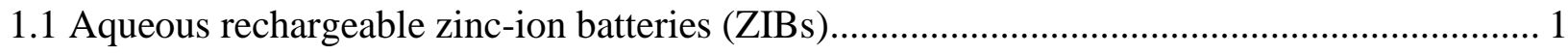

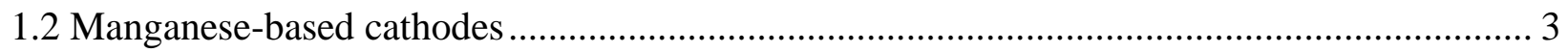

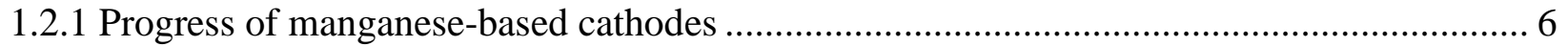

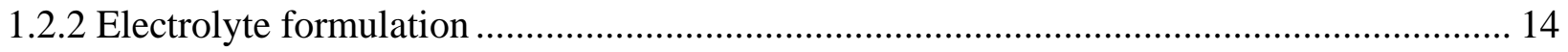

1.2.3 Charge storage mechanisms in manganese-based cathodes ........................................ 18

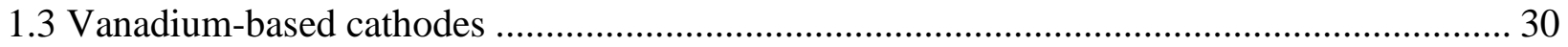

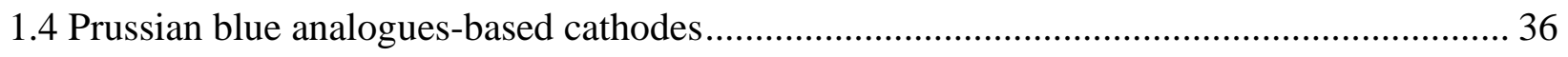

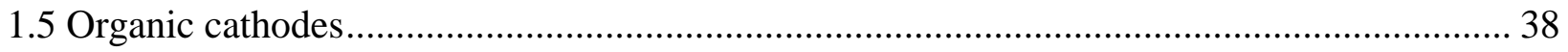

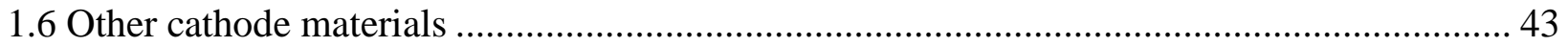

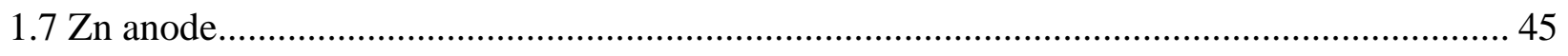

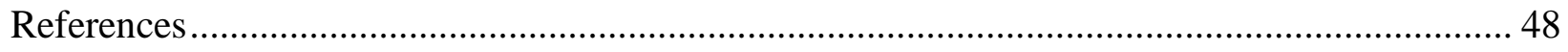

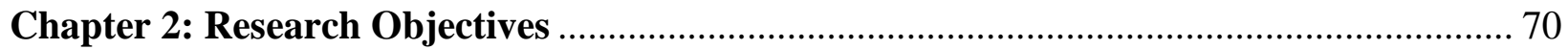

Chapter 3: Charging Activation and Desulfurization of MnS Unlock the Active Sites and Electrochemical Reactivity for Zn-ion Batteries...................................................................... 71

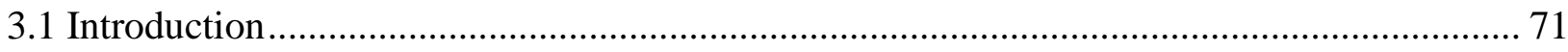

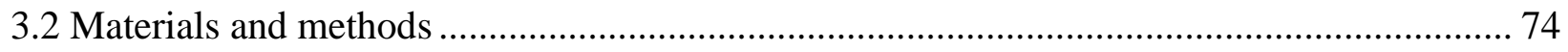

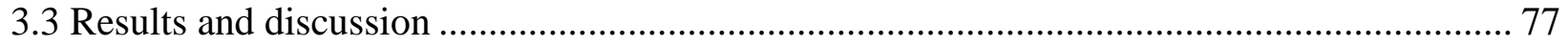

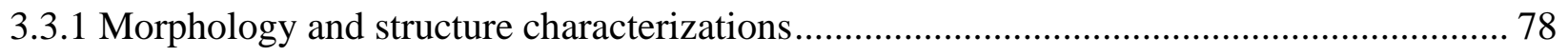

3.3.2 Electrochemical performance of MnS-EDO cathode ................................................ 79

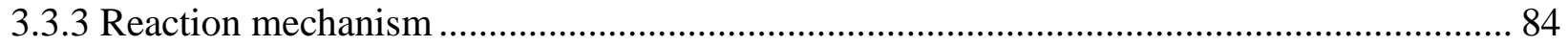

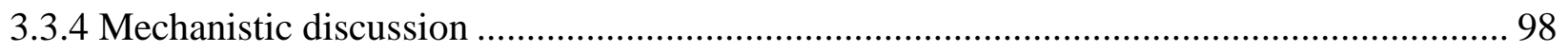

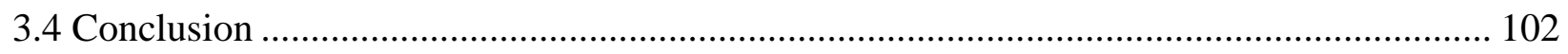

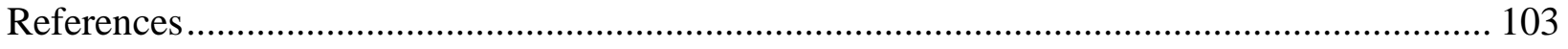


Chapter 4: Engineering Stable $\mathrm{Zn}-\mathrm{MnO}_{2}$ Batteries by Synergistic Stabilization Between the Carbon Nanofiber Core and Birnessite- $\mathrm{MnO}_{2}$ Nanosheets Shell........................................... 109

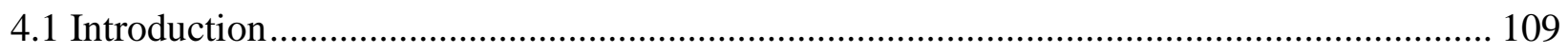

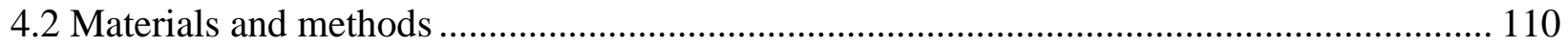

4.3 Morphology and structure characterizations of MOC ……………................................. 112

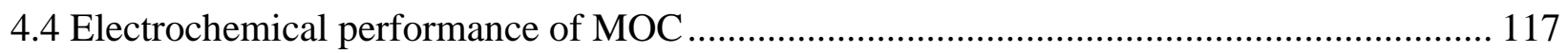

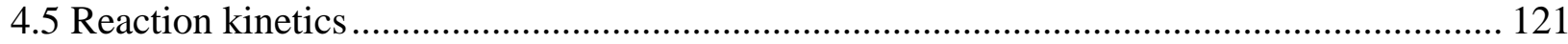

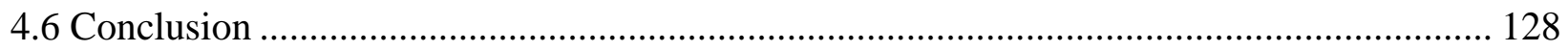

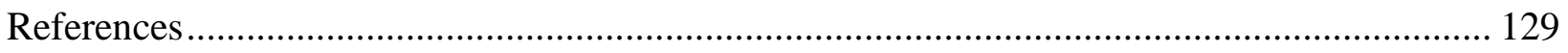

Chapter 5: Stabilizing Zn Plating/Stripping Electrochemistry by PVA Coating-induced Preferred Crystal Orientation ................................................................................................................. 135

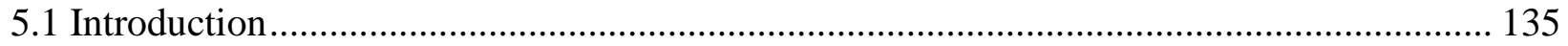

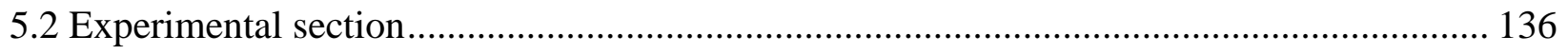

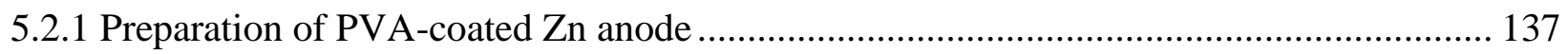

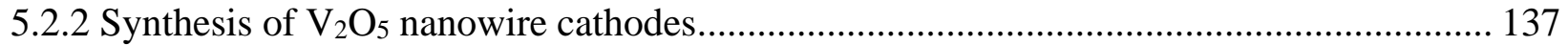

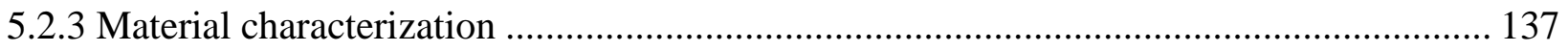

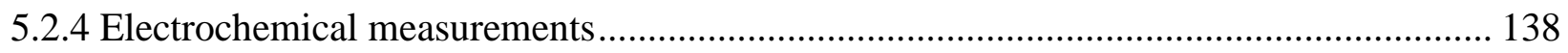

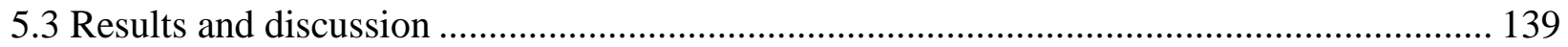

5.3.1 Electrochemical performance of symmetric batteries with PVA-coated Zn electrodes .... 139

5.3.2 Suppression of dendrite growth and side reactions by PVA coating induced preferential

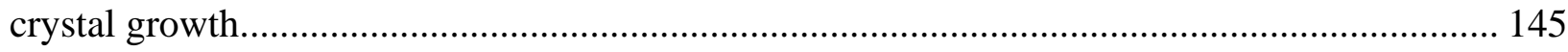

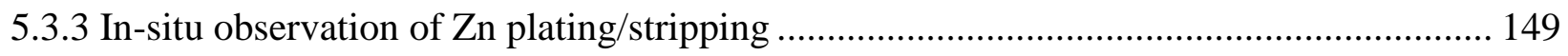

5.3.4 Zn Deposition mechanism of PVA@Zn electrodes......................................................... 151

5.3.5 Electrochemical performance of full batteries .................................................................. 156

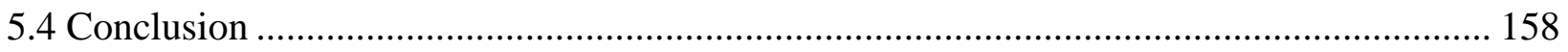

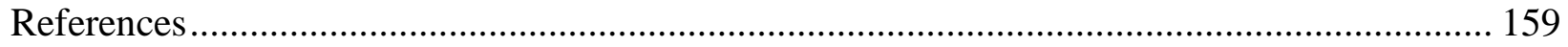

Chapter 6: Conclusions ........................................................................................................................... 164

Chapter 7: Challenges and Perspectives................................................................................................ 166 


\section{List of Figures}

Figure 1. 1 Comparison of typical monovalent/multivalent metal ion charge carriers in a) the theoretical capacity, ionic radius, and b) standard potential.[12] (Reproduced with permission. Copyright 2018, American Chemical Society) ….......................................................... 2 Figure 1. 2 a) Crystallographic structures of $\mathrm{MnO}_{2}$ polymorphs. [73] (Reproduced with permission. Copyright 2015, Springer Nature) b) The synthesis route for $\mathrm{MnO}_{\mathrm{x}} @ \mathrm{~N}-\mathrm{C}$ composite.[59] (Reproduced with permission. Copyright 2018, John Wiley \& Sons) c) Schematic illustration of the synthesis of $\mathrm{MnO}_{\mathrm{x}} @ \mathrm{Ti}_{3} \mathrm{C}_{2} \mathrm{~T}_{\mathrm{x}}$. [95] (Reproduced with permission. Copyright 2019, John Wiley \& Sons) d) Schematic diagram illustrating the 3D structure of CNTs conductive networks (Cs) and fabrication procedure of CMOP cathodes. e) SEM images of CMOP. f) High angle annular darkfield TEM mapping images of $\mathrm{C}, \mathrm{Mn}, \mathrm{O}$, and $\mathrm{S}$ elements in CMOP. [94] (Reproduced with permission. Copyright 2019, John Wiley \& Sons) ........................................................... 9

Figure 1. 3 a) Illustration of $\mathrm{H}^{+}$diffusion in perfect and oxygen-defect $\mathrm{K}_{0.8} \mathrm{Mn}_{8} \mathrm{O}_{16}$. b)

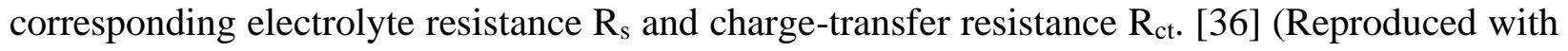
permission. Copyright 2019, John Wiley \& Sons) c) Schematic illustration of oxygen-deficient $\sigma$ $\mathrm{MnO}_{2}$ for $\mathrm{Zn}$ ion storage. [42] (Reproduced with permission. Copyright 2019, John Wiley \& Sons) d) The tunnel structure of pristine and Ti-doped $\alpha-\mathrm{MnO}_{2}$. [97] (Reproduced with permission. Copyright 2019, Elsevier) e) Proposed $\mathrm{Zn}^{2+}$ diffusion pathway in $\mathrm{ZnMn}_{2} \mathrm{O}_{4}$ (ZMO) spinel without and with Mn vacancies. f) GITT profiles and calculated $\mathrm{Zn}^{2+}$ diffusion coefficients of $\mathrm{ZMO} / \mathrm{C}$ and ZMO+C electrodes. [61] (Reproduced with permission. Copyright 2016, American Chemical Society) g) Calculated density of states (DOS) of partial MnO and partial MnO with Mn defect. h) Charge distribution and the structures after $\mathrm{Zn}^{2+}$ insert of $\mathrm{MnO}$ and $\mathrm{Mn}$-deficient $\mathrm{MnO}$. [99] (Reproduced with permission. Copyright 2020, Elsevier)..... 12

Figure 1.4 a) Schematic illustration of $\mathrm{Zn}^{2+}$ insertion/extraction in $\delta-\mathrm{MnO}_{2}$ framework with $\mathrm{Na}$ ion and water molecules pre-intercalation. b) Long-term cycling performance of $\mathrm{Zn}-\delta$-NMOH and $\mathrm{Zn}-\delta$-NMOH-500 batteries. [101] (Reproduced with permission. Copyright 2019, American Chemical Society) c) Primitive cell structures and partial density of states of pure $\mathrm{Mn}_{3} \mathrm{O}_{4}$ and Nidoped samples $\left(\mathrm{NiMn}_{5} \mathrm{O}_{8}, \mathrm{Ni}_{2} \mathrm{Mn}_{4} \mathrm{O}_{8}\right.$, and $\mathrm{Ni}_{3} \mathrm{Mn}_{3} \mathrm{O}_{8}$ ). [102] (Reproduced with permission. Copyright 2019, Royal Society of Chemistry) d) Schematic illustration of expanded intercalated structure of polyaniline (PANI)-intercalated $\mathrm{MnO}_{2}$ nanolayers. [44] (Reproduced with permission. 
Copyright 2018, Springer Nature) e) Zn-intercalated structures and relative energies of cw- $\mathrm{MnO}_{2}$. [89] (Reproduced with permission. Copyright 2019, Royal Society of Chemistry) 14

Figure 1.5 a) $\mathrm{CV}$ of $\mathrm{Zn}$ electrode in $1 \mathrm{M} \mathrm{Zn}\left(\mathrm{CF}_{3} \mathrm{SO}_{3}\right)_{2}$ and b) $1 \mathrm{M} \mathrm{ZnSO}_{4}$ electrolytes. c) Rate performance and long-term cyclability of $\mathrm{Zn} / \mathrm{Zn}$ symmetrical cells in $3 \mathrm{M} \mathrm{ZnSO}_{4}$ and $3 \mathrm{M}$ $\mathrm{Zn}\left(\mathrm{CF}_{3} \mathrm{SO}_{3}\right)_{2}$ electrolytes. [61] (Reproduced with permission. Copyright 2018, American Chemical Society) d) Cycling performance of $\mathrm{Zn}-\mathrm{MnO}_{2}$ batteries with electrolytes of 45 wt. $\%$ $\mathrm{KOH}($ at $0.32 \mathrm{C}), 3 \mathrm{M} \mathrm{ZnSO}_{4}, 3 \mathrm{M} \mathrm{Zn}\left(\mathrm{CF}_{3} \mathrm{SO}_{3}\right)_{2}$, and $3 \mathrm{M} \mathrm{Zn}\left(\mathrm{CF}_{3} \mathrm{SO}_{3}\right)_{2}$ with $0.1 \mathrm{M} \mathrm{Mn}\left(\mathrm{CF}_{3} \mathrm{SO}_{3}\right)_{2}$ additive at 0.65 C. [38] (Reproduced with permission. Copyright 2018, Springer Nature) e) Cycling performance of $\mathrm{MnO}_{2}$ in $2 \mathrm{M} \mathrm{ZnSO}_{4}$ electrolyte with/without $0.1 \mathrm{M} \mathrm{MnSO}_{4}$ additive. [29] (Reproduced with permission. Copyright 2016, Springer Nature) f) Cycling performances of $\delta$ $\mathrm{MnO}_{2}$ cathodes at $5 \mathrm{C}$ in $\left.1 \mathrm{M} \mathrm{Zn(TFSI}\right)_{2}$ with $0.1 \mathrm{~m} \mathrm{Mn}(\mathrm{TFSI})_{2}$ electrolyte and $1 \mathrm{M} \mathrm{ZnSO}_{4}$ with $0.1 \mathrm{M} \mathrm{MnSO}_{4}$ electrolyte. g) Long-term cycling performances of $\delta-\mathrm{MnO}_{2}$ cathodes at $20 \mathrm{C}$ in $1 \mathrm{M}$ $\mathrm{Zn}(\mathrm{TFSI})_{2}$ with $\left.0.1 \mathrm{~m} \mathrm{Mn(TFSI}\right)_{2}$ electrolyte. [108] (Reproduced with permission. Copyright 2019, John Wiley \& Sons). 16

Figure 1.6 a) Schematic illustration of $\mathrm{ZIB}$ with $\mathrm{Zn}$ anode, $\alpha-\mathrm{MnO}_{2}$ cathode and mild electrolyte. [25] (Reproduced with permission. Copyright 2020, John Wiley \& Sons) Schematic illustration of $\mathrm{Zn}^{2+}$ insertion mechanism in b) $\alpha-\mathrm{MnO}_{2}$ tunnel structure with tunnel size expansion, [26] (Reproduced with permission. Copyright 2015, Elsevier) c) $\alpha-\mathrm{MnO}_{2}$ with reversible transformation from $\alpha-\mathrm{MnO}_{2}$ to layered $\mathrm{Zn}$-birnessite, [27] (Reproduced with permission. Copyright 2014, Springer Nature) d) $\gamma-\mathrm{MnO}_{2}$ complex phase transformation. [39] (Reproduced with permission. Copyright 2015, American Chemical Society) e) in $\beta-\mathrm{MnO}_{2}$ with structural transformation from $\beta-\mathrm{MnO}_{2}$ to layered $\mathrm{Zn}$-buserite in the initial discharging step. [38] (Reproduced with permission. Copyright 2020, Springer Nature). 19

Figure 1.7 a) Schematic showing the discharge process of $\alpha-\mathrm{MnO}_{2} / \mathrm{Zn}$ cell in aqueous $\mathrm{ZnSO}_{4}$ electrolyte. b) In situ XRD patterns of $\alpha-\mathrm{MnO}_{2}$ cathode. c) electrolyte $\mathrm{pH}$ variations during the first discharge-charge process. d) $\mathrm{Zn}$ and $\mathrm{Mn}$ contents in the electrolyte at different discharge/charge states. [122] (Reproduced with permission. Copyright 2016, John Wiley \& Sons) e) XRD pattern of $\alpha-\mathrm{MnO}_{2}$ cathode discharged to $1 \mathrm{~V}$ in first cycle. $\mathrm{f}, \mathrm{g}$ ) STEM-EDS mappings in the $\alpha-\mathrm{MnO}_{2}$ electrode in the initial fully discharged state. [29] (Reproduced with permission. Copyright 2016, Springer Nature) Schematic illustration of reaction mechanism of h) $\mathrm{Zn} / \mathrm{MnO}_{2}$ battery in aqueous $\mathrm{ZnSO}_{4}$ electrolyte with $\mathrm{MnSO}_{4}$ additive. [123] (Reproduced with permission. 
Copyright 2016, Springer Nature) i) KMO cathode in aqueous ZIBs. [36] (Reproduced with permission. Copyright 2019, John Wiley \& Sons) 22

Figure 1.8 a) GITT profiles of $\mathrm{Zn} / \varepsilon-\mathrm{MnO}_{2}$ cell. b) Discharge curves of $\varepsilon-\mathrm{MnO}_{2}$ electrodes in the electrolyte with and without $\mathrm{ZnSO}_{4}$. c) Ex situ XRD patterns of $\varepsilon-\mathrm{MnO}_{2}$ electrodes at depth of discharge at 1.3 and 1.0 V, respectively. [47] (Reproduced with permission. Copyright 2018, American Chemical Society) d) Evolution of ex situ XRD patterns of cathode during the charge/discharge process. e) Schematic illustration of sequential insertion of $\mathrm{H}^{+}$and $\mathrm{Zn}^{2+}$. [44] (Reproduced with permission. Copyright 2018, Springer Nature) ......................................... 24 Figure 1. 9 a) Phase evolution of $\alpha-\mathrm{MnO}_{2}$ cathode during the first discharge process and b) the first charge process. [98] (Reproduced with permission. Copyright 2019, Springer Nature) c) Joint nondiffusion controlled $\mathrm{Zn}^{2+}$ intercalation and $\mathrm{H}^{+}$conversion reaction mechanism in $\delta-\mathrm{MnO}_{2}$. d) Charge-discharge curve $\delta-\mathrm{MnO}_{2}$ electrode in the second cycle at $0.2 \mathrm{C}$. e) Ex-situ XRD patterns of $\delta-\mathrm{MnO}_{2}$ electrodes at selected states in (d) [108] (Reproduced with permission. Copyright 2019, John Wiley \& Sons) f) Schematic illustration of the redox reactions and crystal structures of related compounds in the $\mathrm{Zn}$ /carbon black cells with aqueous $1 \mathrm{M} \mathrm{ZnSO}_{4}+0.2 \mathrm{M} \mathrm{MnSO}_{4}$ electrolyte. g) Gibbs free energy vs reaction coordinate showing the thermodynamic and kinetic properties of the redox reactions in $\mathrm{Zn} / \mathrm{MnO}_{2}$ cells with different rates. [127] (Reproduced with permission. Copyright 2018, American Chemical Society) ............................................................... 26

Figure 1. 10 a) Energy storage mechanism in $\mathrm{Zn} / \mathrm{MnO}_{2}$ battery. [120] (Reproduced with permission. Copyright 2020, Elsevier) b) Charge storage mechanism of the electrolytic $\mathrm{Zn}_{-} \mathrm{MnO}_{2}$ battery in $1 \mathrm{M} \mathrm{ZnSO}_{4}+1 \mathrm{M} \mathrm{MnSO}_{4}$ electrolyte with little $\mathrm{H}_{2} \mathrm{SO}_{4}$ additive. [48] (Reproduced with permission. Copyright 2019, John Wiley \& Sons) c) Electrochemical mechanism of the neutral zinc/manganese battery with $\mathrm{Mn}(\mathrm{Ac})_{2}$ electrolyte. [107] (Reproduced with permission. Copyright 2020, Royal Society of Chemistry) d) Schematic illustration of Zn-Mn HAB in the hybrid electrolytes during charge/discharge. [133] (Reproduced with permission. Copyright 2020, John Wiley \& Sons).

Figure 1. 11 a) Proposed crystal structures of pristine VOG, VOG after charging to $1.3 \mathrm{~V}$, and VOG after discharging to 0.2 V. [145] (Reproduced with permission. Copyright 2018, John Wiley \& Sons) b) Atomic structures of $\mathrm{NH}_{4} \mathrm{~V}_{4} \mathrm{O}_{10}, \mathrm{NH}_{4} \mathrm{~V}_{3} \mathrm{O}_{8}$, and $\left(\mathrm{NH}_{4}\right)_{2} \mathrm{~V}_{3} \mathrm{O}_{8}$. [149] (Reproduced with permission. Copyright 2019, Royal Society of Chemistry) c) GCD curves of $\mathrm{Co}_{0.247} \mathrm{~V}_{2} \mathrm{O}_{5} \cdot 0.944 \mathrm{H}_{2} \mathrm{O}$ cathode at various current densities. [158] (Reproduced with permission. 
Copyright 2019, John Wiley \& Sons) d) Crystal structure of $\mathrm{Na}_{3} \mathrm{~V}_{2}\left(\mathrm{PO}_{4}\right)_{3}$. [159] (Reproduced with permission. Copyright 2020, American Chemical Society) e) GCD curves of $\mathrm{Na}_{3} \mathrm{~V}_{2}\left(\mathrm{PO}_{4}\right)_{2} \mathrm{~F}_{3} @ \mathrm{C}$ cathode. [160] (Reproduced with permission. Copyright 2018, Elsevier) ............................... 32 Figure 1. 12 a) Scheme showing the intercalation of $\mathrm{H}_{2} \mathrm{O}$ molecules and the $\mathrm{Zn}^{2+}$ insertion/extraction process in $\mathrm{NH}_{4} \mathrm{~V}_{4} \mathrm{O}_{10}$ during cycling. [149] (Reproduced with permission. Copyright 2029, Royal Society of Chemistry) b) Schematic of displacement/intercalation mechanism in $\mathrm{Ag}_{0.4} \mathrm{~V}_{2} \mathrm{O}_{5}$ cathode. [164] (Reproduced with permission. Copyright 2019, Elsevier) c) Schematic representation for phase transition of $\mathrm{Na}_{3} \mathrm{~V}_{2}\left(\mathrm{PO}_{4}\right)_{3}$ cathode during cycling. [159] (Reproduced with permission. Copyright 2016, Elsevier) d) Schematic illustrations the NVP@rGO during charge/discharge. [166] (Reproduced with permission. Copyright 2019, Elsevier) 35

Figure 1. 13 a) Crystal structure of ZnHCF. [168] (Reproduced with permission. Copyright 2015,

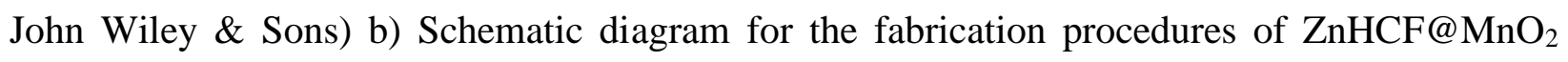
composite. c) Rate capability of $\mathrm{ZnHCF} @ \mathrm{MnO}_{2}$ cathode. [169] (Reproduced with permission. Copyright 2017, Royal Society of Chemistry) d) Schematic illustration of reversible $\mathrm{Zn}^{2+}$ intercalation/deintercalation in $\mathrm{CoFe}(\mathrm{CN})_{6}$ frameworks. e) Rate capability and f) cycling performance of $\mathrm{CoFe}(\mathrm{CN})_{6}$ cathode. [170] (Reproduced with permission. Copyright 2019, John Wiley \& Sons) 36

Figure 1. 14 a) Galvanostatic discharge/charge profiles of C4Q at $20 \mathrm{~mA} \mathrm{~g}^{-1}$. The upper $\mathrm{x}$ axis represents the uptake number of $\mathrm{Zn}$ ions. [173] (Reproduced with permission. Copyright 2018, American Association for the Advancement of Science.) b) Schematic illustration of the $\mathrm{H}_{2} \mathrm{O}$ assisted phase transition mechanism with the formation of $\mathrm{Zn}-\mathrm{p}$-chloranil (gray fibers) in the discharged state and p-chloranil (yellow rhombus) in the charged state. [175] (Reproduced with permission. Copyright 2018, American Chemical Society) c) Schematic of the fabrication procedure (top), photo (bottom left), and zinc ions storage process upon discharging and charging (bottom right) of PDA/CNTs. [176] (Reproduced with permission. Copyright 2019, Royal Society of Chemistry) d) Illustration of the synthetic route for PA-COF. e) Long-term cycling stability of PA-COF. [180] (Reproduced with permission. Copyright 2020, American Chemical Society) .. 40 Figure 1. 15 a) Diagrammatic representation of the interlayer interaction of $\mathrm{Zn}^{2+}$ with the adjacent layers of HqTp. b) The expected electrochemical redox reactions of the oxidized $\mathrm{Hq}$ and $\mathrm{Tp}$ components in HqTp during the discharging/charging process. [179] (Reproduced with permission. 
Copyright 2019, Royal Society of Chemistry) c) Structure of $\mathrm{Cu}_{3}(\mathrm{HHTP})_{2}$, which when viewed down the $\mathrm{c}$ axis, exhibits slipped-parallel stacking of 2D sheets with a honeycomb lattice. The cyan, red, and gray spheres represent $\mathrm{Cu}, \mathrm{O}$, and $\mathrm{C}$ atoms, respectively. d) The expected redox process in the coordination unit of $\mathrm{Cu}_{3}(\mathrm{HHTP})_{2}$. [182] (Reproduced with permission. Copyright 2019, Springer Nature) e) The proposed redox mechanism of PANI/carbon felts cathode in aqueous ZIBs. [192] (Reproduced with permission. Copyright 2018, John Wiley \& Sons) f) Simulation of binding energies with different numbers of $\mathrm{Zn}^{2+}$ in PA-COF cathode of zinc ion supercapatter. $\mathrm{g}$ ) Quantitative analysis of $\mathrm{Zn}^{2+}$ and $\mathrm{H}^{+}$contributions to capacity. [180] (Reproduced with permission. Copyright 2018, American Chemical Society).

Figure 1. 16 a) SEM image of $\mathrm{VS}_{2}$ nanosheets. b) GCD curves of $\mathrm{Zn} / / \mathrm{VS}_{2}$ battery. [196] (Reproduced with permission. Copyright 2017, John Wiley \& Sons) c) Rate performance of $\mathrm{VSe}_{2}$. d) GCD curves of $\mathrm{VSe}_{2}$ at $200 \mathrm{~mA} \mathrm{~g}^{-1}$ and the corresponding ex situ XRD patterns collected at different states. [197] (Reproduced with permission. Copyright 2020, Royal Society of Chemistry) e) Schematic illustration of strategies employed for $\mathrm{MoS}_{2}$. f) GCD profiles of $\mathrm{MoS}_{2}$ at $0.1 \mathrm{~A} \mathrm{~g}^{-1}$. [201] (Reproduced with permission. Copyright 2019, American Chemical Society) g) Calculated energy profiles of $\mathrm{Zn}$ diffusion in $2 \mathrm{H}$ and $1 \mathrm{~T}$ phase of $\mathrm{MoS}_{2}$. [202] (Reproduced with permission. Copyright 2020, Elsevier). 44

Figure 3. 1 Characterization results of pristine $\mathrm{MnS}$ and $\alpha-\mathrm{MnO}_{2}$. (a) XRD pattern, (b) $\mathrm{SEM}$, (c) TEM and (d) HRTEM images of MnS. Insets of (d) are the FFT pattern (top right) and magnified selected zone (bottom right). (e) HAADF-STEM image, elemental maps and $\mathrm{Mn} / \mathrm{S}$ atomic ratio and (f) Mn 3s XPS spectrum of MnS. (g) XRD, (h) SEM, (i) TEM, (j) HRTEM images and (k)

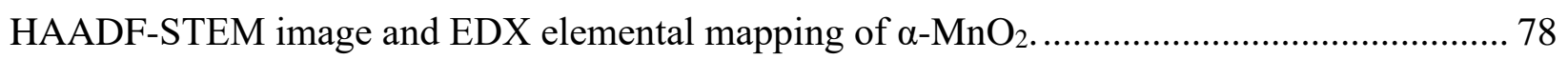
Figure 3. 2 The electrochemical performances of $\mathrm{ZIBs}$ consisting of $\mathrm{MnS}-\mathrm{EDO}$ or $\mathrm{MnO}_{2}$ cathodes, $\mathrm{Zn}$ anodes and aqueous electrolytes of $2 \mathrm{M} \mathrm{ZnSO}_{4}$ with $0.1 \mathrm{M} \mathrm{MnSO}_{4}$. (a) Cycling performance at $1 \mathrm{C}$ (i.e., $0.3 \mathrm{~A} \mathrm{~g}^{-1}$ ). (b) GCD profiles of stabilized MnS-EDO (derived from the third cycle of (c)) at different rates from 0.5 to 10 C. (c) Rate performance at various current densities. (d) The Ragone plots. The values of energy and power densities (based on the mass loading of active material in the cathode) for various developed $\mathrm{MnO}_{2}$ polymorphs, $\mathrm{Zn}_{0.25} \mathrm{~V}_{2} \mathrm{O}_{5}, \mathrm{VS}_{2}, \mathrm{LiV}_{2}\left(\mathrm{PO}_{4}\right)_{3}$ and $\mathrm{Zn}$ hexacyanoferrate cathodes for comparison in (d) are used as reported in the literature [1821, 25-29]. (e) and (f) Long-term cycling performance at 5 and $10 \mathrm{C}$ after pre-activation at $1 \mathrm{C}$ for 
the first ten cycles, respectively. (g) Initial discharge profile of a fresh $\mathrm{MnS}$ cathode at $1 \mathrm{C}$ without electrochemical activation treatment. (h) CV curves of (a) MnS-EDO and (i) $\alpha-\mathrm{MnO}_{2}$ cathodes at a scan rate of $0.1 \mathrm{mV} \mathrm{s}^{-1}$

Figure 3. 3 (a) SEM image and (b) EDX result with $\mathrm{Mn} / \mathrm{S}$ atomic ratio of commercial bulk MnS. (c) The GCD profiles and (d) cycling performance of commercial bulk $\mathrm{MnS}$ cathode in $2 \mathrm{M} \mathrm{ZnSO}_{4}$ and $0.1 \mathrm{M} \mathrm{MnSO}_{4}$ electrolyte at $1 \mathrm{C}$. (e) The GCD profiles of $\alpha-\mathrm{MnO}_{2}$ cathode at current rates from 0.5 to 10 C. (f) Capacity contributions of DP1 (2.0-1.3 V) and DP2 (1.3-0.8 V) for MnSEDO and $\alpha-\mathrm{MnO}_{2}$ cathodes at different rates. 83

Figure 3. 4 Electrochemically active surface area (ECSA) measurements. (a) and (b) CV curves of pristine $\mathrm{MnS}$ and $\alpha-\mathrm{MnO}_{2}$ electrodes, respectively, at various scan rates ranging from 5 to 25

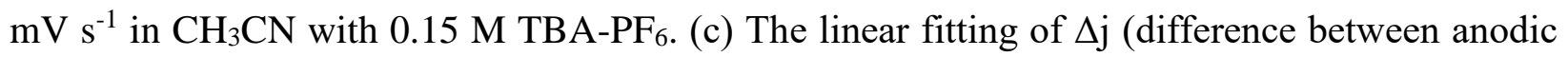
and cathodic current densities) versus scan rate for ECSA estimations of pristine $\mathrm{MnS}$ and $\alpha-\mathrm{MnO}_{2}$ electrodes. CV curves of $\mathrm{MnS}-\mathrm{EDO}$ and $\alpha-\mathrm{MnO}_{2}$ cathodes after $1^{\text {st }}(\mathrm{d}, \mathrm{f})$ and $15^{\text {th }}(\mathrm{e}, \mathrm{g})$ charge processes, respectively. (h) and (i) Quantitative comparison of double-layer capacitance and calculated ECSA results, respectively. 86

Figure 3. 5 (a) The linear fitting of $\Delta \mathrm{j}$ (difference between anodic and cathodic current densities) versus scan rate for ECSA estimations of fully charged $\mathrm{MnS}-\mathrm{EDO}$ and $\mathrm{MnO}_{2}$ electrodes after given GCD cycles. (b) CV curves of MnS-EDO cathode at various sweep rates in $2 \mathrm{M} \mathrm{ZnSO}_{4}$ and $0.1 \mathrm{M}$ $\mathrm{MnSO}_{4}$. (c) Plots of $\log$ (peak current) versus $\log$ (sweep rate) for MnS-EDO at various peaks derived from (b). (d) The percentage of capacitive contributions for MnS-EDO at various sweep rates. (e) Nyquist plots of MnS-EDO and $\mathrm{MnO}_{2}$ cathodes at the discharge depth of 1.40 and 1.25 V (inset). (f) DRT analysis of EIS spectra of $\mathrm{MnS}-\mathrm{EDO}$ and $\mathrm{MnO}_{2}$ cathodes. (g) Plots of Z' versus $\omega^{-0.5}$ of $\mathrm{MnS}-\mathrm{EDO}$ and $\mathrm{MnO}_{2}$ cathodes in the low frequency Warburg impedance region of (e). (h) The time-dependent current of fully charged MnS-EDO electrodes under potentiostatic discharge at 1.1, 1.2 and $1.4 \mathrm{~V}$. The inset of (h) shows the discharge profiles of MnS-EDO (filled magenta circle) and $\mathrm{MnO}_{2}$ (filled green triangle) cathodes discharging galvanostatically from 2.0 to $1.4 \mathrm{~V}$ at $1 \mathrm{C}$ and then kept at $1.4 \mathrm{~V}$ for potentiostatic discharge for $2 \mathrm{~h}$ (left and bottom scale axes) and the theoretical electrolyte $\mathrm{pH}$ changes of cells with MnS-EDO (empty pink circle) and $\mathrm{MnO}_{2}$ (empty olive triangle) cathodes as a function of discharge time assuming that only the proton insertion reaction accounts for their discharge capacities at $\geq 1.4 \mathrm{~V}$. (i) The galvanostatic charge curves of fully discharged MnS-EDO cathodes under different conditions at $1 \mathrm{C}$. 87 
Figure 3. 6 (a) $\mathrm{CV}$ curves of $\alpha-\mathrm{MnO}_{2}$ cathode at various scan rates. (b) Plots of $\log \mathrm{i}$ versus $\log \mathrm{V}$ at specific peak currents. (c) The percentage of capacitive contributions for $\alpha-\mathrm{MnO}_{2}$ cathode at various sweep rates. (d) Comparison of charge transfer resistance $\left(\mathrm{R}_{\mathrm{ct}}\right)$ values of MnS-EDO and $\alpha-\mathrm{MnO}_{2}$ cathodes. Inset is the equivalent circuit used for EIS data fitting. (e) XRD and SEM images of MnS-EDO cathode after galvanostatically discharging from 2.0 to $1.4 \mathrm{~V}$ at $1 \mathrm{C}$ and then kept at $1.4 \mathrm{~V}$ for potentiostatic discharge of $2 \mathrm{~h}$. (f) EDX results of the atomic ratios of $\mathrm{Zn} / \mathrm{Mn}$ for MnS-EDO cathodes at different charge/discharge states: fully charged state, end of DP1 and end of DP2.

Figure 3. 7 Structural and morphological evolution of MnS-EDO. (a) The GCD curve of the first two cycles with selected states where cathodes were ex situ characterized. (b) and (c) The corresponding XRD evolution and patterns (d) of MnS-EDO at different states indicated in (a). (eh) SEM images at selected cathode states of B, C, D and F, respectively. (i) SEM image of MnSEDO at fully discharge state with selected regions for EDX analysis. HAADF-STEM images and elemental maps for fully discharged MnS-EDO corresponding to site $1(\mathrm{j})$ and $2(\mathrm{k})$............... 92 Figure 3. 8 Investigation of cycling stability of the $\mathrm{MnS}-\mathrm{EDO}(\mathrm{a}-\mathrm{d})$ and $\alpha-\mathrm{MnO}_{2}(\mathrm{e}-\mathrm{h})$ cathodes in the potential window of 2.0 -1.3 V (DP1). For MnS-EDO cathode: (a) Cycling performance at 1 C. (b) GCD curves of $1^{\text {st }}, 2^{\text {nd }}, 10^{\text {th }}, 100^{\text {th }}$ and $600^{\text {th }}$ cycles. (c) XRD patterns at different cycle states. (d) SEM image at discharged state $(1.3 \mathrm{~V})$. Inset of (d) is the corresponding EDX result of the element atomic percentage. For $\alpha-\mathrm{MnO}_{2}$ cathode: (a) Cycling performance at $1 \mathrm{C}$. (b) XRD patterns at different cycle states. (c) SEM image of $\mathrm{MnO}_{2}$ at the $1^{\text {st }}$ fully charged state $(2.0 \mathrm{~V})$. (d) SEM image of the $\mathrm{MnO}_{2}$ cathode at the $613^{\text {th }}$ discharged state $(1.3 \mathrm{~V})$. Insets of (c) and (d) are the corresponding EDX results, respectively.

Figure 3. 9 SEM image of MnS-EDO cathode (a) at the selected state I of the second charge process (point I, marked in Figure 7a), (b) at the second fully charged state (point $\mathrm{J}$, marked in Figure 7a), and (c) at selected states K, L, M and N (1.4, 1.3, 1.2 and $0.8 \mathrm{~V}$, respectively) of the second discharge process, as shown in Figure 7a, 95

Figure 3. 10 XRD patterns of the synthesized (a) ZHS, (b) zinc buserite and (c) zinc hydroxide triflate samples under different drying conditions. XPS spectra of (d) Mn $2 p$ and (e) S 2p for pristine MnS and cycled MnS-EDO cathodes at fully charged states. (f) Mn 2p XPS spectra of MnS-EDO cathodes at fully charged and discharged states. 96 
Figure 3. 11 (a) SEM and (b) XRD phase evolution of MnS-EDO cathode at fully charged states upon long-term cycling. (c) SEM images and (d) XRD pattern of $\mathrm{MnO}_{2}$ cathode at fully charged state $(2.0 \mathrm{~V})$ after 2300 cycles at $10 \mathrm{C}$.

Figure 3. 12 (a) and (b) HRTEM images and (c) the superimposition image of HAADF-STEM and EDX mapping for MnS-EDO after $1^{\text {st }}$ charge with elemental maps of (d) Mn, (e) Zn and (f) O. EELS spectra of (g) Mn L 2,3 edges and (h) O K-edges for MnS-EDO after $1^{\text {st }}$ charge and pristine $\mathrm{MnO}_{2}$. (i) EPR spectra of fully charged $\mathrm{MnS}-\mathrm{EDO}$ and pristine $\mathrm{MnO}_{2}$

Figure 3. 13 (a) XRD pattern of MnS-EDO after $1^{\text {st }}$ electrochemical charge in $1 \mathrm{M} \mathrm{KOH}$ solution in comparison with that of MnS-EDO after $1^{\text {st }}$ electrochemical charge in the electrolyte of $2 \mathrm{M}$ $\mathrm{ZnSO}_{4}$ and $0.1 \mathrm{M} \mathrm{MnSO}_{4}$. (b) SEM image and (c) EDX spectrum of MnS-EDO after $1^{\text {st }}$ electrochemical charge in $1 \mathrm{M} \mathrm{KOH}$ solution. (d) Cycling performance of MnS-EDO charged in $1 \mathrm{M} \mathrm{KOH}$ for the ZIB at $1 \mathrm{C}$ consisting of the $\mathrm{Zn}$ anode, new cathode and electrolyte of $2 \mathrm{M} \mathrm{ZnSO}_{4}$ and $0.1 \mathrm{M} \mathrm{MnSO}_{4}$. (e) The image of HAADF-STEM and EDX mapping for MnS-EDO after 15 GCD cycles at the charge state with elemental maps of Mn, Zn and O. (f) EELS spectra of Mn L2,3 edges for MnS-EDO after 1 and 15 GCD cycles at the charge state in coin cells with $2 \mathrm{M} \mathrm{ZnSO}_{4}$ and $0.1 \mathrm{M} \mathrm{MnSO}_{4}$ electrolyte or after $1^{\text {st }}$ charge in $1 \mathrm{M} \mathrm{KOH}$ solution and pristine $\mathrm{MnO}_{2} \ldots 102$

Figure 4. 1 Schematic diagram of the synthetic procedure of MOC. 113

Figure 4. 2 XRD patterns (a) and Raman spectra (b) of as-prepared MOC composites and MO. 114

Figure 4. 3 SEM images of MOC-2 (a), MOC-5 (b), MOC-10 (c), MOC-15 (d) and TEM (e-g), $\operatorname{HRTEM}(\mathrm{h}, \mathrm{i})$ of MOC-5. SEM image of $(\mathrm{j}-\mathrm{k}) \delta-\mathrm{MnO}_{2}$ prepared via a hydrothermal method in the absence of CNFs, (l) pristine CNFs, and (m) the product prepared by the similar wet-chemical reaction without solid grinding pretreatment. 115

Figure 4. 4 XPS spectra of (a) survey spectrum (b) Mn 2p, (c) Mn 3s, (d) O 1s of MOC-5. (e) TG curves of the as-prepared MOC composites and MO. 117

Figure 4. 5 The electrochemical performances of ZIBs with MOC-5, MOC-15 and MO cathodes, $\mathrm{Zn}$ anodes and aqueous electrolyte of $2 \mathrm{M} \mathrm{ZnSO}_{4}$ with $0.1 \mathrm{M} \mathrm{MnSO}_{4}$. (a) CV of MOC-5 cathode at a scan rate of $0.1 \mathrm{mV} \mathrm{s}^{-1}$. (b) GCD profiles of MOC-5 cathode at different current densities from 200 to $3000 \mathrm{~mA} \mathrm{~g}^{-1}$. (c) Rate performance at various current densities. (d) Ragone plot of MOC-5 and other reported cathodes. Cycling performance of MOC-5, MOC-15 and MO at (e) $200 \mathrm{~mA} \mathrm{~g}^{-}$ 
1, (f) $1000 \mathrm{~mA} \mathrm{~g}^{-1}$ and (g) $3000 \mathrm{~mA} \mathrm{~g}^{-1}$. (h) Self-discharge curve and the following discharge profile (shown in the inset) of MOC-5 at $200 \mathrm{~mA} \mathrm{~g}^{-1}$. 118

Figure 4. 6 GCD curves of MOC-15 (a) and MO (b) cathodes at various current densities. (c) The capacities of MOC-5 contributed by DP1 and DP2 at various current densities. (d) Long-term selfdischarge curve of MOC-5 and the following discharge profile at $200 \mathrm{~mA} \mathrm{~g}^{-1}$ (shown in the inset).

Figure 4. 7 (a) $\mathrm{CV}$ curves of MOC-5 cathode at various sweep rates in $2 \mathrm{M} \mathrm{ZnSO}_{4}$ and $0.1 \mathrm{M}$ $\mathrm{MnSO}_{4}$. (b) Plots of $\log$ (peak current density) versus $\log$ (sweep rate) for MOC-5 cathode at various peaks derived from (a). (c) The percentages of capacitive and diffusion contributions for MOC cathode at various sweep rates. (d) GITT profile of MOC-5 cathode. (e) Calculated ion diffusion coefficients of MOC-5 and MO based on the GITT results. Nyquist plots of MOC-5 (f) and MO cathodes (g) at fully charged states after given cycles.

Figure 4.8 (a) $\mathrm{CV}$ curves of $\mathrm{MO}$ cathode at various sweep rates in $2 \mathrm{M} \mathrm{ZnSO}_{4}$ and $0.1 \mathrm{M} \mathrm{MnSO}_{4}$. (b) Plots of log (peak current density) versus log (sweep rate) for MO cathode at various peaks derived from (a). (c) The percentages of capacitive and diffusion contributions for MO cathode at various sweep rates. (d) GITT curve of MO cathode during the discharge process. (e-f) Nyquist plots of MOC-5 at fully charged state, fully discharged state, first discharge platform (1.4 V) and second discharge $(1.25 \mathrm{~V})$.

Figure 4. 9 Structural and morphological evolution of MOC-5. (a) The GCD curve of the first two cycles with selected states where cathodes were ex situ characterized. (b) The corresponding XRD evolution and patterns at different states indicated in (a). (c-h) SEM images collected at the selected states of A (c), B (d), C (e), D (f), E (g) and F (h). 126

Figure 4. 10 (a) EDX elemental mappings of MOC-5 at fully discharged state. SEM images and EDX results of MOC-5 at point $\mathrm{H}$ (the end of DP1) (b) and point J (the end of DP2) (c) in Figure 9a. 127

Figure 4. 11 (a) XRD and (b, c) SEM images of MOC-5 cathode at fully charged state after 750 cycles at a current density of $200 \mathrm{~mA} \mathrm{~g}^{-1}$. 128

Figure 5. 1 a) Cross-sectional SEM images and corresponding EDX elemental maps of $\mathrm{C}$ and $\mathrm{Zn}$ for a)PVA@Zn-1, b) PVA@Zn-2, c) PVA@Zn-3, and d)PVA@Zn-4. Top view of SEM images of e) bare Zn foil and f) PVA@Zn-1. 139 
Figure 5.2 a) X-ray diffraction (XRD) patterns of PVA powder, bare Zn foil and PVA@Zn foil. b) Photographs of the PVA@Zn electrode (pristine Zn foil coated by rhodamine B doped PVA solution for clarity) soaked into $2 \mathrm{M} \mathrm{Zn(OTf})_{2}$ electrolyte for different times. 140

Figure 5. 3 Electrochemical performances of Zn and PVA@Zn electrodes in symmetric cells. Galvanostatic cycling of Zn electrodes and PVA@Zn electrodes with different thickness of PVA layer at a) $0.25 \mathrm{~mA} \mathrm{~cm}^{-2}$ for $0.25 \mathrm{mAh} \mathrm{cm}^{-2}$ and b) $1 \mathrm{~mA} \mathrm{~cm}^{-2}$ for $1 \mathrm{mAh} \mathrm{cm}^{-2}$. c) Rate performance of Zn and PVA@Zn electrodes at different current densities under a fixed capacity of $1 \mathrm{mAh} \mathrm{cm}^{-}$ ${ }^{2}$. d) Cycling performance of Zn and PVA@Zn electrodes at $5 \mathrm{~mA} \mathrm{~cm}{ }^{-2}$ for $1 \mathrm{mAh} \mathrm{cm-2}$. Deep cycling stability of $\mathrm{Zn}$ and PVA@Zn electrodes at e) $0.25 \mathrm{~mA} \mathrm{~cm}{ }^{-2}$ with a plating/stripping capacity of $5 \mathrm{mAh} \mathrm{cm}^{-2}$, f) $5 \mathrm{~mA} \mathrm{~cm}{ }^{-2}$ for $5 \mathrm{mAh} \mathrm{cm}^{-2}$, g) $10 \mathrm{~mA} \mathrm{~cm}^{-2}$ for $5 \mathrm{mAh} \mathrm{cm}^{-2}$.

Figure 5. 4 Cycling performances of $\mathrm{Zn} / / \mathrm{Zn}$ symmetric cells in $2 \mathrm{M} \mathrm{Zn}\left(\mathrm{CF}_{3} \mathrm{SO}_{3}\right)_{2}$ electrolyte with $0.2,0.5$ and $1 \%$ PVA additive at a) $0.25 \mathrm{~mA} \mathrm{~cm}^{-2}$ for $0.25 \mathrm{mAh} \mathrm{cm}^{-2}$, and b) $1 \mathrm{~mA} \mathrm{~cm}^{-2}$ for $1 \mathrm{mAh}$ $\mathrm{cm}^{-2}$. c) Rate performance of symmetric cells of PVA@Zn electrodes in $2 \mathrm{M} \mathrm{Zn}\left(\mathrm{CF}_{3} \mathrm{SO}_{3}\right)_{2}$ electrolyte and bare $\mathrm{Zn}$ electrodes in $2 \mathrm{M} \mathrm{Zn}\left(\mathrm{CF}_{3} \mathrm{SO}_{3}\right)_{2}$ electrolyte with $1 \%$ PVA additive at current densities of $0.25-5 \mathrm{~mA} \mathrm{~cm}$ with a fixed capacity of $1 \mathrm{mAh} \mathrm{cm}^{-2}$. Cycling performances of bare $\mathrm{Zn}$ electrodes in $2 \mathrm{M} \mathrm{Zn}\left(\mathrm{CF}_{3} \mathrm{SO}_{3}\right)_{2}$ electrolyte with $1 \%$ PVA additive at d) $5 \mathrm{~mA} \mathrm{~cm}{ }^{-2}$ for $1 \mathrm{mAh}$ $\mathrm{cm}^{-2}$, e) $5 \mathrm{~mA} \mathrm{~cm}^{-2}$ for $5 \mathrm{mAh} \mathrm{cm}^{-2}$, and f) $10 \mathrm{~mA} \mathrm{~cm}^{-2}$ for $5 \mathrm{mAh} \mathrm{cm}^{-2}$.

Figure 5. 5 Post-mortem characterization of Zn and PVA@Zn electrodes in symmetric cells after galvanostatic cycling at $1 \mathrm{~mA} \mathrm{~cm}{ }^{-2}$ for $1 \mathrm{mAh} \mathrm{cm}^{-2}$. Thickness measurement symmetric cells for a) bare Zn and b) PVA@Zn-1 right after assembly, c) bare Zn after 100 h, d) PVA@Zn-1 after 100 h, and e) PVA@Zn-1 after 1080 h. f) Corresponding XRD patterns of cycled Zn and PVA@Zn-1 electrodes at different plating and stripping states. 146

Figure 5. 6 Post-mortem characterization of Zn electrodes in symmetric cells in $2 \mathrm{M} Z \mathrm{Zn}(\mathrm{OTf})_{2}$ electrolyte with $1 \%$ PVA additive after galvanostatic cycling at $1 \mathrm{~mA} \mathrm{~cm}^{-2}$ for $1 \mathrm{mAh} \mathrm{cm}^{-2}$. Volume expansion measurement of the $\mathrm{Zn}$ symmetric cells in $2 \mathrm{M} \mathrm{Zn}(\mathrm{OTf})_{2}$ electrolyte with $1 \%$ PVA cycled after a) $100 \mathrm{~h}$ and b) $1120 \mathrm{~h}$. c) XRD patterns of cycled Zn electrodes in symmetric

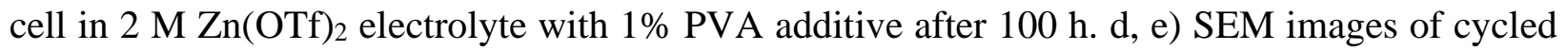
$\mathrm{Zn}$ electrode in $2 \mathrm{M} \mathrm{Zn}(\mathrm{OTf})_{2}$ electrolyte with $1 \%$ PVA.

Figure 5. 7 Post-mortem morphology characterization of Zn and PVA@Zn electrodes in symmetric cells after galvanostatic cycling at $1 \mathrm{~mA} \mathrm{~cm}^{-2}$ for $1 \mathrm{mAh} \mathrm{cm}{ }^{-2}$. Digital images of the separator and electrode disassembled from the symmetric cells for a) bare Zn and b) PVA@Zn 
cycled after 100 h. SEM images of c, d) Zn and e-i) PVA@Zn electrodes after 100 h. g) and h) High-magnification SEM images at the marked area in f). i) SEM image of PVA@Zn electrode after $100 \mathrm{~h}$ and corresponding EDX maps of $\mathrm{Zn}$ and $\mathrm{C}$ elements. 148

Figure 5.8 SEM images of PVA@Zn electrode after long-term cycling at $1 \mathrm{~mA} \mathrm{~cm} \mathrm{~cm}^{-2}$ for $1 \mathrm{mAh}$ $\mathrm{cm}^{-2}$. Inset in (b) is the EDX results at different sites.

Figure 5. 9 a) Photograph of a home-made $\mathrm{Zn} / / \mathrm{Zn}$ transparent cell. b) Image of real-time monitoring of $\mathrm{Zn}$ plating/stripping behavior of $\mathrm{Zn}$ foil in a transparent symmetric cell using an optical microscopy system......

Figure 5. 10 In situ optical microscope observation of $\mathrm{Zn}$ plating/stripping processes for a) $\mathrm{Zn}$ electrode and b) PVA@Zn electrode in symmetric transparent cells in $2 \mathrm{M} \mathrm{Zn}\left(\mathrm{CF}_{3} \mathrm{SO}_{3}\right)_{2}$ electrolytes, and c) $\mathrm{Zn}$ electrode in symmetric transparent cell in $2 \mathrm{M} \mathrm{Zn}\left(\mathrm{CF}_{3} \mathrm{SO}_{3}\right)_{2}$ electrolyte with PVA additive at $2 \mathrm{~mA} \mathrm{~cm}^{-2}$ for $20 \mathrm{~min}$. 150

Figure 5.11 CEs and corresponding voltage profiles of the $\mathrm{Zn} / / \mathrm{Cu}$ and $\mathrm{Zn} / / \mathrm{PVA} @ \mathrm{Cu}$ cells at a, c) $5 \mathrm{~mA} \mathrm{~cm}$ for $1 \mathrm{mAh} \mathrm{cm}^{-2}, \mathrm{~b}, \mathrm{~d}$ ). e) $0.25 \mathrm{~mA} \mathrm{~cm}^{-2}$ for $0.25 \mathrm{mAh} \mathrm{cm}^{-2}$, respectively. 152 Figure 5. 12 Digital images of a) Zn//Cu and b) Zn//PVA@ Cu cells after 1000 cycles at $5 \mathrm{~mA} \mathrm{~cm}^{-}$ 2 for $1 \mathrm{mAh} \mathrm{cm}^{-2}$ and their volume expansion measurements. Digital images of $\mathrm{Cu}$ electrodes, separators and $\mathrm{Zn}$ electrodes disassembled from the c, d, e) Zn//Cu and f, g, h) Zn//PVA@ @ $\mathrm{Cu}$ cells after 1000 cycles. 152

Figure 5. 13 Linear polarization curves of the bare $\mathrm{Zn}$ electrode in $2 \mathrm{M} \mathrm{Zn}\left(\mathrm{CF}_{3} \mathrm{SO}_{3}\right)_{2}$ electrolyte with and without PVA additive, and PVA@Zn electrodes in $2 \mathrm{M} \mathrm{Zn}\left(\mathrm{CF}_{3} \mathrm{SO}_{3}\right)_{2}$ electrolyte at a scan rate of $0.2 \mathrm{mV} \mathrm{s}^{-1}$. 153

Figure 5. $14{ }^{1} \mathrm{H}$ NMR spectra of $2 \mathrm{M} \mathrm{Zn}(\mathrm{OTf})_{2}, 1.0 \% \mathrm{PVA}, 2 \mathrm{M} \mathrm{Zn}(\mathrm{OTf})_{2}$ with $0.2 \%$ PVA, $0.5 \%$ PVA, and $1 \%$ PVA: 154

Figure 5. 15 Schematic illustration of the Zn deposition processes for a) PVA @Zn and b) bare Zn. 156

Figure 5. 16 a) XRD pattern and b) SEM image of synthesized $\mathrm{V}_{2} \mathrm{O}_{5}$ nanowires. c) CV curves of $\mathrm{Zn} / / \mathrm{V}_{2} \mathrm{O}_{5}$ and PVA@ $\mathrm{Zn} / / \mathrm{V}_{2} \mathrm{O}_{5}$ cells at $0.1 \mathrm{mV} \mathrm{s}^{-1}$. d) Voltage profiles of PVA@ $\mathrm{Zn} / / \mathrm{V}_{2} \mathrm{O}_{5}$ cell at different current densities. e) Rate capability and f) cycling performance of $\mathrm{Zn} / / \mathrm{V}_{2} \mathrm{O}_{5}$ and PVA@ $@ \mathrm{Zn} / / \mathrm{V}_{2} \mathrm{O}_{5}$ cells in $2 \mathrm{M} \mathrm{Zn}(\mathrm{OTf})_{2}$ electrolyte and $\mathrm{Zn} / / \mathrm{V}_{2} \mathrm{O}_{5}$ cell in $2 \mathrm{M} \mathrm{Zn}(\mathrm{OTf})_{2}$ electrolyte with $1 \%$ PVA cells at $3000 \mathrm{~mA} \mathrm{~g}^{-1}$. 157 
Figure 5. 17 Digital images of anodes and separators disassembled from the full cells after 500 cycles at $3 \mathrm{~A} \mathrm{~g}^{-1}$. a) $\mathrm{Zn} / / \mathrm{V}_{2} \mathrm{O}_{5}$ cell in $2 \mathrm{M} \mathrm{Zn}\left(\mathrm{CF}_{3} \mathrm{SO}_{3}\right)_{2}$ electrolyte. b) $\mathrm{Zn} / / \mathrm{V}_{2} \mathrm{O}_{5}$ cell in $2 \mathrm{M}$ $\mathrm{Zn}\left(\mathrm{CF}_{3} \mathrm{SO}_{3}\right)_{2}$ electrolyte with $1 \%$ PVA, c) PVA@ $\mathrm{Zn} / / \mathrm{V}_{2} \mathrm{O}_{5}$ cell in $2 \mathrm{M} \mathrm{Zn}\left(\mathrm{CF}_{3} \mathrm{SO}_{3}\right)_{2}$ electrolyte. d) Corresponding XRD patterns of the anodes from the cycled full cells. The full cells were stopped at discharged state, in which the anodes were maintained at the stripping state. SEM images of e) Zn and f)PVA@Zn anodes from the cycled full cells. 158

Figure 6. 1 Schematic summary of the dissertation work that covers the study on both the anode and the cathode of aqueous rechargeable ZIBs 164 


\section{List of Tables}

Table 1. 1 Comparison of the electrochemical performance of reported manganese-based cathodes for ZIBs with mildly acidic or near neutral electrolytes. ................................................... 4

Table 3. 1 The Warburg factor $\sigma$ values for $\mathrm{MnS}-\mathrm{EDO}$ and $\alpha-\mathrm{MnO}_{2}$ cathodes based on EIS results.

Table 3. 2 Theoretical calculations assuming that only a pure proton intercalation accounts for the observed discharge capacity at DP1.

Table 3. 3 Comparison of EELS spectra of $\mathrm{Mn} \mathrm{L}_{2,3}$ edges for MnS-EDO after $1^{\text {st }}$ charge and pristine $\mathrm{MnO}_{2}$. 100

Table 5. 1 Comparison of typical parameters and cycling performance of PVA@Zn symmetric cells in this work with those of reported $\mathrm{Zn}$ electrodes in $\mathrm{Zn}(\mathrm{OTf})_{2}$-based electrolytes. 142 


\section{Chapter 1: Recent Progress in Aqueous Rechargeable ZIBs}

There is continuously growing demand for efficient energy storage devices to ensure the reliability and resiliency of electrical grids with wide integration of intermittent renewable energy sources and to power electronics and electric vehicles. Hence, rechargeable batteries have attracted intensive research interest over the past decades.[1,2] During the past several decades, Lithiumion batteries (LIBs) have rapidly expanded in the secondary battery application from the portable electronic device to automotive vehicles due to their high energy density. However, the limited lithium resources, high cost, safety issues as well as potential environmental issues strongly block the further development of LIBs.[3] These intrinsic limitations have urged the investigation into the so-called "beyond Li-ion" energy storage system alternatives based on greener electrode materials and safer electrolyte.[4]

Water-based electrolyte has attracted considerable research interest, due to, the its safety, lowcost, easy processing, as well as the high ionic conductivity (up to $1000 \mathrm{mS} \mathrm{cm}^{-1}$ for aqueous electrolyte) compared with organic electrolyte (1-10 $\mathrm{mS} \mathrm{cm}^{-1}$ for non-aqueous electrolytes).[5-7]. Moreover, following up to the perspective of greener electrode materials, which focus on both power, energy densities and the lifetime, safety as well as cost, the aqueous rechargeable batteries relying on charge carrier of multivalent cations, such as $\mathrm{Al}^{3+}, \mathrm{Mg}^{2+}, \mathrm{Ca}^{2+}, \mathrm{Zn}^{2+}, \mathrm{Ni}^{2+}$, etc., become possible pathways to achieve the goal because of materials abundance, high safety and environmental friendliness. [4,8]

\subsection{Aqueous rechargeable zinc-ion batteries (ZIBs)}

For large-scale applications and widespread deployment, it is highly desirable for rechargeable batteries of low cost, high safety, high energy densities and rate capability, long cycle life and environmentally benign manufacturing processes. Among various multivalent metal-ion systems, aqueous rechargeable zinc-ion batteries (ZIBs) have attracted considerable attention due to the use of $\mathrm{Zn}$ anodes with a high theoretical capacity $\left(820 \mathrm{~mA} \mathrm{~h} \mathrm{~g}^{-1}\right)$, suitable redox potential $\left(\mathrm{Zn}^{2+} / \mathrm{Zn}\right.$, $0.76 \mathrm{~V}$ vs. standard hydrogen electrode) (Figure 1.1), large abundance, scalable and mature recyclability, low cost and toxicity, and good compatibility with non-flammable aqueous electrolytes.[9-13] The initial investigation of Zn anode in a battery system can be back to 1799, 
after that, it has been used in various primary and secondary Zn-Based batteries. Among them, the primary alkaline $\mathrm{Zn}-\mathrm{MnO}_{2}$ batteries have been widely used to power most handheld devices.[14] However, the advancement of rechargeable aqueous $\mathrm{Zn}-\mathrm{MnO}_{2}$ batteries were hindered by their inferior cycling properties in alkaline electrolyte owing to the formation of irreversible byproducts at neither the cathode $\left(\mathrm{Mn}(\mathrm{OH})_{2}\right.$, etc. $)$ nor anode $\left(\mathrm{ZnO}, \mathrm{Zn}(\mathrm{OH})_{2}\right.$, etc. $)[15,16]$

Since the 1980s, Yamamoto and Shoji et al. have devoted to improving the reachability of aqueous $\mathrm{Zn}-\mathrm{MnO}_{2}$ batteries by replacing alkaline electrolytes with mildly acidic or near neutral zinc sulfate electrolyte. Meanwhile, research efforts focused on screening diverse manganese oxides in aims to develop suitable cathode material. [17-19] These pioneering works provide a new way to construct the aqueous rechargeable ZIBs with excellent cyclability. The conventional configuration of aqueous ZIBs involves following main components: a zinc metal anode, a mildly acidic aqueous electrolyte, a separator, and a suitable (in)organic cathode. The electrochemical principle of ZIBs can be simply presented as follows: $\mathrm{Zn}^{2+}$ ingress/egress takes place at the cathode accompanied with the striping/plating of the $\mathrm{Zn}$ anode, while the electrolyte supports the ions transporting between anode and cathode.
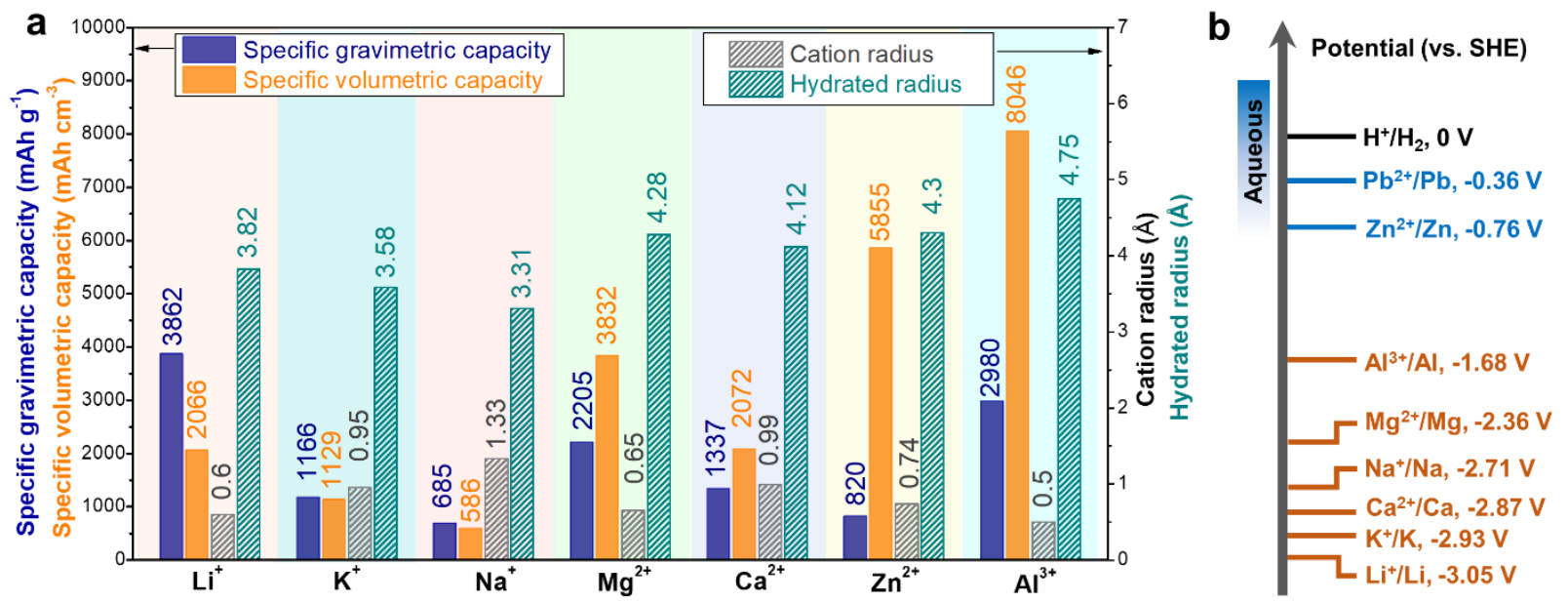

Figure 1. 1 Comparison of typical monovalent/multivalent metal ion charge carriers in a) the theoretical capacity, ionic radius, and b) standard potential.[12] (Reproduced with permission. Copyright 2018, American Chemical Society)

Although the electrochemical performance of rechargeable aqueous ZIBs has been significantly improved, it is still far behind the requirements for ever-advancing energy storage technology. One of the main challenges for viable high-energy and stable aqueous ZIBs is the limitation of suitable 
cathode materials. Suitable cathode materials not only require the reversible charge storage reaction with high operating voltage and capacity but also enable holding superior structural stability during repeated discharge/charge cycles. notably, although the existing host materials developed for mono- and multivalent metal ions storage on the basis of intercalation chemistry can be considered as candidates, these cathode materials may not be suitable for accommodating $\mathrm{Zn}^{2+}$ ions due to the strong electrostatic interaction between $\mathrm{Zn}^{2+}$ and the host lattice of cathodes and intrinsic sluggish kinetics which leads to poor rate capability and cycle stability.[20] Therefore, it is highly desirable to explore the potential cathode materials and study their associated reaction mechanism.

To data, various cathode materials been reported as ZIBs cathode materials, which can be categorized as: (1) manganese-based compounds, (2) vanadium-based compounds, (3) Prussian blue analogues (PBAs), (4) organic materials, and (5) other transition metal-based compounds (Ni, Co, etc.). The basic construction of the reported aqueous ZIBs, including cathode active material, electrolyte, and voltage window, as well as their electrochemical properties, such as specific discharge capacity, rate and cycling performance are summarized. Herein. a relatively comprehensive discussion of the existing cathode materials for aqueous ZIBs will be encompassed, especially the manganese-based cathodes. Special attention will be focused on the relationship between the phase/structure of cathode material and their electrochemical performance. Besides, a targeted in-depth study on the energy storage mechanisms in corresponding cathode material will be discussed. Finally, the challenges and the strategies for performance improvement of these cathode materials are also reviewed.

\subsection{Manganese-based cathodes}

Given the outstanding merits such as low-cost, abundant availability, low toxicity, environmental friendliness, multivalent phases, and structural versatility, manganese oxides have been extensively used in various energy storage systems, including alkaline $\mathrm{Zn}-\mathrm{MnO}_{2}$ batteries,[21,22] lithium-ion batteries, [23] and supercapacitors.[24] As the cathodes for ZIBs with mild electrolytes, manganese oxides show a moderate operating voltage and high theoretical capacities of 308 and $617 \mathrm{mAh} \mathrm{g}^{-1}$ for one and two-electron redox reactions, respectively. Intensive efforts have been devoted to exploring promising manganese oxides-based cathode material for 
aqueous rechargeable ZIBs, investigating their electrochemical reaction mechanisms and developing various novel strategies to enhance electrochemical (Table 1.1). These manganese oxides-based cathode materials mainly include various $\mathrm{MnO}_{2}$ polymorphs, $\mathrm{Mn}$ (II, III) oxides $\left(\mathrm{Mn}_{2} \mathrm{O}_{3}, \mathrm{Mn}_{3} \mathrm{O}_{4}\right.$, and $\left.\mathrm{MnO}\right)$, and $\mathrm{MMn}_{2} \mathrm{O}_{4}(\mathrm{M}=\mathrm{Zn}, \mathrm{Ca}, \mathrm{Mg}, \mathrm{Co}$, etc. $)$.

Table 1. 1 Comparison of the electrochemical performance of reported manganese-based cathodes for ZIBs with mildly acidic or near neutral electrolytes.

\begin{tabular}{|c|c|c|c|c|c|}
\hline Cathode & Electrolyte & Specific capacity & Rate performance & Cycling performance & Ref. \\
\hline$\alpha-\mathrm{MnO}_{2}$ & $0.1 \mathrm{M} \mathrm{Zn}\left(\mathrm{NO}_{3}\right)_{2}$ & $\begin{array}{l}210 \mathrm{mAh} \mathrm{g}^{-1} \\
\text { at } 0.5 \mathrm{C}\end{array}$ & $\begin{array}{l}100 \% \text { after } \\
100 \text { cycles }\end{array}$ & $\begin{array}{c}100 \% \text { retained after } \\
100 \text { cycles }\end{array}$ & {$[25]$} \\
\hline$\alpha-\mathrm{MnO}_{2}$ & $1 \mathrm{M} \mathrm{ZnSO}_{4}$ & $\begin{array}{l}353 \mathrm{mAh} \mathrm{g}^{-1} \\
\text { at } 16 \mathrm{~mA} \mathrm{~g}^{-1}\end{array}$ & N/A & $\begin{array}{c}63 \% \text { retained after } \\
50 \text { cycle at } 83 \mathrm{~mA} \mathrm{~g}^{-1}\end{array}$ & [26] \\
\hline$\alpha-\mathrm{MnO}_{2}$ & $1 \mathrm{M} \mathrm{ZnSO}_{4}$ & $\begin{array}{l}205 \mathrm{mAh} \mathrm{g}^{-1} \\
\text { at } 10.5 \mathrm{~mA} \mathrm{~g}^{-1}\end{array}$ & $\begin{array}{l}57.7 \% \text { retained } \\
\text { at } 210 \mathrm{~mA} \mathrm{~g}^{-1}\end{array}$ & $\begin{array}{c}66 \% \text { retained after } \\
30 \text { cycles at } 10.5 \mathrm{~mA} \mathrm{~g}^{-1}\end{array}$ & {$[27]$} \\
\hline$\alpha-\mathrm{MnO}_{2}$ & $1 \mathrm{M} \mathrm{ZnSO}_{4}$ & $\begin{array}{l}195 \mathrm{mAh} \mathrm{g}^{-1} \\
\text { at } 10.5 \mathrm{~mA} \mathrm{~g}^{-1}\end{array}$ & $\begin{array}{c}129.4 \mathrm{mAh} \mathrm{g}^{-1} \text { after } \\
30 \text { cycles } \\
\text { at } 42 \mathrm{~mA} \mathrm{~g}^{-1}\end{array}$ & $\begin{array}{l}70 \% \text { retained after } \\
30 \text { cycles at } 42 \mathrm{~mA} \mathrm{~g}^{-1}\end{array}$ & {$[28]$} \\
\hline$\alpha-\mathrm{MnO}_{2}$ & $\begin{aligned} & 2 \mathrm{M} \mathrm{ZnSO}_{4} \\
+ & 0.1 \mathrm{M} \mathrm{MnSO}_{4}\end{aligned}$ & $\begin{array}{l}260 \mathrm{mAh} \mathrm{g}^{-1} \\
\text { at } 308 \mathrm{~mA} \mathrm{~g}^{-1}\end{array}$ & $\begin{array}{l}44.2 \% \text { retained } \\
\text { at } 3080 \mathrm{~mA} \mathrm{~g}^{-1}\end{array}$ & $\begin{array}{c}92 \% \text { retained after } 5000 \\
\text { cycles at } 1540 \mathrm{~mA} \mathrm{~g}^{-1}\end{array}$ & [29] \\
\hline$\alpha-\mathrm{MnO}_{2}$ & $0.1 \mathrm{M} \mathrm{ZnSO}_{4}$ & $\begin{array}{l}103 \mathrm{mAh} \mathrm{g}^{-1} \\
\text { at } 300 \mathrm{~mA} \mathrm{~g}^{-1}\end{array}$ & N/A & $\begin{array}{l}166 \% \text { retained after } 500 \\
\text { cycles at } 900 \mathrm{~mA} \mathrm{~g}^{-1}\end{array}$ & {$[30]$} \\
\hline$\alpha-\mathrm{MnO}_{2} / \mathrm{CNT}$ & $\begin{array}{c}2 \mathrm{M} \mathrm{ZnSO}_{4} \\
+0.5 \mathrm{M} \mathrm{MnSO}_{4}\end{array}$ & $\begin{array}{l}665 \mathrm{mAh} \mathrm{g}^{-1} \\
\text { at } 100 \mathrm{~mA} \mathrm{~g}^{-1}\end{array}$ & $\begin{array}{l}41.8 \% \text { retained } \\
\text { at } 5000 \mathrm{~mA} \mathrm{~g}^{-1}\end{array}$ & $\begin{array}{l}99 \% \text { retained after } \\
500 \text { cycles at } 5 \mathrm{~A} \mathrm{~g}^{-1}\end{array}$ & {$[31]$} \\
\hline $\begin{array}{c}\text { Graphene/ } \alpha- \\
\mathrm{MnO}_{2}\end{array}$ & $\begin{array}{c}2 \mathrm{M} \mathrm{ZnSO}_{4} \\
+0.2 \mathrm{M} \mathrm{MnSO}_{4} \\
\end{array}$ & $\begin{array}{l}382 \mathrm{mAh} \mathrm{g}^{-1} \\
\text { at } 300 \mathrm{~mA} \mathrm{~g}^{-1}\end{array}$ & $\begin{array}{l}55 \% \text { retained } \\
\text { at } 3000 \mathrm{~mA} \mathrm{~g}^{-1}\end{array}$ & $\begin{array}{l}94 \% \text { retained after } \\
3000 \text { cycles at } 3 \mathrm{~A} \mathrm{~g}^{-1}\end{array}$ & {$[32]$} \\
\hline $\mathrm{CNT} / \alpha-\mathrm{MnO}_{2}$ & \begin{tabular}{|c|}
$2 \mathrm{M} \mathrm{ZnSO}_{4}$ \\
$+0.2 \mathrm{M} \mathrm{MnSO}_{4}$ \\
Saturated \\
cellulose/ployacryl \\
amide gel \\
\end{tabular} & $\begin{array}{l}260 \mathrm{mAh} \mathrm{g-1} \\
\text { at } 308 \mathrm{~mA} \mathrm{~g}^{-1}\end{array}$ & $\begin{array}{l}73.1 \% \text { retained } \\
\text { at } 1848 \mathrm{~mA} \mathrm{~g}^{-1}\end{array}$ & $\begin{array}{l}88.3 \% \text { retained after } \\
1000 \text { cycles at } 4 \mathrm{~A} \mathrm{~g}^{-1}\end{array}$ & {$[33]$} \\
\hline $\mathrm{CNT} / \alpha-\mathrm{MnO}_{2}$ & $\begin{aligned} & 2 \mathrm{M} \mathrm{ZnSO}_{4} \\
+ & 0.2 \mathrm{M} \mathrm{MnSO}_{4}\end{aligned}$ & $\begin{array}{l}307 \mathrm{mAh} \mathrm{g}^{-1} \\
\text { at } 308 \mathrm{~mA} \mathrm{~g}^{-1}\end{array}$ & $\begin{array}{l}78.5 \% \text { retained } \\
\text { at } 1848 \mathrm{~mA} \mathrm{~g}^{-1}\end{array}$ & $\begin{array}{c}50.9 \% \text { retained after } \\
1000 \text { cycles at } 1232 \mathrm{~mA} \mathrm{~g}^{-1}\end{array}$ & {$[33]$} \\
\hline $\begin{array}{c}\alpha-\mathrm{MnO}_{2} / \\
\mathrm{N} \text {-carbon cloth }\end{array}$ & $\begin{array}{c}2 \mathrm{M} \mathrm{ZnCl}_{2} \\
+0.4 \mathrm{M} \mathrm{MnSO}_{4}\end{array}$ & $\begin{array}{l}353 \mathrm{mAh} \mathrm{g}^{-1} \\
\text { at } 500 \mathrm{~mA} \mathrm{~g}^{-1}\end{array}$ & $\begin{array}{l}70.5 \% \text { retained } \\
\text { at } 6000 \mathrm{~mA} \mathrm{~g}^{-1}\end{array}$ & $\begin{array}{l}93.6 \% \text { retained after } \\
1000 \text { cycles at } 1 \mathrm{~A} \mathrm{~g}^{-1}\end{array}$ & {$[34]$} \\
\hline $\begin{array}{c}\text { polyester- } \\
\text { CNTs@ } \\
\text { a-MnO2 } \\
\end{array}$ & $\begin{array}{r}2 \mathrm{M} \mathrm{ZnSO}_{4} \\
+1 \mathrm{M} \mathrm{MnSO}_{4}\end{array}$ & $\begin{array}{l}0.96 \mathrm{mAh} \mathrm{cm}^{-2} \\
\text { at } 1 \mathrm{~mA} \mathrm{~cm}^{-2}\end{array}$ & $\begin{array}{l}0.17 \mathrm{mAh} \mathrm{cm}^{-2} \\
\text { at } 5 \mathrm{~mA} \mathrm{~cm}\end{array}$ & $\begin{array}{c}100 \% \text { retained after } \\
11000 \text { cycles at } 5 \mathrm{~mA} \mathrm{~cm}^{-2}\end{array}$ & {$[35]$} \\
\hline $\begin{array}{l}\text { K-stabilized } \alpha- \\
\mathrm{MnO}_{2}\end{array}$ & $\begin{array}{c}2 \mathrm{M} \mathrm{ZnSO}_{4} \\
+0.1 \mathrm{M} \mathrm{MnSO}_{4}\end{array}$ & $\begin{array}{l}320 \mathrm{mAh} \mathrm{g}-1^{-1} \\
\text { at } 100 \mathrm{~mA} \mathrm{~g}^{-1}\end{array}$ & $\begin{array}{c}31 \% \text { retained after } \\
\text { at } 2000 \mathrm{~mA} \mathrm{~g}^{-1}\end{array}$ & $\begin{array}{l}76.9 \% \text { retained after } \\
1000 \text { cycles at } 1 \mathrm{~A} \mathrm{~g}^{-1}\end{array}$ & {$[36]$} \\
\hline
\end{tabular}




\begin{tabular}{|c|c|c|c|c|c|}
\hline$\beta-\mathrm{MnO}_{2}$ & $\begin{array}{c}1 \mathrm{M} \mathrm{ZnSO}_{4} \\
+0.1 \mathrm{M} \mathrm{MnSO}_{4}\end{array}$ & $\begin{array}{l}270 \mathrm{mAh} \mathrm{g}^{-1} \\
\text { at } 100 \mathrm{~mA} \mathrm{~g}^{-1}\end{array}$ & $\begin{array}{l}39.4 \% \text { retained } \\
\text { at } 1056 \mathrm{~mA} \mathrm{~g}^{-1}\end{array}$ & $\begin{array}{c}75 \% \text { retained after } \\
200 \text { cycles at } 200 \mathrm{~mA} \mathrm{~g}^{-1}\end{array}$ & [37] \\
\hline$\beta-\mathrm{MnO}_{2}$ & $\begin{array}{c}3 \mathrm{M} \mathrm{Zn}\left(\mathrm{CF}_{3} \mathrm{SO}_{3}\right)_{2} \\
+0.1 \mathrm{M} \\
\mathrm{Mn}\left(\mathrm{CF}_{3} \mathrm{~S}_{3}\right)_{2} \\
\end{array}$ & $\begin{array}{l}225 \mathrm{mAh} \mathrm{g}^{-1} \\
\text { at } 0.65 \mathrm{C}\end{array}$ & $\begin{array}{c}100 \mathrm{mAh} \mathrm{g}^{-1} \text { at } \\
32.50 \mathrm{C}\end{array}$ & $\begin{array}{l}94 \% \text { retention after } \\
2000 \text { cycles at } 6.50 \mathrm{C}\end{array}$ & {$[38]$} \\
\hline$\gamma-\mathrm{MnO}_{2}$ & $1 \mathrm{M} \mathrm{ZnSO}_{4}$ & $\begin{array}{l}285 \mathrm{mAh} \mathrm{g}^{-1} \\
\text { at } 0.05 \mathrm{~mA} \mathrm{~cm}^{-2}\end{array}$ & $\begin{array}{l}57.9 \% \text { retained } \\
\text { at } 0.5 \mathrm{~mA} \mathrm{~cm}^{-2}\end{array}$ & $\begin{array}{c}63.2 \% \text { retained after } \\
40 \text { cycles at } 0.5 \mathrm{~mA} \mathrm{~cm}^{-2}\end{array}$ & [39] \\
\hline$\delta-\mathrm{MnO}_{2}$ & $1 \mathrm{M} \mathrm{ZnSO}_{4}$ & $\begin{array}{l}250 \mathrm{mAh} \mathrm{g}^{-1} \\
\text { at } 83 \mathrm{~mA} \mathrm{~g}^{-1}\end{array}$ & $\begin{array}{l}24.6 \% \text { retained } \\
\text { at } 1333 \mathrm{~mA} \mathrm{~g}^{-1}\end{array}$ & $\begin{array}{c}46 \% \text { retained after } \\
100 \text { cycles at } 83 \mathrm{~mA} \mathrm{~g}^{-1}\end{array}$ & [40] \\
\hline$\delta-\mathrm{MnO}_{2}$ & $\begin{array}{c}0.5 \mathrm{M} \mathrm{Zn}\left(\mathrm{CF}_{3} \mathrm{SO}_{3}\right)_{2} \\
\text { in acetonitrile }\end{array}$ & $\begin{array}{l}120 \mathrm{mAh} \mathrm{g}^{-1} \\
\text { at } 12.3 \mathrm{~mA} \mathrm{~g}^{-1}\end{array}$ & $\begin{array}{l}27.3 \% \text { retained } \\
\text { at } 308 \mathrm{~mA} \mathrm{~g}^{-1}\end{array}$ & $\begin{array}{c}46.7 \% \text { retained after } \\
125 \text { cycles at } 12.3 \mathrm{~mA} \mathrm{~g}^{-1}\end{array}$ & [41] \\
\hline $\begin{array}{c}\mathrm{O}_{\mathrm{d}} \text { - birnessite } \\
\mathrm{MnO}_{2}\end{array}$ & $\begin{array}{c}1 \mathrm{M} \mathrm{ZnSO}_{4}+ \\
0.2 \mathrm{M} \mathrm{MnSO}_{4}\end{array}$ & $\begin{array}{l}345 \mathrm{mAh} \mathrm{g}^{-1} \\
\text { at } 200 \mathrm{~mA} \mathrm{~g}^{-1}\end{array}$ & $\begin{array}{l}16.9 \% \text { retained } \\
\text { at } 30000 \mathrm{~mA} \mathrm{~g}^{-1}\end{array}$ & $\begin{array}{c}84 \% \text { retained after } \\
2000 \text { cycles at } 5 \mathrm{~A} \mathrm{~g}^{-1}\end{array}$ & [42] \\
\hline Layered $\mathrm{MnO}_{2}$ & $1 \mathrm{M} \mathrm{ZnSO}_{4}$ & $\begin{array}{l}289 \mathrm{mAh} \mathrm{g}^{-1} \\
\text { at } 50 \mathrm{~mA} \mathrm{~g}^{-1}\end{array}$ & $\begin{array}{l}21.1 \% \text { retained } \\
\text { at } 1000 \mathrm{~mA} \mathrm{~g}^{-1}\end{array}$ & $\begin{array}{c}43.1 \% \text { retained after } \\
50 \text { cycles at } 100 \mathrm{~mA} \mathrm{~g}^{-1}\end{array}$ & [43] \\
\hline $\begin{array}{c}\text { PANI-- } \\
\text { intercalated } \\
\mathrm{MnO}_{2}\end{array}$ & $\begin{aligned} & 2 \mathrm{M} \mathrm{ZnSO}_{4} \\
+ & 0.1 \mathrm{M} \mathrm{MnSO}_{4}\end{aligned}$ & $\begin{array}{l}298 \mathrm{mAh} \mathrm{g}^{-1} \\
\text { at } 50 \mathrm{~mA} \mathrm{~g}^{-1}\end{array}$ & $\begin{array}{l}36.9 \% \text { retained } \\
\text { at } 3000 \mathrm{~mA} \mathrm{~g}^{-1}\end{array}$ & $\begin{array}{l}89 \% \text { retained after } \\
5000 \text { cycles at } 2 \mathrm{~A} \mathrm{~g}^{-1}\end{array}$ & [44] \\
\hline $\begin{array}{c}\text { Zn stabilized } \\
\text { birnessite } \\
\mathrm{MnO}_{2} \\
\end{array}$ & $\begin{aligned} & 2 \mathrm{M} \mathrm{ZnSO}_{4} \\
+ & 0.1 \mathrm{M} \mathrm{MnSO}_{4}\end{aligned}$ & $\begin{array}{l}358 \mathrm{mAh} \mathrm{g}^{-1} \\
\text { at } 300 \mathrm{~mA} \mathrm{~g}^{-1}\end{array}$ & $\begin{array}{l}44 \% \text { retained } \\
\text { at } 3000 \mathrm{~mA} \mathrm{~g}^{-1}\end{array}$ & $\begin{array}{c}73 \% \text { retained after } \\
2000 \text { cycles at } 3000 \mathrm{~mA} \mathrm{~g}^{-1}\end{array}$ & {$[45]$} \\
\hline $\begin{array}{c}\text { Birnessite } \\
\mathrm{MnO}_{2}\end{array}$ & $\begin{aligned} & 2 \mathrm{M} \mathrm{ZnSO}_{4} \\
&+ 0.1 \mathrm{M} \mathrm{MnSO}_{4} \\
&\end{aligned}$ & $\begin{array}{l}262 \mathrm{mAh} \mathrm{g}{ }^{-1} \\
\text { at } 300 \mathrm{~mA} \cdot \mathrm{g}^{-1}\end{array}$ & $\begin{array}{l}28,6 \% \text { retained } \\
\text { at } 3000 \mathrm{~mA} \mathrm{~g}^{-1}\end{array}$ & $\begin{array}{l}100 \% \text { retained after } \\
5000 \text { cycles at } 2 \mathrm{~A} \cdot \mathrm{g}^{-1}\end{array}$ & [46] \\
\hline$\varepsilon-\mathrm{MnO}_{2}$ & $\begin{array}{l}2 \mathrm{M} \mathrm{ZnSO}_{4}+ \\
0.2 \mathrm{M} \mathrm{MnSO}_{4}\end{array}$ & $\begin{array}{l}290 \mathrm{mAh} \mathrm{g}^{-1} \\
\text { at } 90 \mathrm{~mA} \mathrm{~g}^{-1}\end{array}$ & $\begin{array}{l}60 \% \text { retained } \\
\text { at } 1885 \mathrm{~mA}^{\mathrm{g}-1}\end{array}$ & $\begin{array}{c}99.3 \% \text { retained after } \\
10000 \text { cycles at } 1885 \mathrm{~mA} \mathrm{~g}^{-1}\end{array}$ & [47] \\
\hline$\varepsilon-\mathrm{MnO}_{2}$ & $\begin{array}{c}\mathrm{M} \mathrm{ZnSO}_{4}+1 \mathrm{M} \\
\mathrm{MnSO}_{4}+0.1 \mathrm{M} \\
\mathrm{H}_{2} \mathrm{SO}_{4}\end{array}$ & $570 \mathrm{mAh} \mathrm{g}^{-1}$ & $\begin{array}{c}1.67 \mathrm{mAh} \mathrm{cm}^{-2} \text { at } 60 \\
\mathrm{~mA} \mathrm{~cm}\end{array}$ & $\frac{92 \% \text { retained after } 1800 \text { cycles at }}{30 \mathrm{mAcm}^{-2}}$ & [48] \\
\hline $\begin{array}{l}\text { todorokite- } \\
\mathrm{MnO}_{2}\end{array}$ & $1 \mathrm{M} \mathrm{ZnSO}_{4}$ & $\begin{array}{l}108 \mathrm{mAh} \mathrm{g}^{-1} \\
\text { at } 50 \mathrm{~mA} \mathrm{~g}^{-1}\end{array}$ & N/A & $\begin{array}{c}83 \% \text { retained after } \\
50 \text { cycles at } 50 \mathrm{~mA} \mathrm{~g}^{-1}\end{array}$ & [49] \\
\hline $\mathrm{MnO}_{2}$ & $\begin{aligned} & 2 \mathrm{M} \mathrm{ZnSO}_{4} \\
&+ 0.1 \mathrm{M} \mathrm{MnSO}_{4} \\
&\end{aligned}$ & $\begin{array}{l}253.8 \mathrm{mAh} \mathrm{g}^{-1} \\
\text { at } 500 \mathrm{~mA} \mathrm{~g}^{1}\end{array}$ & $\begin{array}{l}55 \% \text { retained } \\
\text { at } 2000 \mathrm{~mA} \mathrm{~g}^{-1}\end{array}$ & $\begin{array}{c}57.6 \% \text { retained after } \\
200 \text { cycles at } 500 \mathrm{~mA} \mathrm{~g}^{-1}\end{array}$ & {$[50]$} \\
\hline$\gamma-\mathrm{MnO}_{2}$ & $\begin{array}{c}2 \mathrm{M} \mathrm{ZnSO}_{4}+ \\
0.1 \mathrm{M} \mathrm{MnSO}_{4}+20 \\
\text { wt } \% \text { xanthan } \\
\text { gum }\end{array}$ & $\begin{array}{l}260 \mathrm{mAh} \mathrm{g}^{-1} \\
\text { at } 150 \mathrm{~mA} \mathrm{~g}^{-1}\end{array}$ & $\begin{array}{l}67.7 \% \text { retained } \\
\text { at } 1500 \mathrm{~mA} \mathrm{~g}^{-1}\end{array}$ & $\begin{array}{c}90 \% \text { retained after } \\
1000 \text { cycles at } 750 \mathrm{mAg}^{-1}\end{array}$ & {$[51]$} \\
\hline $\mathrm{MnO}_{2} / \mathbf{r G O}$ & $\begin{aligned} & 2 \mathrm{M} \mathrm{ZnSO}_{4} \\
&+ 0.1 \mathrm{M} \mathrm{MnSO}_{4} \\
&\end{aligned}$ & $\begin{array}{l}332 \mathrm{mAh} \mathrm{g}^{-1} \\
\text { at } 300 \mathrm{~mA} \mathrm{~g}^{-1}\end{array}$ & $\begin{array}{l}51.8 \% \text { retained } \\
\text { at } 6000 \mathrm{~A} \mathrm{~g}^{-1}\end{array}$ & $\begin{array}{c}96 \% \text { retained after } \\
500 \text { cycles at } 6000 \mathrm{~mA} \mathrm{~g}^{-1}\end{array}$ & {$[52]$} \\
\hline $\begin{array}{c}\mathrm{MnO}_{2} \mathrm{H}_{0.16} \\
\left(\mathrm{H}_{2} \mathrm{O}\right)_{0.27}\end{array}$ & $\begin{aligned} & 1 \mathrm{M} \mathrm{ZnSO}_{4} \\
&+ 0.2 \mathrm{M} \mathrm{MnSO}_{4} \\
&\end{aligned}$ & $\begin{array}{l}275 \mathrm{mAh} \mathrm{g}^{-1} \\
\text { at } 30.8 \mathrm{~mA} \mathrm{~g}^{-1}\end{array}$ & $\begin{array}{l}41.8 \% \text { retained } \\
\text { at } 3080 \mathrm{~mA} \mathrm{~g}^{-1}\end{array}$ & $\begin{array}{c}79 \% \text { retained after } 2000 \\
\text { at } 1848 \mathrm{~mA} \mathrm{~g}^{-1}\end{array}$ & {$[53]$} \\
\hline $\mathrm{Mn}_{3} \mathrm{O}_{4}$ & $\begin{aligned} & 1 \mathrm{M} \mathrm{ZnSO}_{4} \\
+ & 1 \mathrm{M} \mathrm{MnSO}_{4}\end{aligned}$ & $\begin{array}{l}221 \mathrm{mAh} \mathrm{g}^{-1} \\
\text { at } 100 \mathrm{~mA} \mathrm{~g}^{-1}\end{array}$ & $\begin{array}{l}23 \% \text { retained } \\
\text { at } 2000 \mathrm{~mA} \mathrm{~g}^{-1}\end{array}$ & $\begin{array}{c}92 \% \text { retained after } \\
500 \text { cycles at } 500 \mathrm{~mA} \mathrm{~g}^{-1}\end{array}$ & {$[54]$} \\
\hline
\end{tabular}




\begin{tabular}{|c|c|c|c|c|c|}
\hline $\mathbf{S S W M} @ \mathrm{Mn}_{3} \mathrm{O}_{4}$ & $\begin{aligned} & 2 \mathrm{M} \mathrm{ZnSO}_{4} \\
+ & 0.1 \mathrm{M} \mathrm{MnSO}_{4}\end{aligned}$ & $\begin{array}{l}296 \mathrm{mAh} \mathrm{g}^{-1} \\
\text { at } 100 \mathrm{~mA} \mathrm{~g}^{-1}\end{array}$ & $\begin{array}{l}42.2 \% \text { retained } \\
\text { at } 500 \mathrm{~mA} \mathrm{~g}^{-1}\end{array}$ & $\begin{array}{c}100 \% \text { retained after } \\
500 \text { cycles at } 500 \mathrm{~mA} \mathrm{g-}^{1}\end{array}$ & {$[55]$} \\
\hline Spinel $\mathrm{Mn}_{3} \mathrm{O}_{4}$ & $2 \mathrm{M} \mathrm{ZnSO}_{4}$ & $\begin{array}{l}239 \mathrm{mAh} \mathrm{g}^{-1} \\
\text { at } 100 \mathrm{~mA} \mathrm{~g}^{-1}\end{array}$ & $\begin{array}{l}51.8 \% \text { retained } \\
\text { at } 2000 \mathrm{~mA} \mathrm{~g}^{-1}\end{array}$ & $\begin{array}{c}73 \% \text { retained after } \\
300 \text { cycles at } 500 \mathrm{~mA} \mathrm{~g}^{-1}\end{array}$ & {$[56]$} \\
\hline$\alpha-\mathrm{Mn}_{2} \mathrm{O}_{3}$ & $\begin{array}{c}2 \mathrm{M} \mathrm{ZnSO}_{4} \\
+0.1 \mathrm{M} \mathrm{MnSO}_{4} \\
\end{array}$ & $\begin{array}{l}148 \mathrm{mAh} \mathrm{g}^{-1} \\
\text { at } 100 \mathrm{~mA} \mathrm{~g}^{-1}\end{array}$ & N/A & $\begin{array}{c}51 \% \text { retained after } \\
2000 \text { cycles at } 2 \mathrm{~A} \mathrm{~g}^{-1}\end{array}$ & {$[57]$} \\
\hline 3D MnO $@ \mathrm{C}$ & $\begin{array}{c}0.25 \mathrm{M} \mathrm{ZnSO}_{4} \\
+0.75 \mathrm{M} \mathrm{Na}_{2} \mathrm{SO}_{4} \\
\end{array}$ & $\begin{array}{l}305 \mathrm{mAh} \mathrm{g}^{-1} \\
\text { at } 308 \mathrm{~mA} \mathrm{~g}^{-1}\end{array}$ & $\begin{array}{l}29.7 \% \text { retained } \\
\text { at } 6160 \mathrm{~mA} \mathrm{~g}^{-1}\end{array}$ & $\begin{array}{c}31.6 \% \text { retained after } \\
1000 \text { cycles at } 3080 \mathrm{~mA} \mathrm{~g}^{-1}\end{array}$ & {$[58]$} \\
\hline $\mathrm{MnO}_{\mathbf{x}} @ \mathrm{~N}-\mathrm{C}$ & $\begin{array}{c}2 \mathrm{M} \mathrm{ZnSO}_{4} \\
+0.1 \mathrm{M} \mathrm{MnSO}_{4} \\
\end{array}$ & $\begin{array}{l}385 \mathrm{mAh} \mathrm{g}^{-1} \\
\text { at } 100 \mathrm{~mA} \mathrm{~g}^{-1}\end{array}$ & $\begin{array}{r}62.5 \% \text { retained } \\
\text { at } 2000 \mathrm{~mA} \mathrm{~g}^{-1} \\
\end{array}$ & $\begin{array}{l}99 \% \text { retained after } \\
1600 \text { cycles at } 2 \mathrm{~A} \mathrm{~g}^{-1}\end{array}$ & [59] \\
\hline $\begin{array}{l}\mathrm{ZnMn}_{2} \mathrm{O}_{4} \\
@ \text { PEDOT }\end{array}$ & $1 \mathrm{M} \mathrm{ZnSO}_{4}$ & $\begin{array}{l}223 \mathrm{mAh} \mathrm{g}^{-1} \\
\text { at } 83 \mathrm{~mA} \mathrm{~g}^{-1}\end{array}$ & $\begin{array}{l}28 \% \text { retained } \\
\text { at } 1660 \mathrm{~mA} \mathrm{~g}^{-1}\end{array}$ & $\begin{array}{c}93.8 \% \text { retained after } \\
300 \text { cycles at } 1328 \mathrm{~mA} \mathrm{~g}^{-1}\end{array}$ & {$[60]$} \\
\hline $\begin{array}{c}\text { Cation-deficient } \\
\mathrm{ZnMn}_{2} \mathrm{O}_{4} @ \mathrm{C}\end{array}$ & $3 \mathrm{M} \mathrm{Zn}\left(\mathrm{CF}_{3} \mathrm{SO}_{3}\right)_{2}$ & $\begin{array}{l}150 \mathrm{mAh} \mathrm{g}^{-1} \\
\text { at } 50 \mathrm{~mA} \mathrm{~g}^{-1}\end{array}$ & $\begin{array}{l}48 \% \text { retained } \\
\text { at } 2000 \mathrm{~mA} \mathrm{~g}^{-1}\end{array}$ & $\begin{array}{c}94 \% \text { retained after } \\
500 \text { cycles at } 500 \mathrm{~mA} \mathrm{~g}^{-1}\end{array}$ & {$[61]$} \\
\hline
\end{tabular}

\subsubsection{Progress of manganese-based cathodes}

The fundamental $\left[\mathrm{MnO}_{6}\right]$ octahedral units of the crystal structure of $\mathrm{MnO}_{2}$ are built by a $\mathrm{Mn}^{4+}$ ion occupying octahedral hole and six oxygen neighbors. The basic crystallographic structure of $\mathrm{MnO}_{2}$ is dependent on the linkage of $\left[\mathrm{MnO}_{6}\right]$ octahedral structural units each other and sharing of corners and edges in different ways. Therefore, various crystallographic $\mathrm{MnO}_{2}$ polymorphs are realized, which can be broadly classified into tunnel-type, layered-type, and spinel-type $\mathrm{MnO}_{2}$, as described in Figure 1.2a. The crystal structure related to the tunnel size of $\mathrm{MnO}_{2}$ is determined by the number of $\left[\mathrm{MnO}_{6}\right]$ octahedral units, for example, $\beta-\mathrm{MnO}_{2}$ with $1 \times 1$ tunnels, $\alpha-\mathrm{MnO}_{2}$ with $2 \times 2$ tunnels and todorokite-type $\mathrm{MnO}_{2}$ with $3 \times 3$ tunnels, which are built by $\left[\mathrm{MnO}_{6}\right]$ octahedral single, double and triple chains via corner-sharing, respectively. $\gamma-\mathrm{MnO}_{2}$ possesses both $1 \times 1$ and $1 \times 2$ tunnels, while $\varepsilon-\mathrm{MnO}_{2}$ is structurally similar to $\gamma-\mathrm{MnO}_{2}$ phase yet featuring hexagonal symmetry with random distribution of $\mathrm{Mn}^{4+}$ ions in the octahedral sites of oxygen sublattice.[62] The layeredtype $\mathrm{MnO}_{2}\left(\delta-\mathrm{MnO}_{2}\right)$ is a two-dimensional structure constructed by sheets of edge-shared $\left[\mathrm{MnO}_{6}\right]$ octahedra. The interlayer spacing of layered structure generally depends on the cations and water molecules inserted for structure stabilization, such as chalcophanite $\left(\mathrm{ZnMn}_{3} \mathrm{O}_{7} \cdot 3 \mathrm{H}_{2} \mathrm{O}\right)$, birnessite $\left([\mathrm{Na}, \mathrm{Ca}] \mathrm{Mn}_{7} \mathrm{O}_{14} \cdot 2.8 \mathrm{H}_{2} \mathrm{O}\right), \quad$ buserite $\quad\left([\mathrm{Na}, \mathrm{Ca}] \mathrm{Mn}_{7} \mathrm{O}_{14} \cdot(2.8+\mathrm{n}) \mathrm{H}_{2} \mathrm{O}\right), \quad$ and $\quad$ vernadite $\left(\mathrm{MnO}_{2} \cdot \mathrm{nH}_{2} \mathrm{O}\right)$.[63] $\lambda-\mathrm{MnO}_{2}$ has a spinel-type structure with $\mathrm{Mn}$ filling the octahedral $16 \mathrm{~d}$ site and $\mathrm{O}$ close-packed in the 32e site. The cation inserted spinel- $\mathrm{Mn}_{2} \mathrm{O}_{4}\left(\mathrm{MMn}_{2} \mathrm{O}_{4}\right)$ was formed by the intercalated ion $\mathrm{M}$ occupying the tetrahedral sites (e.g. $\mathrm{ZnMn}_{2} \mathrm{O}_{4}$ ). Featuring the diverse 
crystallographic structure, $\mathrm{MnO}_{2}$ demonstrates substantial differences in the electrochemical properties, as their different crystal structures influence the thermodynamics and kinetics in the ion intercalation and deintercalation.[25,64,65] Therefore, many research efforts focused on crystallographic structure engineering of $\mathrm{MnO}_{2}$ to investigate their effects on the electrochemical performance.

Various $\mathrm{MnO}_{2}$ polymorphs have been reported as cathodes for ZIBs. Among them, $\alpha-\mathrm{MnO}_{2}$ with $2 \times 2$ tunnel structure has received extensive attention. The large tunnel size $(4.6 \times 4.6 \AA)$ of $\alpha-\mathrm{MnO}_{2}$ is suitable for intercalation/deintercalation of $\mathrm{Zn}^{2+}$ ions, leading to a high theoretical capacity. $\mathrm{Xu}$ et al. reported the $\mathrm{Zn} / \mathrm{MnO}_{2}$ electrochemistry in mild aqueous $\mathrm{ZnSO}_{4}$ or $\mathrm{Zn}\left(\mathrm{NO}_{3}\right)_{2}$ electrolytes.[25] The $\alpha-\mathrm{MnO}_{2}$ cathode delivered an initial capacity of $210 \mathrm{mAh} \mathrm{g}^{-1}$ at $0.5 \mathrm{C}$ and maintained a capacity of $100 \mathrm{mAh} \mathrm{g}^{-1}$ after 100 cycles at $6 \mathrm{C}$. Compared with $\alpha-\mathrm{MnO}_{2}$ and $\gamma-\mathrm{MnO}_{2}$, $\beta-\mathrm{MnO}_{2}$ was previously considered unfavorable for intercalation of $\mathrm{Zn}^{2+}$ ions owing to its smallest tunnel size $(1 \times 1)$. $[25,65]$ Islam et al. reported that $\beta-\mathrm{MnO}_{2}$ nanorods exhibited a high discharge capacity of $270 \mathrm{mAh} \mathrm{g}^{-1}$ at $100 \mathrm{~mA} \mathrm{~g}^{-1}$.[37] With the aqueous $3 \mathrm{M} \mathrm{Zn}\left(\mathrm{CF}_{3} \mathrm{SO}_{3}\right)_{2}+0.1 \mathrm{M}$ $\mathrm{Mn}\left(\mathrm{CF}_{3} \mathrm{SO}_{3}\right)_{2}$ electrolyte, Zhang et al. reported that the $\beta-\mathrm{MnO}_{2}$ delivers a high specific capacity of $225 \mathrm{mAh} \mathrm{g}^{-1}$ and excellent cyclability with $94 \%$ capacity retention over 2000 cycles.[38]

Todorokite-type $\mathrm{MnO}_{2}$ with a large $3 \times 3$ tunnel size was believed to favorably host $\mathrm{Zn}^{2+}$ ions. However, the reported todorokite-type $\mathrm{MnO}_{2}\left(\mathrm{Mg}_{1.8} \mathrm{Mn}_{6} \mathrm{O}_{12} \cdot 4.8 \mathrm{H}_{2} \mathrm{O}\right)$ cathode showed a lower specific capacity than the $\alpha-\mathrm{MnO}_{2}$ counterpart in aqueous ZIBs, despite superior cycle stability.[49] These results might be related to the cations (e.g. $\mathrm{Mg}, \mathrm{Ca}, \mathrm{Na}$ ) and water molecules pre-inserted in the tunnels of todorokite-type $\mathrm{MnO}_{2}$, which are beneficial for structural stabilization, but restrain the active sites in tunnels for $\mathrm{Zn}^{2+}$ accommodation.[28] The reaction mechanism of $\mathrm{Zn}^{2+}$ storage in todorokite-type $\mathrm{MnO}_{2}$ remains unclear, thus requiring in-depth investigation to explore its potential as a ZIB cathode.

Layered-type $\delta-\mathrm{MnO}_{2}$ is also a widely investigated cathode host because of its large interlayer spacing $(7 \AA)$ theoretically favorable for $\mathrm{Zn}^{2+}$ transport.[41,66,67] Recent research demonstrated that regardless of the original crystallographic phase of $\alpha$-, $\beta$, or $\gamma$-type, $\mathrm{MnO}_{2}$ commonly undergoes a phase transition from the tunneled to layered structure upon the accommodation of $\mathrm{Zn}^{2+}$.[38] This phase transition may incur structural pulverization of $\mathrm{MnO}_{2}$, thereby leading to capacity loss. Therefore, $\delta-\mathrm{MnO}_{2}$ was considered a favorable cathode candidate that minimizes the 
"sacrificial capacity" caused by phase transition during the initial cycle life.[9,38,44] However, the expected outstanding electrochemical performance has not yet been reported for the $\delta-\mathrm{MnO}_{2}$ cathode in $\mathrm{ZnSO}_{4}$-based electrolyte. $\delta-\mathrm{MnO}_{2}$ still suffers from serious structural degradation of structure collapse and volumetric change during the repeated ingress/egress of $\mathrm{Zn}^{2+}$, resulting in rapid capacity fade upon long-term cycling.[41,68]

Spinel-type Mn-based oxides featured fast ion diffusion kinetics can be potential cathode materials for power batteries.[69,70] Yuan synthesized $\lambda-\mathrm{MnO}_{2}$ by acid leaching $\mathrm{Li}$ from $\mathrm{LiMn}_{2} \mathrm{O}_{4}$, the resultant $\lambda-\mathrm{MnO}_{2}$ showed high intercalation/deintercalation capacities for $\mathrm{Mg}^{2+}$ and $\mathrm{Zn}^{2+}$ in the aqueous electrolyte.[71] Yan et al. developed a rechargeable hybrid aqueous battery via combining the $\mathrm{Li}^{+}$intercalation/deintercalation in $\mathrm{LiMn}_{2} \mathrm{O}_{4}$ cathode and $\mathrm{Zn}^{2+}$ deposition/dissolution at $\mathrm{Zn}$ anode in an aqueous electrolyte containing two electrochemically active cations $\left(\mathrm{Li}^{+}\right.$and $\left.\mathrm{Zn}^{2+}\right)$.[72] Spinel $\mathrm{ZnMn}_{2} \mathrm{O}_{4}$ was considered as a promising cathode candidate for ZIBs. [61,73] However, the ideal spinel structure of $\mathrm{ZnMn}_{2} \mathrm{O}_{4}$ was demonstrated not a suitable host for $\mathrm{Zn}^{2+}$ storage owing to the strong electrostatic repulsion between two $\mathrm{Zn}^{2+}$ ions at different sites impeded ion diffusion.[61,74,75] The existence of abundant cation vacancies enabled a very low electrostatic barrier in the spinel framework that favored $\mathrm{Zn}^{2+}$ diffusion, leading to the attractive performance of cation-deficient spinel $\mathrm{ZnMn}_{2} \mathrm{O}_{4}$ cathode for $\mathrm{ZIBs.[61]}$

In additional to various $\mathrm{MnO}_{2}$ polymorphs, the manganese oxides $\left(\mathrm{MnO}_{\mathrm{x}}, \mathrm{x}<2\right)$ including $\mathrm{Mn}_{2} \mathrm{O}_{3},[57,76] \mathrm{Mn}_{3} \mathrm{O}_{4},[54-56,77,78] \mathrm{MnO},[79,80] \mathrm{MnO}_{x},[58,59,81,82]$ and $\mathrm{ZnMn}_{2} \mathrm{O}_{4}[60,61,83]$ have been reported as promising cathodes for ZIBs. Hao et al. reported a phase transformation of original $\mathrm{Mn}_{3} \mathrm{O}_{4}$ to intermediate $\mathrm{Mn}_{5} \mathrm{O}_{8}$ and finally to birnessite structure during the initial charge process accompanied by continuous oxidation of $\mathrm{Mn}^{3+}$ to $\mathrm{Mn}^{4+}$. No participation of $\mathrm{Zn}^{2+}$ was found in this process. The resultant birnessite served as a host structure for $\mathrm{Zn}^{2+}$ accommodation in the subsequent discharge process. [56] Note that manganese oxides with Mn valance lower than +4 generally exhibited a tendency of capacity increase in the initial cycles, which is mainly due to gradual oxidation/activation of Mn centers. [59,84] $\alpha-\mathrm{Mn}_{2} \mathrm{O}_{3}$ was found to suffer a phase transition to layered $\mathrm{Zn}$-birnessite upon $\mathrm{Zn}$ insertion accompanied by the reduction of $\mathrm{Mn}^{3+}$ to $\mathrm{Mn}^{2+}$.[57] Nevertheless, manganese oxides with low Mn oxidation valance usually suffer from Mn dissolution and trigger the cathode degradation. Given the Mn dissolution in the initial discharge process, the sequence of charge or discharge in the first cycle is critical to the capacity and cycle life of $\mathrm{MnO}_{\mathrm{x}}(\mathrm{x}<2)$ cathodes. 

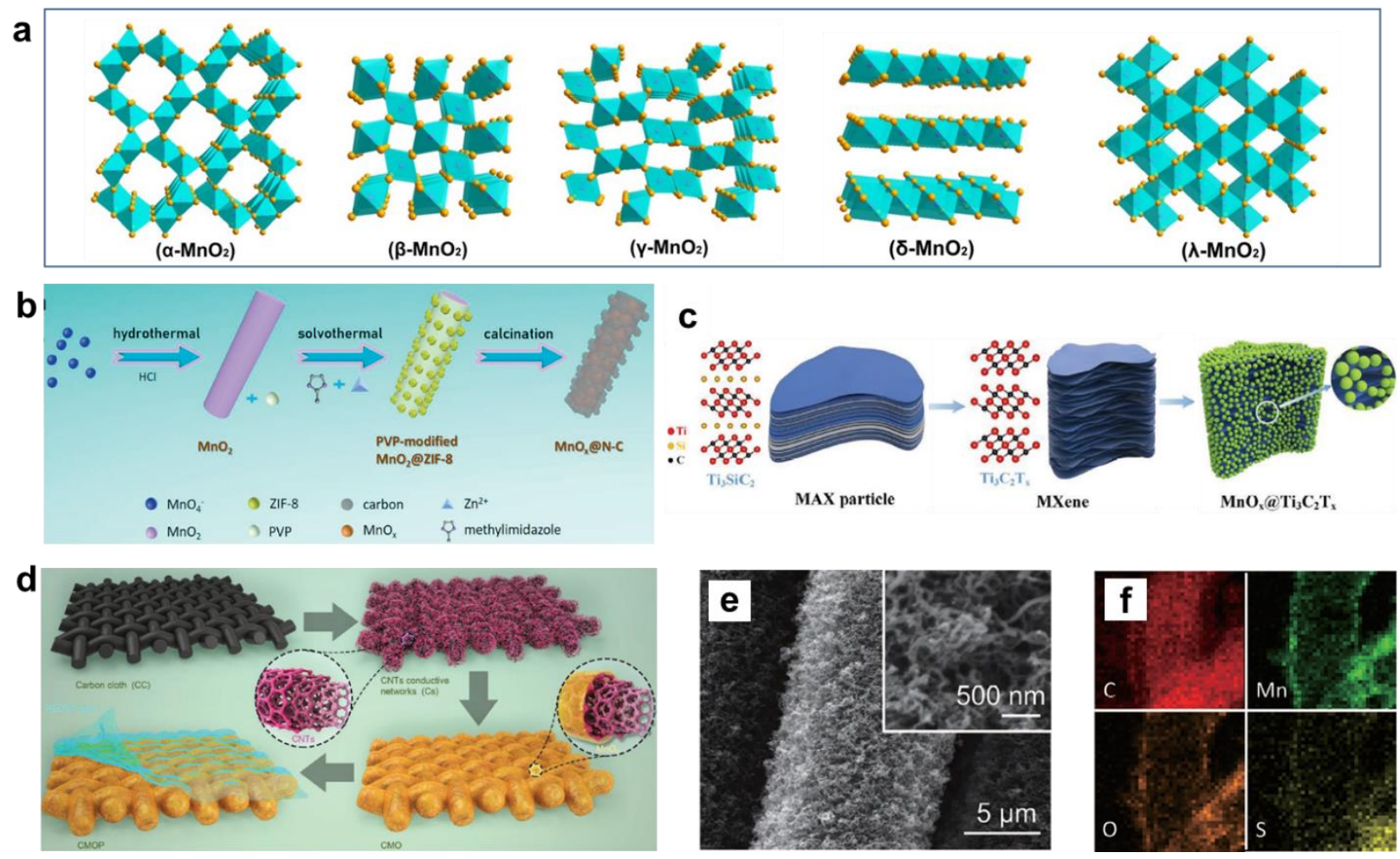

Figure 1. 2 a) Crystallographic structures of $\mathrm{MnO}_{2}$ polymorphs. [73] (Reproduced with permission. Copyright 2015, Springer Nature) b) The synthesis route for $\mathrm{MnO}_{\mathrm{x}} @ \mathrm{~N}-\mathrm{C}$ composite.[59] (Reproduced with permission. Copyright 2018, John Wiley \& Sons) c) Schematic illustration of the synthesis of $\mathrm{MnO}_{\mathrm{x}} @ \mathrm{Ti}_{3} \mathrm{C}_{2} \mathrm{~T}_{\mathrm{x}}$. [95] (Reproduced with permission. Copyright 2019, John Wiley $\&$ Sons) d) Schematic diagram illustrating the 3D structure of CNTs conductive networks (Cs) and fabrication procedure of CMOP cathodes. e) SEM images of CMOP. f) High angle annular darkfield TEM mapping images of C, Mn, O, and S elements in CMOP. [94] (Reproduced with permission. Copyright 2019, John Wiley \& Sons)

Given the limited capacity utilization and electrochemically active surface areas of $\mathrm{MnO}_{2}$ cathodes, the structural engineering of cathode materials on the mesoscopic and microspatial scales is considered an effective way to improve cathode performance. The favorable ionic and electronic transport kinetics inside the nanostructured electrodes can boost the charge storage. Various nanostructures of $\mathrm{MnO}_{2}$, such as nanorods,[37,38,85,86] ultralong nanowires,[87] nanosheets,[42,46,88,89] nanoparticles,[56] and cubic-like nanostructures[76,90] have been reported for ZIBs. The nanostructured $\mathrm{MnO}_{2}$ would enhance the electrode/electrolyte interfacial areas and shorten the diffusion pathway of ions and electrons, thereby promoting reaction kinetics 
and enhancing $\mathrm{MnO}_{2}$ utilization. In addition, the nanostructure is favorable to accommodate the strain generated in the host lattice during repeated (de)intercalation of $\mathrm{Zn}^{2+}$, thus enhancing the structure stability. Ren et al. prepared inverse opal layered birnessite- $\mathrm{MnO}_{2}$ constructed by fewlayered ultrathin nanosheets without stacking or aggregation.[46] Benefiting from the large spacing between monolayer or few-layered nanosheets and abundant active sites, the ultrathin $\mathrm{MnO}_{2}$ nanosheets cathode exhibited a high discharge capacity of $262.9 \mathrm{mAh} \mathrm{g}^{-1}$ after 100 cycles at $300 \mathrm{~mA} \mathrm{~g}^{-1}$ and long-term cycling stability with $121 \mathrm{mAh} \mathrm{g}^{-1}$ maintained after 5000 cycles at $2000 \mathrm{~mA} \mathrm{~g}^{-1}$.

Generally, manganese oxides possess intrinsically low electrical conductivity which restrains the electron transport and results in sluggish reaction kinetics, thereby limiting the rate capability and cycling stability especially at high depth of charge/discharge.[91] To address this issue, integrating manganese oxides with highly conductive matrices is an effective strategy to enhance the conductivity and cycling stability of cathodes. Several methods have been developed to integrate manganese oxides with conductive substrates for ZIB cathodes, including coating with conductive polymers,[44,76,82,92,93] N-doped carbon[59] and graphene layers,[32] immobilization on matrices of carbon cloths, [35,47,94] stainless steel meshes [55] and MXene,[95] and intercalation of conductive polymer molecules into interlayers.[44] Fu et al. synthesized porous $\mathrm{MnO}_{\mathrm{x}}$ nanorods coated by $\mathrm{N}$-doped carbon $\left(\mathrm{MnO}_{\mathrm{x}} @ \mathrm{~N}-\mathrm{C}\right)$ deriving from metal-organic framework (Figure 1.2b).[59] Benefiting from the unique porous structure and conductive carbon network, the $\mathrm{MnO}_{\mathrm{x}} @ \mathrm{~N}-\mathrm{C}$ exhibited superior electrochemical performance compared with pristine $\mathrm{MnO}_{2}$ nanorods. It delivered a high capacity of $305 \mathrm{mAh} \mathrm{g}^{-1}$ after 600 cycles at $500 \mathrm{~mA} \mathrm{~g}^{-1}$ and maintained a capacity of $100 \mathrm{mAh} \mathrm{g}^{-1}$ at $2000 \mathrm{~mA} \mathrm{~g}^{-1}$ after 1600 cycles. Luo et al. constructed the hierarchical structure assembly by intertwining $\mathrm{MnO}_{\mathrm{x}}$ functionalized $\mathrm{MXene}$ stacks $\left(\mathrm{Ti}_{3} \mathrm{C}_{2} \mathrm{~T}_{\mathrm{x}}\right)$ with carbon nanotubes (Figure 1.2c).[95] With the hierarchically layered structure and intertwined assembly, this composite material enabled fast ionic and electronic transfer. Moreover, flexible and binder-free conductive $\mathrm{MnO}_{2}$ electrodes were prepared by electrochemically depositing $\mathrm{MnO}_{2}$ on the carbon nanotube cloth (Figure 1.2d-f).[94]

Defect engineering is an appealing strategy to promote the electrochemical reactivity of manganese oxides by regulating the electronic structure for facilitating the redox reactions in ZIB cathodes.[42,61,96] Various types of defects including oxygen vacancy, cation vacancy, and cation doping have been reported in manganese oxides-based cathodes. Fang et al. demonstrated 
that oxygen vacancies in $\mathrm{K}_{0.8} \mathrm{Mn}_{8} \mathrm{O}_{16}$ not only enhanced the electrical conductivity but also unlocked the $\left[\mathrm{MnO}_{6}\right]$ polyhedron walls, providing sufficient pathways for fast $\mathrm{H}^{+}$insertion into the host framework. The positive effect of oxygen vacancies on boosting insertion reaction kinetics was further confirmed by DFT calculation. The diffusion energy of $\mathrm{H}^{+}$in oxygen-deficient $\mathrm{K}_{0.8} \mathrm{Mn}_{8} \mathrm{O}_{16}$ along the ab-plane was $0.21 \mathrm{eV}$ lower than that in the defect-free $\mathrm{K}_{0.8} \mathrm{Mn}_{8} \mathrm{O}_{16}$ (Figure 1.3a, b).[36] Han et al. claimed that introducing oxygen vacancies into $\beta-\mathrm{MnO}_{2}$ could effectively reduce the energy barrier of $\mathrm{H}^{+}$insertion and enhance $\mathrm{H}^{+}$insertion kinetics.[96] Xiong et al. reported the existence of abundant oxygen vacancies in $\mathrm{MnO}_{2}$ lattice reduced the thermoneutral Gibbs free energy of $\mathrm{Zn}^{2+}$ adsorption and resulted in highly accessible electrochemical active surface areas, thereby boosting the specific capacity and rate capability (Figure 1.3c). For instance, the oxygen-deficient $\mathrm{MnO}_{2}$ exhibited a high specific capacity of $345 \mathrm{mAh} \mathrm{g}^{-1}$ at $0.2 \mathrm{~A} \mathrm{~g}^{-1}$ and excellent capacity retention of $84 \%$ after 2000 cycles at a current density up to $5 \mathrm{~A} \mathrm{~g}^{-1}$.[42] Creating oxygen vacancies was also achieved through the surface gradient Ti doping in $\alpha-\mathrm{MnO}_{2}$. The Ti substitution and oxygen vacancies would induce a built-in electric field in the crystal structure due to the nonuniform charge distribution, stimulating the fast diffusion of $\mathrm{Zn}^{2+} / \mathrm{H}^{+}$in Ti-doped $\mathrm{MnO}_{2}$ (Figure 1.3d).[97] Our group has reported that that the desulfurization, microstructural reconstruction and amorphization during the in situ electrochemical oxidation/activation process of $\mathrm{MnS}$ precursor can produce unusual metastable low-crystallinity manganese oxide phases with abundant defects and vacancies and hence maximize the density of accessible active sites for high electrochemical reactivity, which are difficult to achieve by conventional chemical synthesis. [98] 

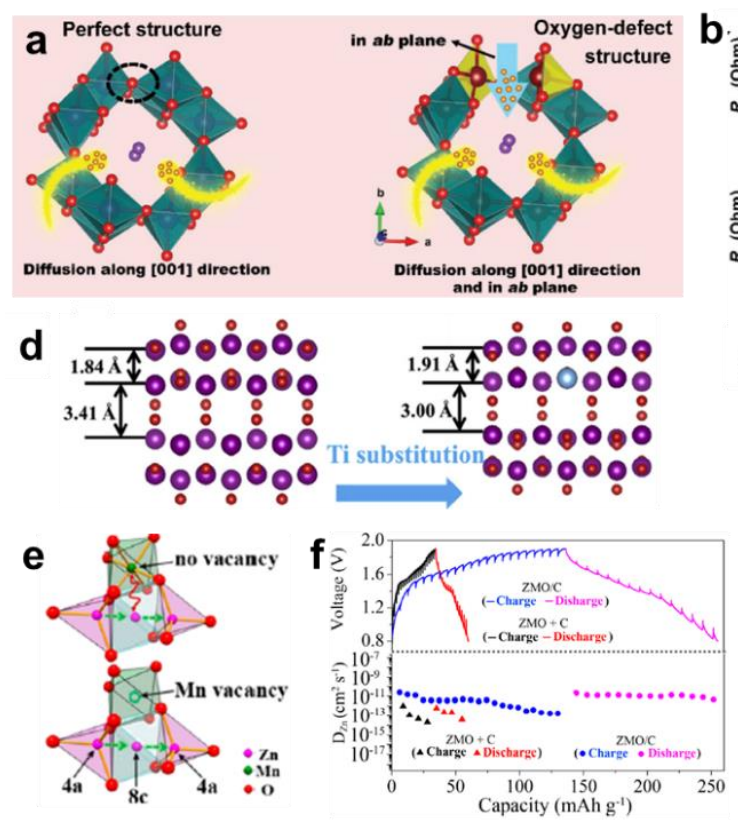
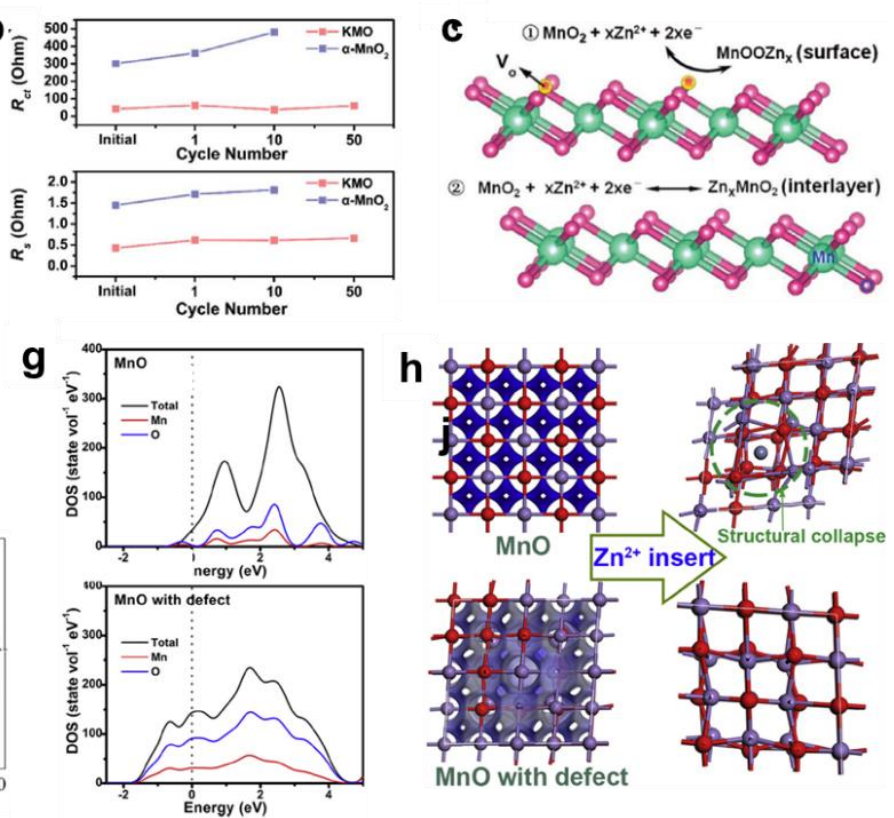

Figure 1. 3 a) Illustration of $\mathrm{H}^{+}$diffusion in perfect and oxygen-defect $\mathrm{K}_{0.8} \mathrm{Mn}_{8} \mathrm{O}_{16}$. b) corresponding electrolyte resistance $\mathrm{R}_{\mathrm{s}}$ and charge-transfer resistance $\mathrm{R}_{\mathrm{ct}}$. [36] (Reproduced with permission. Copyright 2019, John Wiley \& Sons) c) Schematic illustration of oxygen-deficient $\sigma-$ $\mathrm{MnO}_{2}$ for $\mathrm{Zn}$ ion storage. [42] (Reproduced with permission. Copyright 2019, John Wiley \& Sons) d) The tunnel structure of pristine and Ti-doped $\alpha-\mathrm{MnO}_{2}$. [97] (Reproduced with permission. Copyright 2019, Elsevier) e) Proposed $\mathrm{Zn}^{2+}$ diffusion pathway in $\mathrm{ZnMn}_{2} \mathrm{O}_{4}$ (ZMO) spinel without and with Mn vacancies. f) GITT profiles and calculated $\mathrm{Zn}^{2+}$ diffusion coefficients of $\mathrm{ZMO} / \mathrm{C}$ and ZMO+C electrodes. [61] (Reproduced with permission. Copyright 2016, American Chemical Society) g) Calculated density of states (DOS) of partial MnO and partial MnO with Mn defect. h) Charge distribution and the structures after $\mathrm{Zn}^{2+}$ insert of $\mathrm{MnO}$ and $\mathrm{Mn}$-deficient $\mathrm{MnO}$. [99] (Reproduced with permission. Copyright 2020, Elsevier)

Besides the oxygen vacancy, the cation vacancy was also developed to alleviate the electrostatic repulsion of $\mathrm{Zn}^{2+}$ for the host materials. Zhang et al. reported the attractive performance of cationdeficient spinel $\mathrm{ZnMn}_{2} \mathrm{O}_{4}$ cathodes. In the ideal spinel $\mathrm{ZnMn}_{2} \mathrm{O}_{4}$ structure, $\mathrm{Zn}^{2+}$ diffusion suffered from strong electrostatic repulsion from the neighboring Mn cations. While the abundant $\mathrm{Mn}$ vacancies in cation-deficient spinel $\mathrm{ZnMn}_{2} \mathrm{O}_{4}$ could reduce the electrostatic barrier for $\mathrm{Zn}^{2+}$ diffusion, leading to fast $\mathrm{Zn}^{2+}$ migration in the cation deficient spinel framework and thereby unlocking its potential for Zn storage in ZIBs (Figure 1.3e, f).[61] Pre-insertion of $\mathrm{H}^{+}$ions inside the tunnel of $\mathrm{MnO}_{6}$ octahedra was reported as an effective way to improve the electrochemical 
performance of $\mathrm{ZnMn}_{2} \mathrm{O}_{4}$. The stable spinel structure with pre-inserted $\mathrm{H}^{+}$ions benefited diffusion kinetics of the $\mathrm{Zn}^{2+}$ ions in the host framework.[99] Zhu et al. introduced Mn vacancy into $\mathrm{MnO}$. According to the DFT calculation on the density of states of $\mathrm{MnO}$ with/without Mn vacancy (Figure 1.3g), the charge density at Fermi level was enhanced by introducing Mn vacancy into MO structure, which could render higher conductivity compared to the pristine MnO. In addition, the non-uniform charge distribution induced by electrons accumulation at Mn vacancies of the Mn-deficient $\mathrm{MnO}$ would form a strong electrostatic field and thus attract $\mathrm{Zn}^{2+}$ on the $\mathrm{Mn}$ defects. The smooth diffusion of $\mathrm{Zn}^{2+}$ through Mn defects-induced accessible channels further contributed to the structural stability of $\mathrm{MnO}$ during the discharge and charge process (Figure 1.3h).[79]

Cation doping (e.g., $\mathrm{Co}, \mathrm{Ni}, \mathrm{Na}, \mathrm{Zn}, \mathrm{La}$, and $\mathrm{V}$ ) was also considered an effective approach to boosting the electrochemical reactivity of manganese oxides.[45,100-104] For $\delta-\mathrm{MnO}_{2}$, the metal ions $\left(\mathrm{Na}^{+}, \mathrm{Zn}^{2+}, \mathrm{La}^{3+}\right)$ pre-intercalated into the layered structure could serve as "pillars" to strengthen the layered structure and facilitate ion diffusion within the stabilized interlayer channels, thus boosting the $\delta-\mathrm{MnO}_{2}$ cathode performance. Wang et al. pre-intercalated $\mathrm{Na}$ ions and water molecules to stabilize the layered structure of $\delta-\mathrm{MnO}_{2}$ (Figure 1.4a). Benefiting from the enlarged interlayer spacing and structure stabilization, a high capacity of $106 \mathrm{mAh} \mathrm{g}^{-1}$ was still maintained (98\% capacity retention) after 10000 cycles at $20 \mathrm{C}$ (Figure 1.4b).[101] Cation doping was also reported to improve the electronic conductivity of manganese oxides.[102,105] Long et al. investigated the effect of $\mathrm{Ni}$ substitution in $\mathrm{Ni}_{\mathrm{x}} \mathrm{Mn}_{3-\mathrm{x}} \mathrm{O}_{4}$ on its electrical conductivity. $\mathrm{Ni}$ tended to occupy B-site in $\mathrm{Mn}_{3} \mathrm{O}_{4}$. Their projected density of states showed that the increase of $\mathrm{Ni}$ doping concentration $(x=0,0.5,1.0)$ decreased the band gap compared with the semiconductor characteristic of pure $\mathrm{Mn}_{3} \mathrm{O}_{4}$ with a band gap of $1.20 \mathrm{eV}$, thus improving the electrical conductivity (Figure 1.4c).[102] Cation doping was also found to promote the formation of beneficial solid electrolyte interface (SEI) phases. For example, Guo et al. reported the formation of a $\mathrm{CaSO}_{4} \cdot 2 \mathrm{H}_{2} \mathrm{O}$ SEI layer on the surface of $\mathrm{Ca}_{2} \mathrm{MnO}_{4}$ cathode during in situ electrochemical charging process. Featuring the properties of electronic insulation and ionic conductor, it was believed that this SEI layer acted as a protective layer for suppressing Mn dissolution, leading to enhanced cycling stability of $\mathrm{Ca}_{2} \mathrm{MnO}_{4}$ cathode.[106] Very recently, Zhong et al. adopted the Co-doping in the $\delta$ $\mathrm{MnO}_{2}$ cathode, exhibiting notable self-recovery capability. The in situ formed Co-containing species could continuously catalyze the electrochemical deposition of active Mn species, resulting in a self-recovery behavior.[104] 
Tuning interlayer spacing by pre-insertion of guest species has proven effective to enlarge the ion transfer channels and stabilize the structures. In addition to the above-mentioned metal ions, polymer and crystal water molecules were reported to be inserted into layered $\mathrm{MnO}_{2}$. Pre-insertion of conductive polyaniline molecules into interlayers of $\delta-\mathrm{MnO}_{2}$ was revealed advantageous to mitigate the phase transition and structure collapse incurred by hydrated $\mathrm{H}^{+} / \mathrm{Zn}^{2+}$ insertion/extraction, enabling high capacity and durable cycle life (Figure 1.4d).[44] Moreover, introducing water molecule into the layered structure of $\mathrm{MnO}_{2}$ was reported to effectively shield the electrostatic repulsion between the hydrated $\mathrm{Zn}^{2+}$ ions and host frameworks, thus leading to fast diffusion of charge carriers and enhanced structural stability (Figure 1.4e).[89]

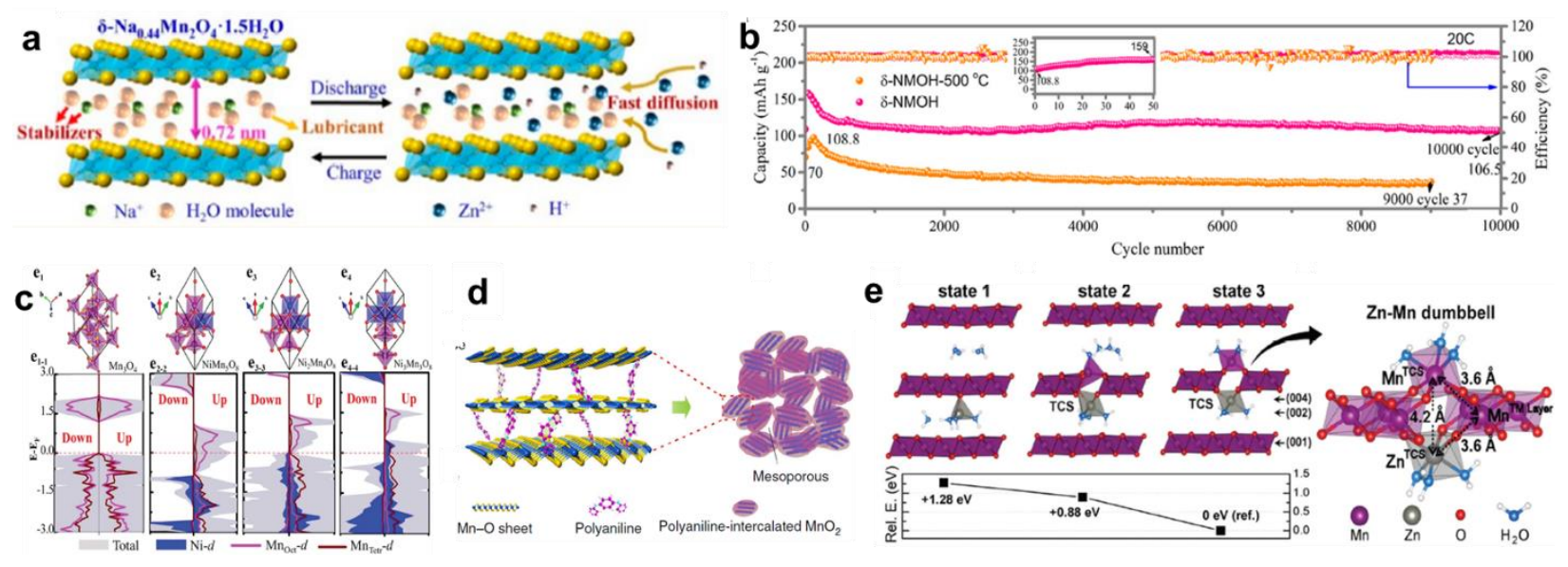

Figure 1.4 a) Schematic illustration of $\mathrm{Zn}^{2+}$ insertion/extraction in $\delta-\mathrm{MnO}_{2}$ framework with $\mathrm{Na}$ ion and water molecules pre-intercalation. b) Long-term cycling performance of $\mathrm{Zn}-\delta$-NMOH and $\mathrm{Zn}-\delta$-NMOH-500 batteries. [101] (Reproduced with permission. Copyright 2019, American Chemical Society) c) Primitive cell structures and partial density of states of pure $\mathrm{Mn}_{3} \mathrm{O}_{4}$ and Nidoped samples $\left(\mathrm{NiMn}_{5} \mathrm{O}_{8}, \mathrm{Ni}_{2} \mathrm{Mn}_{4} \mathrm{O}_{8}\right.$, and $\left.\mathrm{Ni}_{3} \mathrm{Mn}_{3} \mathrm{O}_{8}\right)$. [102] (Reproduced with permission. Copyright 2019, Royal Society of Chemistry) d) Schematic illustration of expanded intercalated structure of polyaniline (PANI)-intercalated $\mathrm{MnO}_{2}$ nanolayers. [44] (Reproduced with permission. Copyright 2018, Springer Nature) e) $\mathrm{Zn}$-intercalated structures and relative energies of cw- $\mathrm{MnO}_{2}$. [89] (Reproduced with permission. Copyright 2019, Royal Society of Chemistry)

\subsubsection{Electrolyte formulation}

Despite the development progress of manganese-based cathode materials, the electrode degradation related to manganese dissolution from $\mathrm{Mn}^{3+}$ disproportionation upon cycling cannot 
not effectively addressed only through modification of manganese oxides. Thus, electrolyte modification has been widely used to curtail the loss of dissolved $\mathrm{Mn}$ ions and regulate the electrochemistry for electrodes. The electrolyte plays a vital role in the performance of ZIBs since the electrochemical reactions at both the cathode and $\mathrm{Zn}$ anode are highly associated with the reaction environment in the electrolyte. Therefore, many research efforts focus on optimizing electrolytes. Several criteria should be taken into account for the electrolytes: i) intrinsic chemical stability, ii) a wide potential window to ensure the electrochemical stability, iii) high ionic conductivity, and iv) safety and low cost.[12] Herein, the mild acidic and near neutral aqueous electrolytes for ZIBs are briefly summarized.

To date, various zinc salts, such as $\mathrm{ZnSO}_{4}, \mathrm{Zn}\left(\mathrm{NO}_{3}\right)_{2}, \mathrm{ZnCl}_{2}, \mathrm{Zn}\left(\mathrm{CF}_{3} \mathrm{SO}_{3}\right)_{2}\left(\mathrm{Zn}(\mathrm{OTf})_{2}\right)$, $\mathrm{Zn}\left[\left(\mathrm{CF}_{3} \mathrm{SO}_{2}\right)_{2} \mathrm{~N}\right]_{2}\left(\mathrm{Zn}(\mathrm{TFSI})_{2}\right)$, and $\mathrm{Zn}\left(\mathrm{CH}_{3} \mathrm{COO}\right)_{2}$, have been used as electrolytes in mild aqueous ZIBs.[25,61,107-110] The investigation of the effect of electrolytes on electrochemical performance mainly focuses on the following factors: i) choice of zinc salts, ii) electrolyte concentrations, and iii) influence of additives. $\mathrm{ZnSO}_{4}$ and $\mathrm{Zn}\left(\mathrm{CF}_{3} \mathrm{SO}_{3}\right)_{2}$ are the most widely used electrolytes in aqueous ZIBs. Compared with $\mathrm{SO}_{4}{ }^{2-}$, fewer water molecules surrounding zinc cations in the presence of bulky $\mathrm{CF}_{3} \mathrm{SO}_{3}{ }^{-}$anions that alleviated the solvation effect, thus enhancing $\mathrm{Zn}^{2+}$ diffusion kinetics in the manganese oxide cathodes (Figure 1.5a, b). Meanwhile, it mitigated the Mn diffusion caused by the structural collapse of cathode active materials. In addition, the $\mathrm{Zn}\left(\mathrm{CF}_{3} \mathrm{SO}_{3}\right)_{2}$ electrolyte benefited the long-term stability of $\mathrm{Zn}$ anodes (Figure 1.5c).[38,61] Nevertheless, the higher price of $\mathrm{Zn}\left(\mathrm{CF}_{3} \mathrm{SO}_{3}\right)_{2}$ limits its widespread application in practical ZIBs. Besides, the high-concentration electrolytes was demonstrated to be advantageous for achieving high Coulombic efficiency and capacity retention of aqueous ZIBs.[30,61] However, capacity fade was still observed in manganese based cathodes with high-concentration electrolytes.

The water-in-salt electrolyte was reported an effective way to widen the suitable electrochemical potential window of ZIBs cathodes.[110,111] As aforementioned, $\mathrm{Zn}^{2+}$ ions were generally transported in water medium as a hydrated form surrounded by numerous water molecules. The water-in-salt electrolyte reduced the water activity, in other words, suppressed the solvation of $\mathrm{Zn}^{2+}$ ions and boosted their transportation, thus enhancing the stability of aqueous ZIBs.[112] Nevertheless, compared with the "water-in-salt" and organic electrolytes, it was demonstrated that aqueous electrolytes were preferred for the activation of manganese-based 
cathodes. With sufficient active water in an aqueous electrolyte, $\mathrm{Zn}^{2+}$ desolvation could be greatly facilitated due to its low desolvation energy, resulting in a high capacity for the manganese-based cathodes.[113]
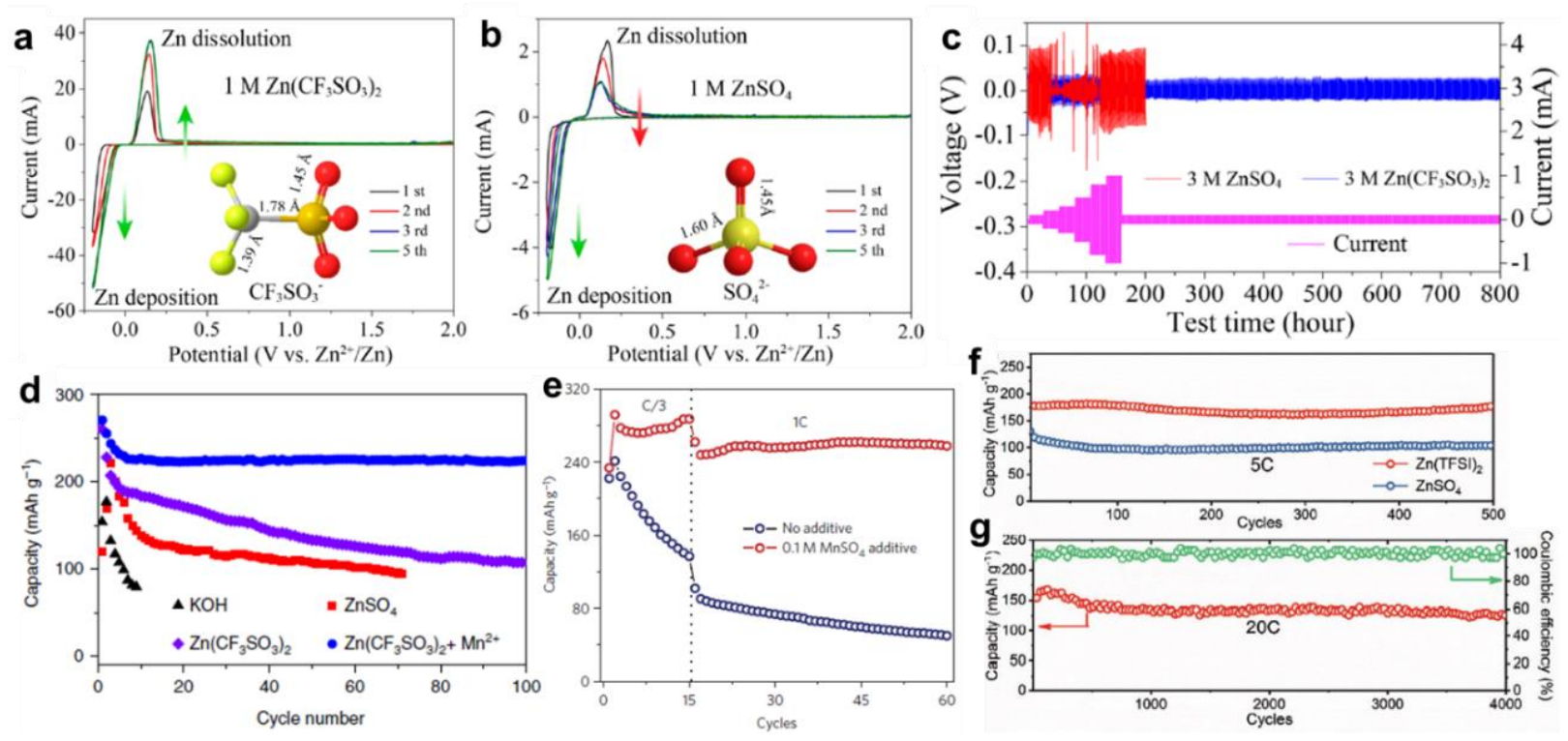

Figure 1.5 a) $\mathrm{CV}$ of $\mathrm{Zn}$ electrode in $1 \mathrm{M} \mathrm{Zn}\left(\mathrm{CF}_{3} \mathrm{SO}_{3}\right)_{2}$ and b) $1 \mathrm{M} \mathrm{ZnSO}_{4}$ electrolytes. c) Rate performance and long-term cyclability of $\mathrm{Zn} / \mathrm{Zn}$ symmetrical cells in $3 \mathrm{M} \mathrm{ZnSO}_{4}$ and $3 \mathrm{M}$ $\mathrm{Zn}\left(\mathrm{CF}_{3} \mathrm{SO}_{3}\right)_{2}$ electrolytes. [61] (Reproduced with permission. Copyright 2018, American Chemical Society) d) Cycling performance of $\mathrm{Zn}-\mathrm{MnO}_{2}$ batteries with electrolytes of 45 wt.\% $\mathrm{KOH}$ (at $0.32 \mathrm{C}), 3 \mathrm{M} \mathrm{ZnSO}_{4}, 3 \mathrm{M} \mathrm{Zn}\left(\mathrm{CF}_{3} \mathrm{SO}_{3}\right)_{2}$, and $3 \mathrm{M} \mathrm{Zn}\left(\mathrm{CF}_{3} \mathrm{SO}_{3}\right)_{2}$ with $0.1 \mathrm{M} \mathrm{Mn}\left(\mathrm{CF}_{3} \mathrm{SO}_{3}\right)_{2}$ additive at 0.65 C. [38] (Reproduced with permission. Copyright 2018, Springer Nature) e) Cycling performance of $\mathrm{MnO}_{2}$ in $2 \mathrm{M} \mathrm{ZnSO}_{4}$ electrolyte with/without 0.1 $\mathrm{M} \mathrm{MnSO}_{4}$ additive. [29] (Reproduced with permission. Copyright 2016, Springer Nature) f) Cycling performances of $\delta$ $\mathrm{MnO}_{2}$ cathodes at $5 \mathrm{C}$ in $\left.1 \mathrm{M} \mathrm{Zn(TFSI}\right)_{2}$ with $\left.0.1 \mathrm{~m} \mathrm{Mn(TFSI}\right)_{2}$ electrolyte and $1 \mathrm{M} \mathrm{ZnSO}_{4}$ with $0.1 \mathrm{M} \mathrm{MnSO}_{4}$ electrolyte. g) Long-term cycling performances of $\delta-\mathrm{MnO}_{2}$ cathodes at $20 \mathrm{C}$ in $1 \mathrm{M}$ $\mathrm{Zn}(\mathrm{TFSI})_{2}$ with $0.1 \mathrm{~m} \mathrm{Mn}(\mathrm{TFSI})_{2}$ electrolyte. [108] (Reproduced with permission. Copyright 2019, John Wiley \& Sons)

Pre-addition of Mn salts in the electrolytes was reported as a promising approach to improving capacity retention of manganese-based cathodes. The improvement in the stability and reversibility of $\mathrm{Zn} / \mathrm{MnO}_{2}$ batteries is presented in Figure 1.5d. With the aqueous $3 \mathrm{M} \mathrm{Zn}\left(\mathrm{CF}_{3} \mathrm{SO}_{3}\right)_{2}+0.1 \mathrm{M}$ $\mathrm{Mn}\left(\mathrm{CF}_{3} \mathrm{SO}_{3}\right)_{2}$ electrolyte, $\beta-\mathrm{MnO}_{2}$ delivered a high specific capacity of $225 \mathrm{mAh} \mathrm{g}^{-1}$ and excellent 
cyclability with 94\% capacity retention over 2000 cycles.[38] Pan et al. reported the pre-addition of $\mathrm{MnSO}_{4}$ into $\mathrm{ZnSO}_{4}$ electrolyte to balance the dissolution equilibrium of $\mathrm{Mn}^{2+}$. With $\mathrm{Mn}^{2+}$ preadding in the electrolyte, the excellent long-cycle stability could be achieved with $92 \%$ capacity retention over 5,000 cycles at a rate of $5 \mathrm{C}$. Specifically, the capacity of $285 \mathrm{mAh} \mathrm{g}^{-1}$ was maintained after initial 15 cycles at $\mathrm{C} / 3$ with $\mathrm{MnSO}_{4}$ pre-addition in the electrolyte. In contrast, the capacity quickly faded from 240 to $140 \mathrm{mAh} \mathrm{g}^{-1}$ without $\mathrm{MnSO}_{4}$ in the electrolyte (Figure 1.5e). The optimal concentration of $\mathrm{MnSO}_{4}$ additive in the $\mathrm{ZnSO}_{4}$-based electrolyte was 0.1 M.[29] Recently, Jin et al. reported that $\delta-\mathrm{MnO}_{2}$ cathode exhibited favorable charge storage kinetics in $\mathrm{Zn}(\mathrm{TFSI})_{2}$ electrolyte compared with the $\mathrm{ZnSO}_{4}$ electrolyte, which was responsible for enabling high capacity and rate capability (Figure 1.5f). With the addition of $\mathrm{Mn}(\mathrm{TFSI})_{2}$, a discharge capacity of $136.9 \mathrm{mAh} \mathrm{g}^{-1}$ (93\% capacity retention) was still maintained after 4000 cycles even at 20 C (Figure 1.5g).[108]

As the cyclability of the manganese-based cathode could be significantly improved by preaddition of $\mathrm{Mn}^{2+}$ in the electrolyte, the role of $\mathrm{Mn}^{2+}$ additive in the electrochemistry of aqueous ZIBs has become a topic of debate. The pre-addition of $\mathrm{Mn}^{2+}$ into the electrolyte was demonstrated to establish a dynamic equilibrium between Mn dissolution and deposition during discharging and charging, thus restricting the capacity loss from Mn dissolution and promoting cycling stability of manganese-based cathodes.[29,114,115] Moreover, the $\mathrm{Mn}^{2+}$ additive in the electrolyte was also involved in the electrochemical reactions during the charge process, which introduced additional active materials into the original cathodes and thus provide additional capacity.[116] It was demonstrated that $\mathrm{Mn}^{2+}$ could be electrochemically deposited upon charging on the cathode in two ways: direct electrochemical oxidation and reaction with discharge byproduct ZHS (see details in section 1.4).[35,48,115,117-120] Given the positive role of $\mathrm{Mn}^{2+}$ deposition in enhancing the cycling stability, increasing the electrode surface areas by engineering nanostructures or doping was utilized to facilitate deposition rate of Mn species on cathodes.[104,120] Therefore, studies on developing reversible manganese-based cathodes with low dissolution rates and high deposition rates may help to realize practical ZIBs, which needs the synergistic modification of active materials and electrolytes.

All in all, manganese-based cathodes show great potentials in aqueous rechargeable ZIBs. Research interests in manganese-based cathodes have focused on developing various strategies including crystallographic structure engineering, micro/nanostructure engineering, compositing 
with conductive substrates, defect engineering, cation doping, interlayer engineering and electrolyte modification. New methods are still required in the future to enable the high-capacity two-electron redox reactions of Mn centers and improve their rate capability and cyclability for practical application.

\subsubsection{Charge storage mechanisms in manganese-based cathodes}

In addition to developing advanced manganese-based cathode materials of ZIBs, extensive efforts have been devoted to understanding the charge storage mechanisms. Nonetheless, the underlying electrochemical reaction mechanisms remain unclear and even controversial. To date, several reaction mechanisms have been proposed for aqueous $\mathrm{ZIBs,} \mathrm{including} \mathrm{pure} \mathrm{Zn}^{2+}$ intercalation/deintercalation, chemical conversion reactions, $\mathrm{H}^{+} / \mathrm{Zn}^{2+}$ co-insertion, mixed intercalation and conversion reactions, and dissolution/deposition mechanism. A comprehensive review and deep discussion on these reported mechanisms are summarized as follows.

\section{(1) $\mathrm{Zn}^{2+}$ intercalation/deintercalation mechanism}

Owing to the favorable large tunnel structure and high charge storage capability, the early studies in $\mathrm{Zn}^{2+}$ intercalation/deintercalation mechanism of manganese oxide cathodes were mainly focused on $\alpha$ and $\delta$ polymorphs. Xu et al. claimed $\mathrm{Zn}^{2+}$ intercalation in the tunnels of $\alpha-\mathrm{MnO}_{2}$ to form spinel $\mathrm{ZnMn}_{2} \mathrm{O}_{4}$ upon discharging (Figure 1.6a). The corresponding reactions can be described as follows:[25]

Cathodic reaction: $\mathrm{Zn}^{2+}+2 \mathrm{e}^{-}+2 \alpha-\mathrm{MnO}_{2} \leftrightarrow \mathrm{ZnMn}_{2} \mathrm{O}_{4}$

Anodic reaction: $\mathrm{Zn} \leftrightarrow \mathrm{Zn}^{2+}+2 \mathrm{e}^{-}$

Later, the same group revealed the $\mathrm{Zn}^{2+}$ insertion/extraction into/from tunnels of $\alpha-, \beta-, \gamma-$, and $\delta$ type $\mathrm{MnO}_{2}$. It was demonstrated that the discharge capacity of $\mathrm{MnO}_{2}$ was highly associated with the crystallographic form, while no direct correlation with the surface area. Large tunnel size was favorable for the accommodation of $\mathrm{Zn}^{2+}$, consequently, the initial discharge capacity showed a trend of $\delta-\mathrm{MnO}_{2}>\alpha-\mathrm{MnO}_{2}>\gamma-\mathrm{MnO}_{2}>\beta-\mathrm{MnO}_{2}$.[65] Similarly, Alfaruqi et al. reported $\mathrm{Zn}^{2+}$ insertion through tunnel structure of $\alpha-\mathrm{MnO}_{2}$, which induced expansion of the [2×2] tunnels (Figure 1.6b). Additionally, the reversible change of $\mathrm{Mn}$ valance state between $\mathrm{Mn}^{4+}$ and $\mathrm{Mn}^{3+}$ was identified by ex-situ synchrotron XAS measurements.[26] 


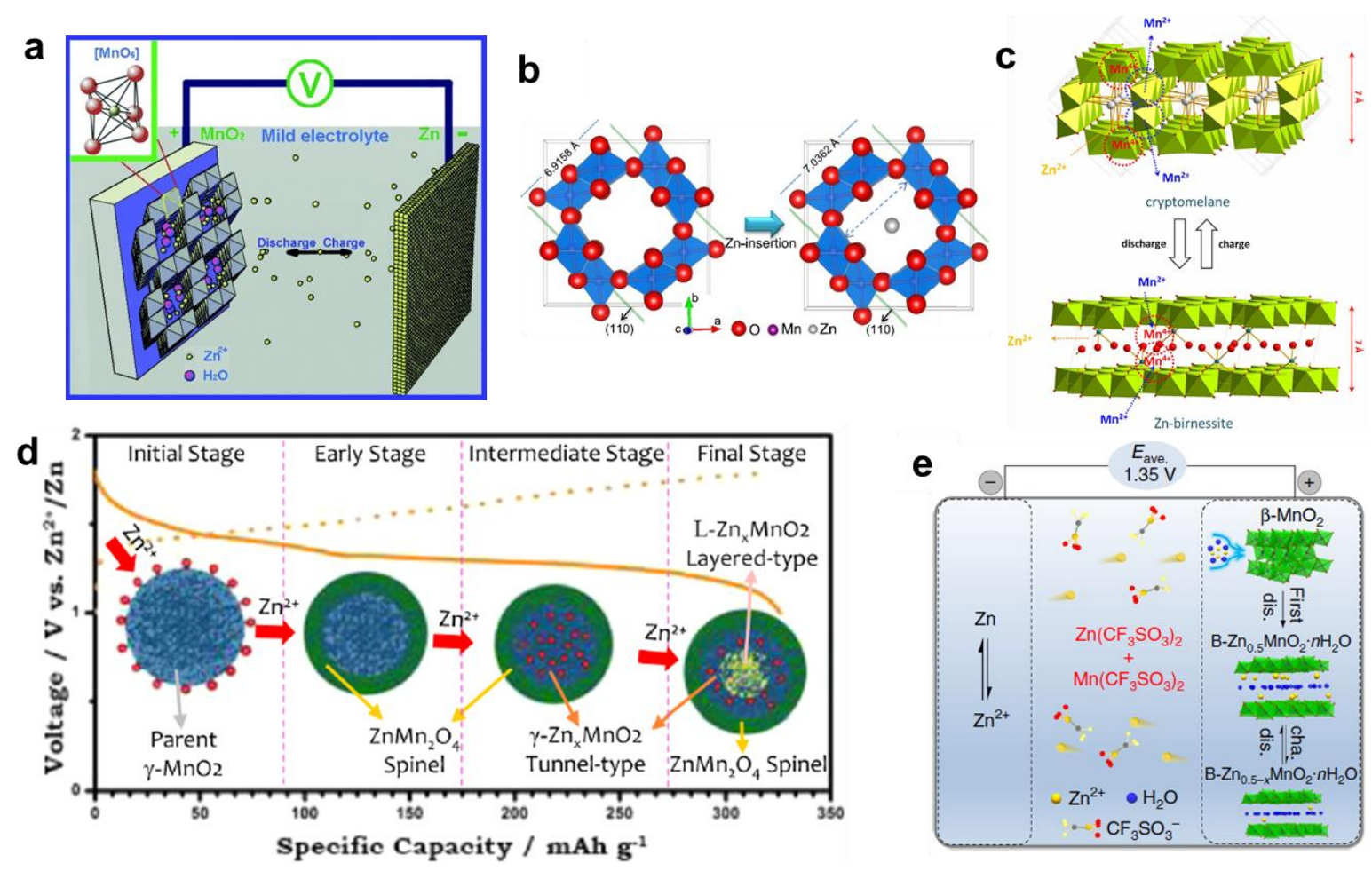

Figure 1.6 a) Schematic illustration of $\mathrm{ZIB}$ with $\mathrm{Zn}$ anode, $\alpha-\mathrm{MnO}_{2}$ cathode and mild electrolyte. [25] (Reproduced with permission. Copyright 2020, John Wiley \& Sons) Schematic illustration of $\mathrm{Zn}^{2+}$ insertion mechanism in b) $\alpha-\mathrm{MnO}_{2}$ tunnel structure with tunnel size expansion, [26] (Reproduced with permission. Copyright 2015, Elsevier) c) $\alpha-\mathrm{MnO}_{2}$ with reversible transformation from $\alpha-\mathrm{MnO}_{2}$ to layered Zn-birnessite, [27] (Reproduced with permission. Copyright 2014, Springer Nature) d) $\gamma-\mathrm{MnO}_{2}$ complex phase transformation. [39] (Reproduced with permission. Copyright 2015, American Chemical Society) e) in $\beta-\mathrm{MnO}_{2}$ with structural transformation from $\beta-\mathrm{MnO}_{2}$ to layered $\mathrm{Zn}$-buserite in the initial discharging step. [38] (Reproduced with permission. Copyright 2020, Springer Nature)

Different from the view of $\mathrm{ZnMn}_{2} \mathrm{O}_{4}$ formation, Lee et al. reported that $\mathrm{Zn}^{2+}$ intercalation in $\alpha$ $\mathrm{MnO}_{2}$ induced a reversible phase transition from tunnel-type to layered $\mathrm{Zn}$-birnessite. As $\mathrm{Zn}^{2+}$ intercalation, $\mathrm{Mn}^{4+}$ was partially reduced to unstable $\mathrm{Mn}^{3+}$ and then disproportionated into $\mathrm{Mn}^{4+}$ and $\mathrm{Mn}^{2+}$ due to the Jahn-Teller distortion (Equation 3 and 4), resulting in the destructive dissolution of around $1 / 3 \mathrm{Mn}$ from $\alpha-\mathrm{MnO}_{2}$ cathode into the electrolyte as $\mathrm{Mn}^{2+}$.

$$
\mathrm{Mn}^{4+}(\mathrm{s})+\mathrm{e}^{-} \rightarrow \mathrm{Mn}^{3+}(\mathrm{s})
$$




$$
\begin{gathered}
2 \mathrm{Mn}^{3+}(\mathrm{s}) \rightarrow \mathrm{Mn}^{4+}(\mathrm{s})+\mathrm{Mn}^{2+}(\mathrm{aq}) \\
\mathrm{Mn}^{2+}(\mathrm{aq}) \rightarrow \mathrm{Mn}^{4+}(\mathrm{s})+2 \mathrm{e}^{-}
\end{gathered}
$$

The Mn dissolution broke the chains between layers of $\alpha-\mathrm{MnO}_{2}$ structure and created $\mathrm{Mn}$ vacancy in the upper and underlying layers, thus triggering a phase transition to layered Zn-birnessite (Figure 1.6c). During the charging step, the dissolved $\mathrm{Mn}^{2+}$ ions inserted back into Zn-birnessite to construct bridges between layers, thus recovering the original tunnel-type $\alpha-\mathrm{MnO}_{2}$ structure (Equation 5).[27] Nevertheless, their following work of in situ XRD analysis suggested that Znbuserite (interlayer spacing of $11 \AA$ ) rather than Zn-birnessite $(7 \AA)$ was directly formed as a result of $\mathrm{Zn}^{2+}$ insertion into a- $\mathrm{MnO}_{2}$. They found the challenge to exactly determinate the layered phase product just through the ex situ XRD analysis as the drying treatment easily caused dehydration of $\mathrm{Zn}$-buserite and the shrinkage of interlayer spacing.[28]. In another representative study, $\mathrm{Zn}^{2+}$ intercalation was suggested to associate with different discharge platforms. Wu et al. expounded a two-step $\mathrm{Zn}^{2+}$ intercalation mechanism, in which $\mathrm{Zn}^{2+}$ initially inserted in the water layers of hydrated Zn-buserite at the first discharge platform (DP1) and then inserted in the tunnel structure of $\mathrm{MnO}_{2}$ at the second discharge platform (DP2). According to the galvanostatic intermittent titration technique (GITT) analysis, the $\mathrm{Zn}^{2+}$ insertion speed at DP2 was much lower than that at DP1, which was attributed to the different insertion sites. $\mathrm{Zn}^{2+}$ intercalation at DP2 induced larger volume change and stronger electrostatic interaction than that at DP1, leading to a lower $\mathrm{Zn}^{2+}$ insertion rate.[32]

The successive $\mathrm{Zn}^{2+}$ intercalation induced complex phase transformation was also elucidated in $\gamma-\mathrm{MnO}_{2}$. In the early discharge stage, $\gamma-\mathrm{MnO}_{2}$ partially transformed to spinel-type $\mathrm{ZnMn}_{2} \mathrm{O}_{4}$. Then tunnel-type $\gamma-\mathrm{Zn}_{\mathrm{x}} \mathrm{MnO}_{2}$ phase was formed as inserted $\mathrm{Zn}^{2+}$ further occupied the $1 \times 2$ tunnels of $\gamma$ $\mathrm{MnO}_{2}$. In the final stage of discharging, the fully inserted tunnels opened the structure to form

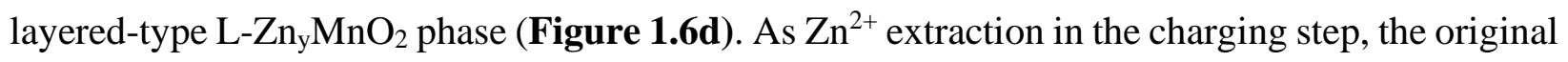
$\gamma-\mathrm{MnO}_{2}$ phase could be recovered.[39] $\beta-\mathrm{MnO}_{2}$ was later reported to present $\mathrm{Zn}^{2+}$ insertion/extraction mechanism with a combination of solid solution and conversion reactions.[37] Zhang et al. elucidated a versatile mechanism for tunnel-type $\mathrm{MnO}_{2}$ based on a comprehensive investigation of $\alpha, \beta$ and $\gamma-\mathrm{MnO}_{2}$ cathodes.[38] Unlike the previous view of the reversible phase transformation of parent tunneled to layered structure upon discharging/charging,[27,39] they clarified that this phase transition only occurred in the initial discharging step, while the resulting 
layered $\mathrm{Zn}$-buserite was employed as a new host for reversible $\mathrm{Zn}^{2+}$ intercalation in subsequent cycles (Figure 1.6e).[38] Given the possible structural pulverization and capacity loss caused by generally existed phase transformation from tunneled to layered structure, directly using layered $\mathrm{MnO}_{2}$ as an intercalation host was considered to be intrinsically favorable for minimizing capacity loss.[44,121]

\section{(2) Chemical conversion reaction (or $\mathrm{H}^{+}$intercalation) mechanism}

In contrast to the classic $\mathrm{Zn}^{2+}$ intercalation mechanism, Lee et al. believed that a conversion reaction mechanism that involved $\mathrm{Mn}$ reduction-disproportionation-dissolution and ZHS formation was responsible for the electrochemical charge storage in $\alpha-\mathrm{MnO}_{2}$ cathode (Figure 1.7a).[122] $\mathrm{MnO}_{2}$ was initially electrochemically reduced to $\mathrm{Mn}^{3+}$, the unstable $\mathrm{Mn}^{3+}$ then underwent a disproportionation reaction, resulting in $\mathrm{Mn}$ dissolution into the electrolyte as $\mathrm{Mn}^{2+}$. The in situ XRD analysis confirmed the reversible precipitation/dissolution of ZHS upon discharging/charging (Figure 1.7b). A special cell was designed to in situ monitor the $\mathrm{pH}$ variation during the discharge and charge process. Meanwhile, the $\mathrm{Zn}$ and $\mathrm{Mn}$ contents in the electrolyte were evaluated using atomic absorption spectroscopy (AAS). The results revealed a strong correlation between ZHS precipitation/dissolution and electrolyte $\mathrm{pH}$ variation. The increasing $\mathrm{pH}$ resulted from continuous $\mathrm{Mn}$ dissolution triggered the consequent ZHS precipitation upon discharging. In contrast, upon charging, the re-oxidation of manganese led to a decreasing $\mathrm{pH}$ of

electrolyte, which accelerated ZHS dissolution (Figure 1.7c, d). Note that only $\alpha-\mathrm{MnO}_{2}$ phase was detected in the discharged cathode after removing the cover layer of ZHS and no $\mathrm{Zn}^{2+}$ or $\mathrm{H}^{+}$ insertion was found. This $\mathrm{pH}$ related conversion reaction can be described as follows:

$$
3 \mathrm{MnO}_{2}+3 \mathrm{Zn}+5 \mathrm{Zn}^{2+}+2 \mathrm{SO}_{4}^{2-}+16 \mathrm{H}_{2} \mathrm{O} \leftrightarrow 3 \mathrm{Mn}^{2+}+2 \mathrm{Zn}_{4}(\mathrm{OH})_{6}\left(\mathrm{SO}_{4}\right) \cdot 5 \mathrm{H}_{2} \mathrm{O} \downarrow
$$

Another view on the conversion reaction mechanism was raised by Pan et al. The XRD result indicated that $\mathrm{MnOOH}$ was the product of the $\mathrm{H}^{+}$insertion reaction in $\mathrm{MnO}_{2}$ (Figure 1.7e). In addition, STEM-EDS mapping evidenced that $\mathrm{Zn}$ was mainly concentrated on the flake-like ZHS instead of on the $\alpha-\mathrm{MnO}_{2}$ nanorods (Figure 1.7f, g). The detailed discharging reactions were formulated as follows.[29]

$$
\begin{gathered}
\mathrm{H}_{2} \mathrm{O} \leftrightarrow \mathrm{H}^{+}+\mathrm{OH}^{-} \\
\mathrm{MnO}_{2}+\mathrm{H}^{+}+\mathrm{e}^{-} \leftrightarrow \mathrm{MnOOH}
\end{gathered}
$$




$$
\frac{1}{2} \mathrm{Zn}^{2+}+\mathrm{OH}^{-}+\frac{1}{6} \mathrm{ZnSO}_{4}+\frac{x}{6} \mathrm{H}_{2} \mathrm{O} \leftrightarrow \frac{1}{6} \mathrm{ZnSO}_{4}\left[\mathrm{Zn}\left(\mathrm{OH}_{2}\right)\right]_{3} \cdot \mathrm{xH}_{2} \mathrm{O}
$$

Contrary to the previous explanation on ZHS formation, Pan et al. ascribed it to the consumption/release of $\mathrm{H}^{+}$related to conversion reaction rather than the $\mathrm{pH}$ variation induced by $\mathrm{Mn}$ dissolution/deposition suggested by Lee et al. Upon discharging, $\alpha-\mathrm{MnO}_{2}$ Upon discharging, $\alpha-\mathrm{MnO}_{2}$ converted to $\mathrm{MnOOH}$ at cost of $\mathrm{H}^{+}$consumption, the $\mathrm{OH}^{-}$left behind combined with $\mathrm{Zn}^{2+}$ and $\mathrm{SO}_{4}{ }^{2+}$ in the electrolyte to form ZHS precipitate. This conversion reaction mechanism accompanied by ZHS precipitation was schematically illustrated by Ha et al. in Figure 1.7h.[123]
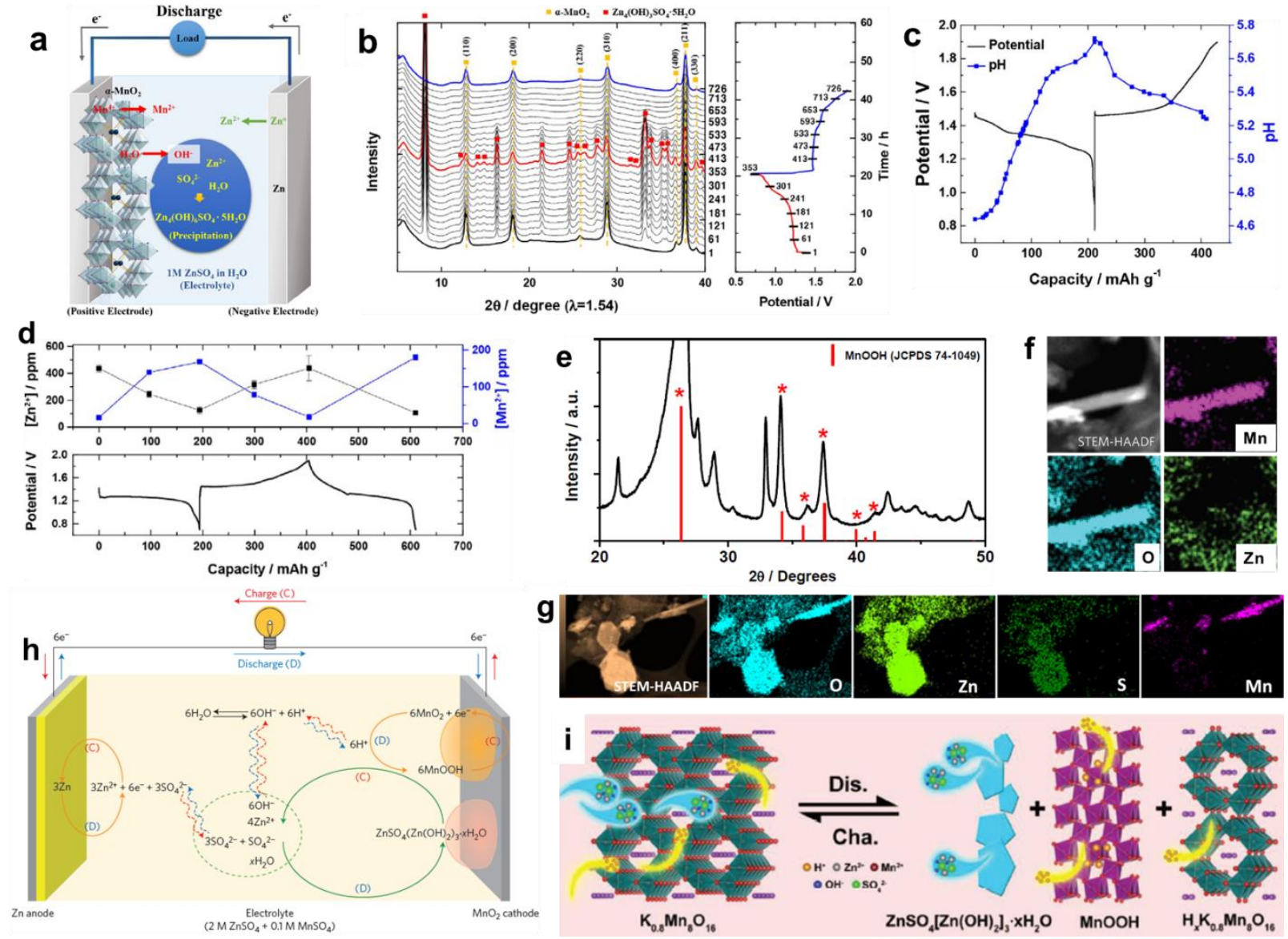

Figure 1. 7 a) Schematic showing the discharge process of $\alpha-\mathrm{MnO}_{2} / \mathrm{Zn}$ cell in aqueous $\mathrm{ZnSO}_{4}$ electrolyte. b) In situ XRD patterns of $\alpha-\mathrm{MnO}_{2}$ cathode. c) electrolyte $\mathrm{pH}$ variations during the first discharge-charge process. d) $\mathrm{Zn}$ and $\mathrm{Mn}$ contents in the electrolyte at different discharge/charge states. [122] (Reproduced with permission. Copyright 2016, John Wiley \& Sons) e) XRD pattern of $\alpha-\mathrm{MnO}_{2}$ cathode discharged to $1 \mathrm{~V}$ in first cycle. $\mathrm{f}, \mathrm{g}$ ) STEM-EDS mappings in the $\alpha-\mathrm{MnO}_{2}$ electrode in the initial fully discharged state. [29] (Reproduced with permission. 
Copyright 2016, Springer Nature) Schematic illustration of reaction mechanism of h) $\mathrm{Zn} / \mathrm{MnO}_{2}$ battery in aqueous $\mathrm{ZnSO}_{4}$ electrolyte with $\mathrm{MnSO}_{4}$ additive. [123] (Reproduced with permission. Copyright 2016, Springer Nature) i) KMO cathode in aqueous ZIBs. [36] (Reproduced with permission. Copyright 2019, John Wiley \& Sons)

It should be pointed out that the similar conversion reaction in mild aqueous $\mathrm{Zn} / \mathrm{MnO}_{2}$ batteries dated back to the 1980s. Shoji et al. (1993) developed a rechargeable $\mathrm{Zn}\left|\mathrm{ZnSO}_{4}(\mathrm{aq})\right| \gamma-\mathrm{MnO}_{2}$ battery and claimed the formation of basic zinc sulfate (BZS, same as ZHS) and $\mathrm{MnOOH}$ intermediate at the discharged cathode.[18] Later, Kim et al. (1998) reported the similar reaction in the $\mathrm{Zn}\left|\mathrm{ZnSO}_{4}(\mathrm{aq})\right| \delta-\mathrm{MnO}_{2}$ battery. [68] It was believed that the $\mathrm{Mn}$ dissolution was attributed to a two-step, two-electron pathway, wherein the $\mathrm{MnO}_{2}$ was initially transformed to $\mathrm{MnOOH}$ phase $\left(\mathrm{MnO}_{2}+\mathrm{H}^{+}+\mathrm{e}^{-} \rightarrow \mathrm{MnOOH}\right)$ and then further reduced to $\mathrm{Mn}^{2+}\left(\mathrm{MnOOH}+3 \mathrm{H}^{+}+\mathrm{e}^{-} \rightarrow \mathrm{Mn}^{2+}+\right.$ $2 \mathrm{H}_{2} \mathrm{O}$ ). They demonstrated that the formation of electrochemical inactive ZHS and Mn dissolution were responsible for the capacity decay. Moreover, the deposited ZHS was associated with the amount of $\mathrm{MnSO}_{4}$ additive in $\mathrm{ZnSO}_{4}$-based electrolyte.[68]

A controversy then arose, whether $\mathrm{H}^{+}$insertion induced phase transformation of $\mathrm{MnO}_{2}$. Oberholzer et al. proposed a $\mathrm{H}^{+}$(de)intercalation-based charge storage mechanism for $\alpha-\mathrm{MnO}_{2}$ $\left(\mathrm{MnO}_{2}+\mathrm{H}^{+}+\mathrm{e}^{-} \leftrightarrow \mathrm{HMnO}_{2}\right)$. Interestingly, the lattice expansion of $\alpha-\mathrm{MnO}_{2}$ was observed upon the solid-solution type $\mathrm{H}^{+}$intercalation, while no structural transformation of $\alpha-\mathrm{MnO}_{2}$ to $\mathrm{MnOOH}$ was detected.[124] Fang et al. demonstrated a $\mathrm{H}^{+}$storage mechanism that simultaneously involved insertion and conversion reactions in $\mathrm{K}_{0.8} \mathrm{Mn}_{8} \mathrm{O}_{16}$ (Figure 1.7i). Three kinds of products were identified at the fully discharged state, including the $\mathrm{H}_{x} \mathrm{~K}_{0.8} \mathrm{Mn}_{8} \mathrm{O}_{16}$ resulted from $\mathrm{H}^{+}$insertion, $\mathrm{MnOOH}$ or $\mathrm{K}_{0.1} \mathrm{MnOOH}$ derived from conversion reaction, and the consequent ZHS precipitate. The similar reaction behavior was also observed in the control sample of $\alpha-\mathrm{MnO}_{2} \cdot[36]$

\section{(3) $\mathrm{Zn}^{2+} / \mathrm{H}^{+}$co-insertion mechanism}

In contrast to the pure $\mathrm{Zn}^{2+}$ or $\mathrm{H}^{+}$insertion mechanisms, co-insertion of $\mathrm{H}^{+}$and $\mathrm{Zn}^{2+}$ intercalations were demonstrated to account for the charge storage in manganese-based cathodes. However, the assignment of $\mathrm{H}^{+}$and $\mathrm{Zn}^{2+}$ insertions in the two-step discharge process (DP1 and DP2) is still under debate. The detailed controversy on this mechanism was summarized as follows. 
i) Consecutive $\mathrm{Zn}^{2+}$ and $\mathrm{H}^{+}$insertion. Sun et al. proposed a consequent reaction mechanism with $\mathrm{H}^{+}$insertion at DP1 followed by $\mathrm{Zn}^{2+}$ insertion at DP2 in $\varepsilon-\mathrm{MnO}_{2}$ (Figure 1.8a).[47] The GITT and EIS measurements at different discharging states exhibited that the reaction at DP2 demonstrated larger overvoltage, higher charge transfer and diffusion resistances compared with that at DP1. It was conceived that the DP1 was attributed to the insertion reaction of smaller-sized $\mathrm{H}^{+}$with fast kinetics, while the DP2 was assigned to the insertion of large-sized $\mathrm{Zn}^{2+}$ with sludges reaction kinetics. This speculation was subsequently supported by the significantly different electrochemical behaviors of $\mathrm{MnO}_{2}$ cathode in the electrolytes without $\mathrm{H}^{+}$or $\mathrm{Zn}^{2+}$. In the absence of $\mathrm{Zn}^{2+}$, the DP2 disappeared whereas the DP1 was still maintained (Figure 1.8b). Moreover, the formation of $\mathrm{MnOOH}$ at DP1 and $\mathrm{ZnMn}_{2} \mathrm{O}_{4}$ at DP2 further verified the consequent $\mathrm{H}^{+}$and $\mathrm{Zn} 2+$ insertion mechanism (Figure 1.8c). Since then, such co-insertion process involving $\mathrm{H}^{+}$ intercalation in DP1 and $\mathrm{Zn}^{2+}$ intercalation in DP2 has been frequently reported in ZIBs with various manganese oxide-based cathodes, such as $\alpha-\mathrm{MnO}_{2},[97,125,126] \delta-\mathrm{MnO}_{2},[45,46,66,101]$ EMD (mix of $\varepsilon-\mathrm{MnO}_{2}$ and $\gamma-\mathrm{MnO}_{2}$ ),[114] $\mathrm{Mn}_{3} \mathrm{O}_{4},[56] \mathrm{Mn}_{2} \mathrm{O}_{3},[76] \mathrm{MnO}_{\mathrm{x}},[95] \mathrm{ZnMn}_{2} \mathrm{O}_{4},[60]$ etc.
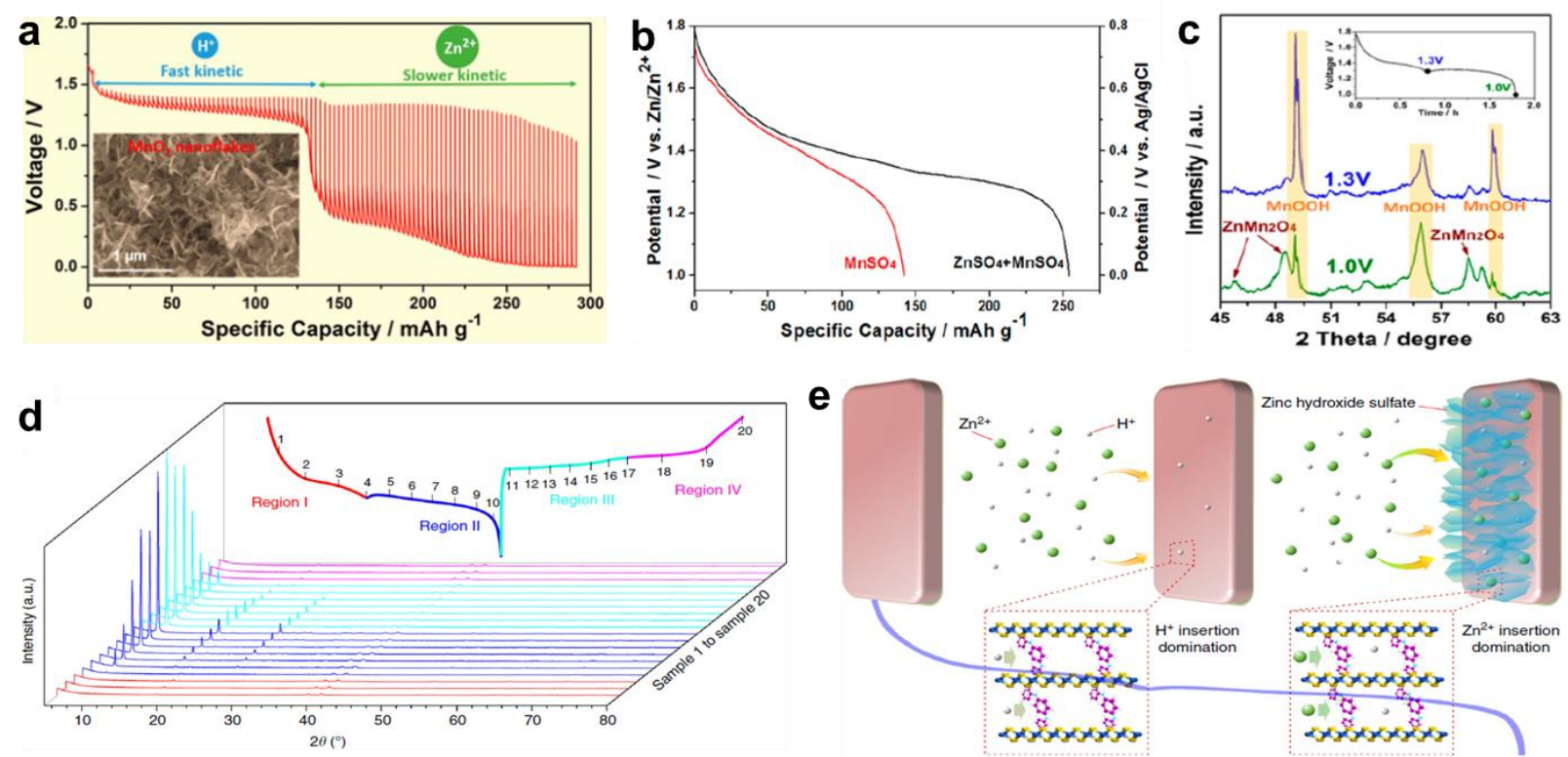

Figure 1.8 a) GITT profiles of $\mathrm{Zn} / \varepsilon-\mathrm{MnO}_{2}$ cell. b) Discharge curves of $\varepsilon-\mathrm{MnO}_{2}$ electrodes in the electrolyte with and without $\mathrm{ZnSO}_{4}$. c) Ex situ XRD patterns of $\varepsilon-\mathrm{MnO}_{2}$ electrodes at depth of discharge at 1.3 and $1.0 \mathrm{~V}$, respectively. [47] (Reproduced with permission. Copyright 2018, American Chemical Society) d) Evolution of ex situ XRD patterns of cathode during the 
charge/discharge process. e) Schematic illustration of sequential insertion of $\mathrm{H}^{+}$and $\mathrm{Zn}^{2+}$. [44] (Reproduced with permission. Copyright 2018, Springer Nature)

ii) $\mathrm{H}^{+}$insertion at DP1 followed by co-insertion of $\mathrm{H}^{+} / \mathrm{Zn}^{2+}$ at DP2. The later mechanism investigation demonstrated that $\mathrm{H}^{+}$insertion dominated in DP1, while co-insertion of $\mathrm{H}^{+}$and $\mathrm{Zn}^{2+}$ existed in DP2.[44,88] Huang et al. developed a polyaniline (PANI)-intercalated layered $\mathrm{MnO}_{2}$ cathode for aqueous ZIBs. [44] The phase and morphology evolutions of cathode under discharging and charging were carefully investigated by ex situ XRD and SEM. No new phase was detected by XRD in DP1. Simultaneously, no obvious morphology changes appeared in DP1 (Figure 1.8d). Moreover, the abundant Zn and ZHS large flakes only emerged in DP2. As a result, the discharge process was considered to involve $\mathrm{H}^{+}$dominated insertion in the DP1 and $\mathrm{H}^{+} / \mathrm{Zn}^{2+}$ co-insertion in the DP2 (Figure 1.8e).

iii) $\mathrm{Zn}^{2+}$ insertion at DP1 and subsequent $\mathrm{H}^{+}$insertion at DP2. Li et al. reported a reversed charge storage sequence, in which the $\mathrm{Zn}^{2+}$ insertion reaction to form $\mathrm{ZnMn}_{2} \mathrm{O}_{4}$ occurred at DP1, while the conversion reaction between $\mathrm{H}^{+}$and $\mathrm{MnO}_{2}$ to produce $\mathrm{MnOOH}$ took place at DP2.[35] Later, Huang et al. claimed a similar concept of $\mathrm{Zn}^{2+}$ insertion followed by $\mathrm{H}^{+}$insertion. The electrochemical measurements revealed that the two-step redox reactions involved a homogeneous reaction at DP1 and a heterogeneous reaction at DP2. Further, according to the XRD and TEM results, they concluded that the $\mathrm{Zn}^{2+}$ insertion occurred at DP1, while the $\mathrm{H}^{+}$insertion into $\mathrm{MnO}_{2}$ to produce $\mathrm{MnOOH}$, formation of $\mathrm{ZHS}$, together with the conversion reaction of $\mathrm{MnO}_{2}$ to $\mathrm{Mn}_{2} \mathrm{O}_{3}$, took place at DP2 as follows (Figure 1.9a):

$$
\begin{aligned}
& \left.\mathrm{MnO}_{2}+\mathrm{xZn}^{2+}+2 \mathrm{xe}^{-} \rightarrow \mathrm{Zn}_{\mathrm{x}} \mathrm{MnO}_{2} \quad \text { (at above } 1.4 \mathrm{~V}\right) \\
& \mathrm{MnO}_{2}+\mathrm{H}^{+}+\mathrm{e}^{-} \rightarrow \mathrm{MnOOH} \quad(\text { at } 1.3 \text { to } 1.0 \mathrm{~V}) \\
& 2 \mathrm{MnO}_{2}+2 \mathrm{H}^{+}+2 \mathrm{e}^{-} \rightarrow \mathrm{Mn}_{2} \mathrm{O}_{3}+\mathrm{H}_{2} \mathrm{O} \quad \text { (at } 1.3 \text { to } 1.0 \mathrm{~V} \text { ) }
\end{aligned}
$$

In the subsequent charge process, the $\mathrm{MnOOH}, \mathrm{Mn}_{2} \mathrm{O}_{3}$, and $\mathrm{Zn}_{\mathrm{x}} \mathrm{MnO}_{2}$ were converted back to $\mathrm{MnO}_{2}$ (Figure 1.9b). [98]

Similarly, Jin et al. proposed the reaction mechanism that $\mathrm{Zn}^{2+}$ insertion at DP1 followed by $\mathrm{H}^{+}$ conversion reaction at DP2 for $\delta-\mathrm{MnO}_{2}$ cathode in $\mathrm{Zn}(\mathrm{TFSI})_{2}$ electrolyte (Figure 1.9c).[108] The ex situ XRD and HR-TEM results suggested that the $\mathrm{Zn}^{2+}$ storage in $2 \mathrm{D}$ structured $\delta-\mathrm{MnO}_{2}$ was implemented via a nondiffusion-controlled "pseudocapacitive-like" intercalation process at high 
discharge voltage (> $1.43 \mathrm{~V}$ ) without a phase variation (Figure 1.9d, e). The lower discharge voltage domain was explained based on the diffusion-controlled $\mathrm{H}^{+}$conversion reaction, accompanied by the formation of $\mathrm{MnOOH}$ and $\mathrm{Zn}(\mathrm{TFSI})_{2}\left[\mathrm{Zn}(\mathrm{OH})_{2}\right]_{3} \cdot \mathrm{xH}_{2} \mathrm{O}$ (an analogy of ZHS produced in $\mathrm{ZnSO}_{4}$-based electrolyte). Note that, in contrast to the insoluble $\mathrm{ZHS}$, this $\mathrm{Zn}(\mathrm{TFSI})_{2}\left[\mathrm{Zn}(\mathrm{OH})_{2}\right]_{3} . \mathrm{xH}_{2} \mathrm{O}$ byproduct was evidenced soluble in water.

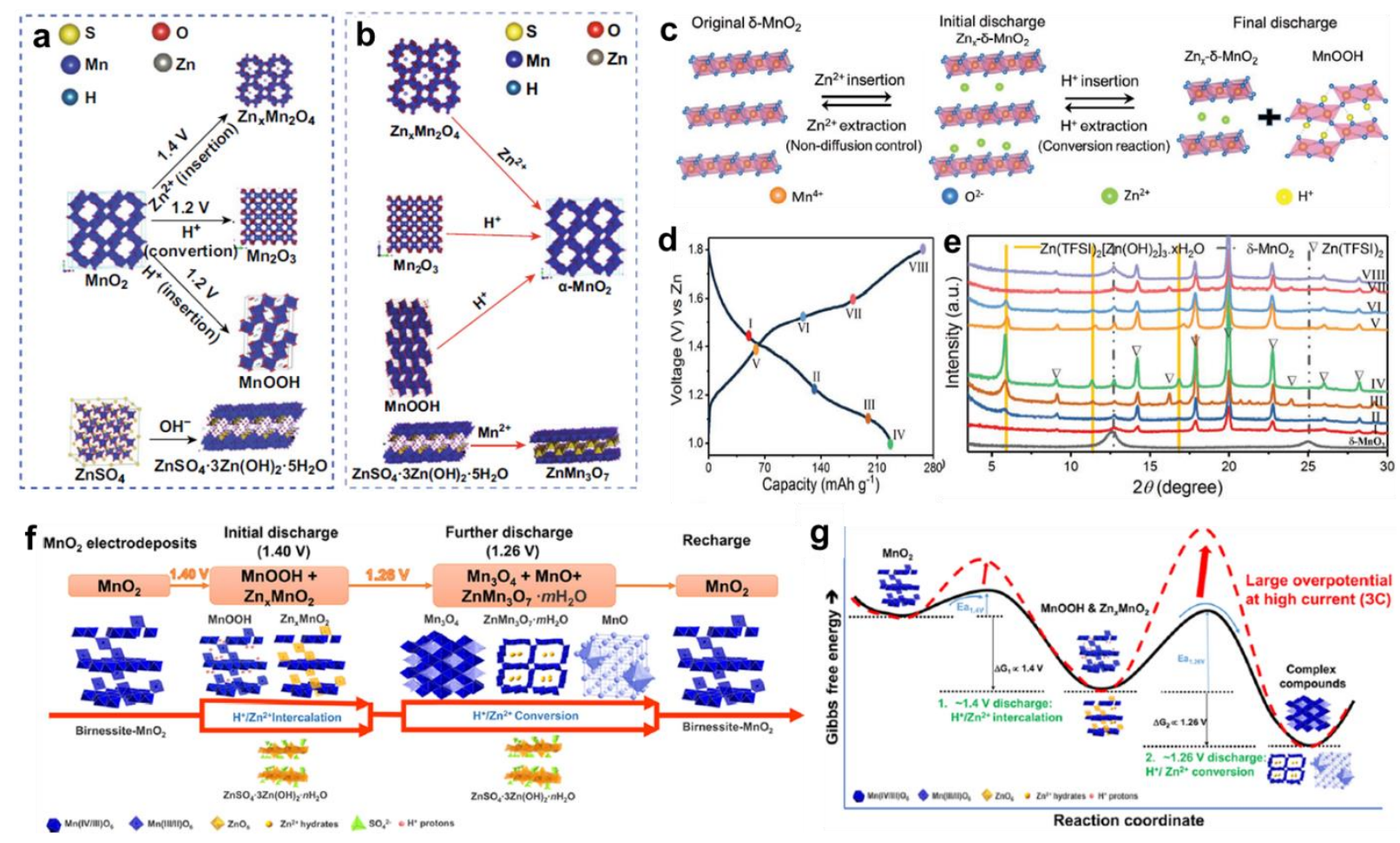

Figure 1. 9 a) Phase evolution of $\alpha-\mathrm{MnO}_{2}$ cathode during the first discharge process and b) the first charge process. [98] (Reproduced with permission. Copyright 2019, Springer Nature) c) Joint nondiffusion controlled $\mathrm{Zn}^{2+}$ intercalation and $\mathrm{H}^{+}$conversion reaction mechanism in $\delta-\mathrm{MnO}_{2}$. d) Charge-discharge curve $\delta-\mathrm{MnO}_{2}$ electrode in the second cycle at $0.2 \mathrm{C}$. e) Ex-situ XRD patterns of $\delta-\mathrm{MnO}_{2}$ electrodes at selected states in (d) [108] (Reproduced with permission. Copyright 2019, John Wiley \& Sons) f) Schematic illustration of the redox reactions and crystal structures of related compounds in the $\mathrm{Zn}$ /carbon black cells with aqueous $1 \mathrm{M} \mathrm{ZnSO}_{4}+0.2 \mathrm{M} \mathrm{MnSO}_{4}$ electrolyte. g) Gibbs free energy vs reaction coordinate showing the thermodynamic and kinetic properties of the redox reactions in $\mathrm{Zn} / \mathrm{MnO}_{2}$ cells with different rates. [127] (Reproduced with permission. Copyright 2018, American Chemical Society) 
iv) Concomitant $\mathrm{Zn}^{2+} / \mathrm{H}^{+}$related reaction at both DP1 and DP2. Li et al. proposed that the aqueous $\mathrm{Zn} / \mathrm{MnO}_{2}$ chemistry simultaneously involved $\mathrm{H}^{+} / \mathrm{Zn}^{2+}$ intercalation reactions at DP1 and $\mathrm{H}^{+} / \mathrm{Zn}^{2+}$ conversion reactions at DP2 (Figure 1.9f). The significantly different kinetics of these two types of reactions were responsible for the rate-dependent performance. Compared with the small energy barrier of co-intercalation reactions at DP1, the conversion reactions at DP2 exhibited a higher activation barrier owing to their smaller rate constant and higher charge-transfer resistance, making it kinetic-limited (Figure 1.9g). At a low current density, the rapid capacity decay was ascribed to the kinetic-limited and irreversible conversion reaction at DP2. In contrast, at a high current density, the low voltage conversion reactions were significantly inhibited due to the kinetic-limited property, thus leading to high-capacity retention and cycle stability.[127]

\section{(4) Dissolution/deposition mechanism}

Apart from the insertion and conversion reaction, the dissolution-deposition reaction of $\mathrm{MnO}_{2} / \mathrm{Mn}^{2+}$ redox pairs also contributed charge storage in manganese-based ZIBs.[35,115,128] Soundharrajan et al. investigated the role of $\mathrm{Mn}^{2+}$ electrolyte additive in the electrochemical contribution of $\mathrm{ZnMn}_{2} \mathrm{O}_{4}$ cathode. They elucidated that, in addition to the $\mathrm{Zn}^{2+}$ insertion in the bulk $\mathrm{ZnMn}_{2} \mathrm{O}_{4}$ (equation 22), $\mathrm{MnO}_{\mathrm{x}}$ deposition from $\mathrm{Mn}^{2+}$ additive onto the cathode surface (equation 23) and the $\mathrm{Zn}^{2+}$ insertion in the undissolved $\mathrm{MnO}_{\mathrm{x}}$ (equation 24) also contributed the discharge capacity.[115]

$$
\begin{gathered}
\mathrm{ZnMn}_{2} \mathrm{O}_{4} \leftrightarrow \mathrm{Zn}_{(1-\mathrm{y})} \mathrm{Mn}_{2} \mathrm{O}_{4}+\mathrm{yZn}^{2+}+\mathrm{y} 2 \mathrm{e}^{-} \\
\mathrm{Mn}_{\text {(electrolyte) }}^{2+}+\mathrm{xH}_{2} \mathrm{O} \leftrightarrow \mathrm{MnO}_{\mathrm{x} \text { (surface) }}+2 \mathrm{xH}^{+}+2 \mathrm{e}^{-} \\
\mathrm{MnO}_{\mathrm{x} \text { (surface) }}+\mathrm{Zn}_{\text {(electrolyte) }}^{2+}+2 \mathrm{e}^{-} \leftrightarrow \mathrm{Zn}_{\text {(electrolyte) }} \mathrm{MnO}_{\mathrm{x}}
\end{gathered}
$$

Very recently, Guo et al. claimed that the dissolution-deposition reaction dominated in $\mathrm{MnO}_{2}$ cathode. $\mathrm{MnO}_{2}$ was effectively dissolved to $\mathrm{Mn}^{2+}$ during the initial discharging step. Then the dissolved $\mathrm{Mn}^{2+}$ could be deposited as birnessite- $\mathrm{MnO}_{2}$ on the cathode surface during the subsequent charging step. In the following cycles, the dissolution-deposition reactions between birnesstie- $\mathrm{MnO}_{2}, \mathrm{Mn}^{2+}$ and ZHS mainly contributed battery capacities, whereas the very limited contribution from $\mathrm{H}^{+} / \mathrm{Zn}^{2+}$ intercalation/deintercalation (Figure 1.10a).[120] However, the $\mathrm{MnO}_{2}$ dissolution was effectively suppressed by ZHS precipitate after the initial cycle since the formation 
of ZHS consumed a large number of water molecules surrounding the cathode surface, thus leading to a limited specific capacity from the two-electron reaction.

In addition to the direct electrodeposition of $\mathrm{Mn}^{2+}$ to $\mathrm{MnO}_{2}$ on the cathode, the reaction between discharged product ZHS and dissolved $\mathrm{Mn}^{2+}$ upon charging also enabled immobilization of soluble $\mathrm{Mn}^{2+}$ onto the cathode.[98,117,118,120] This finding was supported by the electrochemical behavior of ZHS cathode in ZIBs. Negligible capacity was observed for ZHS cathode in the $\mathrm{ZnSO}_{4}$ electrolyte without $\mathrm{Mn}^{2+}$ additive, whereas the electrode after initial charging in $\mathrm{Mn}^{2+}$ contained electrolyte displayed considerable capacity. This result revealed the critical role of ZHS in Mn deposition on the cathode.[117,119]

Recently, Chao et al. proposed a new electrolytic $\mathrm{Zn}-\mathrm{MnO}_{2}$ battery that unlocked the twoelectron redox reaction by pre-addition of slight $\mathrm{H}_{2} \mathrm{SO}_{4}$ in $\mathrm{ZnSO}_{4}+\mathrm{MnSO}_{4}$-based electrolyte. With $0.1 \mathrm{M} \mathrm{H}_{2} \mathrm{SO}_{4}$ in the electrolyte, an exceptional capacity of $570 \mathrm{mAh} \mathrm{g}^{-1}$ (theoretical capacity of $\left.616 \mathrm{mAh}\left(\mathrm{g}-\mathrm{MnO}_{2}\right)^{-1}\right)$ was obtained with a high discharge plateau of $1.95 \mathrm{~V}$. This study on electrolyte beyond mildly acidic or neutral medium claimed a new charge storage chemistry. The discharge process was separated in three steps, including $\mathrm{MnO}_{2}$ dissolution at $\mathrm{D} 1(2.0-1.7 \mathrm{~V}), \mathrm{H}^{+}$ insertion at D2 (1.7-1.4 V), and $\mathrm{Zn}^{2+}$ insertion at D3 (1.4-0.8 V) (Figure 1.10b). The reaction mechanism during the charge and discharge process was shown below:

$$
\begin{gathered}
\mathrm{Mn}^{2+}+2 \mathrm{H}_{2} \mathrm{O} \leftrightarrow \mathrm{MnO}_{2}+4 \mathrm{H}^{+}+2 \mathrm{e}^{-} \quad \text { (initial charge process) } \\
\mathrm{MnO}_{2}+4 \mathrm{H}^{+}+2 \mathrm{e}^{-} \leftrightarrow \mathrm{Mn}^{2+}+2 \mathrm{H}_{2} \mathrm{O} \quad \text { (following cycles) } \\
\mathrm{MnO}_{2}+\mathrm{H}^{+}+\mathrm{e}^{-} \leftrightarrow \mathrm{MnOOH} \quad \text { (following cycles) } \\
\mathrm{MnO}_{2}+0.5 \mathrm{Zn}^{2+}+\mathrm{e}^{-} \leftrightarrow \mathrm{Zn}_{0.5} \mathrm{MnO}_{2} \quad \text { (following cycles) }
\end{gathered}
$$

More importantly, the electrolyte acidity was found to notably affect the dissolution/deposition potential of $\mathrm{MnO}_{2}$, thus eventually influenced the operation voltage of battery. The average discharge plateau potential of electrolytic $\mathrm{Zn}-\mathrm{MnO}_{2}$ battery could be increased from 1.79 to 1,99 $\mathrm{V}$ as $\mathrm{H}_{2} \mathrm{SO}_{4}$ concentration increased from 0.05 to $0.3 \mathrm{M}$ (pH below 1.47).[48] The two-electron dissolution-deposition reaction mechanism was also raised by Xie et al. in the $\mathrm{Mn}\left(\mathrm{CH}_{3} \mathrm{COO}\right)_{2}$ $\left(\mathrm{Mn}(\mathrm{Ac})_{2}\right)$ electrolyte-based neutral $\mathrm{Zn} /$ manganese batteries (Figure 1.10c).[107] Unlike $\mathrm{MnSO}_{4}$ and $\mathrm{MnCl}_{2}$, the coordination ability of $\mathrm{Ac}^{-}$was favorable for the direct oxidation of $\mathrm{Mn}^{2+}$ to $\mathrm{MnO}_{2}$ 
during charge process, which avoided the capacity fade caused by disproportionation of soluble $\mathrm{Mn}^{3+}$. The reaction mechanism of $\mathrm{Zn}-\mathrm{Mn}(\mathrm{Ac})_{2}$ battery at cathode was expressed as follows:

$$
\mathrm{MnAc}_{2}+2 \mathrm{H}_{2} \mathrm{O}-2 \mathrm{e}^{-} \leftrightarrow \mathrm{MnO}_{2}+4 \mathrm{HAc}+\mathrm{Mn}^{2+}
$$

Moreover, they suggested that the dissolution-deposition solid-liquid reaction between $\mathrm{MnO}_{2}$ and $\mathrm{Mn}(\mathrm{Ac})_{2}$ refrained the phase transition and structure collapse issues induced by repeated (de)intercalation reaction, leading to significant enhancement in stability leading to significantly enhanced cycling stability.

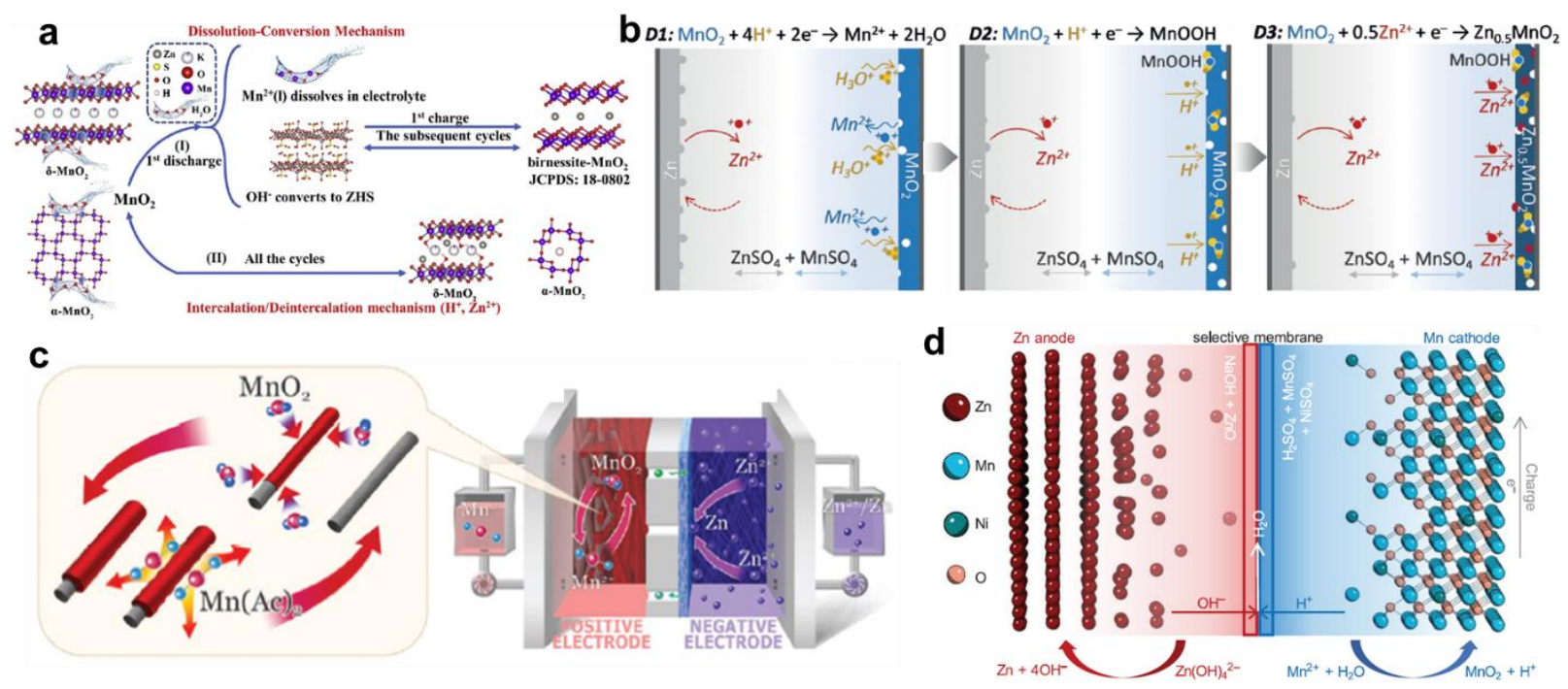

Figure 1. 10 a) Energy storage mechanism in $\mathrm{Zn} / \mathrm{MnO}_{2}$ battery. [120] (Reproduced with permission. Copyright 2020, Elsevier) b) Charge storage mechanism of the electrolytic $\mathrm{Zn}_{-} \mathrm{MnO}_{2}$ battery in $1 \mathrm{M} \mathrm{ZnSO}_{4}+1 \mathrm{M} \mathrm{MnSO}_{4}$ electrolyte with little $\mathrm{H}_{2} \mathrm{SO}_{4}$ additive. [48] (Reproduced with permission. Copyright 2019, John Wiley \& Sons) c) Electrochemical mechanism of the neutral zinc/manganese battery with $\mathrm{Mn}(\mathrm{Ac})_{2}$ electrolyte. [107] (Reproduced with permission. Copyright 2020, Royal Society of Chemistry) d) Schematic illustration of Zn-Mn HAB in the hybrid electrolytes during charge/discharge. [133] (Reproduced with permission. Copyright 2020, John Wiley \& Sons)

Although the acidic electrolyte was beneficial to unlock the two-electron $\mathrm{Mn}^{2+} / \mathrm{Mn}^{4+}$ redox couple, it unable to compatible with the commonly used $\mathrm{Zn}$ metal anodes, as serious side reactions like corrosion and hydrogen evolution restrict the stability and practicability of $\mathrm{Zn}$ anode. In view of the limitations of shared electrolyte, a new hybrid battery concept that decoupling the different 
electrolyte working conditions of $\mathrm{Zn}$ anode and $\mathrm{MnO}_{2}$ cathode in a battery system was raised recently. Unlike the dissolution-deposition reaction mechanism that involves redox reactions of $\mathrm{Zn}^{2+} / \mathrm{Zn}$ and $\mathrm{Mn}^{2+} / \mathrm{MnO}_{2}$ in the same electrolyte, the new hybrid batteries applied different electrolytes at the separated anode and cathode sides.[129-132] For instance, Chao et al. developed a hybrid aqueous $\mathrm{Zn}-\mathrm{MnO}_{2}$ battery with adding alkaline electrolyte ( $\left.3 \mathrm{M} \mathrm{NaOH}+0.3 \mathrm{M} \mathrm{ZnO}\right)$ at the anode and mildly acidic electrolyte $\left(3 \mathrm{M} \mathrm{MnSO}_{4}+0.3 \mathrm{M} \mathrm{H}_{2} \mathrm{SO}_{4}+0.06 \mathrm{M} \mathrm{NiSO}_{4}\right)$ at the cathode (Figure 1.10d).[133] Liu et al. reported an aqueous $\mathrm{Zn}-\mathrm{Mn}^{2+}$ battery with two dissolution/deposition redox reactions separated by an ion-selective membrane, including $\mathrm{MnO}_{2} / \mathrm{Mn}^{2+}$ reaction in acid electrolyte and $\mathrm{Zn} / \mathrm{Zn}(\mathrm{OH})_{4}{ }^{2-}$ reaction in alkaline electrolyte.[131] The two-electron reaction mechanism of $\mathrm{Zn}-\mathrm{MnO}_{2}$ chemistry provided a promising direction for achieving advanced aqueous ZIBs in terms of high cell voltage and energy density.

\subsection{Vanadium-based cathodes}

Vanadium-based materials are another kind of promising cathodes for ZIBs. The multiple oxidation states $\left(\mathrm{V}^{5+}, \mathrm{V}^{4+}, \mathrm{V}^{3+}\right.$, and $\left.\mathrm{V}^{2+}\right)$ and diverse coordination polyhedral of vanadium-based compounds endow them with high flexibility to accommodate multivalent ions.[11] Generally, vanadium-based cathodes show high specific capacities, superior rate capability, and long cycle life but low working voltages in aqueous ZIBs. The reported vanadium-based cathode materials in ZIBs mainly include vanadium oxides, vanadates, vanadyl phosphates, and vanadium chalcogenides.

Among various vanadium-based oxides, $\mathrm{V}_{2} \mathrm{O}_{5}$ possesses substantial potential as a host for electrochemical intercalation of $\mathrm{Zn}^{2+}$ due to its highest theoretical capacity $\left(589 \mathrm{mAh} \mathrm{g}^{-1}\right)$ based on a two-electron reaction of the $\mathrm{V}^{5+} / \mathrm{V}^{3+}$ redox pair. Zhang et al. demonstrated that the ball-milled commercial $\mathrm{V}_{2} \mathrm{O}_{5}$ exhibited a high capacity of $470 \mathrm{mAh} \mathrm{g}^{-1}$ at $0.2 \mathrm{~A} \mathrm{~g}^{-1}$ and excellent cycling stability ( $372 \mathrm{mAh} \mathrm{g}^{-1}$ with $91.1 \%$ capacity retention after 4000 cycles at $5 \mathrm{~A} \mathrm{~g}^{-1}$ ) in $3 \mathrm{M}$ $\mathrm{Zn}\left(\mathrm{CF}_{3} \mathrm{SO}_{3}\right)_{2}$ electrolyte. The exceptional performance was ascribed to the charge-shielding function of co-intercalated water rendering fast $\mathrm{Zn}^{2+}$ diffusion in $\mathrm{V}_{2} \mathrm{O}_{5}$ host.[134] $\mathrm{B}$ phase $\mathrm{VO}_{2}$ with a layered structure built by edge-sharing $\mathrm{VO}_{6}$ octahedra was reported as a host for fast $\mathrm{Zn}^{2+}$ (de)intercalation.[135] For example, Chen et al. confirmed the excellent structural stability of $\mathrm{VO}_{2}(\mathrm{~B})$ for $\mathrm{Zn}^{2+}$ insertion/extraction.[136] In addition to $\mathrm{VO}_{2}(\mathrm{~B})$, other types of $\mathrm{VO}_{2}$ such as 
$\mathrm{VO}_{2}(\mathrm{D})$ and $\mathrm{VO}_{2}(\mathrm{M})$ have been reported as ZIB cathodes.[137,138] Compared to $\mathrm{V}_{2} \mathrm{O}_{5}$ and $\mathrm{VO}_{2}$ with pure valence state, $\mathrm{V}_{6} \mathrm{O}_{13}$ is composed of alternating single and double vanadium oxide layers by sharing corners featuring open structure, mixed-valence states of $\mathrm{V}^{4+} / \mathrm{V}^{5+}$, and abundant active sites, which makes it suitable for ion intercalation.[139] Moreover, the metallic character of $\mathrm{V}_{6} \mathrm{O}_{13}$ at room temperature enables its high rate capability.[140] Liang et al. revealed the higher $\mathrm{Zn}^{2+}$ diffusion coefficient and higher electrical conductivity for $\mathrm{V}_{6} \mathrm{O}_{13}$ than that of $\mathrm{V}_{2} \mathrm{O}_{5}$ and $\mathrm{VO}_{2}$, accounting for the higher capacity of $\mathrm{V}_{6} \mathrm{O}_{13}$ in aqueous ZIBs.[141]) Besides $\mathrm{V}_{6} \mathrm{O}_{13}$, various vanadium oxides including $\mathrm{V}_{3} \mathrm{O}_{7}, \mathrm{~V}_{5} \mathrm{O}_{12}, \mathrm{~V}_{10} \mathrm{O}_{24}$, and their hydrated variants which possess mixed vanadium states of $\mathrm{V}^{4+} / \mathrm{V}^{5+}$ have been screened as cathode materials for ZIBs.

Regarding the layered vanadium oxides, their narrow interlayer distance and high diffusion energy barrier can lead to sluggish diffusion kinetics. The introduction of "pillars" such as metal ions, water molecules, and organic molecules into interlayers has been regarded as one of the most effective approaches to improving electrochemical performance of layered vanadium-based cathodes. Generally, the intercalated "pillars" are able to enlarge the interlayer spacing and stabilize the host structure, thus enhancing the zinc ions intercalation kinetics and capacities.[142144] Structural $\mathrm{H}_{2} \mathrm{O}$ has been widely used as an interlayer species for intercalation modification. Coordinated water molecules function as charge shield sites to effectively diminish the strong electrostatic interaction between hydrated $\mathrm{Zn}^{2+}$ and host framework. Moreover, they serve as an interlayer buffer reversibly expanding and contracting the intercalation spacing to enable fast $\mathrm{Zn}^{2+}$ transportation. Yan et al. presented water-lubricated intercalation in bilayer $\mathrm{V}_{2} \mathrm{O}_{5} \cdot \mathrm{nH}_{2} \mathrm{O}(\mathrm{VOG})$ which involved 1.29 structural water per formula unit (Figure 1.11a). Due to fast ions transport kinetics supported by the lubricating effect of intercalated $\mathrm{H}_{2} \mathrm{O}$, VOG achieved outstanding rate capability as compared with the sample without structural water.[145] The superior electrochemical performance was also reported in $\mathrm{H}_{2} \mathrm{~V}_{3} \mathrm{O}_{8}\left(\mathrm{~V}_{3} \mathrm{O}_{7} \cdot \mathrm{H}_{2} \mathrm{O}\right)$ cathode.

Apart from coordination with structural water, the strategy of pre-intercalation of metal ions including monovalent ions $\left(\mathrm{Li}^{+}, \mathrm{Na}^{+}, \mathrm{K}^{+}\right.$, and $\left.\mathrm{Ag}^{+}\right)$and multivalent ions $\left(\mathrm{Ca}^{2+}, \mathrm{Fe}^{2+}, \mathrm{Co}^{2+}, \mathrm{Ni}^{2+}\right.$, $\mathrm{Mn}^{2+}, \mathrm{Cu}^{2+}, \mathrm{Zn}^{2+}$, and $\mathrm{Mg}^{2+}$ ) into layered vanadium oxides has been also widely employed to develop high-performance vanadium-based cathodes such as $\mathrm{LiV}_{3} \mathrm{O}_{8}$,[146] $\mathrm{Na}_{0.33} \mathrm{~V}_{2} \mathrm{O}_{5}$,[147] $\mathrm{Zn}_{2} \mathrm{~V}_{2} \mathrm{O}_{7}$.[148] Note that introducing metal ions that have high molar weights may reduce the specific gravimetric capacity of cathodes and energy density of ZIBs. Hence, cations with low 
molar weights like $\mathrm{NH}_{4}{ }^{+}$have been screened as guest species for the vanadium oxides. The intercalated $\mathrm{NH}_{4}^{+}$"pillars" between the vanadium-oxide layers and network of $\mathrm{N}-\mathrm{H} \cdots \mathrm{O}$ hydrogen bonds between $\mathrm{NH}_{4}{ }^{+}$cations and vanadium-oxide layer both benefited the structural stability of ammonium vanadate cathode for long-term cycling.[149,150] Specifically, Tang et al. employed $\mathrm{NH}_{4} \mathrm{~V}_{4} \mathrm{O}_{10}, \mathrm{NH}_{4} \mathrm{~V}_{3} \mathrm{O}_{8}$, and $\left(\mathrm{NH}_{4}\right)_{2} \mathrm{~V}_{3} \mathrm{O}_{8}$ as the cathodes for ZIBs. Compared with the others, $\mathrm{NH}_{4} \mathrm{~V}_{4} \mathrm{O}_{10}$ simultaneously possessed the largest expansive diffusion channel $(9.8 \AA)$ and singleconnected oxygen atoms that developed strong interactions with $\mathrm{NH}_{4}{ }^{+}$ions within the interlayer, thus enabling superior structural stability and ion transport kinetics (Figure 1.11b).[149]

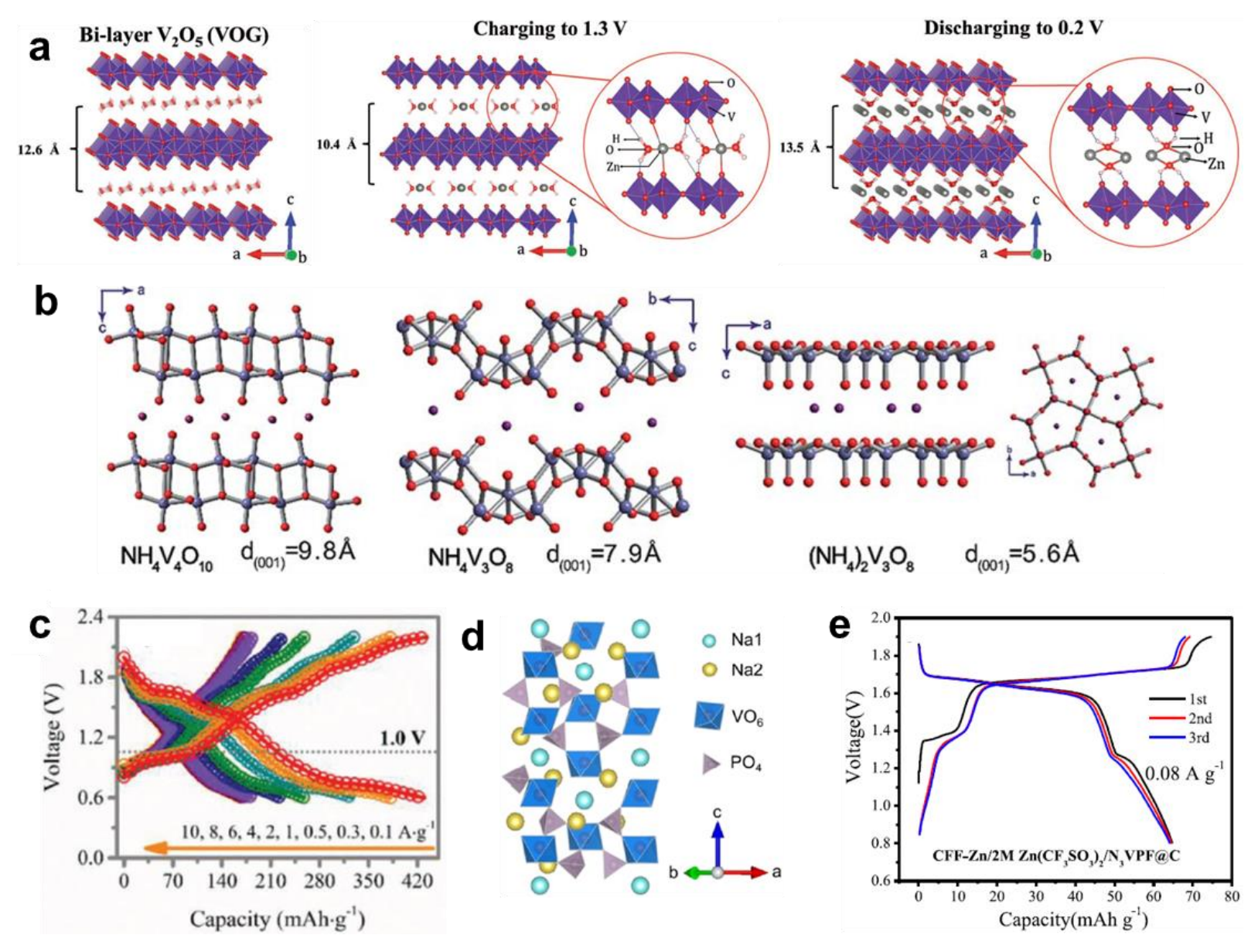

Figure 1. 11 a) Proposed crystal structures of pristine VOG, VOG after charging to $1.3 \mathrm{~V}$, and VOG after discharging to 0.2 V. [145] (Reproduced with permission. Copyright 2018, John Wiley \& Sons) b) Atomic structures of $\mathrm{NH}_{4} \mathrm{~V}_{4} \mathrm{O}_{10}, \mathrm{NH}_{4} \mathrm{~V}_{3} \mathrm{O}_{8}$, and $\left(\mathrm{NH}_{4}\right)_{2} \mathrm{~V}_{3} \mathrm{O}_{8}$. [149] (Reproduced with permission. Copyright 2019, Royal Society of Chemistry) c) GCD curves of $\mathrm{Co}_{0.247} \mathrm{~V}_{2} \mathrm{O}_{5} \cdot 0.944 \mathrm{H}_{2} \mathrm{O}$ cathode at various current densities. [158] (Reproduced with permission. 
Copyright 2019, John Wiley \& Sons) d) Crystal structure of $\mathrm{Na}_{3} \mathrm{~V}_{2}\left(\mathrm{PO}_{4}\right)_{3}$. [159] (Reproduced with permission. Copyright 2020, American Chemical Society) e) GCD curves of $\mathrm{Na}_{3} \mathrm{~V}_{2}\left(\mathrm{PO}_{4}\right)_{2} \mathrm{~F}_{3} @ \mathrm{C}$ cathode. [160] (Reproduced with permission. Copyright 2018, Elsevier)

Recent research interests on vanadium oxides-based cathodes have focused on exploring the synergistic effect of metal ions and structural water to construct flexible host frameworks for reversible $\mathrm{Zn}^{2+}$ intercalation. Compared with monovalent alkali metal ions (e.g., $\mathrm{Li}^{+}, \mathrm{Na}^{+}, \mathrm{K}^{+}$), the chemically pre-intercalated divalent metal ions can develop stronger ionic bonds with oxygen atoms that effectively connect the adjacent layers together against structural collapse.[151-153] Nazar's group initially employed $\mathrm{Zn}_{0.25} \mathrm{~V}_{2} \mathrm{O}_{5} \bullet \mathrm{nH}_{2} \mathrm{O}$ as a cathode for aqueous ZIBs.[6] Likewise, $\mathrm{Zn}_{0.3} \mathrm{~V}_{2} \mathrm{O}_{5} \cdot 1.5 \mathrm{H}_{2} \mathrm{O}$ cathode has been reported to deliver cycling life to 20,000 cycles with over $96 \%$ capacity retention at $10 \mathrm{~A} \mathrm{~g}^{-1}$.[154] $\mathrm{Ca}_{0.25} \mathrm{~V}_{2} \mathrm{O}_{5} \bullet \mathrm{nH}_{2} \mathrm{O}$ was proposed as a more suitable $\mathrm{Zn}^{2+}$ intercalation host than $\mathrm{Zn}_{0.25} \mathrm{~V}_{2} \mathrm{O}_{5} \bullet \mathrm{nH}_{2} \mathrm{O}$. It was found that the $\mathrm{Ca}-\mathrm{O}$ bond in $\mathrm{CaO}_{7}$ pillars was much longer than the $\mathrm{Zn}-\mathrm{O}$ bond in $\mathrm{ZnO}_{6}$ pillars, resulting in further expanded interlayer spacing in $\mathrm{Ca}_{0.25} \mathrm{~V}_{2} \mathrm{O}_{5} \bullet \mathrm{HH}_{2} \mathrm{O}(10.6 \AA)$ than $\mathrm{Zn}_{0.25} \mathrm{~V}_{2} \mathrm{O}_{5} \bullet \mathrm{nH}_{2} \mathrm{O}$. Moreover, $\mathrm{Ca}_{0.25} \mathrm{~V}_{2} \mathrm{O}_{5} \bullet \mathrm{nH}_{2} \mathrm{O}$ displayed higher electrical conductivity and smaller molar weight than $\mathrm{Zn}_{0.25} \mathrm{~V}_{2} \mathrm{O}_{5} \bullet \mathrm{nH}_{2} \mathrm{O}$ beneficial for delivering higher power and energy densities.[151] The exemplary "pillars effect" inspired the extensive efforts to develop hydrated vanadium oxides with diverse ion pre-intercalation for aqueous $\mathrm{Zn}^{2+} \quad$ storage, such as $\mathrm{Li}_{\mathrm{x}} \mathrm{V}_{2} \mathrm{O}_{5} \bullet \mathrm{nH}_{2} \mathrm{O},[143] \quad \mathrm{Mg}_{\mathrm{x}} \mathrm{V}_{2} \mathrm{O}_{5} \bullet \mathrm{nH}_{2} \mathrm{O},[155]$ $\mathrm{Na}_{2} \mathrm{~V}_{6} \mathrm{O}_{16} \bullet 1.63 \mathrm{H}_{2} \mathrm{O}$,[156] and $\mathrm{Zn}_{3} \mathrm{~V}_{2} \mathrm{O}_{7}(\mathrm{OH})_{2} \cdot 2 \mathrm{H}_{2} \mathrm{O}$.[157]

Another critical shortcoming of the vanadium-based cathodes is their relatively low discharge voltages $(\sim 0.7 \mathrm{~V})$. Therefore, it is highly desired to develop vanadium-based cathodes with both high voltage and capacity. Compared with $\mathrm{V}_{2} \mathrm{O}_{5} \cdot \mathrm{nH}_{2} \mathrm{O}(0.43$ and $0.16 \mathrm{~V}), \mathrm{Co}_{0.247} \mathrm{~V}_{2} \mathrm{O}_{5} \cdot 0.944 \mathrm{H}_{2} \mathrm{O}$ enabled two reduction peaks at much higher potentials (1.03 and $0.88 \mathrm{~V})$. Particularly, $\mathrm{Co}_{0.247} \mathrm{~V}_{2} \mathrm{O}_{5} \cdot 0.944 \mathrm{H}_{2} \mathrm{O}$ delivered $52.54 \%$ of its full capacity at the discharge voltage above $1.0 \mathrm{~V}$, outperforming other reported vanadium-based cathodes (Figure 1.11c). The high working voltage and specific capacity were attributed to increased $\mathrm{Zn}^{2+}$ absorption energy of vanadium oxides by cobalt ion intercalation, and its unique $\mathrm{p}-\mathrm{d}$ hybridization among $\mathrm{Co}-3 \mathrm{~d}, \mathrm{~V}-3 \mathrm{~d}$, and $\mathrm{O}-2 \mathrm{p}$ orbitals that allowed for accommodation of bivalent $\mathrm{Zn}^{2+}$.[158] Vanadium phosphates were regarded as promising high-voltage cathode candidates. Moreover, the robust sodium superionic conductor (NASICON)-type crystal structure built by highly covalent three-dimensional framework rendered 
vanadium phosphates high structural stability for reversible $\mathrm{Zn}^{2+}$ (de)intercalation (Figure 1.11d). Li et al firstly reported the graphene wrapped $\mathrm{Na}_{3} \mathrm{~V}_{2}\left(\mathrm{PO}_{4}\right)_{3}$ cathode for aqueous ZIBs which showed a high discharge voltage of $1.1 \mathrm{~V}$ ) but low discharge capacity of $97 \mathrm{mAh} \mathrm{g}^{-1}$ at $0.5 \mathrm{C}$.[159] Given the inductive effect of fluorine atoms, F-doped $\mathrm{Na}_{3} \mathrm{~V}_{2}\left(\mathrm{PO}_{4}\right)_{2} \mathrm{~F}_{3}$ was demonstrated to deliver a higher discharge voltage of $\sim 1.62 \mathrm{~V}$ compared to that of F-free $\mathrm{Na}_{3} \mathrm{~V}_{2}\left(\mathrm{PO}_{4}\right)_{3}$ in $\mathrm{Zn}\left(\mathrm{CF}_{3} \mathrm{SO}_{3}\right)_{2}$ electrolyte (Figure 1.11e).[160,161] In addition, $\mathrm{Li}_{3} \mathrm{~V}_{2}\left(\mathrm{PO}_{4}\right)_{3}$ was adopted as a starting template to prepare $\mathrm{LiV}_{2}\left(\mathrm{PO}_{4}\right)_{3}$ host for $\mathrm{Zn}^{2+}$ intercalation by in situ electrochemical extraction of two $\mathrm{Li}^{+}$. The $\mathrm{LiV}_{2}\left(\mathrm{PO}_{4}\right)_{3}$ cathode exhibited $78 \%$ capacity retention after 4,000 cycles and a high operating voltage of $1.7 \mathrm{~V}$ in $4 \mathrm{M} \mathrm{Zn}\left(\mathrm{CF}_{3} \mathrm{SO}_{3}\right)_{2}$ electrolyte. The exceptional performance was attributed to the ultrafast $\mathrm{Zn}^{2+}$ intercalation caused by the delocalization of effective valence of the inserted $\mathrm{Zn}$ cation (from 2 to 1.336) via the p-d hybridization between V-d and O-p orbitals. [162] The waterin-salt electrolyte was demonstrated favorable for cyclability and specific capacity of $\mathrm{Na}_{3} \mathrm{~V}_{2}\left(\mathrm{PO}_{4}\right)_{2} \mathrm{O}_{1.6} \mathrm{~F}_{1.4}$ cathode in ZIBs.[163]

Unlike the complicated charge storage mechanisms in manganese-based cathodes, the capacity of vanadium-based cathode in aqueous ZIBs was dominantly contributed by ion intercalation/deintercalation. Kundu et al. firstly reported the reversible $\mathrm{Zn}^{2+}$ intercalation/deintercalation reaction in $\mathrm{Zn}_{0.25} \mathrm{~V}_{2} \mathrm{O}_{5} \bullet \mathrm{nH}_{2} \mathrm{O}$ cathode for aqueous ZIBs. When fresh cathode was immersed in the aqueous electrolyte, $\mathrm{Zn}_{0.25} \mathrm{~V}_{2} \mathrm{O}_{5} \cdot \mathrm{nH}_{2} \mathrm{O}$ was transformed to $\mathrm{Zn}_{0.25} \mathrm{~V}_{2} \mathrm{O}_{5} \cdot \mathrm{yH}_{2} \mathrm{O}$ accompanied by the expansion of interlayer distance from $10.8 \AA$ to $12.9 \AA$ due to water intercalation. As $\mathrm{Zn}^{2+}$ intercalated into $\mathrm{Zn}_{0.25} \mathrm{~V}_{2} \mathrm{O}_{5} \cdot \mathrm{yH}_{2} \mathrm{O}$ upon discharging, the preintercalated water molecules deintercalated simultaneously due to the increased interlayer electrostatic repulsion. During the subsequent charge process, $\mathrm{Zn}^{2+}$ deintercalation and water intercalation occurred reversibly, accompanied by the contraction of interlayer spacing. [6] Unlike the regular intercalation mechanism in vanadium oxides without structural transformation, a part of the layered $\mathrm{NH}_{4} \mathrm{~V}_{4} \mathrm{O}_{10} \cdot \mathrm{nH}_{2} \mathrm{O}$ cathode was detected to transform into $\mathrm{Zn}_{3}(\mathrm{OH})_{2} \mathrm{~V}_{2} \mathrm{O}_{7} \cdot 2 \mathrm{H}_{2} \mathrm{O}$ except for the regular inserted phase $\mathrm{Zn}_{\mathrm{m}} \mathrm{NH}_{4} \mathrm{~V}_{4} \mathrm{O}_{10} \cdot \mathrm{nH}_{2} \mathrm{O}$ in the initial discharge step. These two products were acted as the active materials for reversible $\mathrm{Zn}^{2+}$ insertion in the following cycles (Figure 1.12a).[149] Contrary to the previous view of reverse ingress/egress of $\mathrm{H}_{2} \mathrm{O}$ and $\mathrm{Zn}^{2+}$,[6] Shin et al. proposed a hydrated intercalation mechanism, in which $\mathrm{H}_{2} \mathrm{O}$ molecules and $\mathrm{Zn}^{2+}$ ions were co-intercalated upon discharging. They revealed that this hydrated intercalation reaction 
facilitated $\mathrm{Zn}^{2+}$ transfer as the co-intercalated water contributed to expanding diffusion channel and shielding electrostatic effect in the $\mathrm{V}_{6} \mathrm{O}_{13}$ host lattice.[140]

Another important proposition on the intercalation chemistry of vanadium-based ZIBs was the displacement/intercalation reaction mechanism, which was usually introduced in vanadates (e.g., $\mathrm{Mg}_{0.34} \mathrm{~V}_{2} \mathrm{O}_{5}$ and $\left.\mathrm{Ag}_{0.4} \mathrm{~V}_{2} \mathrm{O}_{5}\right)$ [155,164] and polyanionic vanadium phosphates $\left(\mathrm{Na}_{3} \mathrm{~V}_{2}\left(\mathrm{PO}_{4}\right)_{3}\right)$.[159] Take the $\mathrm{Ag}_{0.4} \mathrm{~V}_{2} \mathrm{O}_{5}$ cathode as an example, besides the normal $\mathrm{Zn}^{2+}$ intercalation reaction, a part of the $\mathrm{Ag}^{+}$sites in $\mathrm{Ag}_{0.4} \mathrm{~V}_{2} \mathrm{O}_{5}$ was displaced by $\mathrm{Zn}^{2+}$ to form a new phase of $\mathrm{Zn}_{2}\left(\mathrm{~V}_{3} \mathrm{O}_{8}\right)_{2}$ accompanied by the reduction of $\mathrm{Ag}^{+}$to metallic $\mathrm{Ag}$ during the discharge process (Figure 1.12b).[164] NASICON-like $\mathrm{Na}_{3} \mathrm{~V}_{2}\left(\mathrm{PO}_{4}\right)_{3}$ with open accessible framework was also reported as intercalation host for $\mathrm{Zn}^{2+}$ storage. Two $\mathrm{Na}^{+}$ions were initially extracted from $\mathrm{Na}_{3} \mathrm{~V}_{2}\left(\mathrm{PO}_{4}\right)_{3}$ to form $\mathrm{NaV}_{2}\left(\mathrm{PO}_{4}\right)_{3}$ host in the first charging step followed by reversible $\mathrm{Zn}^{2+}$ insertion in the resultant host structure in the subsequent cycles, accompanied by the redox reaction of $\mathrm{V}^{3+} / \mathrm{V}^{4+}$ (Figure 1.12c).[159] Different with the single $\mathrm{Zn}^{2+}$ intercalation, the later studies proposed quasitwo-stage intercalation of both $\mathrm{Na}^{+}$and $\mathrm{Zn}^{2+}$ in $\mathrm{NaV}_{2}\left(\mathrm{PO}_{4}\right)_{3}$ (Figure 1.12d).[165,166]
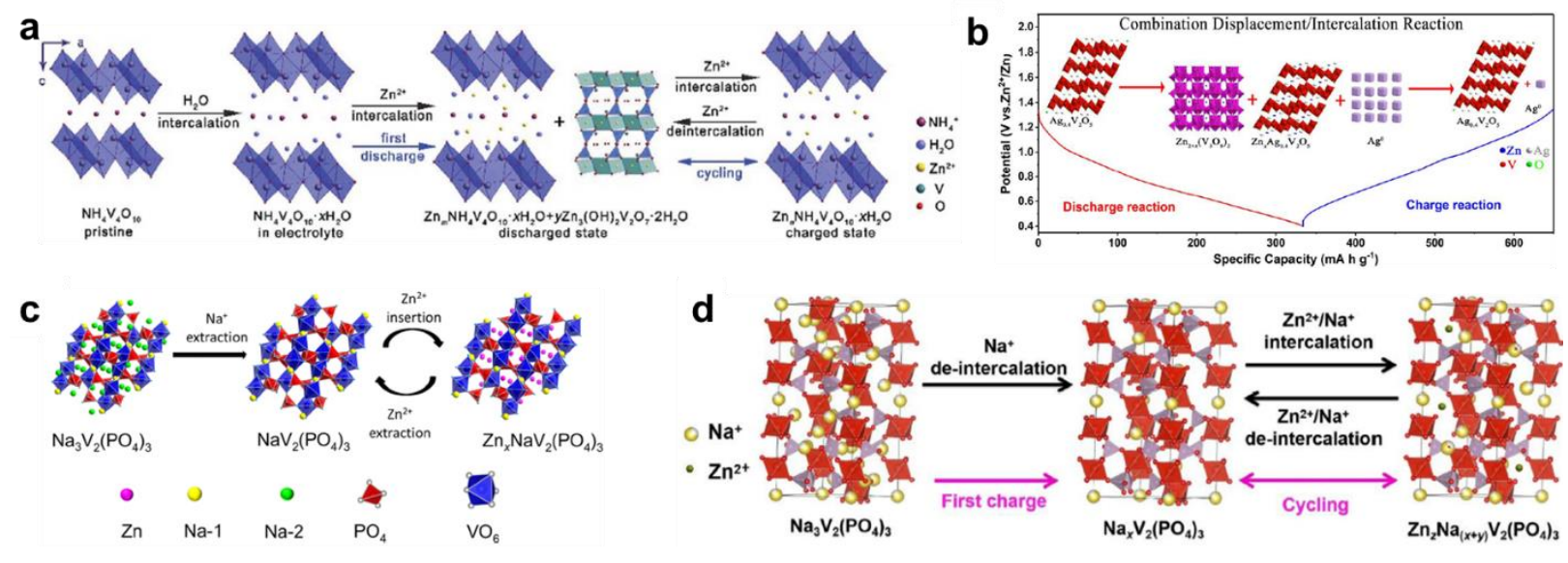

Figure 1. 12 a) Scheme showing the intercalation of $\mathrm{H}_{2} \mathrm{O}$ molecules and the $\mathrm{Zn}^{2+}$ insertion/extraction process in $\mathrm{NH}_{4} \mathrm{~V}_{4} \mathrm{O}_{10}$ during cycling. [149] (Reproduced with permission. Copyright 2029, Royal Society of Chemistry) b) Schematic of displacement/intercalation mechanism in $\mathrm{Ag}_{0.4} \mathrm{~V}_{2} \mathrm{O}_{5}$ cathode. [164] (Reproduced with permission. Copyright 2019, Elsevier) c) Schematic representation for phase transition of $\mathrm{Na}_{3} \mathrm{~V}_{2}\left(\mathrm{PO}_{4}\right)_{3}$ cathode during cycling. [159] (Reproduced with permission. Copyright 2016, Elsevier) d) Schematic illustrations the NVP@rGO during charge/discharge. [166] (Reproduced with permission. Copyright 2019, Elsevier) 


\subsection{Prussian blue analogues-based cathodes}

Prussian blue analogues (PBAs), a family of metal hexacyanoferrates (MHCFs), have been extensively explored as potential metal ion hosts for aqueous battery systems, as their openframework structures with abundant interstitial sites allow for rapid ionic conduction and structural stability upon cycling.[167] Generally, PBAs can be formulated as $\left.\mathrm{A}_{x} \mathrm{M}_{1}\left[\mathrm{M}_{2}(\mathrm{CN})_{6}\right)\right]_{\mathrm{y}} \cdot n \mathrm{H}_{2} \mathrm{O}$, where A represents an alkali-metal ion, and $\mathrm{M}_{1}$ and $\mathrm{M}_{2}$ are transition-metal ions. In the typical crystal structure of PBAs, $\mathrm{M}_{1}$ and $\mathrm{M}_{2}$ transition metal ions (e.g., $\mathrm{Mn}, \mathrm{Fe}, \mathrm{Zn}, \mathrm{Co}, \mathrm{Ni}$, and $\mathrm{Cu}$ ) occupy alternating sites on the corner of the octahedron cubic linked by cyanide $\mathrm{CN}$ ligand to form a porous 3D network with large vacant sites, in which $\mathrm{A}^{+}$alkaline cations $\left(\mathrm{Na}^{+}\right.$, and $\left.\mathrm{K}^{+}\right)$are located at the cubic interstices and $\mathrm{H}_{2} \mathrm{O}$ molecules fill in the vacant $\left[\mathrm{M}_{2}(\mathrm{CN})_{6}\right]^{3-}$ sites or empty interstitial cages. To date, various PBAs, including ZnHCFs, CuHCFs, FeHCFs, NiHCFs, and CoHCF, have been adopted as cathode materials for ZIBs.
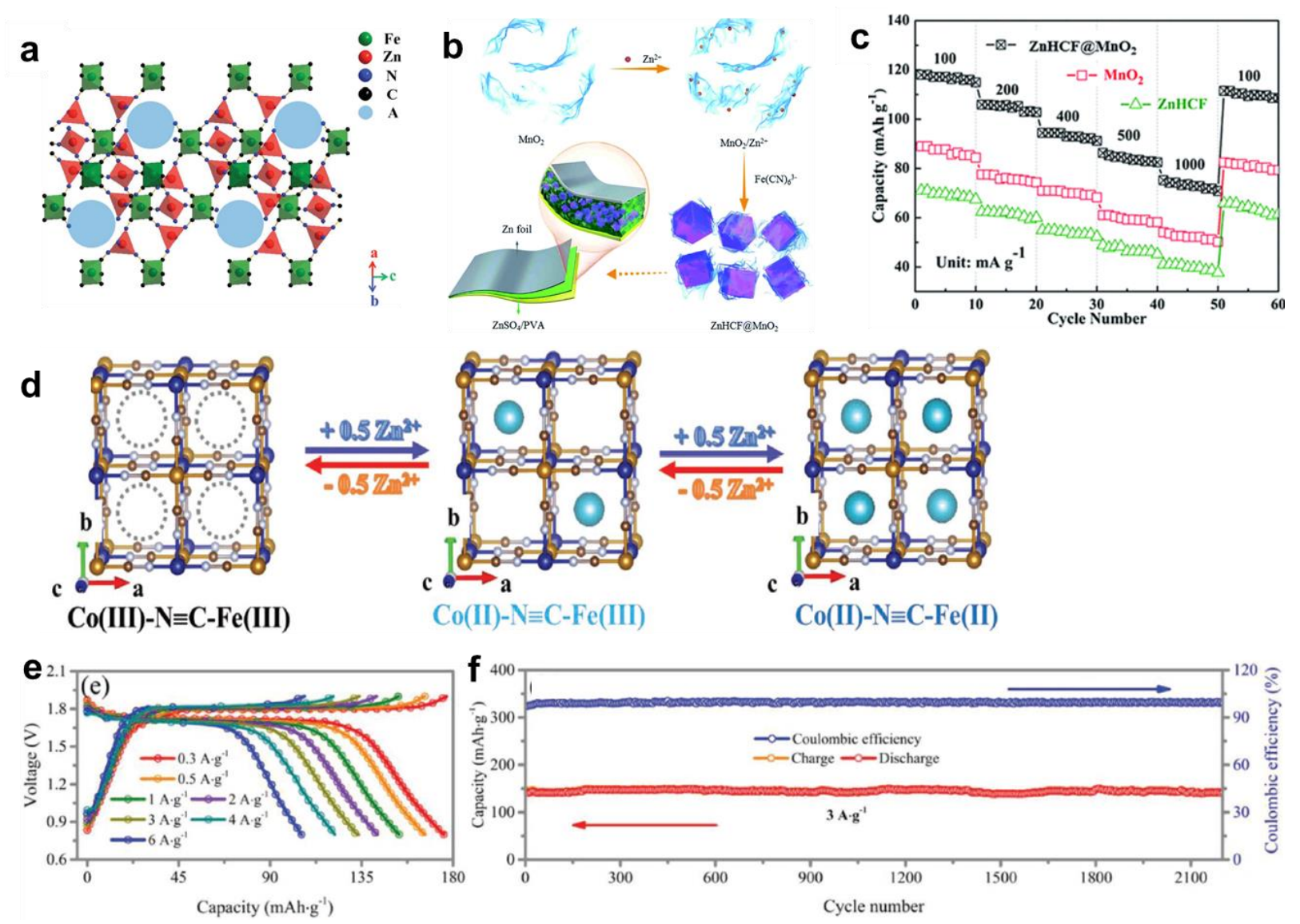

Figure 1. 13 a) Crystal structure of ZnHCF. [168] (Reproduced with permission. Copyright 2015,

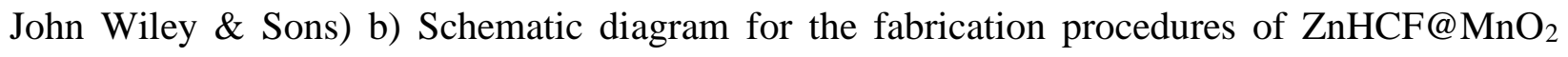


composite. c) Rate capability of $\mathrm{ZnHCF} @ \mathrm{MnO}_{2}$ cathode. [169] (Reproduced with permission. Copyright 2017, Royal Society of Chemistry) d) Schematic illustration of reversible $\mathrm{Zn}^{2+}$ intercalation/deintercalation in $\mathrm{CoFe}(\mathrm{CN})_{6}$ frameworks. e) Rate capability and f) cycling performance of $\mathrm{CoFe}(\mathrm{CN})_{6}$ cathode. [170] (Reproduced with permission. Copyright 2019, John Wiley \& Sons)

Zhang et al. firstly reported ZnHCF as a cathode for aqueous ZIBs (Figure 1.13a). The ZnHCF cathode exhibited a capacity of $65.4 \mathrm{mAh} \mathrm{g}^{-1}$ at $60 \mathrm{~mA} \mathrm{~g}^{-1}$ with an average operation voltage up to 1.7 V. Despite a high operation voltage, its energy density $\left(100 \mathrm{Wh} \mathrm{kg}^{-1}\right)$ was still limited by its low capacity. Later, Liu et al. further found that the electrochemical performance of $\left.\mathrm{Zn}_{3}\left[\mathrm{Fe}(\mathrm{CN})_{6}\right)\right]_{2}$ was highly dependent on its morphology. Three morphologies of ZnHCF with different particle sizes were explored, including cuboctahedron, truncated octahedron, and octahedron. It was found that the less dense atomic arrangements along the F111 directions of $\mathrm{ZnHCF}$ tended to react with the electrolyte accelerating the material dissolution. As a result, the cuboctahedron ZnHCF with fewer F111 orientations in the surface areas displayed better rate and cycling performance. These results suggested that the material surface orientations closely associated with $\mathrm{Zn}^{2+}$ diffusion and active material dissolution.[168] Interestingly, $\mathrm{Lu}$ et al. synthesized the hierarchical $\mathrm{ZnHCF} @ \mathrm{MnO}_{2}$ structure with 3D ZnHCF nanotubes encapsulated by $2 \mathrm{D} \mathrm{MnO}_{2}$ nanosheets (Figure 1.13b). Integrating the intercalation characteristic of $\mathrm{ZnHCF}$ with the capacitive property of $\mathrm{MnO}_{2}$ was demonstrated capable of adjusting the charge storage process of ZIBs. The layered $\mathrm{MnO}_{2}$ was employed as a buffer to reduce the diffusion limitations and enable rapid $\mathrm{Zn}^{2+}$ storage. With the synergistic effect of two components, the $\mathrm{ZnHCF} @ \mathrm{MnO}_{2}$ cathode delivered a enhanced rate capability and long-term stability with 77\% capacity retention after 1000 cycles at $500 \mathrm{~mA} \mathrm{~g}^{-1}$ (Figure 1.13c).[169]

Despite improvements in capacity and cyclability achieved by regulation of PBA morphology and electrolyte composition, the electrochemical performance of PBAs was still intrinsically limited by the single redox-reaction species of Fe ions incorporated in MHCFs. Based on the $\mathrm{Fe}^{3+} / \mathrm{Fe}^{2+}$ redox couple, only $0.3 \mathrm{Zn}^{2+}$ could be stored with $\sim 0.6$ electron transfer. Therefore, incorporating dual redox-active species at both $\mathrm{M}_{1}$ and $\mathrm{M}_{2}$ sites of $\mathrm{MHCFs}$ was regarded as an effective approach to enhancing the capacities. Ma et al. prepared $\mathrm{CoFe}(\mathrm{CN})_{6}$ cube particles involving two redox couples of $\mathrm{Co}(\mathrm{II}) / \mathrm{Co}(\mathrm{III})$ and $\mathrm{Fe}(\mathrm{II}) / \mathrm{Fe}(\mathrm{III})$ through extracting $\mathrm{K}$ ions from 
$\mathrm{KCoFe}(\mathrm{CN})_{6}$. These two redox centers exhibited different activation energies, which resulted in a two-step $\mathrm{Zn}^{2+}$ insertion /extraction mechanism in $\mathrm{CoFe}(\mathrm{CN})_{6}$ framework (Figure 1.13d). The incorporated redox centers contributed to the enhanced capacity. Impressively, as current densities increased from 0.3 to $6 \mathrm{~A} \mathrm{~g}^{-1}$, the working voltage plateaus remained almost stable at $\sim 1.75 \mathrm{~V}$ (Figure 1.13e). A superior cycling stability of 2200 cycles at $3 \mathrm{~A} \mathrm{~g} \mathrm{~g}^{-1}$ with nearly $100 \%$ capacity retention was also achieved (Figure 1.13f).[170] In short, although they feature favorable open framework structure and high working voltages $\left(\sim 1.7 \mathrm{~V}\right.$ vs $\left.\mathrm{Zn}^{2+} / \mathrm{Zn}\right)$, PBA-based cathode materials still suffer from relatively low specific capacity $\left(<200 \mathrm{mAh} \mathrm{g}^{-1}\right)$, inferior rate capability, and unsatisfied cycle life. Further optimization of PBAs is highly desired to make them suitable for high-energy and high-rate energy storage.

\subsection{Organic cathodes}

Organic materials have been explored as a new type of promising cathode material for aqueous ZIBs due to their sustainability, environmental friendliness, structural diversity, high theoretical capacity, and cost-effectiveness. To date, various organic cathode materials have been reported for aqueous ZIBs, including carbonyl compounds, imine compounds, conductive polymers, nitronyl nitroxide, and organosulfur polymers.[171-173] The charge storage mechanism of organic cathodes is principally through coordination/incoordination reaction between the cations (e.g. $\mathrm{Zn}^{2+}$ and $\left.\mathrm{H}^{+}\right)$and the active sites, such as quinoid structures, conjugated chemical bonds $(\mathrm{C}=\mathrm{O}, \mathrm{C}=\mathrm{N})$, and N-H functional groups.[173,174]

Carbonyl compounds, especially quinone derivatives, have been demonstrated as an important type of organic cathode materials with high specific capacities in rechargeable batteries. However, the discharged products of quinones usually suffer from dissolution in aqueous electrolytes, leading to significant capacity decline and inferior cyclability. Additionally, their intrinsically poor electronic conductivity restricts the rate performance. Extensive research efforts, therefore, have been devoted to improving the cyclability and rate capability of quinone-based cathodes. Zhao et al. explored the feasibility of a series of quinone compounds as potential cathodes for aqueous ZIBs.[173] Among the investigated quinone compounds, calix[4]quinone (C4Q) was demonstrated as a high-performance cathode for aqueous ZIBs in $\mathrm{Zn}(\mathrm{OTf})_{2}$-based electrolyte, which achieved a high capacity of $335 \mathrm{mAh} \mathrm{g}^{-1}$ at $20 \mathrm{~mA} \mathrm{~g}^{-1}$ with a low voltage polarization (70 
$\mathrm{mV}$ ) (Figure 1.14a), and a long cycle life of 1000 cycles with a capacity retention of $87 \%$ at 500 $\mathrm{mA} \mathrm{g}^{-1}$. Note that a cation selective Nafion membrane was employed as a separator to restrain the discharged products dissolution and protect zinc anode. However, the high price and harsh experimental conditions of Nafion separators hinder their further practical application for largescale ZIBs. To address the dissolution limitation, some other carbonyl compounds possessing high stability and insolubility in aqueous electrolyte were considered as potential cathode candidates, such as pyrene-4,5,9,10-tetraone (PTO) (a ketone compound). Benefiting from the inherent insolubility of PTO, a conventional porous glass fiber membrane was directly used as a separator in the system. The PTO cathode exhibited a high specific capacity of $336 \mathrm{mAh} \mathrm{g}^{-1}$ and a high full cell energy density of $186.7 \mathrm{Wh} \mathrm{kg}^{-1}$.[174] Moreover, incorporating the quinone compounds with insoluble composite was evidenced as a feasible strategy to suppress the dissolution problem. Kundu et al. confined the tetrachloro-1,4-benzoquinone (p-chloranil) in the mesoporous nanochannels of CMK3 carbon to effectively tame the phase evolution process, thus improving the electrochemical cyclability (Figure 1.14b).[175] Furthermore, the dissolution of carbonyl compounds was relieved by the polymerization of small redox-active carbonyl monomers.[176178] For example, by polymerizing dopamine on carbon nanotubes, the polydopamine/carbon nanotube (PDA) composite enabled great structural stability with maintaining two redox-active quinone groups, thus improving the cyclability and rate capability (Figure 1.14c).[176] 

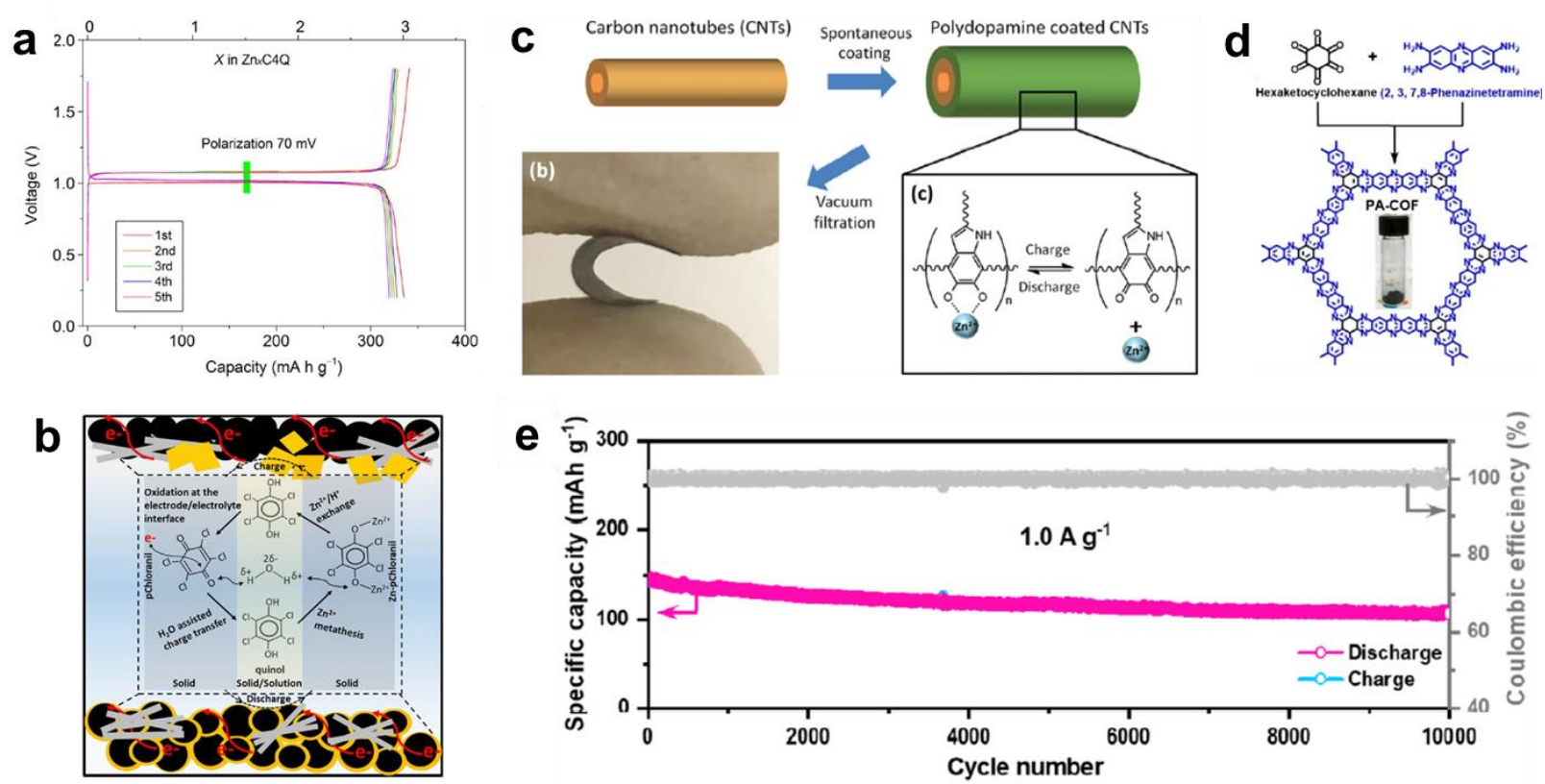

Figure 1. 14 a) Galvanostatic discharge/charge profiles of C4Q at $20 \mathrm{~mA} \mathrm{~g}^{-1}$. The upper $\mathrm{x}$ axis represents the uptake number of Zn ions. [173] (Reproduced with permission. Copyright 2018, American Association for the Advancement of Science.) b) Schematic illustration of the $\mathrm{H}_{2} \mathrm{O}-$ assisted phase transition mechanism with the formation of $\mathrm{Zn}$-p-chloranil (gray fibers) in the discharged state and p-chloranil (yellow rhombus) in the charged state. [175] (Reproduced with permission. Copyright 2018, American Chemical Society) c) Schematic of the fabrication procedure (top), photo (bottom left), and zinc ions storage process upon discharging and charging (bottom right) of PDA/CNTs. [176] (Reproduced with permission. Copyright 2019, Royal Society of Chemistry) d) Illustration of the synthetic route for PA-COF. e) Long-term cycling stability of PA-COF. [180] (Reproduced with permission. Copyright 2020, American Chemical Society)

The covalent organic framework (COF) assembled by small organic compounds were considered as an attractive organic host material for aqueous ZIBs.[179-181] The high porosity and chemical stability as well as the abundant redox-active groups (e.g. $\mathrm{C}=\mathrm{O}, \mathrm{N}-\mathrm{H}$ ) are favorable for reversible and efficient cations storage. Consequently, a superior cyclability of 10000 cycles with $0.38 \%$ capacity decline per cycle at $1.0 \mathrm{~A} \mathrm{~g}^{-1}$ was achieved by a phenanthroline based COF cathode (Figure 1.14d, e).[180] Abdul Khayum $M$ et al. reported the hydroquinone based HqTp $\mathrm{COF}$ as cathode material for aqueous $\mathrm{ZIB}$, in which both $\mathrm{C}=\mathrm{O}$ and $\mathrm{N}-\mathrm{H}$ functional groups were introduced into HqTp as coordination sites to anchor $\mathrm{Zn}^{2+}$ ions via the $\mathrm{C}=\mathrm{O} \cdots \mathrm{Zn}$ and $\mathrm{Zn} \cdots \mathrm{N}-\mathrm{H}$ 
interactions (Figure 1.15a, b). These two types of interactions could be reversibly formed/broken as the $\mathrm{Zn}^{2+}$ insertion/extraction during the redox reaction.[179] As the active organic species are anchored by metal-ligand coordinate covalent bonds, conductive metal-organic frameworks (MOFs) possessing abundant active sites and multifunctionality were considered as the potential cathode without dissolution issues of conventional organic material in aqueous organic electrolytes. Nam et al. developed the $2 \mathrm{D} \mathrm{MOF} \mathrm{Cu}_{3}(\mathrm{HHTP})_{2}$ as a promising cathode material in aqueous ZIBs. The experimental results and theoretical computation demonstrated that both the quinoid structure and the $\mathrm{Cu}^{2+}$ in $\mathrm{Cu}_{3}(\mathrm{HHTP})_{2}$ were used as the redox center for charge storage. Upon discharging, partial $\mathrm{Cu}^{2+}$ was first reduced to $\mathrm{Cu}^{+}$accompanied by 0.3 electrons transfer (at $0.90 \mathrm{~V}$ vs. $\mathrm{Zn} / \mathrm{Zn}^{2+}$ ), followed by the coordination of $\mathrm{Zn}^{2+}$ with two electrons transfer at the quinoid component redox center (at $0.65 \mathrm{~V}$ vs. $\mathrm{Zn} / \mathrm{Zn}^{2+}$ ) (Figure 1.15c, d). As a result, $\mathrm{Cu}_{3}(\mathrm{HHTP})_{2}$ exhibited an initial capacity of $228 \mathrm{mAh} \mathrm{g}^{-1}$ corresponded to 2.3 electrons transfer, which was higher than the theoretical capacity of $197 \mathrm{mAh} \mathrm{g}^{-1}$ with two electrons transfer when only the quinoid structure served as the redox center.[182]

Conductive polymers such as polyaniline (PANI)[183,184], polypyrrole (PPy),[185-187] and poly(p-phenylene) (PPP) [188] have also been explored as organic cathodes of ZIBs. Generally, an acidic electrolyte is required for the PANI protonation, however, it promotes the corrosion of $\mathrm{Zn}$ anode. Consequently, the $\mathrm{pH}$ value of the electrolyte is the critical factor that influences the electrochemical performance of Zn/PANI system. To address this problem, various strategies have been proposed for modification of PANI, including copolymerization with other monomers, [184] mixing with materials of proton-donating ability,[189] and integration with conductive materials such as carbon fiber,[183] graphene oxide,[190]) and metal oxides.[44,191] $\mathrm{Zn}^{2+}$ storage based on coordination reaction was also reported in PANI. A hybrid mechanism with the combination of $\mathrm{Zn}^{2+}$ intercalation/extraction and dual-ion mechanism was proposed in PANI cathode in $\mathrm{Zn}\left(\mathrm{CF}_{3} \mathrm{SO}_{3}\right)_{2}$ electrolyte (Figure 1.15e). In the initial discharging step, the doped $=\mathrm{NH}^{+}$- and undoped $=\mathrm{N}$ - groups in the as-prepared half-oxidized PANI would gain electrons to be reduced to -NH- and $-\mathrm{N}^{-}$-, respectively. Meanwhile, the doped $\mathrm{Cl}^{-}$would removal and the obtained $-\mathrm{N}^{-}$- could coordinate with $\mathrm{Zn}^{2+}$. In the subsequent charging step, the $-\mathrm{N}^{-}-$and $-\mathrm{NH}-$ could be reversibly oxidized to $=\mathrm{N}$ - and $=\mathrm{NH}^{+}$-, respectively. At the same time, the coordinated $\mathrm{Zn}^{2+}$ released from PANI, while oxidized $=\mathrm{NH}^{+}-$in PANI interacted with $\mathrm{CF}_{3} \mathrm{SO}_{3}^{-}$in the electrolyte simultaneously.[192] 

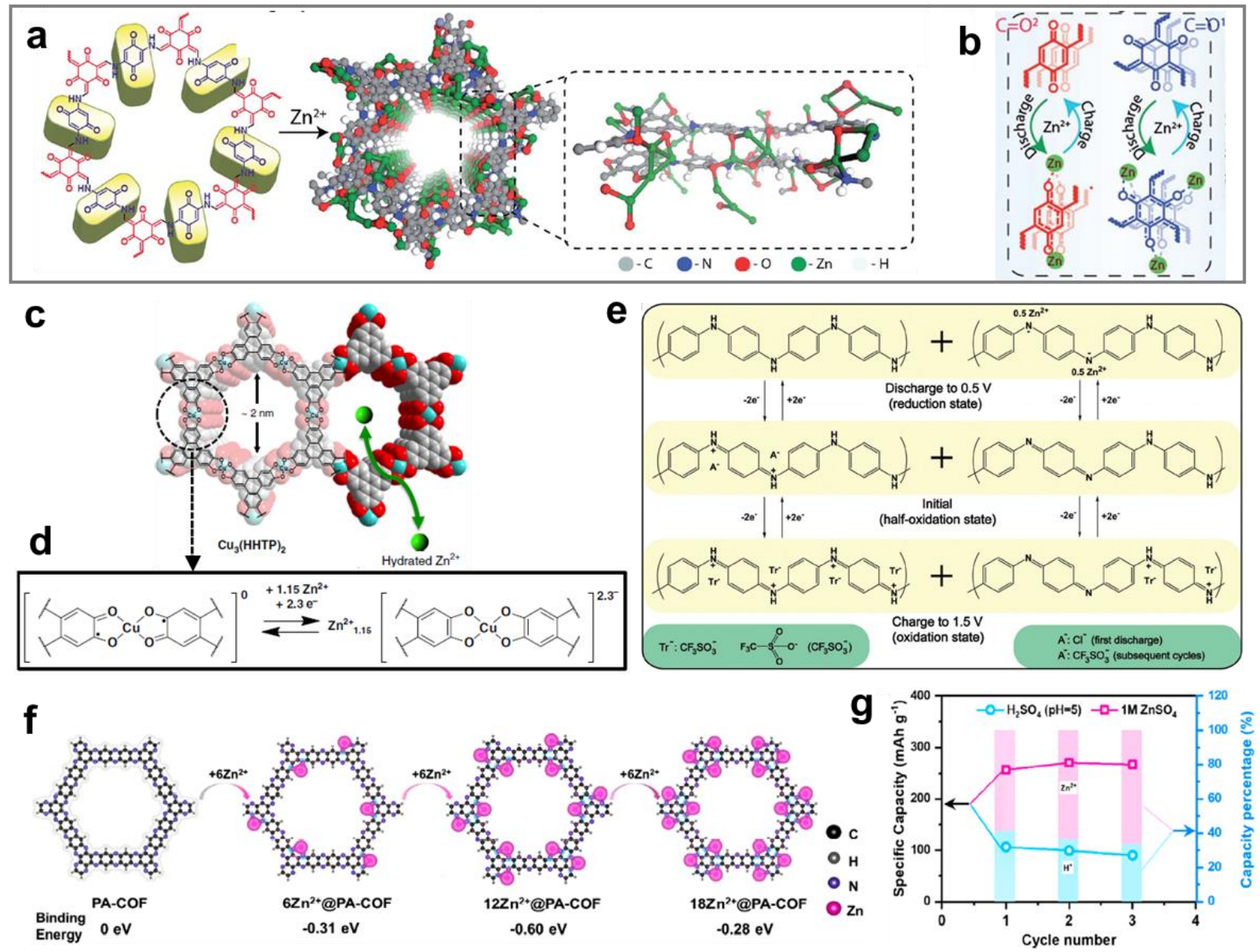

Figure 1.15 a) Diagrammatic representation of the interlayer interaction of $\mathrm{Zn}^{2+}$ with the adjacent layers of HqTp. b) The expected electrochemical redox reactions of the oxidized $\mathrm{Hq}$ and $\mathrm{Tp}$ components in HqTp during the discharging/charging process. [179] (Reproduced with permission. Copyright 2019, Royal Society of Chemistry) c) Structure of $\mathrm{Cu}_{3}(\mathrm{HHTP})_{2}$, which when viewed down the $\mathrm{c}$ axis, exhibits slipped-parallel stacking of 2D sheets with a honeycomb lattice. The cyan, red, and gray spheres represent $\mathrm{Cu}, \mathrm{O}$, and $\mathrm{C}$ atoms, respectively. d) The expected redox process in the coordination unit of $\mathrm{Cu}_{3}(\mathrm{HHTP})_{2}$. [182] (Reproduced with permission. Copyright 2019, Springer Nature) e) The proposed redox mechanism of PANI/carbon felts cathode in aqueous ZIBs. [192] (Reproduced with permission. Copyright 2018, John Wiley \& Sons) f) Simulation of binding energies with different numbers of $\mathrm{Zn}^{2+}$ in PA-COF cathode of zinc ion supercapatter. $\mathrm{g}$ ) Quantitative analysis of $\mathrm{Zn}^{2+}$ and $\mathrm{H}^{+}$contributions to capacity. [180] (Reproduced with permission. Copyright 2018, American Chemical Society) 
Apart from $\mathrm{Zn}^{2+}, \mathrm{H}^{+}$was also reported as an attractive charge carrier in organic-based cathode for aqueous ZIBs.[180,193,194] Very recently, Wang et al. reported that the phenanthroline functional groups in phenanthroline covalent organic framework (PA-COF) could serve as active sites for $\mathrm{Zn}^{2+}$ storage. Electrostatic potential surface (EPS) analysis confirmed the strong chemical affinity of nitrogen sites in phenanthroline rings for cation coordination (Figure 1.15f). Impressively, besides the coordination of $\mathrm{Zn}^{2+}$ ions, the capturing of $\mathrm{H}^{+}$at phenanthroline active sites was also confirmed based on electrochemical analysis and ${ }^{2} \mathrm{D}$-state NMR. The capacity contribution form $\mathrm{Zn}^{2+}$ and $\mathrm{H}^{+}$storages in PA-COF were further quantitatively calculated to be $60 \%$ and 40\%, respectively (Figure 1.15g).[180] In contrast to the inconvenient $\mathrm{Zn}^{2+}$ storagedominated mechanism, Tie et al. claimed the $\mathrm{H}^{+}$uptake/removal mechanism via coordination/incoordination reaction with $\mathrm{C}=\mathrm{N}$ groups rather than conventional $\mathrm{Zn}^{2+}$ insertion/extraction in diquinoxalino [2,3-a:2',3'-c] phenazine (HATN) cathode for aqueous Znorganic battery. Six $\mathrm{H}^{+}$ions might react with the $\mathrm{C}=\mathrm{N}$ groups of HATN accompanying by the reversible structure evolution from original HATN to HATN-6H.[194] The mechanism investigation of 1,4,5,8-naphthalene diimide (NDI) cathode demonstrated that the reduced NDI first interacted with water molecules, then proceeded the stepwise uptake of $\mathrm{H}^{+}$and $\mathrm{Zn}^{2+}$.[193]

Besides the previously reported typical $\mathrm{Zn}^{2+}$ coordination in organic cathode materials like carbonyl compounds, it has been started to acknowledge the existence of $\mathrm{H}^{+}$(or co-existence of $\mathrm{Zn}^{2+} / \mathrm{H}^{+}$) uptake in the organic electrodes. However, the investigations of organic cathode in terms of in-depth understanding of the $\mathrm{Zn}^{2+} / \mathrm{H}^{+}$storage mechanism and electrochemical performance improvement based on this mechanism are still in the initial stage.

\subsection{Other cathode materials}

Recently, transition metal chalcogenides (TMCs) have attracted tremendous attention as promising cathode candidates for ZIBs. Featuring layered structures analogous to graphite with adjacent planes connected via weak van der Waals interactions, TMCs hold potential for reversible (de)intercalation of cations.[195] For example, $V_{2}$ possesses an interlayer spacing of $5.76 \AA$ and metallic characteristic that ensures high electrical conductivity, making it a suitable cathode host for $\mathrm{Zn}^{2+}$ storage. When the layered $\mathrm{VS}_{2}$ nanosheets were used as a cathode material for aqueous ZIBs, a capacity of $190.3 \mathrm{mAh} \mathrm{g}^{-1}$ was presented at $0.05 \mathrm{~A} \mathrm{~g}^{-1}$ with two voltage plateaus at $\sim 0.7$ 
and $0.63 \mathrm{~V}$ (Figure 1.16a, b).[196] Using VS $\mathrm{V}_{2} @$ stainless steel mesh as a binder-free cathode for ZIBs, over $80 \%$ capacity retention over 2000 cycles at $2 \mathrm{~A} \mathrm{~g}^{-1}$ was realized.[197] $\mathrm{VS}_{4}$ possesses a chain-like structure constructed by a central $\mathrm{V}^{4+}$ and two $\mathrm{S}_{2}{ }^{2-}$ units. Due to a large distance between V-S chains (6.2 $\AA$ ) and abundant sites in loosely bound chains, $1 \mathrm{D} \mathrm{VS} 4$ is beneficial for the fast diffusion of $\mathrm{Zn}^{2+}$. Different from the intercalation mechanism of $\mathrm{VS}_{2}$, both intercalation and conversion reactions were involved in the discharging step of $\mathrm{VS}_{4}$ cathode in $\mathrm{ZIBs}$, in which the conversion reaction was associated with both $\mathrm{V}^{4+}$ and $\mathrm{S}_{2}{ }^{2-}$.[198] Overall, vanadium sulfides still suffered from limited energy densities because of their low operating voltages $(\sim 0.6-0.9 \mathrm{~V})$ and unsatisfied capacities. Compared with $\mathrm{VS}_{2}, \mathrm{VSe}_{2}$ was regarded to hold greater capability for $\mathrm{Zn}$ storage, due to its higher electronic conductivity, larger interlayer spacing (6.10 $⿱$ A), and lower ion migration barriers induced by the smaller electronegativity of $\mathrm{Se}$. The $\mathrm{VSe}_{2}$ cathode delivered a high capacity $\left(250.6 \mathrm{mAh} \mathrm{g}^{-1}\right.$ at $\left.200 \mathrm{~mA} \mathrm{~g}^{-1}\right)$, superior rate capability $\left(132.6 \mathrm{mAh} \mathrm{g}^{-1}\right.$ at $5000 \mathrm{~mA}$ $\mathrm{g}^{-1}$ ) (Figure 1.16c), and excellent cycle performance (83\% capacity retention over 800 cycles at $2000 \mathrm{~mA} \mathrm{~g}^{-1}$ ), outperforming other TMDs cathodes for aqueous ZIBs. VSe 2 interlayer spacing expanded and shrunk periodically upon discharge and charge process respectively, suggesting the reversible insertion and extraction of $\mathrm{Zn}^{2+}$ (Figure 1.16d).[199]
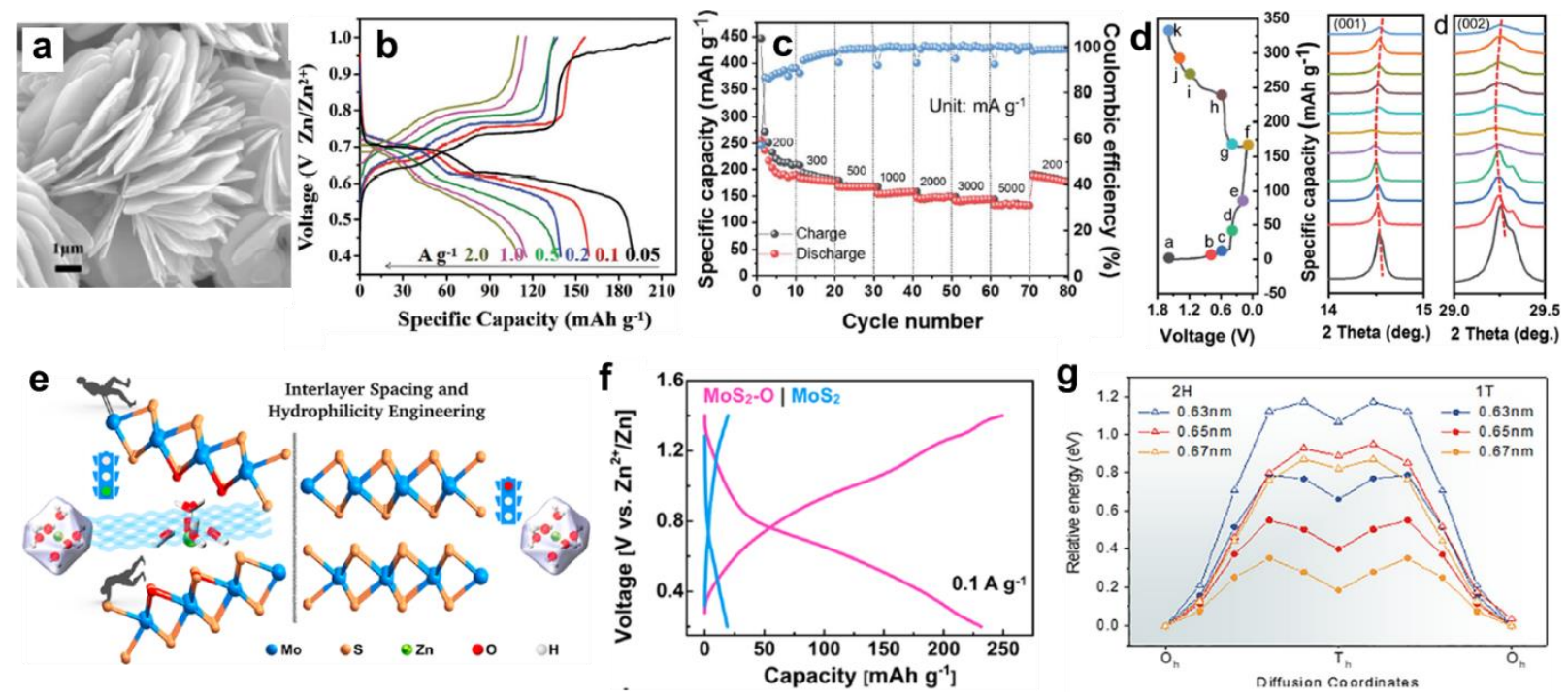

Figure 1. 16 a) SEM image of $\mathrm{VS}_{2}$ nanosheets. b) GCD curves of $\mathrm{Zn} / / \mathrm{VS}_{2}$ battery. [196] (Reproduced with permission. Copyright 2017, John Wiley \& Sons) c) Rate performance of VSe 2. d) GCD curves of $\mathrm{VSe}_{2}$ at $200 \mathrm{~mA} \mathrm{~g}^{-1}$ and the corresponding ex situ XRD patterns collected at different states. [197] (Reproduced with permission. Copyright 2020, Royal Society of Chemistry) 
e) Schematic illustration of strategies employed for $\mathrm{MoS}_{2}$. f) GCD profiles of $\mathrm{MoS}_{2}$ at $0.1 \mathrm{~A} \mathrm{~g}^{-1}$. [201] (Reproduced with permission. Copyright 2019, American Chemical Society) g) Calculated energy profiles of $\mathrm{Zn}$ diffusion in $2 \mathrm{H}$ and $1 \mathrm{~T}$ phase of $\mathrm{MoS}_{2}$. [202] (Reproduced with permission. Copyright 2020, Elsevier).

$\mathrm{MoS}_{2}$ is another representative member of the TMCs family with similar 2D structure and physicochemical properties to $\mathrm{VS}_{2}$ for $\mathrm{Zn}^{2+}$ storage.[200] Liang et al. proposed an effective strategy to unlock the $\mathrm{Zn}^{2+}$ diffusivity of inactive $\mathrm{MoS}_{2}$ by incorporating oxygen into the $\mathrm{MoS}_{2}$ framework, which expanded interlayer spacing from 6.2 to $9.5 \AA$ and improved $\mathrm{MoS}_{2}$ hydrophilicity (Figure 1.16e). As a result, $\mathrm{Zn}^{2+}$ diffusion kinetics was enhanced by three orders of magnitude. The capacity of $\mathrm{MoS}_{2}$ dramatically increased from 21 to $232 \mathrm{mAh} \mathrm{g}^{-1}$ (Figure 1.16f).[201] In addition, $1 \mathrm{~T}$ phase $\mathrm{MoS}_{2}$ was elucidated to favor $\mathrm{Zn}^{2+}$ transport compared to the $2 \mathrm{H}$ phase counterpart owing to a much lower $\mathrm{Zn}$ diffusion energy barrier of the former (Figure 1.16g).[202] Besides, Chevrel phase $\mathrm{Zn}_{\mathrm{x}} \mathrm{Mo}_{6} \mathrm{~S}_{8}$ was developed as a potential cathode material for $\mathrm{Zn}^{2+}$ intercalation, accompanied by a phase transition from $\mathrm{Mo}_{6} \mathrm{~S}_{8}$ to $\mathrm{Zn}_{\mathrm{x}} \mathrm{Mo}_{6} \mathrm{~S}_{8}$, however, it exhibited a limited capacity and low working voltage (134 $\mathrm{mAh} \mathrm{g}^{-1}$, below $\left.0.5 \mathrm{~V}\right)$.[203] A low working voltage $(0.3 \mathrm{~V})$ was also found in pre-sodiated $\mathrm{TiS}_{2}\left(\mathrm{Na}_{0.14} \mathrm{TiS}_{2}\right)$ cathode.[204]

Earlier, Liu et al. evaluated the electrochemical properties of some commercially available

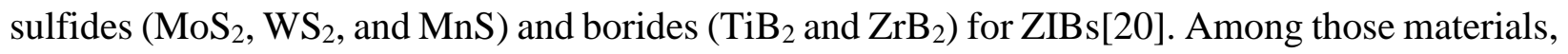
only $\mathrm{MnS}$ showed promising electrochemical performance. Note that the inferior performance might be associated with the large size of bulk particles which are unfavorable for ion diffusion and effective contact with electrolytes. Their electrochemical mechanism was not elucidated. We have systematically investigated $\mathrm{MnS}$ nanorods and found that the charge process oxidized inactive $\mathrm{MnS}$ into an electrochemically derived oxide (MnS-EDO), the latter of which was the true electrochemically active species.[98]

\section{7 $\mathrm{Zn}$ anode}

Metallic Zn has been widely applied as an anode material in various type of batteries because it features the merits of low cost, high abundance and safety, eco-friendliness, recyclability, easy processing, and high compatibility and stability in water. Especially, aqueous Zn-based battery promising in electrical energy storage systems especially for grid-level application. Although the 
primary aqueous $\mathrm{Zn}$-based batteries have achieved commercial success, the development of electrically rechargeable aqueous Zn-based batteries reached the bottleneck since the rechargeability and cycling stability limited by poor reversibility of $\mathrm{Zn}$ anode in the alkaline electrolyte. $\mathrm{Zn}$ anode usually suffers from the drawbacks in alkaline medium, including growth of Zn dendrite, low Coulombic efficiency, sustained water consumption and formation or irreversible byproducts.[205,206] leading to capacity decay during plating/stripping of zinc anode. It was considered that, to some great extent, the ZIBs using neutral or mildly acidic aqueous electrolyte without concern of these issues that typically emerged in an alkaline electrolyte.[29,151] Recently, however, it has been acknowledged the importance of $\mathrm{Zn}$ anode to overall performance of ZIBs. The electrochemical property of $\mathrm{Zn}$ anode is still far from the requirements for their practical applications, especially for the commercialization of high-energy density and cost-effective ZIBs.[207-209] In fact, the useful zinc may continuously lose from the anode due to the formation of the dendrite and passivation layer during the repeated stripping and plating, thereby inducing inferior reversibility. Nevertheless, in most of the current studies about ZIBs regarding the evaluation of cathode material, $\mathrm{Zn}$ metal plate is directly used as the anode. This excess zinc can compensate for its potential negative effect on the overall battery performance. Regarding the practical application that aims to construct high energy density ZIBs, the excess Zn may give rise to a mortal drawback in energy density as well as cost increasing.[208]

The limited $\mathrm{Zn}$ chemistry reversibility and poor cycling stability were highly associated with the undesired reactions that occurred at the interface between metal $\mathrm{Zn}$ and aqueous electrolyte, involving $\mathrm{Zn}$ dendrite growth, $\mathrm{H}_{2}$ evolution reaction, passive byproduct formation. These side reactions can be represented as follows:

Metallic Zn deposition: $\mathrm{Zn}\left(\mathrm{H}_{2} \mathrm{O}\right)_{6}^{2+}+2 \mathrm{e}^{-} \rightarrow \mathrm{Zn}+6 \mathrm{H}_{2} \mathrm{O}$

$\mathrm{H}_{2}$ evolution reaction (HER): $2 \mathrm{H}_{2} \mathrm{O}+2 \mathrm{e}^{-} \rightarrow 2 \mathrm{OH}^{-}+\mathrm{H}_{2} \uparrow$

By-product formation (for $\left(\mathrm{Zn}(\mathrm{OTf})_{2}\right.$ electrolyte)):

$\mathrm{xZn}^{2+}+\mathrm{yOTf}^{-}+(2 \mathrm{x}-\mathrm{y}) \mathrm{OH}^{-}+\mathrm{nH}_{2} \mathrm{O} \rightarrow \mathrm{Zn}_{\mathrm{x}}(\mathrm{OTf})_{\mathrm{y}}(\mathrm{OH})_{2 \mathrm{x}-\mathrm{y}} \cdot \mathrm{nH}_{2} \mathrm{O} \downarrow$

For the metallic $\mathrm{Zn}$ electrodeposition process, the main issue would be dendrite formation. The dendrite formation primarily arises because of concentration-controlled $\mathrm{Zn}$ electrodeposition, whereby a sloped concentration gradient of $\mathrm{Zn}^{2+}$ ions is established as a function of distance from the $\mathrm{Zn}$ electrode surface. The dissolved $\mathrm{Zn}^{2+}$ ions are initially adsorbed on the protruded 
heterogeneous surface and are preferentially reduced at the energetically favorable sites (priority nucleation site) to form the small tips. This local heterogeneity on the surface of $\mathrm{Zn}$ anode further aggravates the uneven electric field distribution in the interfacial of electrode/electrolyte and attracts more zinc ions unevenly accumulate on the small tips due to the cusp effect, thus form dendrites. As the repeated stripping/plating, the dendrites grow constantly and finally penetrate the separator, leading to a short circuit. Although dendrite growth can be mitigated in a nearly neutral or mildly acidic electrolyte, the formation of mossy, layered, or boulder-like $\mathrm{Zn}$ dendrites is still inevitably observed since the impossibility of eliminating the localized heterogeneous nucleation on the surface of $\mathrm{Zn}$ and the subsequent ions prefer the existing protrusion to minimize the surface energy.[112,210]

The dendrite formation induces a loose dendritic surface, in which more freshly deposited $\mathrm{Zn}$ is exposed to the aqueous electrolyte, thus aggravates the corrosion reaction on the electrode surface and promotes $\mathrm{H}_{2}$ evolution. the HER at cost of proton consumption increases the local electrolyte $\mathrm{pH}$, which in turn facilitates the formation of passive by-products on the electrode surface. These issues remain a challenge for rechargeable aqueous $\mathrm{Zn}$ anode. Therefore, it is highly desirable to suppress side reactions and improve the stability of $\mathrm{Zn}$ anode in aqueous ZIBs for future large-scale applications. To solve these issues of $\mathrm{Zn}$ anode mentioned above, the investigation mainly focused on three directions, including modulating $\mathrm{Zn}^{2+}$ coordination environment, uniforming interfacial electric field, and inducing $\mathrm{Zn}$ deposition.[211] Accordingly, plenty of effective strategies have been put forward recently to improve the reversibility of $\mathrm{Zn}$ anode, including electrolyte optimization, structure design for novel $\mathrm{Zn}$ host structure, and electrode surface modification.

Electrolyte optimization is a promising way to regulate the interfacial reactions between anodes and electrolyte. Compared with the $\mathrm{SO}_{4}{ }^{2-}$ in normal $\mathrm{ZnSO}_{4}$ electrolyte, the $\mathrm{Zn}\left(\mathrm{CF}_{3} \mathrm{SO}_{3}\right)_{2}$ electrolyte was reported favorable to regulate uniform deposition on $\mathrm{Zn}$ electrode with no dendrite formation. the bulky $\mathrm{CF}_{3} \mathrm{SO}_{3}{ }^{-}$anions might reduce the number of water molecules in coordination with $\mathrm{Zn}^{2+}$ cations, facilitating $\mathrm{Zn}^{2+}$ transfer.[61] In addition, the high-concentration electrolyte, so called "water in salt" electrolyte $(1 \mathrm{~m} \mathrm{Zn(TFSI})_{2}+20 \mathrm{~m}$ LiTFSI), was proposed as a good electrolyte candidate, which greatly weakens water reaction activity and effectively prevents HER, thereby leading to highly reversible Zn plating/stripping.[111] Further, introduction of electrolyte additives is also effective strategy for regulating interfacial reactions to achieve uniform $\mathrm{Zn}$ 
deposition. Electrolyte additives like diethyl ether, cyclic ether (1,4-dioxane), glucose, polyacrylamide, polyethylene glycol, $\mathrm{TBA}_{2} \mathrm{SO}_{4}$, and so on have been used to promote the generation of uniform $\mathrm{Zn}$ electrodeposition nucleation and growth for stable aqueous $\mathrm{Zn}$ anode.[212-216]

According to the epitaxial electrodeposition mechanism, the nucleation and growth of the epilayer on a substrate were highly oriented by the plane with minimal lattice strain.[211] The crystal texture engineering that creating more exposed preferred surface was considered an effective approach to achieving dendrite-free $\mathrm{Zn}$ anode. For example, $\mathrm{Zn}$ electrode with more exposed $(002)_{Z n}$ plane produced by rolling deformation enabled guiding the preferential crystal growth parallel to the electrode surface, thus resulted in uniform $\mathrm{Zn}$ deposition and inhabitation of corrosion, dendrite and byproduct formation.[217] Likewise, the crystal texture engineering methods, including acid etching, $\mathrm{Zn}$ electrodeposition in desirable electrolytes and various substrates have been adopted to produce $(002)_{\mathrm{Zn}}$ textured $\mathrm{Zn}$ electrode for reversible $\mathrm{Zn}$ plating/stripping.[218-221] In addition, surface modification using coating layers of polymers,[210,222,223] metal oxides,[224,225] and metal-organic frameworks [226,227] has been reported to effectively stabilize $\mathrm{Zn}$ deposition and suppress side reactions by regulating interfacial reactions.

\section{References}

[1] T.M. Gür, Review of electrical energy storage technologies, materials and systems: Challenges and prospects for large-scale grid storage, Energy Environ. Sci. 11 (2018) 26962767.

[2] M. Li, J. Lu, Z. Chen, K. Amine, 30 Years of Lithium-Ion Batteries, Adv. Mater. 30 (2018) 1800561.

[3] J.B. Goodenough, Y. Kim, Challenges for rechargeable Li batteries, Chem. Mater. 22 (2010) 587-603.

[4] P. Canepa, G. Sai Gautam, D.C. Hannah, R. Malik, M. Liu, K.G. Gallagher, K.A. Persson, G. Ceder, Odyssey of multivalent cathode materials: Open questions and future challenges, Chem. Rev. 117 (2017) 4287-4341.

[5] H. Kim, J. Hong, K.-Y. Park, H. Kim, S.-W. Kim, K. Kang, Aqueous rechargeable Li and 
na ion batteries, Chem. Rev. 114 (2014) 11788-11827.

[6] D. Kundu, B.D. Adams, V. Duffort, S.H. Vajargah, L.F. Nazar, A high-capacity and longlife aqueous rechargeable zinc battery using a metal oxide intercalation cathode, Nat. Energy. 1 (2016) 16119.

[7] Z. Chang, Y. Yang, M. Li, X. Wang, Y. Wu, Green energy storage chemistries based on neutral aqueous electrolytes, J. Mater. Chem. A. 2 (2014) 10739-10755.

[8] J. Chen, F. Cheng, Combination of lightweight elements and nanostructured materials for batteries, Acc. Chem. Res. 42 (2009) 713-723.

[9] H. Li, L. Ma, C. Han, Z. Wang, Z. Liu, Z. Tang, C. Zhi, Advanced rechargeable zinc-based batteries: Recent progress and future perspectives, Nano Energy. 62 (2019) 550-587.

[10] G. Fang, J. Zhou, A. Pan, S. Liang, Recent advances in aqueous zinc-ion batteries, ACS Energy Lett. 3 (2018) 2480-2501.

[11] M. Song, H. Tan, D. Chao, H.J. Fan, Recent advances in Zn-ion batteries, Adv. Funct. Mater. 28 (2018) 1802564.

[12] A. Konarov, N. Voronina, J.H. Jo, Z. Bakenov, Y.-K. Sun, S.-T. Myung, Present and future perspective on electrode materials for rechargeable zinc-ion batteries, ACS Energy Lett. 3 (2018) 2620-2640.

[13] Y. Li, J. Fu, C. Zhong, T. Wu, Z. Chen, W. Hu, K. Amine, J. Lu, Recent Advances in flexible zinc-based rechargeable batteries, Adv. Energy Mater. 9 (2019) 1802605.

[14] M. Winter, R.J. Brodd, What are batteries, fuel cells, and supercapacitors?, Chem. Rev. 104 (2004) 4245-4270.

[15] Y. Shen, K. Kordesch, The mechanism of capacity fade of rechargeable alkaline manganese dioxide zinc cells, J. Power Sources. 87 (2000) 162-166.

[16] A.M. Kannan, S. Bhavaraju, F. Prado, M.M. Raja, A. Manthiram, Characterization of the bismuth-modified manganese dioxide cathodes in rechargeable alkaline cells, J. Electrochem. Soc. 149 (2002) 483-492.

[17] T. Shoji, M. Hishinuma, T. Yamamoto, Zinc-manganese dioxide galvanic cell using zinc sulphate as electrolyte. Rechargeability of the cell, J. Appl. Electrochem. 18 (1988) 521526.

[18] T. Shoji, T. Yamamoto, Charging and discharging behavior of zinc-manganese galvanic cells using zinc sulfate as electrolyte, J. EIectroana\&ical Chem. 362 (1993) 153-157. 
[19] T. Yamamoto, T. Shoji, Rechargeable $\mathrm{Zn}\left|\mathrm{ZnSO}_{4}\right| \mathrm{MnO}_{2}$-type cells, Inorganica Chim. Acta. 117 (1986) L27-L28.

[20] W. Liu, J. Hao, C. Xu, J. Mou, L. Dong, F. Jiang, Z. Kang, J. Wu, B. Jiang, F. Kang, Investigation of zinc ion storage of transition metal oxides, sulfides, and borides in zinc ion battery systems, Chem. Commun. 53 (2017) 6872-6874.

[21] F.Y. Cheng, J. Chen, X.L. Gou, P.W. Shen, High-power alkaline $\mathrm{Zn}-\mathrm{MnO}_{2}$ batteries using $\gamma-\mathrm{MnO}_{2}$ nanowires/nanotubes and electrolytic zinc powder, Adv. Mater. 17 (2005) 27532756.

[22] B.J. Hertzberg, A. Huang, A. Hsieh, M. Chamoun, G. Davies, J.K. Seo, Z. Zhong, M. Croft, C. Erdonmez, Y.S. Meng, D. Steingart, Effect of multiple cation electrolyte mixtures on rechargeable $\mathrm{Zn}-\mathrm{MnO}_{2}$ alkaline battery, Chem. Mater. 28 (2016) 4536-4545.

[23] T.T. Truong, Y. Liu, Y. Ren, L. Trahey, Y. Sun, Morphological and Crystalline Evolution of Nanostructured $\mathrm{MnO}_{2}$ and its application in lithium-air batteries, ACS Nano. (2012) 8067-8077.

[24] M. Huang, F. Li, F. Dong, X. Zhang, L. Li, MnO2-based nanostructures for highperformance supercapacitors, J. Mater. Chem. A. 3 (2015) 21380-21423.

[25] C. Xu, B. Li, H. Du, F. Kang, Energetic zinc ion chemistry: The rechargeable zinc ion battery, Angew. Chem. Int. Ed. 51 (2012) 933-935.

[26] M.H. Alfaruqi, J. Gim, S. Kim, J. Song, J. Jo, S. Kim, V. Mathew, J. Kim, Enhanced reversible divalent zinc storage in a structurally stable $\alpha-\mathrm{MnO}_{2}$ nanorod electrode, J. Power Sources. 288 (2015) 320-327.

[27] B. Lee, C.S. Yoon, H.R. Lee, K.Y. Chung, B.W. Cho, S.H. Oh, Electrochemically-induced reversible transition from the tunneled to layered polymorphs of manganese dioxide, Sci. Rep. 4 (2014) 1-8.

[28] B. Lee, H.R. Lee, H. Kim, K.Y. Chung, B.W. Cho, S.H. Oh, Elucidating the intercalation mechanism of zinc ions into $\alpha-\mathrm{MnO}_{2}$ for rechargeable zinc batteries, Chem. Commun. 51 (2015) 9265-9268.

[29] H. Pan, Y. Shao, P. Yan, Y. Cheng, K.S. Han, Z. Nie, C. Wang, J. Yang, X. Li, P. Bhattacharya, K.T. Mueller, J. Liu, Reversible aqueous zinc/manganese oxide energy storage from conversion reactions, Nat. Energy. 1 (2016) 16039.

[30] A.S. Poyraz, J. Laughlin, Z. Zec, Improving the cycle life of cryptomelane type manganese 
dioxides in aqueous rechargeable zinc ion batteries: The effect of electrolyte concentration, Electrochim. Acta. 305 (2019) 423-432.

[31] D. Xu, B. Li, C. Wei, Y.B. He, H. Du, X. Chu, X. Qin, Q.H. Yang, F. Kang, Preparation and characterization of $\mathrm{MnO}_{2}$ /acid-treated CNT nanocomposites for energy storage with zinc ions, Electrochim. Acta. 133 (2014) 254-261.

[32] B. Wu, G. Zhang, M. Yan, T. Xiong, P. He, L. He, X. Xu, L. Mai, Graphene scroll-coated $\alpha-\mathrm{MnO}_{2}$ nanowires as high-performance cathode materials for aqueous $\mathrm{Zn}$-ion battery, Small. 14 (2018) 1703850.

[33] D. Wang, H. Li, Z. Liu, Z. Tang, G. Liang, F. Mo, Q. Yang, L. Ma, C. Zhi, A nanofibrillated cellulose/polyacrylamide electrolyte-based flexible and sewable high-performance $\mathrm{Zn}-$ $\mathrm{MnO}_{2}$ battery with superior shear resistance, Small. 14 (2018) 1803978.

[34] W. Qiu, Y. Li, A. You, Z. Zhang, G. Li, X. Lu, Y. Tong, High-performance flexible quasisolid-state $\mathrm{Zn}-\mathrm{MnO}_{2}$ battery based on $\mathrm{MnO}_{2}$ nanorod arrays coated 3D porous nitrogendoped carbon cloth, J. Mater. Chem. A. 5 (2017) 14838-14846.

[35] M. Li, Q. He, Z. Li, Q. Li, Y. Zhang, J. Meng, X. Liu, S. Li, B. Wu, L. Chen, Z. Liu, W. Luo, C. Han, L. Mai, A novel dendrite-free $\mathrm{Mn}^{2+} / \mathrm{Zn}^{2+}$ hybrid battery with $2.3 \mathrm{~V}$ voltage window and 11000-cycle lifespan, Adv. Energy Mater. 9 (2019) 1901469.

[36] G. Fang, C. Zhu, M. Chen, J. Zhou, B. Tang, X. Cao, X. Zheng, A. Pan, S. Liang, Suppressing manganese dissolution in potassium manganate with rich oxygen defects engaged high-energy-density and durable aqueous zinc-ion battery, Adv. Funct. Mater. 29 (2019) 1808375.

[37] S. Islam, M.H. Alfaruqi, V. Mathew, J. Song, S. Kim, S. Kim, J. Jo, J.P. Baboo, D.T. Pham, D.Y. Putro, Y.K. Sun, J. Kim, Facile synthesis and the exploration of the zinc storage mechanism of $\beta-\mathrm{MnO}_{2}$ nanorods with exposed (101) planes as a novel cathode material for high performance eco-friendly zinc-ion batteries, J. Mater. Chem. A. 5 (2017) 23299-23309.

[38] N. Zhang, F. Cheng, J. Liu, L. Wang, X. Long, X. Liu, F. Li, J. Chen, Rechargeable aqueous zinc-manganese dioxide batteries with high energy and power densities, Nat. Commun. 8 (2017) 405.

[39] M.H. Alfaruqi, V. Mathew, J. Gim, S. Kim, J. Song, J.P. Baboo, S.H. Choi, J. Kim, Electrochemically induced structural transformation in a $\gamma-\mathrm{MnO}_{2}$ cathode of a high capacity zinc-ion battery system, Chem. Mater. 27 (2015) 3609-3620. 
[40] M.H. Alfaruqi, J. Gim, S. Kim, J. Song, D.T. Pham, J. Jo, Z. Xiu, V. Mathew, J. Kim, A layered $\delta-\mathrm{MnO}_{2}$ nanoflake cathode with high zinc-storage capacities for eco-friendly battery applications, Electrochem. Commun. 60 (2015) 121-125.

[41] S.D. Han, S. Kim, D. Li, V. Petkov, H.D. Yoo, P.J. Phillips, H. Wang, J.J. Kim, K.L. More, B. Key, R.F. Klie, J. Cabana, V.R. Stamenkovic, T.T. Fister, N.M. Markovic, A.K. Burrell, S. Tepavcevic, J.T. Vaughey, Mechanism of $\mathrm{Zn}$ insertion into nanostructured $\delta-\mathrm{MnO}_{2}: \mathrm{A}$ nonaqueous rechargeable Zn metal battery, Chem. Mater. 29 (2017) 4874-4884.

[42] T. Xiong, Z.G. Yu, H. Wu, Y. Du, Q. Xie, J. Chen, Y.W. Zhang, S.J. Pennycook, W.S.V. Lee, J. Xue, Defect engineering of oxygen-deficient manganese oxide to achieve highperforming aqueous zinc ion battery, Adv. Energy Mater. 9 (2019) 1803815.

[43] M.H. Alfaruqi, S. Islam, D.Y. Putro, V. Mathew, S. Kim, J. Jo, S. Kim, Y.K. Sun, K. Kim, J. Kim, Structural transformation and electrochemical study of layered $\mathrm{MnO}_{2}$ in rechargeable aqueous zinc-ion battery, Electrochim. Acta. 276 (2018) 1-11.

[44] J. Huang, Z. Wang, M. Hou, X. Dong, Y. Liu, Y. Wang, Y. Xia, Polyaniline-intercalated manganese dioxide nanolayers as a high-performance cathode material for an aqueous zincion battery, Nat. Commun. 9 (2018) 2906.

[45] J. Wang, J.G. Wang, H. Liu, C. Wei, F. Kang, Zinc ion stabilized $\mathrm{MnO}_{2}$ nanospheres for high capacity and long lifespan aqueous zinc-ion batteries, J. Mater. Chem. A. 7 (2019) 13727-13735.

[46] H. Ren, J. Zhao, L. Yang, Q. Liang, S. Madhavi, Q. Yan, Inverse opal manganese dioxide constructed by few-layered ultrathin nanosheets as high-performance cathodes for aqueous zinc-ion batteries, Nano Res. 12 (2019) 1-7.

[47] W. Sun, F. Wang, S. Hou, C. Yang, X. Fan, Z. Ma, T. Gao, F. Han, R. Hu, M. Zhu, C. Wang, $\mathrm{Zn} / \mathrm{MnO}_{2}$ battery chemistry with $\mathrm{H}^{+}$and $\mathrm{Zn}^{2+}$ coinsertion, J. Am. Chem. Soc. 139 (2017) 9775-9778.

[48] D. Chao, W. Zhou, C. Ye, Q. Zhang, Y. Chen, L. Gu, K. Davey, S.Z. Qiao, An electrolytic $\mathrm{Zn}-\mathrm{MnO}_{2}$ battery for high-voltage and scalable energy storage, Angew. 58 (2019) 7823.

[49] J. Lee, J.B. Ju, W. Il Cho, B.W. Cho, S.H. Oh, Todorokite-type $\mathrm{MnO}_{2}$ as a zinc-ion intercalating material, Electrochim. Acta. 112 (2013) 138-143.

[50] G. Sun, X. Jin, H. Yang, J. Gao, L. Qu, An aqueous $\mathrm{Zn}-\mathrm{MnO}_{2}$ rechargeable microbattery, J. Mater. Chem. A. 6 (2018) 10926-10931. 
[51] S. Zhang, N. Yu, S. Zeng, S. Zhou, M. Chen, J. Di, Q. Li, An adaptive and stable bioelectrolyte for rechargeable Zn-ion batteries, J. Mater. Chem. A. 6 (2018) 12237-12243.

[52] Y. Huang, J. Liu, Q. Huang, Z. Zheng, P. Hiralal, F. Zheng, D. Ozgit, S. Su, S. Chen, P.-H. Tan, S. Zhang, H. Zhou, Flexible high energy density zinc-ion batteries enabled by binderfree $\mathrm{MnO}_{2} /$ reduced graphene oxide electrode, Npj Flex. Electron. 2 (2018) 21.

[53] Q. Zhao, X. Chen, Z. Wang, L. Yang, R. Qin, J. Yang, Y. Song, S. Ding, M. Weng, W. Huang, J. Liu, W. Zhao, G. Qian, K. Yang, Y. Cui, H. Chen, F. Pan, Unravelling $\mathrm{H}^{+} / \mathrm{Zn}^{2+}$ synergistic intercalation in a novel phase of manganese oxide for high-performance aqueous rechargeable battery, Small. 15 (2019) 1904545.

[54] L. Wang, X. Cao, L. Xu, J. Chen, J. Zheng, Transformed akhtenskite MnO2 from $\mathrm{Mn}_{3} \mathrm{O}_{4}$ as cathode for a rechargeable aqueous zinc ion battery, ACS Sustain. Chem. Eng. 6 (2018) 16055-16063.

[55] C. Zhu, G. Fang, J. Zhou, J. Guo, Z. Wang, C. Wang, J. Li, Y. Tang, S. Liang, Binder-free stainless steel@ $\mathrm{Mn}_{3} \mathrm{O}_{4}$ nanoflower composite: A high-activity aqueous zinc-ion battery cathode with high-capacity and long-cycle-life, J. Mater. Chem. A. 6 (2018) 9677-9683.

[56] J. Hao, J. Mou, J. Zhang, L. Dong, W. Liu, C. Xu, F. Kang, Electrochemically induced spinel-layered phase transition of $\mathrm{Mn}_{3} \mathrm{O}_{4}$ in high performance neutral aqueous rechargeable zinc battery, Electrochim. Acta. 259 (2018) 170-178.

[57] B. Jiang, C. Xu, C. Wu, L. Dong, J. Li, F. Kang, Manganese sesquioxide as cathode material for multivalent zinc ion battery with high capacity and long cycle life, Electrochim. Acta. 229 (2017) 422-428.

[58] J.S. Ko, M.B. Sassin, J.F. Parker, D.R. Rolison, J.W. Long, Combining battery-like and pseudocapacitive charge storage in 3D $\mathrm{MnO}_{\mathrm{X}} @$ carbon electrode architectures for zinc-ion cells, Sustain. Energy Fuels. 2 (2018) 626-636.

[59] Y. Fu, Q. Wei, G. Zhang, X. Wang, J. Zhang, Y. Hu, D. Wang, L. Zuin, T. Zhou, Y. Wu, S. Sun, High-performance reversible aqueous $\mathrm{Zn}$-ion battery based on porous $\mathrm{MnOx}$ nanorods coated by MOF-derived N-doped carbon, Adv. Energy Mater. 8 (2018) 1801445.

[60] H. Zhang, J. Wang, Q. Liu, W. He, Z. Lai, X. Zhang, M. Yu, Y. Tong, X. Lu, Extracting oxygen anions from $\mathrm{ZnMn}_{2} \mathrm{O}_{4}$ : Robust cathode for flexible all-solid-state $\mathrm{Zn}$-ion batteries, Energy Storage Mater. 21 (2019) 154-161.

[61] N. Zhang, F. Cheng, Y. Liu, Q. Zhao, K. Lei, C. Chen, X. Liu, J. Chen, Cation-deficient 
spinel $\mathrm{ZnMn}_{2} \mathrm{O}_{4}$ cathode in $\mathrm{Zn}\left(\mathrm{CF}_{3} \mathrm{SO}_{3}\right)_{2}$ electrolyte for rechargeable aqueous $\mathrm{Zn}$-ion battery, J. Am. Chem. Soc. 138 (2016) 12894-12901.

[62] C.-H. Kim, Z. Akase, L. Zhang, A.H. Heuer, A.E. Newman, P.J. Hughes, The structure and ordering of $\varepsilon-\mathrm{MnO}_{2}$, J. Solid State Chem. 179 (2006) 753-774.

[63] J.E. POST, Manganese oxide minerals: Crystal structures and economic and environmental significance, Proc. Natl. Acad. Sci. 96 (1999) 3447-3454.

[64] W. Wei, X. Cui, D.G. Ivey, Manganese oxide-based materials as electrochemical supercapacitor electrodes, Chem Soc Rev. (2011) 1697-1721.

[65] C. Wei, C. Xu, B. Li, H. Du, F. Kang, Preparation and characterization of manganese dioxides with nano-sized tunnel structures for zinc ion storage, J. Phys. Chem. Solids. 73 (2012) 1487-1491.

[66] N. Qiu, H. Chen, Z. Yang, S. Sun, Y. Wang, Low-cost birnessite as a promising cathode for high-performance aqueous rechargeable batteries, Electrochim. Acta. 272 (2018) 154-160.

[67] L. Chen, Z. Yang, F. Cui, J. Meng, Y. Jiang, J. Long, X. Zeng, Ultrathin $\mathrm{MnO}_{2}$ nanoflakes grown on N-doped hollow carbon spheres for high-performance aqueous zinc ion batteries, Mater. Chem. Front. 4 (2020) 213-221.

[68] S.H. Kim, S.M. Oh, Degradation mechanism of layered $\mathrm{MnO}_{2}$ cathodes in $\mathrm{Zn} / \mathrm{ZnSO} / \mathrm{MnO}_{2}$ rechargeable cells, J. Power Sources. 72 (1998) 150-158.

[69] J.C. Kai Zhang, Xiaopeng Han, Zhe Hu, Xiaolong Zhang, Zhanliang Tao, Nanostructured Mn-based oxides for electrochemical energy storage and conversion, Chem. Soc. Rev. 44 (2015).

[70] M. Liu, Z. Rong, R. Malik, P. Canepa, A. Jain, G. Ceder, K.A. Persson, Spinel compounds as multivalent battery cathodes : a systematic evaluation based on ab initio, Energy Environ. Sci. (2015) 964-974.

[71] C. Yuan, Y. Zhang, Y. Pan, X. Liu, G. Wang, D. Cao, Investigation of the intercalation of polyvalent cations $\left(\mathrm{Mg}^{2+}, \mathrm{Zn}^{2+}\right)$ into $\lambda-\mathrm{MnO}_{2}$ for rechargeable aqueous battery, Electrochim. Acta. 116 (2014) 404-412.

[72] J. Yan, J. Wang, H. Liu, Z. Bakenov, D. Gosselink, P. Chen, Rechargeable hybrid aqueous batteries, J. Power Sources. 216 (2012) 222-226.

[73] C. Xu, Y. Chen, S. Shi, J. Li, F. Kang, D. Su, Secondary batteries with multivalent ions for energy storage, Sci. Rep. 5 (2015) 14120. 
[74] J.C. Knight, S. Therese, A. Manthiram, On the utility of spinel oxide hosts for magnesiumion batteries, ACS Appl. Mater. Interfaces. (2015).

[75] J.C. Knight, S. Therese, A. Manthiram, Chemical extraction of $\mathrm{Zn}$ from $\mathrm{ZnMn}_{2} \mathrm{O}_{4}$-based spinels, J. Mater. Chem. A. 3 (2015) 21077-21082.

[76] Y. Liu, X. Zhou, R. Liu, X. Li, Y. Bai, H. Xiao, Y. Wang, G. Yuan, Tailoring threedimensional composite architecture for advanced zinc-ion batteries, ACS Appl. Mater. Interfaces. 11 (2019) 19191-19199.

[77] L. Jiang, Z. Wu, Y. Wang, W. Tian, Z. Yi, C. Cai, Y. Jiang, L. Hu, Ultrafast zinc-ion diffusion ability observed in 6.0-nanometer spinel nanodots, ACS Nano. 13 (2019) 1037610385.

[78] Q. Zhang, C. Li, Q. Li, Z. Pan, J. Sun, Z. Zhou, B. He, P. Man, L. Xie, L. Kang, X. Wang, J. Yang, T. Zhang, P.P. Shum, Q. Li, Y. Yao, L. Wei, Flexible and high-voltage coaxialfiber aqueous rechargeable zinc-ion battery, Nano Lett. 19 (2019) 4035-4042.

[79] C. Zhu, G. Fang, S. Liang, Z. Chen, Z. Wang, J. Ma, H. Wang, B. Tang, X. Zheng, J. Zhou, Electrochemically induced cationic defect in $\mathrm{MnO}$ intercalation cathode for aqueous zincion battery, Energy Storage Mater. 24 (2020) 394-401.

[80] W. Li, X. Gao, Z. Chen, R. Guo, G. Zou, H. Hou, W. Deng, X. Ji, J. Zhao, Electrochemically activated $\mathrm{MnO}$ cathodes for high performance aqueous zinc-ion battery, Chem. Eng. J. 402 (2020) 125509.

[81] J.S. Ko, M.D. Donakowski, M.B. Sassin, J.F. Parker, D.R. Rolison, J.W. Long, Deciphering charge-storage mechanisms in 3D MnOx@carbon electrode nanoarchitectures for rechargeable zinc-ion cells, MRS Commun. 9 (2019) 99-106.

[82] J. Z. Li, Y. Huang, S.Z. and H.Z. Zhang, S. Jin, One-step synthesis of MnOx PPy nanocomposite as a high-performance cathode for a rechargeable zinc-ion battery and insight into its energy storage mechanism, Nanoscale. (2020).

[83] X. Wu, Y. Xiang, Q. Peng, X. Wu, Y. Li, F. Tang, R. Song, Z. Liu, Z. He, X. Wu, Greenlow-cost rechargeable aqueous zinc-ion batteries using hollow porous spinel $\mathrm{ZnMn}_{2} \mathrm{O}_{4}$ as the cathode material, J. Mater. Chem. A. 5 (2017) 17990-17997.

[84] M. Sun, D.S. Li, Y.F. Wang, W.L. Liu, M.M. Ren, F.G. Kong, S.J. Wang, Y.Z. Guo, Y.M. Liu, $\mathrm{Mn}_{3} \mathrm{O}_{4} @ \mathrm{NC}$ composite nanorods as a cathode for rechargeable aqueous Zn-ion batteries, ChemElectroChem. 6 (2019) 2510-2516. 
[85] X. Ma, J. Cheng, L. Dong, W. Liu, J. Mou, L. Zhao, Multivalent ion storage towards highperformance aqueous zinc-ion hybrid supercapacitors, Energy Storage Mater. 20 (2019) 335-342.

[86] M.H. Alfaruqi, S. Islam, J. Gim, J. Song, S. Kim, D.T. Pham, J. Jo, Z. Xiu, V. Mathew, J. Kim, A high surface area tunnel-type $\alpha-\mathrm{MnO}_{2}$ nanorod cathode by a simple solvent-free synthesis for rechargeable aqueous zinc-ion batteries, Chem. Phys. Lett. 650 (2016) 64-68.

[87] X. Gao, H. Wu, W. Li, Y. Tian, Y. Zhang, H. Wu, L. Yang, G. Zou, H. Hou, X. Ji, H+Insertion Boosted $\alpha-\mathrm{MnO}_{2}$ for an Aqueous Zn-Ion Battery, Small. 16 (2020) 1905842.

[88] C. Guo, H. Liu, J. Li, Z. Hou, J. Liang, J. Zhou, Y. Zhu, Y. Qian, Ultrathin $\delta-\mathrm{MnO}_{2}$ nanosheets as cathode for aqueous rechargeable zinc ion battery, Electrochim. Acta. 304 (2019) 370-377.

[89] K.W. Nam, H. Kim, J.H. Choi, J.W. Choi, Crystal water for high performance layered manganese oxide cathodes in aqueous rechargeable zinc batteries, Energy Environ. Sci. 12 (2019) 1999-2009.

[90] H. Chen, W. Zhou, D. Zhu, Z. Liu, Z. Feng, J. Li, Y. Chen, Porous cube-like $\mathrm{Mn}_{3} \mathrm{O}_{4} @ \mathrm{C}$ as an advanced cathode for low-cost neutral zinc-ion battery, J. Alloys Compd. 813 (2020) 151812 .

[91] J.A. Vigil, T.N. Lambert, J. Duay, C.J. Delker, T.E. Beechem, B.S. Swartzentruber, Nanoscale Carbon Modified $\alpha-\mathrm{MnO} 2$ Nanowires: Highly Active and Stable Oxygen Reduction Electrocatalysts with Low Carbon Content, ACS Appl. Mater. Interfaces. 10 (2018) 2040-2050.

[92] Y. Zeng, X. Zhang, Y. Meng, M. Yu, J. Yi, Y. Wu, X. Lu, Y. Tong, Achieving ultrahigh energy density and long durability in a flexible rechargeable quasi-solid-state $\mathrm{Zn}-\mathrm{MnO}_{2}$ battery, Adv. Mater. 29 (2017) 1700274.

[93] Z. Lei, J. Zhang, X.S. Zhao, Ultrathin $\mathrm{MnO}_{2}$ nanofibers grown on graphitic carbon spheres as high-performance asymmetric supercapacitor electrodes, J. Mater. Chem. 22 (2012) 153160.

[94] X. Zhang, S. Wu, S. Deng, W. Wu, Y. Zeng, X. Xia, G. Pan, Y. Tong, X. Lu, 3D CNTs networks enable $\mathrm{MnO}_{2}$ cathodes with high capacity and superior rate capability for flexible rechargeable $\mathrm{Zn}-\mathrm{MnO}_{2}$ batteries, Small Methods. 3 (2019) 1900525.

[95] S. Luo, L. Xie, F. Han, W. Wei, Y. Huang, H. Zhang, M. Zhu, O.G. Schmidt, L. Wang, 
Nanoscale parallel circuitry based on interpenetrating conductive assembly for flexible and high-power zinc ion battery, Adv. Funct. Mater. 29 (2019) 1901336.

[96] M. Han, J. Huang, S. Liang, L. Shan, X. Xie, Z. Yi, Y. Wang, S. Guo, J. Zhou, Oxygen defects in $\beta-\mathrm{MnO}_{2}$ enabling high-performance rechargeable aqueous zinc/manganese dioxide battery, IScience. 23 (2020) 100797.

[97] S. Lian, C. Sun, W. Xu, W. Huo, Y. Luo, K. Zhao, G. Yao, W. Xu, Y. Zhang, Z. Li, K. Yu, H. Zhao, H. Cheng, J. Zhang, L. Mai, Built-in oriented electric field facilitating durable Zn$\mathrm{MnO}_{2}$ battery, Nano Energy. 62 (2019) 79-84.

[98] X. Chen, W. Li, Y. Xu, Z. Zeng, H. Tian, M. Velayutham, W. Shi, W. Li, C. Wang, D. Reed, V. V Khramtsov, X. Li, X. Liu, Charging activation and desulfurization of MnS unlock the active sites and electrochemical reactivity for Zn-Ion batteries, Nano Energy. (2020) 104869.

[99] Y. Wu, K. Zhang, S. Chen, Y. Liu, Y. Tao, X. Zhang, Y. Ding, S. Dai, Proton Inserted manganese dioxides as a reversible cathode for aqueous $\mathrm{Zn}$-ion batteries, ACS Appl. Energy Mater. 3 (2020) 319-327.

[100] H. Zhang, Q. Liu, J. Wang, K. Chen, D. Xue, J. Liu, X. Lu, Boosting the Zn-ion storage capability of birnessite manganese oxide nanoflorets by $\mathrm{La}^{3+}$ intercalation, J. Mater. Chem. A. 7 (2019) 22079-22083.

[101] D. Wang, L. Wang, G. Liang, H. Li, Z. Liu, Z. Tang, J. Liang, C. Zhi, A superior $\delta-\mathrm{MnO}_{2}$ cathode and a self-healing $\mathrm{Zn}-\delta-\mathrm{MnO}_{2}$ battery, ACS Nano. 13 (2019) 10643-10652.

[102] J. Long, J. Gu, Z. Yang, J. Mao, J. Hao, Z. Chen, Z. Guo, Highly porous, low band-gap $\mathrm{Ni}_{\mathrm{x}} \mathrm{Mn}_{3-\mathrm{x}} \mathrm{O}_{4}(0.55 \leq \mathrm{x} \leq 1.2)$ spinel nanoparticles with in situ coated carbon as advanced cathode materials for zinc-ion batteries, J. Mater. Chem. A. 7 (2019) 17854-17866.

[103] Y. Tao, Z. Li, L. Tang, X. Pu, T. Cao, D. Cheng, Q. Xu, H. Liu, Y. Wang, Y. Xia, Nickel and cobalt Co-substituted spinel $\mathrm{ZnMn}_{2} \mathrm{O}_{4} @ \mathrm{~N}-\mathrm{rGO}$ for increased capacity and stability as a cathode material for rechargeable aqueous zinc-ion battery, Electrochim. Acta. 331 (2020) 135296.

[104] Y. Zhong, X. Xu, J.-P. Veder, Z. Shao, Self-Recovery Chemistry and Cobalt-Catalyzed Electrochemical Deposition of Cathode for Boosting Performance of Aqueous Zinc-Ion Batteries, IScience. 23 (2020) 100943.

[105] F. Kataoka, T. Ishida, K. Nagita, V. Kumbhar, K. Yamabuki, M. Nakayama, Cobalt-Doped Layered $\mathrm{MnO}_{2}$ Thin Film Electrochemically Grown on Nitrogen-Doped Carbon Cloth for 
Aqueous Zinc-Ion Batteries, ACS Appl. Energy Mater. 3 (2020) 4720-4726.

[106] S. Guo, S. Liang, B. Zhang, G. Fang, D. Ma, J. Zhou, Cathode interfacial layer formation via in situ electrochemically charging in aqueous zinc-ion battery, ACS Nano. 13 (2019) 13456-13464.

[107] C. Xie, T. Li, C. Deng, Y. Song, H. Zhang, X. Li, A highly reversible neutral zinc/manganese battery for stationary energy storage, Energy Environ. Sci. 13 (2020) 135143.

[108] Y. Jin, L. Zou, L. Liu, M.H. Engelhard, R.L. Patel, Z. Nie, K.S. Han, Y. Shao, C. Wang, J. Zhu, H. Pan, J. Liu, Joint charge storage for high-rate aqueous zinc-manganese dioxide batteries, Adv. Mater. 31 (2019) 1900567.

[109] H. Pan, J.F. Ellis, X. Li, Z. Nie, H.J. Chang, D. Reed, Electrolyte effect on the electrochemical performance of mild aqueous zinc-electrolytic manganese dioxide batteries, ACS Appl. Mater. Interfaces. 11 (2019) 37524-37530.

[110] L. Zhang, I.A. Rodríguez-pérez, H. Jiang, C. Zhang, D.P. Leonard, Q. Guo, W. Wang, S. Han, L. Wang, X. Ji, $\mathrm{ZnCl}_{2}$ "Water-in-Salt” electrolyte transforms the performance of vanadium oxide as a Zn battery cathode, Adv. Funct. Mater. 29 (2019) 1902653.

[111] F. Wang, O. Borodin, T. Gao, X. Fan, W. Sun, F. Han, A. Faraone, J.A. Dura, K. Xu, C. Wang, Highly reversible zinc metal anode for aqueous batteries, Nat. Mater. 17 (2018) 543549.

[112] C. Li, X. Xie, S. Liang, J. Zhou, Issues and future perspective on zinc metal anode for rechargeable aqueous zinc-ion batteries, Energy Environ. Mater. 3 (2020) 146-159.

[113] T. Zhang, Y. Tang, G. Fang, C. Zhang, H. Zhang, X. Guo, X. Cao, J. Zhou, A. Pan, S. Liang, Electrochemical activation of manganese-based cathode in aqueous zinc-ion electrolyte, Adv. Funct. Mater. 30 (2020) 2002711.

[114] M. Chamoun, W.R. Brant, C.W. Tai, G. Karlsson, D. Noréus, Rechargeability of aqueous sulfate $\mathrm{Zn} / \mathrm{MnO}_{2}$ batteries enhanced by accessible $\mathrm{Mn}^{2+}$ ions, Energy Storage Mater. 15 (2018) 351-360.

[115] V. Soundharrajan, B. Sambandam, S. Kim, S. Islam, The dominant role of $\mathrm{Mn}^{2+}$ additive on the electrochemical reaction in $\mathrm{ZnMn}_{2} \mathrm{O}_{4}$ cathode for aqueous zinc-ion batteries, Energy Storage Mater. (2019).

[116] D. Wu, L.M. Housel, S.J. Kim, N. Sadique, C.D. Quilty, L. Wu, R. Tappero, S.L. Nicholas, 
S. Ehrlich, Y. Zhu, A.C. Marschilok, E.S. Takeuchi, D.C. Bock, K.J. Takeuchi, Quantitative temporally and spatially resolved X-ray fluorescence microprobe characterization of the manganese dissolution-deposition mechanism in aqueous $\mathrm{Zn} / \alpha-\mathrm{MnO}_{2}$ batteries, Energy Environ. Sci. 13 (2020) 4322-4333.

[117] S. Zhao, B. Han, D. Zhang, Q. Huang, L. Xiao, L. Chen, D.G. Ivey, Y. Deng, W. Wei, Unravelling the reaction chemistry and degradation mechanism in aqueous $\mathrm{Zn} / \mathrm{MnO}_{2}$ rechargeable batteries, J. Mater. Chem. A. 6 (2018) 5733-5739.

[118] Y. Huang, J. Mou, W. Liu, X. Wang, L. Dong, F. Kang, C. Xu, Novel insights into energy storage mechanism of aqueous rechargeable $\mathrm{Zn} / \mathrm{MnO}_{2}$ batteries with participation of $\mathrm{Mn}^{2+}$, Nano-Micro Lett. 11 (2019) 49.

[119] X. Chen, W. Li, Z. Zeng, D. Reed, X. Li, X. Liu, Engineering stable $\mathrm{Zn}-\mathrm{MnO}_{2}$ batteries by synergistic stabilization between the carbon nanofiber core and birnessite- $\mathrm{MnO}_{2}$ nanosheets shell, Chem. Eng. J. 405 (2021) 126969.

[120] X. Guo, J. Zhou, C. Bai, X. Li, G. Fang, $\mathrm{Zn} / \mathrm{MnO}_{2}$ battery chemistry with dissolutiondeposition mechanism, Mater. Today Energy. 16 (2020) 100396.

[121] Y. Jiang, D. Ba, Y. Li, J. Liu, Noninterference Revealing of "layered to layered" zinc storage mechanism of $\delta-\mathrm{MnO}_{2}$ toward neutral $\mathrm{Zn}-\mathrm{Mn}$ batteries with superior performance, Adv. Sci. 7 (2020) 1902795.

[122] B. Lee, H.R. Seo, H.R. Lee, C.S. Yoon, J.H. Kim, K.Y. Chung, B.W. Cho, S.H. Oh, Critical role of $\mathrm{pH}$ Evolution of Electrolyte in the reaction mechanism for rechargeable zinc batteries, ChemSusChem. 9 (2016) 2948-2956.

[123] S. Ha, K.T. Lee, Batteries: Converting to long stability, Nat. Energy. 1 (2016) 16057.

[124] P. Oberholzer, E. Tervoort, A. Bouzid, A. Pasquarello, D. Kundu, Oxide versus nonoxide cathode materials for aqueous $\mathrm{Zn}$ batteries: An insight into the charge storage mechanism and consequences thereof, ACS Appl. Mater. Interfaces. 11 (2019) 674-682.

[125] X. Gao, H. Wu, W. Li, Y. Tian, Y. Zhang, H. Wu, L. Yang, G. Zou, $\mathrm{H}^{+}$-insertion boosted $\alpha$ $-\mathrm{MnO}_{2}$ for an aqueous $\mathrm{Zn}$-ion battery, 1905842 (2020) 1-10.

[126] F. Mo, G. Liang, Q. Meng, Z. Liu, H. Li, J. Fan, C. Zhi, A flexible rechargeable aqueous zinc manganese-dioxide battery working at-20 ${ }^{\circ} \mathrm{C}$, Energy Environ. Sci. 12 (2019) 706-715.

[127] Y. Li, S. Wang, J.R. Salvador, J. Wu, B. Liu, W. Yang, J. Yang, W. Zhang, J. Liu, J. Yang, Reaction mechanisms for long-life rechargeable $\mathrm{Zn} / \mathrm{MnO}_{2}$ batteries, Chem. Mater. 31 (2019) 
2036-2047.

[128] G. Liang, F. Mo, H. Li, Z. Tang, Z. Liu, D. Wang, Q. Yang, L. Ma, C. Zhi, A Universal principle to design reversible aqueous batteries based on deposition-dissolution mechanism, Adv. Energy Mater. 9 (2019) 1-12.

[129] C. Zhong, B. Liu, J. Ding, X. Liu, Y. Zhong, Y. Li, C. Sun, X. Han, Y. Deng, N. Zhao, W. $\mathrm{Hu}$, Decoupling electrolytes towards stable and high-energy rechargeable aqueous zincmanganese dioxide batteries, Nat. Energy. 5 (2020) 440-449.

[130] J. Huang, Y. Xie, L. Yan, B. Wang, T. Kong, X. Dong, Y. Wang, Y. Xia, Decoupled amphoteric water electrolysis and its integration with Mn-Zn battery for flexible utilization of renewables, Energy Environ. Sci. (2021).

[131] C. Liu, X. Chi, Q. Han, Y. Liu, A high energy density aqueous battery achieved by dual dissolution/deposition reactions separated in acid-alkaline electrolyte, Adv. Energy Mater. 10 (2020) 1903589.

[132] G.G. Yadav, D. Turney, J. Huang, X. Wei, S. Banerjee, Breaking the $2 \mathrm{~V}$ barrier in aqueous zinc chemistry: Creating 2.45 and 2.8 $\mathrm{V} \mathrm{MnO}_{2}-\mathrm{Zn}$ aqueous batteries, ACS Energy Lett. 4 (2019) 2144-2146.

[133] D. Chao, C. Ye, F. Xie, W. Zhou, Q. Zhang, Q. Gu, K. Davey, L. Gu, S. Qiao, Atomic engineering catalyzed $\mathrm{MnO}_{2}$ electrolysis kinetics for a hybrid aqueous battery with high power and energy density, Adv. Mater. 2001894 (2020) 1-8.

[134] N. Zhang, Y. Dong, M. Jia, X. Bian, Y. Wang, M. Qiu, J. Xu, Y. Liu, L. Jiao, F. Cheng, Rechargeable aqueous $\mathrm{Zn}-\mathrm{V}_{2} \mathrm{O}_{5}$ battery with high energy density and long cycle life, ACS Energy Lett. 3 (2018) 1366-1372.

[135] J. Ding, Z. Du, L. Gu, B. Li, L. Wang, S. Wang, Y. Gong, S. Yang, Ultrafast Zn ${ }^{2+}$ intercalation and deintercalation in vanadium dioxide, Adv. Mater. 30 (2018) 2-7.

[136] L. Chen, Y. Ruan, G. Zhang, Q. Wei, Y. Jiang, T. Xiong, P. He, W. Yang, M. Yan, Q. An, L. Mai, Ultrastable and high-performance $\mathrm{Zn} / \mathrm{VO}_{2}$ battery based on a reversible singlephase reaction, Chem. Mater. 31 (2019) 699-706.

[137] L. Zhang, L. Miao, B. Zhang, J. Wang, J. Liu, Q. Tan, H. Wan, J. Jiang, A durable $\mathrm{VO}_{2}(\mathrm{M}) / \mathrm{Zn}$ battery with ultrahigh rate capability enabled by pseudocapacitive proton insertion, J. Mater. Chem. A. 8 (2020) 1731-1740.

[138] L. Chen, Z. Yang, Y. Huang, Monoclinic $\mathrm{VO}_{2}(\mathrm{D})$ hollow nanospheres with super-long cycle 
life for aqueous zinc ion batteries, Nanoscale. 11 (2019) 13032-13039.

[139] W. Meng, R. Pigliapochi, P.M. Bayley, O. Pecher, M.W. Gaultois, I.D. Seymour, H.-P. Liang, W. Xu, K.M. Wiaderek, K.W. Chapman, C.P. Grey, Unraveling the complex delithiation and lithiation mechanisms of the high capacity cathode material $\mathrm{V}_{6} \mathrm{O}_{13}$, Chem. Mater. 29 (2017) 5513-5524.

[140] J. Shin, D.S. Choi, H.J. Lee, Y. Jung, J.W. Choi, Hydrated intercalation for highperformance aqueous zinc ion batteries, Adv. Energy Mater. 9 (2019) 1900083.

[141] L. Shan, J. Zhou, W. Zhang, C. Xia, S. Guo, X. Ma, G. Fang, X. Wu, S. Liang, Highly reversible phase transition endows $\mathrm{V}_{6} \mathrm{O}_{13}$ with enhanced performance as aqueous zinc-ion battery cathode, Energy Technol. 7 (2019) 1900022.

[142] G. Sai Gautam, P. Canepa, W.D. Richards, R. Malik, G. Ceder, Role of structural $\mathrm{H}_{2} \mathrm{O}$ in intercalation electrodes: The case of $\mathrm{Mg}$ in nanocrystalline Xerogel- $\mathrm{V}_{2} \mathrm{O}_{5}$, Nano Lett. 16 (2016) 2426-2431.

[143] Y. Yang, Y. Tang, G. Fang, L. Shan, J. Guo, W. Zhang, C. Wang, L. Wang, J. Zhou, S. Liang, $\mathrm{Li}^{+}$intercalated $\mathrm{V}_{2} \mathrm{O}_{5} \cdot \mathrm{nH}_{2} \mathrm{O}$ with enlarged layer spacing and fast ion diffusion as an aqueous zinc-ion battery cathode, Energy Environ. Sci. 11 (2018) 3157-3162.

[144] B. Yong, D. Ma, Y. Wang, H. Mi, C. He, P. Zhang, Understanding the design principles of advanced aqueous zinc-ion battery cathodes: From transport kinetics to structural engineering, and future perspectives, Adv. Energy Mater. 10 (2020) 2002354.

[145] M. Yan, P. He, Y. Chen, S. Wang, Q. Wei, K. Zhao, X. Xu, Q. An, Y. Shuang, Y. Shao, K.T. Mueller, L. Mai, J. Liu, J. Yang, Water-lubricated intercalation in $\mathrm{V}_{2} \mathrm{O}_{5} \cdot \mathrm{nH}_{2} \mathrm{O}$ for highcapacity and high-rate aqueous rechargeable zinc batteries, Adv. Mater. 30 (2018) 1703725.

[146] M.H. Alfaruqi, V. Mathew, J. Song, S. Kim, S. Islam, D.T. Pham, J. Jo, S. Kim, J.P. Baboo, Z. Xiu, K.S. Lee, Y.K. Sun, J. Kim, Electrochemical zinc intercalation in lithium vanadium oxide: A high-capacity zinc-ion battery cathode, Chem. Mater. 29 (2017) 1684-1694.

[147] P. He, G. Zhang, X. Liao, M. Yan, X. Xu, Q. An, J. Liu, L. Mai, Sodium ion stabilized vanadium oxide nanowire cathode for high-performance zinc-ion batteries, Adv. Energy Mater. 8 (2018) 1-6.

[148] B. Sambandam, V. Soundharrajan, S. Kim, M.H. Alfaruqi, J. Jo, S. Kim, V. Mathew, Y.K. Sun, J. Kim, Aqueous rechargeable Zn-ion batteries: An imperishable and high-energy $\mathrm{Zn}_{2} \mathrm{~V}_{2} \mathrm{O}_{7}$ nanowire cathode through intercalation regulation, J. Mater. Chem. A. 6 (2018) 
$3850-3856$.

[149] B. Tang, J. Zhou, G. Fang, F. Liu, C. Zhu, C. Wang, A. Pan, S. Liang, Engineering the interplanar spacing of ammonium vanadates as a high-performance aqueous zinc-ion battery cathode, J. Mater. Chem. A. 7 (2019) 940-945.

[150] Q. Li, X. Rui, D. Chen, Y. Feng, N. Xiao, L. Gan, Q. Zhang, Y. Yu, S. Huang, A highcapacity ammonium vanadate cathode for zinc-ion battery, Nano-Micro Lett. 12 (2020) 67.

[151] C. Xia, J. Guo, P. Li, X. Zhang, H.N. Alshareef, Highly stable aqueous zinc-ion storage using a layered calcium vanadium oxide bronze cathode, Angew. Chem. Int. Ed. 57 (2018) 3943-3948.

[152] Y. Ma, H. Zhou, S. Zhang, S. Gu, X. Cao, S. Bao, H. Yao, S. Ji, P. Jin, Long straczekite $\delta-$ $\mathrm{Ca}_{0.24} \mathrm{~V}_{2} \mathrm{O}_{5} \cdot \mathrm{H}_{2} \mathrm{O}$ nanorods and derived $\beta-\mathrm{Ca}_{0.24} \mathrm{~V}_{2} \mathrm{O}_{5}$ nanorods as novel host materials for lithium storage with excellent cycling stability, Chem. Eur. J. 23 (2017) 13221-13232.

[153] C. Liu, Z. Neale, J. Zheng, X. Jia, J. Huang, M. Yan, M. Tian, M. Wang, J. Yang, G. Cao, Expanded hydrated vanadate for high-performance aqueous zinc-ion batteries, Energy Environ. Sci. 12 (2019) 2273-2285.

[154] L. Wang, K.-W. Huang, J. Chen, J. Zheng, Ultralong cycle stability of aqueous zinc-ion batteries with zinc vanadium oxide cathodes, Sci. Adv. 5 (2019) eaax4279.

[155] F. Ming, H. Liang, Y. Lei, S. Kandambeth, M. Eddaoudi, H.N. Alshareef, Layered $\mathrm{Mg}_{\mathrm{x}} \mathrm{V}_{2} \mathrm{O}_{5} \cdot \mathrm{nH}_{2} \mathrm{O}$ as cathode material for high-performance aqueous zinc ion batteries, ACS Energy Lett. 3 (2018) 2602-2609.

[156] P. Hu, T. Zhu, X. Wang, X. Wei, M. Yan, J. Li, W. Luo, W. Yang, W. Zhang, L. Zhou, Z. Zhou, L. Mai, Highly durable $\mathrm{Na}_{2} \mathrm{~V}_{6} \mathrm{O}_{16} \cdot 1.63 \mathrm{H}_{2} \mathrm{O}$ nanowire cathode for aqueous zinc-ion battery, Nano Lett. 18 (2018) 1758-1763.

[157] C. Xia, J. Guo, Y. Lei, H. Liang, C. Zhao, H.N. Alshareef, Rechargeable aqueous zinc-ion battery based on porous framework zinc pyrovanadate intercalation cathode, Adv. Mater. 30 (2018) 1705580.

[158] L. Ma, N. Li, C. Long, B. Dong, D. Fang, Z. Liu, Y. Zhao, X. Li, J. Fan, S. Chen, S. Zhang, C. Zhi, Achieving both high voltage and high capacity in aqueous zinc-ion battery for record high energy density, Adv. Funct. Mater. 29 (2019) 1906142.

[159] G. Li, Z. Yang, Y. Jiang, C. Jin, W. Huang, X. Ding, Y. Huang, Towards polyvalent ion batteries: A zinc-ion battery based on NASICON structured $\mathrm{Na}_{3} \mathrm{~V}^{2}\left(\mathrm{PO}_{4}\right)_{3}$, Nano Energy. 25 
(2016) 211-217.

[160] W. Li, K. Wang, S. Cheng, K. Jiang, A long-life aqueous Zn-ion battery based on $\mathrm{Na}_{3} \mathrm{~V}_{2}\left(\mathrm{PO}_{4}\right)_{2} \mathrm{~F}_{3}$ cathode, Energy Storage Mater. 15 (2018) 14-21.

[161] M.J. Park, A. Manthiram, Unveiling the Charge Storage Mechanism in nonaqueous and aqueous $\mathrm{Zn} / \mathrm{Na}_{3} \mathrm{~V}_{2}\left(\mathrm{PO}_{4}\right)_{2} \mathrm{~F}_{3}$ batteries, ACS Appl. Energy Mater. 3 (2020) 5015-5023.

[162] F. Wang, E. Hu, W. Sun, T. Gao, X. Ji, X. Fan, F. Han, X.Q. Yang, K. Xu, C. Wang, A rechargeable aqueous $\mathrm{Zn}^{2+}$-battery with high power density and a long cycle-life, Energy Environ. Sci. 11 (2018) 3168-3175.

[163] Q. Ni, H. Jiang, S. Sandstrom, Y. Bai, H. Ren, X. Wu, Q. Guo, D. Yu, C. Wu, X. Ji, A Na3V2(PO4)2O1.6F1.4 Cathode of Zn-Ion battery enabled by a water-in-bisalt electrolyte, Adv. Funct. Mater. 30 (2020) 2003511.

[164] L. Shan, Y. Yang, W. Zhang, H. Chen, G. Fang, J. Zhou, S. Liang, Observation of combination displacement/intercalation reaction in aqueous zinc-ion battery, Energy Storage Mater. 18 (2019) 10-14.

[165] J.S. Ko, P.P. Paul, G. Wan, N. Seitzman, R.H. DeBlock, B.S. Dunn, M.F. Toney, J. Nelson Weker, NASICON $\mathrm{Na}_{3} \mathrm{~V}_{2}\left(\mathrm{PO}_{4}\right)_{3}$ enables quasi-two-stage $\mathrm{Na}^{+}$and $\mathrm{Zn}^{2+}$ intercalation for multivalent zinc batteries, Chem. Mater. 32 (2020) 3028-3035.

[166] P. Hu, T. Zhu, X. Wang, X. Zhou, X. Wei, X. Yao, W. Luo, C. Shi, K.A. Owusu, L. Zhou, L. Mai, Aqueous $\mathrm{Zn} / / \mathrm{Zn}\left(\mathrm{CF}_{3} \mathrm{SO}_{3}\right)_{2} / / \mathrm{Na}_{3} \mathrm{~V}_{2}\left(\mathrm{PO}_{4}\right)_{3}$ batteries with simultaneous $\mathrm{Zn}^{2+} / \mathrm{Na}^{+}$ intercalation/de-intercalation, Nano Energy. 58 (2019) 492-498.

[167] K. Hurlbutt, S. Wheeler, I. Capone, M. Pasta, Prussian blue analogs as battery materials, Joule. 2 (2018) 1950-1960.

[168] L. Zhang, L. Chen, X. Zhou, Z. Liu, Morphology-dependent electrochemical performance of zinc hexacyanoferrate cathode for zinc-ion battery, Sci. Rep. 5 (2015) 18263.

[169] K. Lu, B. Song, Y. Zhang, H. Ma, J. Zhang, Encapsulation of zinc hexacyanoferrate nanocubes with manganese oxide nanosheets for high-performance rechargeable zinc ion batteries, J. Mater. Chem. A. 5 (2017) 23628-23633.

[170] L. Ma, S. Chen, C. Long, X. Li, Y. Zhao, Z. Liu, Z. Huang, B. Dong, J.A. Zapien, C. Zhi, Achieving high-voltage and high-capacity aqueous rechargeable zinc ion battery by incorporating two-species redox reaction, Adv. Energy Mater. 9 (2019) 1902446.

[171] J. Cui, Z. Guo, J. Yi, X. Liu, K. Wu, P. Liang, Q. Li, Y. Liu, Y. Wang, Y. Xia, J. Zhang, 
Organic cathode materials for rechargeable zinc batteries: mechanisms, challenges, and perspectives, ChemSusChem. 13 (2020) 2160-2185.

[172] P. Poizot, J. Gaubicher, S. Renault, L. Dubois, Y. Liang, Y. Yao, Opportunities and challenges for organic electrodes in electrochemical energy storage, Chem. Rev. 120 (2020) 6490-6557.

[173] Q. Zhao, W. Huang, Z. Luo, L. Liu, Y. Lu, Y. Li, L. Li, J. Hu, H. Ma, J. Chen, High-capacity aqueous zinc batteries using sustainable quinone electrodes, Sci. Adv. 4 (2018) eaao1761.

[174] Z. Guo, Y. Ma, X. Dong, J. Huang, Y. Wang, Y. Xia, An environmentally friendly and flexible aqueous zinc battery using an organic cathode, Angew. Chem. Int. Ed. 57 (2018) 11737-11741.

[175] D. Kundu, P. Oberholzer, C. Glaros, A. Bouzid, E. Tervoort, A. Pasquarello, M. Niederberger, Organic cathode for aqueous zn-ion batteries: taming a unique phase evolution toward stable electrochemical cycling, Chem. Mater. 30 (2018) 3874-3881.

[176] X. Yue, H. Liu, P. Liu, Polymer grafted on carbon nanotubes as a flexible cathode for aqueous zinc ion batteries, Chem. Commun. 55 (2019) 1647-1650.

[177] G. Dawut, Y. Lu, L. Miao, J. Chen, High-performance rechargeable aqueous Zn-ion batteries with a poly(benzoquinonyl sulfide) cathode, Inorg. Chem. Front. 5 (2018) 13911396.

[178] Z. Tie, Z. Niu, Design strategies for high-performance aqueous zn/organic batteries, Angew. Chem. Int. Ed. 59 (2020) 2-13.

[179] A. Khayum M, M. Ghosh, V. Vijayakumar, A. Halder, M. Nurhuda, S. Kumar, M. Addicoat, S. Kurungot, R. Banerjee, Zinc ion interactions in a two-dimensional covalent organic framework based aqueous zinc ion battery, Chem. Sci. 10 (2019) 8889-8894.

[180] W. Wang, V.S. Kale, Z. Cao, S. Kandambeth, W. Zhang, J. Ming, P.T. Parvatkar, E. AbouHamad, O. Shekhah, L. Cavallo, M. Eddaoudi, H.N. Alshareef, Phenanthroline covalent organic framework electrodes for high-performance zinc-ion supercapattery, ACS Energy Lett. 5 (2020) 2256-2264.

[181] B. Häupler, C. Rössel, A.M. Schwenke, J. Winsberg, D. Schmidt, A. Wild, U.S. Schubert, Aqueous zinc-organic polymer battery with a high rate performance and long lifetime, NPG Asia Mater. 8 (2016) e283-e283.

[182] K.W. Nam, S.S. Park, R. dos Reis, V.P. Dravid, H. Kim, C.A. Mirkin, J.F. Stoddart, 
Conductive 2D metal-organic framework for high-performance cathodes in aqueous rechargeable zinc batteries, Nat. Commun. 10 (2019) 4948.

[183] C. Kim, B.Y. Ahn, T.-S. Wei, Y. Jo, S. Jeong, Y. Choi, I.-D. Kim, J.A. Lewis, High-power aqueous zinc-ion batteries for customized electronic devices, ACS Nano. 12 (2018) 1183811846.

[184] H.-Y. Shi, Y.-J. Ye, K. Liu, Y. Song, X. Sun, A long-cycle-life self-doped polyaniline cathode for rechargeable aqueous zinc batteries, Angew. Chem. Int. Ed. 57 (2018) 16359.

[185] B.N. Grgur, M.M. Gvozdenović, J. Stevanović, B.Z. Jugović, V.M. Marinović, Polypyrrole as possible electrode materials for the aqueous-based rechargeable zinc batteries, Electrochim. Acta. 53 (2008) 4627-4632.

[186] S. Li, I. Sultana, Z. Guo, C. Wang, G.G. Wallace, H.-K. Liu, Polypyrrole as cathode materials for Zn-polymer battery with various biocompatible aqueous electrolytes, Electrochim. Acta. 95 (2013) 212-217.

[187] A. Lahiri, L. Yang, G. Li, F. Endres, Mechanism of Zn-ion intercalation/deintercalation in a zn-polypyrrole secondary battery in aqueous and bio-ionic liquid electrolytes, ACS Appl. Mater. Interfaces. 11 (2019) 45098-45107.

[188] Z. Liu, A. Prowald, O. Höfft, G. Li, A. Lahiri, F. Endres, An ionic liquid-surface functionalized polystyrene spheres hybrid electrolyte for rechargeable zinc/conductive polymer batteries, ChemElectroChem. 5 (2018) 2321-2325.

[189] Y. Liu, L. Xie, W. Zhang, Z. Dai, W. Wei, S. Luo, X. Chen, W. Chen, F. Rao, L. Wang, Y. Huang, Conjugated system of pedot:pss-induced self-doped pani for flexible zinc-ion batteries with enhanced capacity and cyclability, ACS Appl. Mater. Interfaces. 11 (2019) 30943-30952.

[190] W. Du, J. Xiao, H. Geng, Y. Yang, Y. Zhang, E.H. Ang, M. Ye, C.C. Li, Rational-design of polyaniline cathode using proton doping strategy by graphene oxide for enhanced aqueous zinc-ion batteries, J. Power Sources. 450 (2020) 227716.

[191] M. Wang, J. Zhang, L. Zhang, J. Li, W. Wang, Z. Yang, L. Zhang, Y. Wang, J. Chen, Y. Huang, D. Mitlin, X. Li, Graphene-like vanadium oxygen hydrate (VOH) nanosheets intercalated and exfoliated by polyaniline (pani) for aqueous zinc-ion batteries (zibs), ACS Appl. Mater. Interfaces. 12 (2020) 31564-31574.

[192] F. Wan, L. Zhang, X. Wang, S. Bi, Z. Niu, J. Chen, An aqueous rechargeable zinc-organic 
battery with hybrid mechanism, Adv. Funct. Mater. 28 (2018) 1804975.

[193] M. Na, Y. Oh, H.R. Byon, Effects of $\mathrm{Zn}^{2+}$ and $\mathrm{H}^{+}$association with naphthalene diimide electrodes for aqueous Zn-ion batteries, Chem. Mater. 32 (2020) 6990-6997.

[194] Z. Tie, L. Liu, S. Deng, D. Zhao, Z. Niu, Proton insertion chemistry of a zinc-organic battery, Angew. Chem. Int. Ed. 59 (2020) 4920-4924.

[195] D. Jariwala, V.K. Sangwan, L.J. Lauhon, T.J. Marks, M.C. Hersam, Emerging device applications for semiconducting two-dimensional transition metal dichalcogenides, ACS Nano. 8 (2014) 1102-1120.

[196] P. He, M. Yan, G. Zhang, R. Sun, L. Chen, Q. An, L. Mai, Layered VS 2 nanosheet-based aqueous zn ion battery cathode, Adv. Energy Mater. 7 (2017) 1601920.

[197] T. Jiao, Q. Yang, S. Wu, Z. Wang, D. Chen, D. Shen, B. Liu, J. Cheng, H. Li, L. Ma, C. Zhi, W. Zhang, Binder-free hierarchical $\mathrm{VS}_{2}$ electrodes for high-performance aqueous $\mathrm{Zn}$ ion batteries towards commercial level mass loading, J. Mater. Chem. A. 7 (2019) 1633016338.

[198] H. Qin, Z. Yang, L. Chen, X. Chen, L. Wang, A high-rate aqueous rechargeable zinc ion battery based on the $\mathrm{VS}_{4} @ \mathrm{rGO}$ nanocomposite, J. Mater. Chem. A. 6 (2018) 23757-23765.

[199] L. Wang, Z. Wu, M. Jiang, J. Lu, Q. Huang, Y. Zhang, L. Fu, M. Wu, Y. Wu, Layered VSe 2 : a promising host for fast zinc storage and its working mechanism, J. Mater. Chem. A. 8 (2020) 9313-9321.

[200] W.S.V. Lee, T. Xiong, X. Wang, J. Xue, Unraveling $\mathrm{MoS}_{2}$ and transition metal dichalcogenides as functional zinc-ion battery cathode: A perspective, Small Methods. 5 (2020) 2000815.

[201] H. Liang, Z. Cao, F. Ming, W. Zhang, D.H. Anjum, Y. Cui, L. Cavallo, H.N. Alshareef, Aqueous zinc-ion storage in $\mathrm{MoS}_{2}$ by tuning the intercalation energy, Nano Lett. 19 (2019) 3199-3206.

[202] J. Liu, P. Xu, J. Liang, H. Liu, W. Peng, Y. Li, F. Zhang, X. Fan, Boosting aqueous zincion storage in $\mathrm{MoS}_{2}$ via controllable phase, Chem. Eng. J. 389 (2020) 124405.

[203] M.S. Chae, J.W. Heo, S.-C. Lim, S.-T. Hong, Electrochemical zinc-ion intercalation properties and crystal structures of $\mathrm{ZnMo}_{6} \mathrm{~S}_{8}$ and $\mathrm{Zn}_{2} \mathrm{Mo}_{6} \mathrm{~S}_{8}$ chevrel phases in aqueous electrolytes, Inorg. Chem. 55 (2016) 3294-3301.

[204] W. Li, K. Wang, S. Cheng, K. Jiang, An ultrastable presodiated titanium disulfide anode for 
aqueous "rocking-chair” zinc ion battery, Adv. Energy Mater. 9 (2019) 1900993.

[205] J. Fu, Z.P. Cano, M.G. Park, A. Yu, M. Fowler, Z. Chen, Electrically rechargeable zinc-air batteries: progress, challenges, and perspectives, Adv. Mater. 29 (2017).

[206] Y. Li, H. Dai, Recent advances in zinc-air batteries, Chem. Soc. Rev. 43 (2014) 5257-5275.

[207] L.E. Blanc, D. Kundu, L.F. Nazar, Scientific Challenges for the Implementation of Zn-Ion Batteries, Joule. 4 (2020) 771-799.

[208] J. Shin, J. Lee, Y. Park, J.W. Choi, Aqueous zinc ion batteries: focus on zinc metal anodes, Chem. Sci. 11 (2020) 2028-2044.

[209] H. Jia, Z. Wang, B. Tawiah, Y. Wang, C.-Y. Chan, B. Fei, F. Pan, Recent advances in zinc anodes for high-performance aqueous Zn-ion batteries, Nano Energy. 70 (2020) 104523.

[210] Z. Zhao, J. Zhao, Z. Hu, J. Li, J. Li, Y. Zhang, C. Wang, G. Cui, Long-life and deeply rechargeable aqueous $\mathrm{Zn}$ anodes enabled by a multifunctional brightener-inspired interphase, Energy Environ. Sci. 12 (2019) 1938-1949.

[211] Z. Cao, P. Zhuang, X. Zhang, M. Ye, J. Shen, P.M. Ajayan, Strategies for dendrite-free anode in aqueous rechargeable zinc ion batteries, Adv. Energy Mater. 10 (2020) 2001599.

[212] R. Feng, X. Chi, Q. Qiu, J. Wu, J. Huang, J. Liu, Y. Liu, Cyclic ether-water hybrid electrolyte-guided dendrite-free lamellar zinc deposition by tuning the solvation structure for high-performance aqueous zinc-ion batteries, ACS Appl. Mater. Interfaces. 13 (2021) $40638-40647$.

[213] A. Bayaguud, X. Luo, Y. Fu, C. Zhu, Cationic surfactant-type electrolyte additive enables three-dimensional dendrite-free zinc anode for stable zinc-ion batteries, ACS Energy Lett. 5 (2020) 3012-3020.

[214] Y. Jin, K.S. Han, Y. Shao, M.L. Sushko, J. Xiao, H. Pan, J. Liu, Stabilizing zinc anode reactions by polyethylene oxide polymer in mild aqueous electrolytes, Adv. Funct. Mater. 30 (2020) 2003932.

[215] P. Sun, L. Ma, W. Zhou, M. Qiu, Z. Wang, D. Chao, W. Mai, Simultaneous regulation on solvation shell and electrode interface for dendrite-free $\mathrm{zn}$ ion batteries achieved by a lowcost glucose additive, Angew. Chem. Int. Ed. 60 (2021) 18247-18255.

[216] Q. Zhang, J. Luan, L. Fu, S. Wu, Y. Tang, X. Ji, H. Wang, The three-dimensional dendritefree zinc anode on a copper mesh with a zinc-oriented polyacrylamide electrolyte additive, Angew. Chem. Int. Ed. 58 (2019) 15841-15847. 
[217] M. Zhou, S. Guo, J. Li, X. Luo, Z. Liu, T. Zhang, X. Cao, M. Long, B. Lu, A. Pan, G. Fang, J. Zhou, S. Liang, Surface-preferred crystal plane for a stable and reversible zinc anode, Adv. Mater. 33 (2021) 2100187.

[218] X. Wang, J. Meng, X. Lin, Y. Yang, S. Zhou, Y. Wang, A. Pan, Stable zinc metal anodes with textured crystal faces and functional Zinc compound coatings, Adv. Funct. Mater. (2021) https://doi.org/10.1002/adfm.202106114.

[219] T. Foroozan, V. Yurkiv, S. Sharifi-Asl, R. Rojaee, F. Mashayek, R. Shahbazian-Yassar, Non-dendritic zn electrodeposition enabled by zincophilic graphene substrates, ACS Appl. Mater. Interfaces. 11 (2019) 44077-44089.

[220] D. Yuan, J. Zhao, H. Ren, Y. Chen, R. Chua, E.T.J. Jie, Y. Cai, E. Edison, W. Manalastas Jr., M.W. Wong, M. Srinivasan, Anion texturing towards dendrite-free $\mathrm{Zn}$ anode for aqueous rechargeable batteries, Angew. Chem. Int. Ed. 60 (2021) 7213-7219.

[221] J. Zheng, Q. Zhao, T. Tang, J. Yin, C.D. Quilty, G.D. Renderos, X. Liu, Y. Deng, L. Wang, D.C. Bock, C. Jaye, D. Zhang, E.S. Takeuchi, K.J. Takeuchi, A.C. Marschilok, L.A. Archer, Reversible epitaxial electrodeposition of metals in battery anodes, Science 366 (2019) 645648.

[222] J. Hao, X. Li, S. Zhang, F. Yang, X. Zeng, S. Zhang, G. Bo, C. Wang, Z. Guo, Designing dendrite-free zinc anodes for advanced aqueous zinc batteries, Adv. Funct. Mater. 30 (2020) 2001263.

[223] Z. Cao, X. Zhu, D. Xu, P. Dong, M.O.L. Chee, X. Li, K. Zhu, M. Ye, J. Shen, Eliminating Zn dendrites by commercial cyanoacrylate adhesive for zinc ion battery, Energy Storage Mater. 36 (2021) 132-138.

[224] P. Liang, J. Yi, X. Liu, K. Wu, Z. Wang, J. Cui, Y. Liu, Y. Wang, Y. Xia, J. Zhang, Highly reversible zn anode enabled by controllable formation of nucleation sites for Zn-based batteries, Adv. Funct. Mater. 30 (2020) 1908528.

[225] L. Kang, M. Cui, F. Jiang, Y. Gao, H. Luo, J. Liu, W. Liang, C. Zhi, Nanoporous $\mathrm{CaCO}_{3}$ coatings enabled uniform $\mathrm{Zn}$ stripping/plating for long-life zinc rechargeable aqueous batteries, Adv. Energy Mater. 8 (2018) 1801090.

[226] Y. Cui, Q. Zhao, X. Wu, X. Chen, J. Yang, Y. Wang, R. Qin, S. Ding, Y. Song, J. Wu, K. Yang, Z. Wang, Z. Mei, Z. Song, H. Wu, Z. Jiang, G. Qian, L. Yang, F. Pan, An interfacebridged organic-inorganic layer that suppresses dendrite formation and side reactions for 
ultra-long-life aqueous zinc metal anodes, Angew. Chem. Int. Ed. 59 (2020) 16594-16601.

[227] H. Yang, Z. Chang, Y. Qiao, H. Deng, X. Mu, P. He, H. Zhou, Constructing a supersaturated electrolyte front surface for stable rechargeable aqueous zinc batteries, Angew. Chem. Int. Ed. 59 (2020) 9377-9381. 


\section{Chapter 2: Research Objectives}

As discussed in chapter 1, manganese oxides suffer from limited electrochemically active surface areas (ECSAs) and inherent sluggish kinetics of $\mathrm{Zn}^{2+}$ diffusion into lattice framework, which restrain the utilization of high theoretical capacity and rate capability. In addition, manganese oxide hosts experience phase transition, structural transformation, and structure collapse upon $\mathrm{Zn}^{2+}$ insertion especially in a high depth of discharge and charge process, leading to poor cyclability of manganese oxide. Therefore, novel strategies to address those intrinsic limitations in manganese oxide are required for the development of high-performance manganese oxide cathodes.

The research work on the cathode focused on two directions. On the one hand, the work purpose was developing the vacancy-rich manganese oxides by the in-situ electrochemical activation, which featured abundant ECSAs and density of active sites to enhance ion transfer and diffusion kinetics and stabilize the structures against phase transformation, thus leading to high reversible capacities and excellent rate capability.

On the other hand, the hierarchical manganese oxides cathode materials were developed by integrating $\delta-\mathrm{MnO}_{2}$ nanosheets with conductive carbon nanofibers. The intimate contact between carbon nanofiber core backbone and $\delta-\mathrm{MnO}_{2}$ nanosheets shell rendered a synergistic stabilization effect to boost charge transfer kinetics, overall utilization of active Mn centres, and collaborative stability, thus resulting in stable and cost-effective $\mathrm{Zn}-\mathrm{MnO}_{2}$ batteries.

$\mathrm{Zn}$ metal anodes suffer from limited reversibility and poor Coulombic efficiency due to the dendrite growth and spontaneous side reactions occurring at the interfaces between $\mathrm{Zn}$ anodes and aqueous electrolytes, including, corrosion, competitive hydrogen evolution, and surface passivation. These issues of $\mathrm{Zn}$ anode in mildly acidic electrolytes hinder the further development of aqueous ZIBs. Therefore, this research developed stabilized Zn metal electrodes by surface engineering to suppress $\mathrm{Zn}$ dendrite growth and undesired side reactions. Specifically, the artificial coating layer was adopted to regulate interfacial ion diffusion and induce smooth $\mathrm{Zn}$ deposition, thus enhancing the reversibility of $\mathrm{Zn}$ plating/stripping to achieve highly stable $\mathrm{Zn}$ anodes. 


\section{Chapter 3: Charging Activation and Desulfurization of MnS Unlock the Active Sites and Electrochemical Reactivity for Zn-ion Batteries}

\subsection{Introduction}

There is continuously growing demand for efficient energy storage devices to ensure the reliability and resiliency of electrical grids with wide integration of intermittent renewable energy sources and to power electronics and electric vehicles [1-5]. Hence, rechargeable batteries have attracted intensive research interest over the past decades [6-10]. For large-scale applications and widespread deployment, it is highly desirable for rechargeable batteries of low cost, high safety, high energy densities and rate capability, long cycle life and environmentally benign manufacturing processes. Aqueous ZIBs have attracted considerable attention due to the use of $\mathrm{Zn}$ anodes with a high theoretical capacity, suitable redox potential, large abundance, scalable and mature recyclability, low cost and toxicity, and good compatibility with non-flammable aqueous electrolytes [11-14]. One of the key challenges for viable high-energy and stable ZIBs is to find suitable and reliable cathodes, due to the strong electrostatic interaction between $\mathrm{Zn}^{2+}$ and the host lattice of cathodes and intrinsic sluggish kinetics [15-17]. To date, various cathode materials for ZIBs have been explored including Prussian blue analogues (PBAs) [18], vanadium-based compounds [19-24], manganese-based compounds [25-29], organic cathodes [30], and other metal compounds [31-33]. Compared to PBAs and organic cathodes with low specific capacities and vanadium oxides with high toxicity and low discharge voltage, the family of manganese oxides is particularly advantageous, featuring high gravimetric capacities, moderate operation voltages, cost effectiveness, high abundance in widely distributed minerals, hypotoxicity, tunable functionality and structural versatility of $\mathrm{MnO}_{2}$ polymorphs $[13,34]$. The typical alkaline $\mathrm{Zn}-\mathrm{MnO}_{2}$ batteries have been profoundly studied and achieved great success as primary cells but suffered from poor rechargeability due to the formation of electrochemically irreversible products in alkaline electrolytes [35-36].

To solve these problems, research efforts have been devoted to replacing basic electrolytes with mildly acidic or near neutral zinc salt solutions since 1980s. Diverse aqueous electrolytes of soluble zinc salts and manganese oxide cathodes were screened by Yamamoto and Shoji to develop rechargeable ZIBs with selected $\gamma-\mathrm{MnO}_{2}$ and $\mathrm{ZnSO}_{4}$ solution in their pioneering works [37-39], 
which showed improved cycle life of 30 cycles and identified the formation of basic zinc hydroxide sulfate (ZHS) and $\mathrm{MnOOH}$ intermediate in the discharged cathodes. In 1998, Kim and Oh developed similar $\mathrm{ZnSO}_{4}$-based $\mathrm{ZIB}$ with $\delta-\mathrm{MnO}_{2}$ cathodes to support those results and demonstrated that the formation of ZHS precipitates and loss of dissolved Mn species in the cathode are responsible for the battery capacity fade [40]. They improved the cycle life of ZIBs by using $\mathrm{MnSO}_{4}$ additive in the electrolyte to enhance the reversible $\mathrm{ZHS}$ dissolution and compensate the Mn loss. Recently, aqueous rechargeable ZIBs integrating manganese oxide cathodes, Zn anodes and mildly acidic or near neutral electrolytes are reviving [25, 28, 41-45], due to the increasing safety and cost concerns of organic electrolyte-based alkali ion batteries. Research efforts for development of manganese oxide cathodes have largely focused on exploration of various $\mathrm{MnO}_{2}$ polymorphs [13], $\mathrm{Mn}_{2} \mathrm{O}_{3}$ [46], and $\mathrm{MnO}$ [47], leading to improved cyclability and enhanced $\mathrm{MnO}_{2}$ utilization using $\mathrm{Mn}^{2+}$ additive in aqueous electrolytes. However, the rate capability, energy density and long-term cycling stability of most developed manganese oxides still cannot meet the demands for resilient, high-capacity and reliable energy storage, because the strong electrostatic interaction between $\mathrm{Zn}^{2+}$ and manganese oxide lattice framework causes large energy barrier of $\mathrm{Zn}^{2+}$ migration and sluggish diffusion kinetics [15], and manganese oxides are easily agglomerated with limited exposure of electrochemically active sites and subjected to severe structure collapse, complex crystallographic transformation and phase transition during continuous discharge-charge cycles [29, 48], resulting in low MnO2 utilization and capacity, poor rate performance and capacity fade. Several mitigation strategies have been developed, including introduction of crystal water or polymer molecules into the interlayers [15, 48], coating with conductive polymers [49], $\mathrm{N}$-doped carbon or graphene layers [26, 50], immobilization on carbonaceous matrices [51], and creation of $\mathrm{Mn}$ or oxygen vacancies in parent manganese oxides through aliovalent cation substitution and extraction of minor oxygen anions [29, 47, 52-55]. Hybridizing transition metal oxides with carbon has been proved successful to modulate electronic interaction for promoting interfacial electron transfer and ion diffusion and optimizing the adsorption capability for alki ions in $\mathrm{Li}$ and $\mathrm{K}$ ion batteries with organic electrolytes [56-58]. Nevertheless, most polymer molecules and carbon cannot significantly increase the electrochemically active surface areas (ECSAs) for high electrochemical reactivity, promote the inherent sluggish kinetics of $\mathrm{Zn}^{2+}$ diffusion into manganese oxide lattice framework and withstand the anodic oxidation and internal strains from crystallographic and phase transformation and 
volume changes during the charge and discharge process in aqueous electrolytes. Likewise, the cation or oxygen vacancies in fabricated manganese oxides, generated by synthetic wet chemistry, will likely be reduced or damaged by in situ phase transition, re-crystallization and structural collapse associated with redox reactions upon cycling [48].

Moreover, the electrochemical mechanisms of the $\mathrm{Zn} / \mathrm{MnO}_{2} \mathrm{ZIB}$ system with mildly acidic or near neutral electrolytes still remain open to debate. The controversy and ambiguity primarily lie in three aspects: i) What are the electrochemical reactions (e.g., insertion of ionic species) at two discharge platforms with different voltages [59-60]? ii) It is oversimplified for the presently reported mechanism that the insertion of $\mathrm{Zn}^{2+}$ and $\mathrm{H}^{+}$and the phase change from $\mathrm{MnO}_{2}$ to $\mathrm{ZnMn}_{2} \mathrm{O}_{4}$ and/or $\mathrm{MnOOH}$ are reversible in long-term cycles [25, 42]. Actually, the real reactions between $\mathrm{Zn}^{2+}, \mathrm{Mn}^{2+}, \mathrm{MnO}_{2}$, ZHS and $\mathrm{H} 2 \mathrm{O}$ are complex and can produce various forms of turbostratic phyllomanganates, which is predicted by the E-pH diagram and widely found in $\mathrm{Zn}$ Mn-O minerals by geochemists [60-64]. Therefore, the electrochemical processes should be complex and dynamic upon cycles. iii) Some research reported the formation of layered zinc buserite and birnessite (Mn-rich species) [26, 43-44], while others found the formation of layered hydrated ZHS (Mn-free species) [25, 40, 45, 65]. Since both kinds of materials have similar lamellar structures and interlayer distances leading to analogous X-ray diffraction patterns [62, 66], the formation of zinc buserite, birnessite and ZHS is still ambiguous in studies of $\mathrm{Zn} / \mathrm{MnO}_{2} \mathrm{ZIBs}$ [15, 26-27, 42-46, 50, 67-68]. Therefore, novel strategies to address those intrinsic limitations in manganese oxide are required to increase their ECSAs and density of active sites, promote ion transfer and diffusion kinetics and stabilize the structures against phase transformation and electrochemical stress for development of high-performance manganese oxide cathodes. Meanwhile, some ambiguities in the discharge-charge process of manganese oxide should be clarified to provide new insights into the understanding of electrochemical mechanisms for the rational design of manganese oxide cathodes.

Herein, we report a high-performance manganese oxide cathode for aqueous rechargeable ZIBs, which was derived from intrinsically inactive $\alpha-\mathrm{MnS}$ precursor through in situ electrochemical activation. This in situ electrochemical activation strategy unlocks the electrochemical reactivity of MnS derived oxide cathode (MnS-EDO). The MnS-EDO exhibits larger ECSA, superior ion diffusion kinetics and charge transfer compared to $\alpha-\mathrm{MnO}_{2}$ counterpart. The advanced MnS-EDO cathode demonstrates a high specific capacity and exceptional long-term stability retaining as well 
as remarkable rate capability. The performance of MnS-EDO cathode outperforms that of many state-of-the-art ZIB cathodes. The underlying electrochemical mechanisms were elucidated, and a hybrid discharge mechanism was proposed involving homogeneous $\mathrm{Zn}^{2+}$ intercalation at $\sim 1.4 \mathrm{~V}$ and subsequent heterogeneous reactions of insertion of both $\mathrm{H}^{+}$and $\mathrm{Zn}^{2+}$ at $\sim 1.25 \mathrm{~V}$ and the ambiguities among Zn buserite, birnessite and ZHS were clarified. This work provides a facile and low-cost approach to the development of reliable, high-capacity, high-power and stable manganese oxide cathodes for viable aqueous rechargeable ZIBs and new findings to guide the future mechanistic studies of ZIBs.

\subsection{Materials and methods}

Chemicals and materials. Potassium permanganate ( $\geq 99.0 \%$, Sigma-Aldrich), zinc sulfate heptahydrate ( $\geq 99.0 \%$, Alfa Aesar), zinc trifluoromethanesulfonate (98\%, Sigma-Aldrich), manganese chloride tetrahydrate ( $\geq 98.0 \%$, Alfa Aesar), manganese sulfate monohydrate $(99.0 \%$, Alfa Aesar), sulfur powder (99.5\%, Sigma-Aldrich), sodium hydroxide solution (50\% w/w, Fisher Chemical) and hydrochloric acid solution (36.5-38.0 wt.\%, Alfa Aesar) were used as received without any further purification.

Synthesis of $\alpha-\mathrm{MnO}_{2}$ nanowires. The $\alpha-\mathrm{MnO}_{2}$ nanowires were synthesized via a hydrothermal

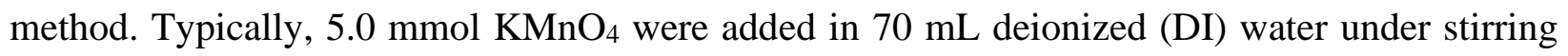
until it was completely dissolved. Then, $1.75 \mathrm{~mL} \mathrm{HCl}$ (36.5-38.0 wt.\%) was dropped into the above solution and continuously stirred for $30 \mathrm{~min}$ at room temperature. Then, the mixture solution was transferred into a $100 \mathrm{~mL}$ Teflon-lined stainless-steel autoclave and heated at $140{ }^{\circ} \mathrm{C}$ for $12 \mathrm{~h}$. After cooling to room temperature, the obtained product was collected by centrifugation, and then thoroughly washed with DI water and ethanol for several times. The $\alpha-\mathrm{MnO}_{2}$ nanowires were obtained after drying the product in a vacuum oven at $60{ }^{\circ} \mathrm{C}$ overnight.

Synthesis of MnS nanorods. The MnS product was prepared though a one-step thermal vaporsolid sulfurization process. The as-prepared $\mathrm{MnO}_{2}$ precursor and sulfur powder with a molar ratio of $\mathrm{Mn}: \mathrm{S}=1: 10$ were loaded in a ceramic boat with a distance of $6 \mathrm{~cm}$, while the sulfur side was placed in the upstream side. The ceramic boat was put in a horizontal tube furnace (NBD-O1200) with a two-inch diameter quartz tube. The furnace was purged with nitrogen $\left(\mathrm{N}_{2}\right.$, MATHESON $99.999 \%$ ) and then heated to $450{ }^{\circ} \mathrm{C}$ with a ramping rate of $5{ }^{\circ} \mathrm{C} \mathrm{min}^{-1}$ and kept at $450{ }^{\circ} \mathrm{C}$ for 30 
min. Finally, the furnace was naturally cooled down to room temperature. The $\mathrm{N}_{2}$ flow $(100 \mathrm{sccm})$ was maintained throughout the whole process. The resultant powder turned from original brown to green, indicating the formation of $\mathrm{MnS}$ product.

Synthesis of zinc hydroxide sulfate (ZHS) and zinc hydroxide triflate. $\mathrm{Zn}_{4} \mathrm{SO}_{4}(\mathrm{OH})_{6} \cdot 5 \mathrm{H}_{2} \mathrm{O}$ was synthesized by a precipitation method [66]. $\mathrm{NaOH}$ solution (2 M, $40 \mathrm{~mL}$ ) was added into 300 $\mathrm{mL}$ of $\mathrm{ZnSO}_{4}$ solution $(1 \mathrm{M}$ ) with stirring for $12 \mathrm{~h}$ at room temperature. The resulting suspension solution was then centrifuged and washed with DI water. The wet white precipitate was collected. The wet $\mathrm{Zn}_{4} \mathrm{SO}_{4}(\mathrm{OH})_{6} \cdot 5 \mathrm{H}_{2} \mathrm{O}$ was further treated under different drying conditions in terms of temperature and time to obtain corresponding dehydrated products (e.g., $\mathrm{Zn}_{4} \mathrm{SO}_{4}(\mathrm{OH})_{6} \cdot \mathrm{xH}_{2} \mathrm{O}, \mathrm{x}=$ 4, 3, 1 and 0.5). Zinc hydroxide triflate was prepared via the similar method. $\mathrm{KOH}$ solution (6 M, $3 \mathrm{~mL})$ was dropwise added into $5 \mathrm{~mL}$ of $\mathrm{Zn}\left(\mathrm{CF}_{3} \mathrm{SO}_{3}\right)_{2}$ with stirring for $15 \mathrm{~min}$. Then, the suspension solution was quickly centrifuged and washed with DI water. The wet precipitate was collected.

Synthesis of Zn-buserite. Zn-buserite was prepared using a method reported in previous literature [62]. Firstly, $47.5 \mathrm{~mL}$ of $\mathrm{NaOH}(50 \% \mathrm{w} / \mathrm{w})$ was dissolved into $102 \mathrm{~mL}$ of DI water with stirring until room temperature. Then the $\mathrm{NaOH}$ solution was poured to $120 \mathrm{~mL}$ of $\mathrm{MnCl}_{2}(0.5 \mathrm{M})$ solution with vigorous stirring at room temperature, At the same time, oxygen gas was bubbled into above mixture solution at a rate of $>2 \mathrm{~L} \mathrm{~min}^{-1}$. After $6 \mathrm{~h}$ of oxygen bubbling, the resulting black precipitate was centrifuged and washed several times with DI water. The obtained wet solid was Na-buserite. Zn-buserite was synthesized by the ion exchange of Na-buserite. Wet Na-buserite $(4 \mathrm{~g})$ was dispersed in $200 \mathrm{~mL}$ of $\mathrm{ZnSO}_{4}(1 \mathrm{M})$ solution under stirring at room temperature for 24 h. Then, the precipitate was centrifuged and washed with DI water to remove excess cations. Finally, the wet Zn-buserite was obtained. Note that phyllomanganate includes chalcophanite with interlayered $\mathrm{Zn}$ (i.e., $\mathrm{ZnMn}_{3} \mathrm{O}_{7} \cdot 3 \mathrm{H}_{2} \mathrm{O}$ ), birnessite with a variety of interlayer cations, buserite with hydrated interlayer cations, asbolane with interlayer cations octahedrally coordinated by $\mathrm{OH}^{-}$and vernadite [61].

Material characterization. The morphology and composition of materials were characterized using a scanning electron microscope (SEM) equipped with an energy dispersive X-ray (EDX) spectroscopy (Hitachi, S-4700F w/ EDAX system, Japan). The X-ray diffraction (XRD) measurements were conducted using an X'Pert Pro diffractometer (PANalytical, Almelo, 
Netherlands) with a $\mathrm{Cu} \mathrm{K \alpha}$ X-ray source at $45 \mathrm{kV}$ and $40 \mathrm{~mA}$. The XRD patterns were indexed according to the Joint Committee on Powder Diffraction Standards (JCPDS) database. The chemical surface states were examined by the X-ray photoelectron spectroscopy (XPS) using a Physical Electronics, PHI 5000 Versa Probe spectrometer (Chanhassen, MN) with a monochromatic Al Ka source operated at $300 \mathrm{~W}$ and a base pressure of $1 \times 10^{-7}$ Torr. Transmission electron microscopy (TEM), high-resolution TEM (HRTEM), high-angle annular dark-field scanning transmission electron microscopy (HAADF-STEM) and EDX elemental mapping studies were performed on a $300 \mathrm{kV}$ FEI Titan monochromated (scanning) transmission electron microscope ((S)TEM) equipped with a probe aberration corrector. The electron paramagnetic resonance (EPR) measurements were performed using a Bruker ELEXSYS spectrometer (Bruker Biosciences, Billerica, MA) operating at X-band with a $100 \mathrm{kHz}$ modulation frequency as described previously [69]. Solid samples were loaded in to a $4 \mathrm{~mm}$ quartz tube and the tube was inserted in to the EPR resonator. The sample was adjusted to the middle of the resonator. Data acquisition was performed using Bruker Xepr software. All spectra were recorded with the following parameters: microwave frequency: $9.76 \mathrm{GHz}$, sweep width: $1000 \mathrm{G}$, microwave power: $15 \mathrm{~mW}$, modulation amplitude: $4.9 \mathrm{G}$, receiver gain: $60 \mathrm{~dB}$, conversion time: $40 \mathrm{~ms}$, sweep time: $164 \mathrm{~s}$, and number of scans: 10. Data processing was performed using GraphPad Prism 8 program. After the cycled coin cells had been disassembled, the working electrodes were collected and washed by DI water several times, and then immersed in $10 \mathrm{~mL}$ DI water for $5 \mathrm{~min}$. After drying at $50{ }^{\circ} \mathrm{C}$ under vacuum, the electrodes were used for characterization. To further investigate the composition of cycled $\mathrm{MnS}$ electrodes, the cleaned electrodes were sometimes immersed in $5 \mathrm{~mL}$ acetic acid for $1 \mathrm{~h}$ to remove the surface layer and then thoroughly washed by DI water.

Electrochemical measurements. The electrodes were prepared by mixing the active materials $\left(\mathrm{MnS}\right.$ or $\alpha-\mathrm{MnO}_{2}$ ), carbon black super $\mathrm{P}$ and polyvinylidene fluoride (PVDF) at a weight ratio of 7:2:1 in N-methyl pyrrolidone solvent. Then, the slurry was coated onto a carbon paper (Sigracet 39 AA, Fuel Cell Store) followed by drying in a vacuum oven at $60^{\circ} \mathrm{C}$ overnight. The mass loading of active material in each electrode was around 1.5-2.0 $\mathrm{mg} \mathrm{cm}^{-2}$. The $\mathrm{Zn}$-ion batteries were assembled in CR2032 coin cells using MnS electrodes as the cathodes, Zn metal plate (Alfa Aesar) as the anodes, nylon membrane (MILLPORE, GNWP) as the separators and $2.0 \mathrm{M} \mathrm{ZnSO}_{4}$ with $0.1 \mathrm{M} \mathrm{MnSO}_{4}$ aqueous solution as the electrolytes. For comparison, the control $\mathrm{Zn}$-ion batteries were also assembled using a similar process except for the use of $\alpha-\mathrm{MnO}_{2}$ instead of $\mathrm{MnS}$. All 
electrochemical measurements of the coin cells were performed after $4 \mathrm{~h}$ aging at room temperature. The galvanostatic charge and discharge (GCD) tests were performed on a multichannel battery test equipment (Arbin BT2143 32CH) with a potential window of $0.8-2.0 \mathrm{~V}$ vs. $\mathrm{Zn}^{2+} / \mathrm{Zn}$, similar to reported voltage windows[28, 43, 70-71]. The corresponding current density was selected from $300-3000 \mathrm{~mA} \mathrm{~g}^{-1}$. In this work, the current rate was denoted as $1 \mathrm{C}=$ $300 \mathrm{~mA} \mathrm{~g}^{-1}$, and the specific capacity was normalized by the mass of $\mathrm{MnS}$ or $\alpha-\mathrm{MnO}_{2}$. CV test of fresh $\mathrm{MnS}$ and $\alpha-\mathrm{MnO}_{2}$ electrodes was carried out in the corresponding coin cells using an electrochemical workstation (Bio-Logic, SP-300) at a scan rate of $1.0 \mathrm{mV} \mathrm{s}^{-1}$ with a potential window of 0.8-2.0 V vs. $\mathrm{Zn}^{2+} / \mathrm{Zn}$. The $\mathrm{CV}$ curves of stabilized $\mathrm{MnS}-\mathrm{EDO}$ and $\alpha-\mathrm{MnO}_{2}$ electrodes were collected at different scan rates of $0.1,0.2,0.4,0.60 .8$ and $1.0 \mathrm{mV} \mathrm{s}^{-1}$ after 15 galvanostatic charge/discharge cycles at $1 \mathrm{C}$.

\subsection{Results and discussion}

The crystalline $\alpha-\mathrm{MnO}_{2}$ has been extensively investigated as cathode for ZIBs [25, 41, 43]. As the crystalline tunneled $\alpha-\mathrm{MnO}_{2}$ contains few defects and strong electrostatic interaction between $\mathrm{Zn}^{2+}$ and manganese oxide lattice framework brings about large energy barrier of $\mathrm{Zn}^{2+}$ migration and spatial hindrance to ionic transport, the density of electrochemically active sites of $\alpha-\mathrm{MnO}_{2}$ is severely restricted and the ionic diffusion and electrolyte permeation are markedly impeded, leading to sluggish reaction kinetics and limited capacity[15, 29, 55, 65]. To mitigate these limitations and barriers, this work developed a strategy to boost the ECSAs and accelerate the electrochemical reaction kinetics through in situ electrochemical oxidation activation. The MnS was synthesized through thermal vapor-solid sulfurization of $\alpha-\mathrm{MnO}_{2}$. Subsequently, the $\mathrm{Mn}(\mathrm{II}) \mathrm{S}$ was activated by charging, in which $S^{2-}$ was leached out and oxidized to soluble high-valence sulfate species in aqueous electrolyte and $\mathrm{MnS}$ was in situ electrochemically oxidized to manganese oxide (MnS-EDO) under anodic potentials. This process is thermodynamically favored according to the Pourbaix E-pH diagrams of $\mathrm{Mn}$ and $\mathrm{S}$ [72-73]. A similar electrochemical activation approach was used to develop efficient transition metal oxide electrocatalysts from metal chalcogenide parents [72, 74-76]. Here, it is proposed that the desulfurization, microstructural reconstruction and amorphization during the in situ electrochemical oxidation/activation process will produce unusual metastable low-crystallinity manganese oxide phases with abundant defects and vacancies and hence maximize the density of accessible active 
sites for high ECSAs and electrochemical reactivity, which are difficult to achieve by conventional chemical synthesis $[72,74,76]$. The structural and electrochemical characterizations below corroborate our hypothesis. It is envisioned that this promising approach will unlock the potential of MnS-EDO cathode for high-performance rechargeable ZIBs.

\subsubsection{Morphology and structure characterizations}
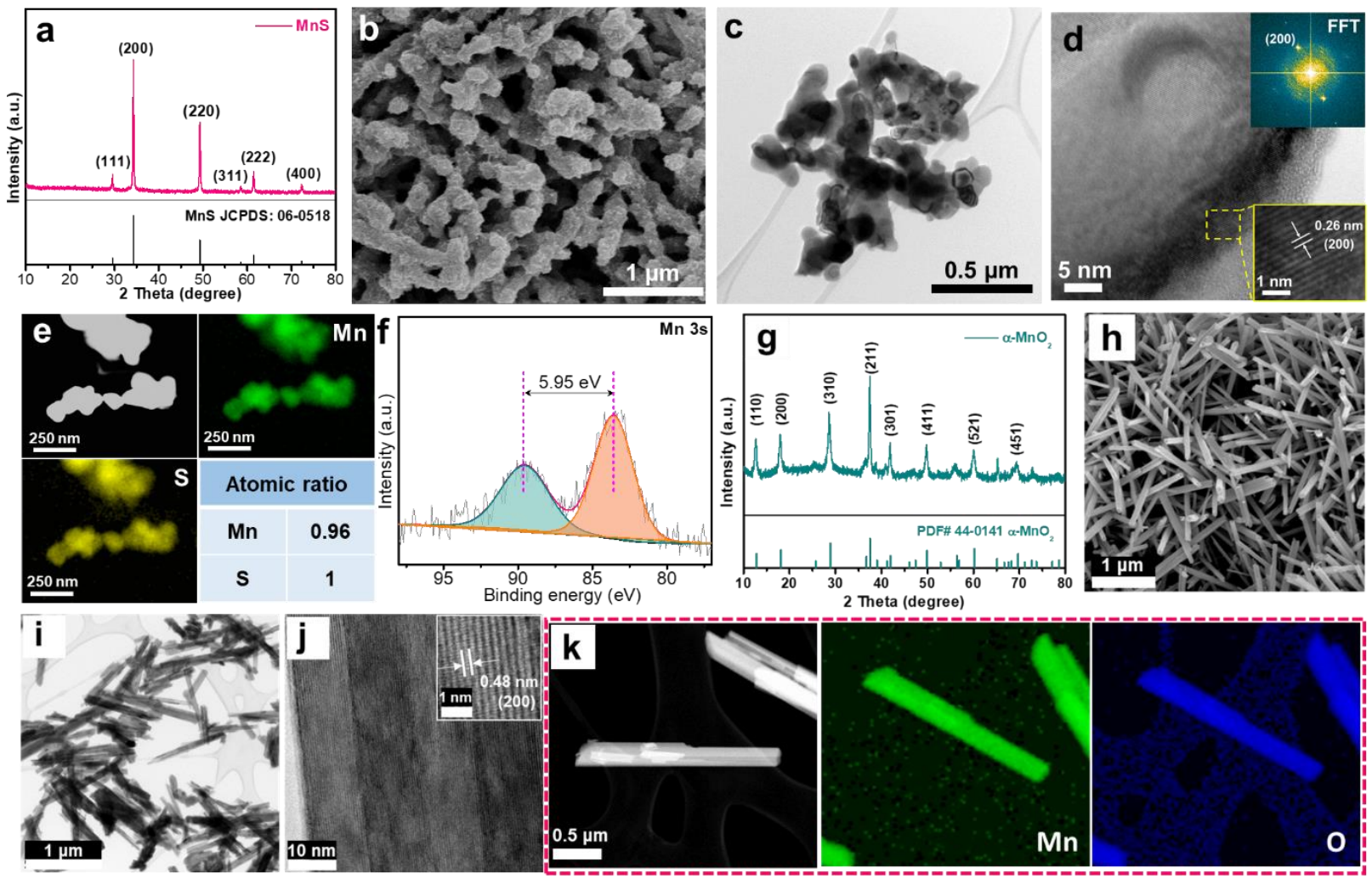

Figure 3. 1 Characterization results of pristine $\mathrm{MnS}$ and $\alpha-\mathrm{MnO}_{2}$. (a) XRD pattern, (b) SEM, (c) TEM and (d) HRTEM images of MnS. Insets of (d) are the FFT pattern (top right) and magnified selected zone (bottom right). (e) HAADF-STEM image, elemental maps and $\mathrm{Mn} / \mathrm{S}$ atomic ratio and (f) Mn 3s XPS spectrum of MnS. (g) XRD, (h) SEM, (i) TEM, (j) HRTEM images and (k) HAADF-STEM image and EDX elemental mapping of $\alpha-\mathrm{MnO}_{2}$.

The MnS was synthesized via a one-step sulfurization reaction of hydrothermally synthesized $\alpha-\mathrm{MnO}_{2}$ nanowires (Figures 3.1j-k). The XRD pattern of the product (Figure 3.1a) is indexed to pure cubic $\alpha$-MnS (JCPDS: 06-0518). The SEM image shows that the as-prepared MnS has a rodlike structure (Figure 3.1b). The $\mathrm{MnS}$ nanorods have a rough surface in contrast to $\mathrm{MnO}_{2}$ 
nanowires with smooth surface, indicating the roughening and crystallization ripening during the conversion. The TEM image shows that the MnS short nanorods consist of nanocrystal particles (Figure 3.1c). The HRTEM image (Figure 3.1d) exhibits the clear lattice fringes of a nanocrystal with inter-planar spacing of $0.26 \mathrm{~nm}$ corresponding to the (200) crystal plane of cubic $\mathrm{MnS}$, corroborated by fast Fourier transform (FFT) pattern. The HAADF-STEM image and elemental mapping results (Figure 3.1e) suggest homogeneous distribution of $\mathrm{Mn}$ and $\mathrm{S}$ elements in the $\mathrm{MnS}$ nanocrystals with the atomic ratio close to 1 . The XPS spectra reveal a spin-energy separation of $5.95 \mathrm{eV}$ for $\mathrm{Mn} 3 \mathrm{~s}$ doublet proving $\mathrm{Mn}^{2+}$ oxidation state (Figure 3.1f), consistent with the reported $\mathrm{MnS}$ [77-78]. These results confirm the transformation of $\alpha-\mathrm{MnO}_{2}$ to $\alpha-\mathrm{MnS}$.

\subsubsection{Electrochemical performance of MnS-EDO cathode}

The electrochemical performance of $\mathrm{MnS}$ in $2 \mathrm{M} \mathrm{ZnSO}_{4}$ and $0.1 \mathrm{M} \mathrm{MnSO}_{4}$ electrolyte for aqueous rechargeable ZIBs was investigated. The performance of $\alpha-\mathrm{MnO}_{2}$ precursor was compared as the control sample under similar electrochemical activation and testing conditions to probe whether the proposed method combining pre-thermal-sulfurization and subsequent electrochemical oxidation can promote the performance of resultant MnS-EDO beyond that of $\mathrm{MnO}_{2}$ parent. Since the $\mathrm{Mn}$ component has a nominal valence of +2 , the pristine $\mathrm{MnS}$ shows a negligible discharge capacity and low open circuit voltage (OCV, $\sim 0.9$ V) (Figure 3.2g), indicating that starting $\mathrm{MnS}$ is intrinsically at fully discharged state of the two-electron reaction. The cyclic voltammogram (CV) curves of MnS were studied (Figure 3.2h). In the first anodic scan, two major oxidation peaks at 1.12 and $1.53 \mathrm{~V}$ vs $\mathrm{Zn}^{2+} / \mathrm{Zn}$ correspond to the anodic oxidation of $\mathrm{S}^{2-}$ and $\mathrm{Mn}$ species in $\mathrm{MnS}$, respectively, consistent with the redox potentials in the E-pH diagrams of S and Mn [72-73]. Subsequently, one cathodic peak appears at 1.27 V, indicating the occurrence of ionic intercalation in the activated MnS-EDO distinct from pristine MnS. In the second cycle, there are one major anodic peak at $1.53 \mathrm{~V}$ with a shoulder peak at $1.59 \mathrm{~V}$ and a pair of cathodic peaks, suggesting the emerging electrochemical redox activity. This indicates that electrochemically inactive $\mathrm{MnS}$ is irreversibly oxidized to MnS-EDO with electrochemical reactivity for reversible discharge and charge for ZIBs upon the first electrochemical oxidation activation. After 5 cycles, two pairs of redox peaks at around 1.35/1.65 V and 1.23/1.59 V are relatively stabilized in the following cathodic/anodic scans. These characteristic stabilized redox peaks of MnS-EDO are consistent with those of the $\mathrm{MnO}_{2}$ cathode (Figure 3.2i) and other reported 
$\mathrm{MnO}_{2}[25,51,67]$, suggesting that activated MnS-EDO may have the similar electrochemical charge storage mechanism as manganese oxide. After electrochemical activation, the in situ formed MnS-EDO delivers a slope profile with continuous voltage decrease to $1.30 \mathrm{~V}$ and a relatively flat plateau at around $1.25 \mathrm{~V}$ in the first discharge curve, which are denoted as the discharge platform 1 (DP1) and 2 (DP2), respectively. Two platforms show a clear inflection or dip point[26, 51], indicating that different electrochemical processes may occur in two discharge stages. The DP1 becomes prominent as cycling proceeds.
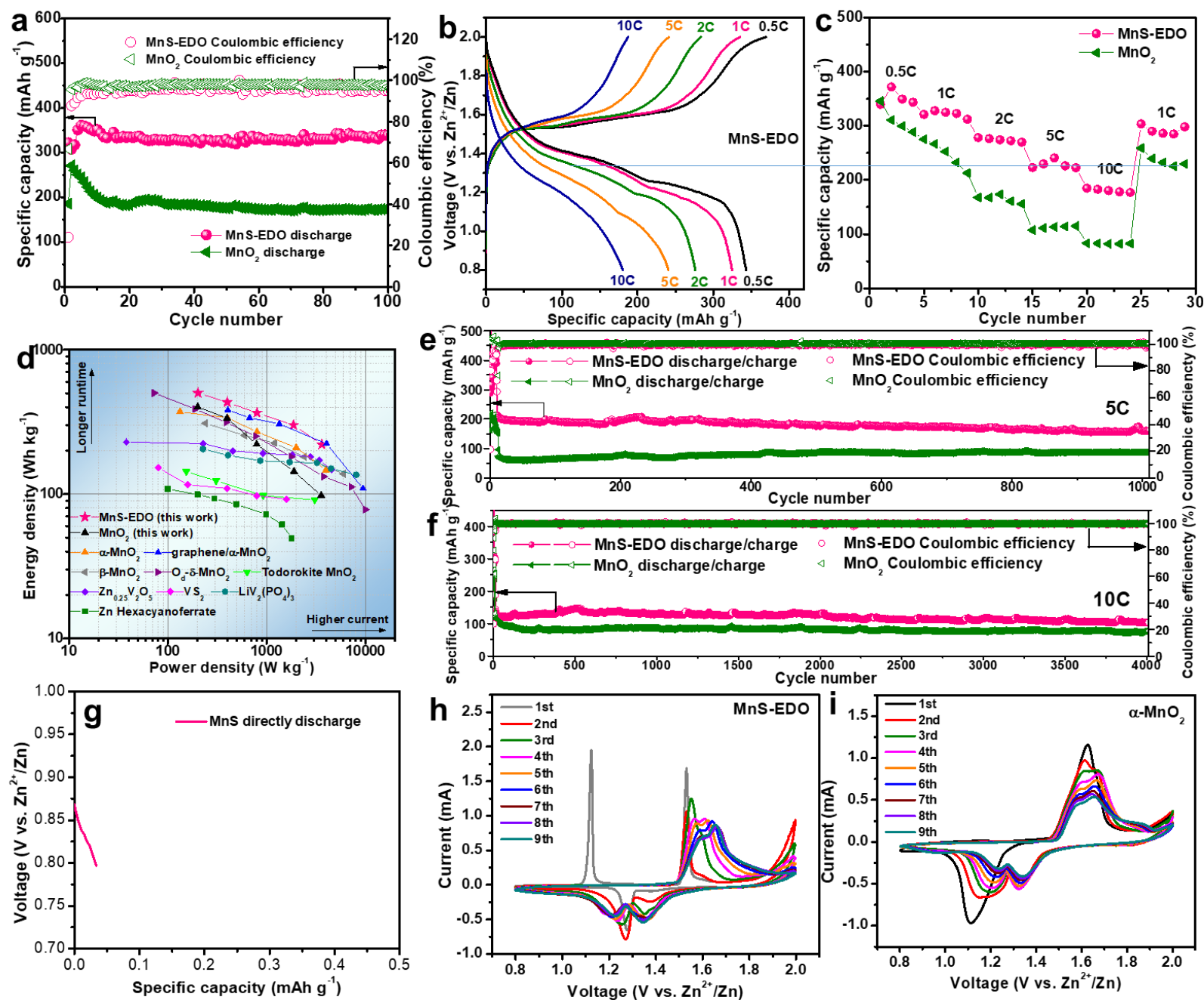

Figure 3. 2 The electrochemical performances of $\mathrm{ZIBs}$ consisting of $\mathrm{MnS}-\mathrm{EDO}$ or $\mathrm{MnO}_{2}$ cathodes, $\mathrm{Zn}$ anodes and aqueous electrolytes of $2 \mathrm{M} \mathrm{ZnSO}_{4}$ with $0.1 \mathrm{M} \mathrm{MnSO}_{4}$. (a) Cycling performance at $1 \mathrm{C}$ (i.e., $0.3 \mathrm{~A} \mathrm{~g}^{-1}$ ). (b) GCD profiles of stabilized MnS-EDO (derived from the third cycle of (c)) at different rates from 0.5 to $10 \mathrm{C}$. (c) Rate performance at various current densities. (d) The Ragone plots. The values of energy and power densities (based on the mass loading of active 
material in the cathode) for various developed $\mathrm{MnO}_{2}$ polymorphs, $\mathrm{Zn}_{0.25} \mathrm{~V}_{2} \mathrm{O}_{5}, \mathrm{VS}_{2}, \mathrm{LiV}_{2}\left(\mathrm{PO}_{4}\right)_{3}$ and $\mathrm{Zn}$ hexacyanoferrate cathodes for comparison in (d) are used as reported in the literature [1821, 25-29]. (e) and (f) Long-term cycling performance at 5 and $10 \mathrm{C}$ after pre-activation at $1 \mathrm{C}$ for the first ten cycles, respectively. (g) Initial discharge profile of a fresh $\mathrm{MnS}$ cathode at $1 \mathrm{C}$ without electrochemical activation treatment. (h) CV curves of (a) MnS-EDO and (i) $\alpha-\mathrm{MnO}_{2}$ cathodes at a scan rate of $0.1 \mathrm{mV} \mathrm{s}^{-1}$.

Figure 3.2a shows the cycling performance of $\mathrm{MnS}-\mathrm{EDO}$ and $\mathrm{MnO}_{2}$ cathodes at $1 \mathrm{C}$. The specific discharge capacity of MnS-EDO gradually increases to $360 \mathrm{mAh} \mathrm{g}^{-1}$ in the first 5 cycles and quickly gets stabilized after 10 cycles, suggesting an electrochemical activation process in the early cycles. The Coulombic efficiency of MnS-EDO gradually increases during the activation process, and then is maintained above $96 \%$ when MnS-EDO gets stabilized, which is comparable to that of the $\mathrm{MnO}_{2}$ cathode and other reported ZIB cathodes [15, 26, 79-80]. The MnS-EDO cathode maintains a high discharge capacity of $335.7 \mathrm{mAh} \mathrm{g}^{-1}$ after 100 cycles with capacity retention of $93 \%$. In contrast, the $\mathrm{MnO}_{2}$ cathode displays dramatic capacity fade in the initial 10 cycles and delivers $174 \mathrm{mAh} \mathrm{g}^{-1}$ after 100 cycles with capacity retention of merely $64 \%$. Note that the bare carbon cathode demonstrates low discharge capacity signifying that MnS-EDO makes a major contribution to the whole capacity with minimal capacity contribution from any possible in situ electrodeposited $\mathrm{MnO}_{\mathrm{x}}$ from the electrolyte. Moreover, the capacity of MnS-EDO cathode considerably declines in $2 \mathrm{M} \mathrm{ZnSO}_{4}$, while it is negligible in $0.1 \mathrm{M} \mathrm{MnSO}_{4}$. Therefore, the high capacity and Mn utilization and excellent cycling stability of activated MnS-EDO cathode at 1C are correlated with its intrinsic properties, abundant $\mathrm{Zn}^{2+}$ ions and the role of $\mathrm{MnSO}_{4}$ electrolyte additive in mitigating Mn dissolution and stabilizing the cycles. The discrepancy of MnS-EDO and $\mathrm{MnO}_{2}$ in electrochemical performance should result from their different intrinsic properties. The commercial bulk MnS also shows low OCV when used as the cathode for ZIBs, implying the bulk MnS is also inherently inactive for ZIBs similar to synthesized MnS nanorods. The GCD and cycling curves of bulk MnS-EDO demonstrate the oxidation activation can unlock its electrochemical performance similar to $\mathrm{MnS}$ nanorods (Figure 3.3a-d). The discharge capacity of bulk MnS-EDO rises gradually in the first 15 cycles for activation and is stabilized at $238 \mathrm{mAh} \mathrm{g}^{-}$ 1. Although the discharge capacity of bulk $\mathrm{MnS}$ is lower than that of synthesized $\mathrm{MnS}$, it is still much higher than that of $\alpha-\mathrm{MnO}_{2}$ nanowires. Compared to the commercial bulk $\mathrm{MnS}$ with larger particle size and smooth surface, the nanosized structure and rough surface of MnS nanorods can 
likely enhance the density of exposed active sites, electrolyte/electrode contact area and shorten the diffusion length for fast electronic and ionic transport, which will endow high electrochemical reactivity and ion diffusion kinetics for the MnS nanorods. These positive effects of synthesized nanostructured $\mathrm{MnS}$ are expected to shorten the required activation time, enable thorough activation, and quickly stabilize the electrode with higher capacity. This is consistent with the reported positive effects of nanostructures on the electrochemistry in other rechargeable batteries [81-83]. Despite the lack of systematic investigation whether it was oxidized or activated, commercial bulk MnS was previously reported as an active cathode for ZIBs showing rapid capacity decay to $70 \mathrm{mAh} \mathrm{g}^{-1}$ after 100 cycles [31], inferior to this work. Therefore, the electrochemical oxidation activation strategy can indeed stimulate the electrochemical reactivity of $\mathrm{MnS}$ for ZIBs. This new approach and the use of bulk MnS showcase substantial promise for simple, scalable and low-cost fabrication of a highly active and stable cathode material in aqueous rechargeable ZIBs.

The rate capabilities of $\mathrm{MnS}-\mathrm{EDO}$ and $\mathrm{MnO}_{2}$ were evaluated at various current densities. The GCD curves of stabilized MnS-EDO and $\mathrm{MnO}_{2}$ collected under the corresponding current densities are shown in Figures 3.2b, 3.3e respectively, where the characteristic DP1 and DP2 and their inflection points can be observed. The voltage plateaus of MnS-EDO are consistent with the redox peaks in its stabilized CV curves starting from the 4th cycle (Figure 3.2h). The discharge capacities of MnS-EDO are significantly higher than those of $\mathrm{MnO}_{2}$ at various current densities, demonstrating its superior rate capability. The reactions at two discharge platforms have distinct rate-dependent kinetics. With the increased rate from 0.5 to $10 \mathrm{C}, \mathrm{MnS}$-EDO exhibits a slight decrease in the capacity contribution at DP1 (216 to $140 \mathrm{mAh} \mathrm{g}^{-1}$ ) but an apparent loss in the capacity contribution at DP2 (127 to $41 \mathrm{mAh} \mathrm{g}^{-1}$ ) (Figure 3.3f). Therefore, the capacity at DP1 for MnS-EDO can be retained well with remarkable kinetics, while the electrochemical reaction at DP2 is comparatively not favored as the discharge rate rises. The similar trend of capacity retention at DP1 and DP2 for $\mathrm{MnO}_{2}$ was also observed, in line with the previous reports[26, 53, 80]. However, the capacity contributions of $\mathrm{MnO}_{2}$ decline more dramatically compared to those of MnS-EDO at both platforms. At $10 \mathrm{C}$, the capacity contributions of MnS-EDO are 2.5-fold and 1.6-fold higher than those of $\mathrm{MnO}_{2}$ at DP1 and DP2, respectively. As shown in Figure 3.2c, MnSEDO exhibits the specific capacities of 343, 325, 276, 241 and $181 \mathrm{mAh} \mathrm{g}^{-1}$ at $0.5,1,2,5$ and 10 $\mathrm{C}$, respectively. In contrast, $\mathrm{MnO}_{2}$ has substantially lower capacities. For example, the capacities 
of MnS-EDO cathodes are more than twice as high as those of $\mathrm{MnO}_{2}$ counterpart at 5 and $10 \mathrm{C}$. When the rate returns to $1 \mathrm{C}$, the capacity of $\mathrm{MnS}-\mathrm{EDO}$ is recovered indicating its exceptional resilience and robustness, which is of vital importance to smooth the fluctuation and intermittence of real renewable energy power [1]. Note that the $\mathrm{MnS}$ parent can undergo electrochemical oxidation for longer duration in each charging process at $0.5 \mathrm{C}$, which may enable thorough activation to realize stabilized state of MnS-EDO earlier (Figure 3.2c) than in the charge process at $1 \mathrm{C}$ (Figure 3.2a). The unprecedented rate performance of MnS-EDO is further illustrated in the Ragone plots (Figure 3.2d). It delivers a high specific energy and power density of $502 \mathrm{Wh}$ $\mathrm{kg}^{-1}$ at $202 \mathrm{~W} \mathrm{~kg}^{-1}, 433 \mathrm{Wh} \mathrm{kg}^{-1}$ at $400 \mathrm{~W} \mathrm{~kg}^{-1}, 365 \mathrm{Wh} \mathrm{kg}^{-1}$ at $799 \mathrm{~W} \mathrm{~kg}^{-1}, 301 \mathrm{Wh} \mathrm{kg}^{-1}$ at 1874 $\mathrm{W} \mathrm{kg}^{-1}$ and $220 \mathrm{Wh} \mathrm{kg}^{-1}$ at $3618 \mathrm{~W} \mathrm{~kg}^{-1}$ based on the weight of $\mathrm{MnS}$, which outperforms the reported values of $\mathrm{MnO}_{2}$, vanadium-based and PBA-based cathodes of aqueous ZIBs under the similar conditions in the literature [18-21, 25-29].
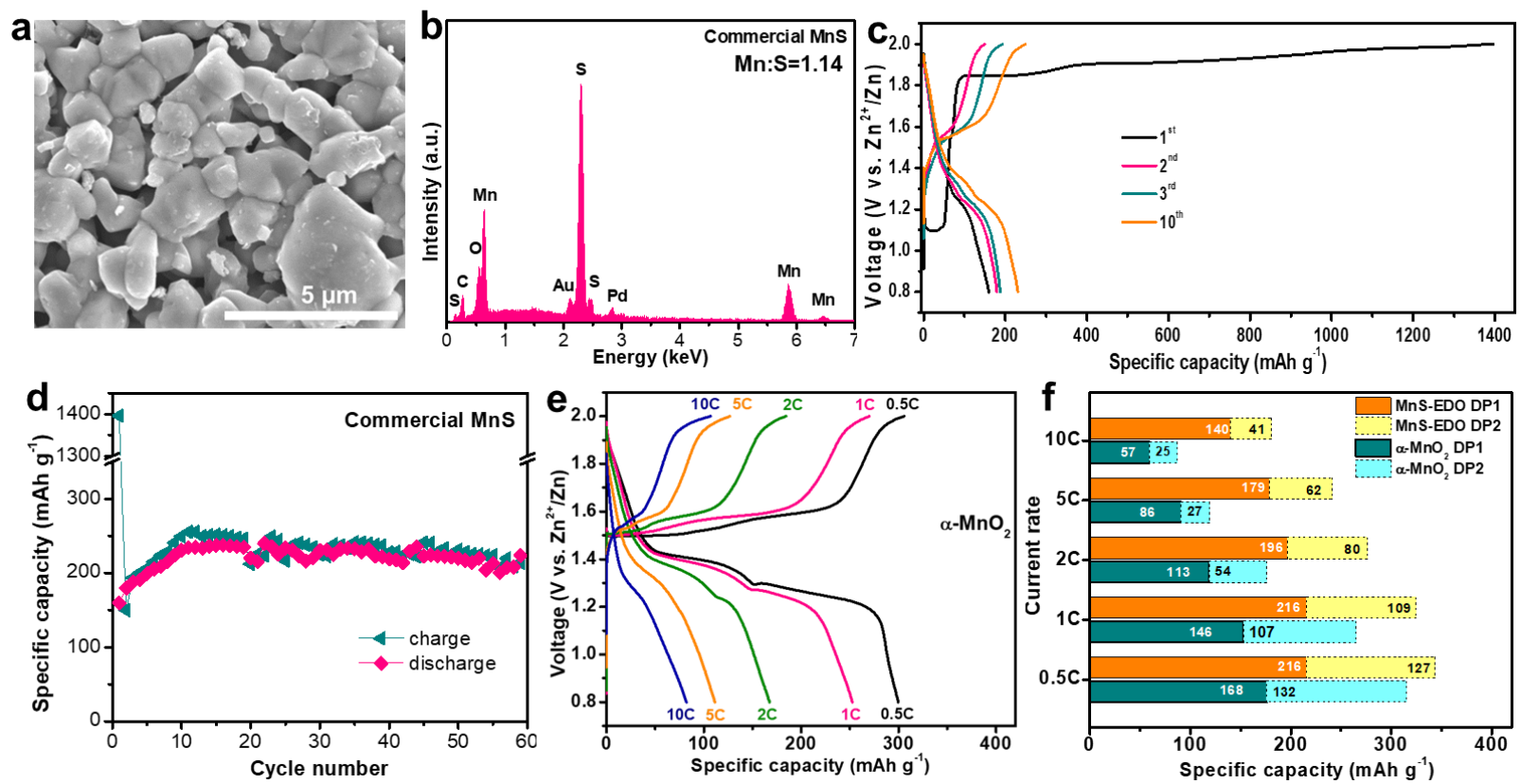

Figure 3. 3 (a) SEM image and (b) EDX result with Mn/S atomic ratio of commercial bulk MnS. (c) The GCD profiles and (d) cycling performance of commercial bulk $\mathrm{MnS}$ cathode in $2 \mathrm{M} \mathrm{ZnSO}_{4}$ and $0.1 \mathrm{M} \mathrm{MnSO}_{4}$ electrolyte at $1 \mathrm{C}$. (e) The GCD profiles of $\alpha-\mathrm{MnO}_{2}$ cathode at current rates from 0.5 to $10 \mathrm{C}$. (f) Capacity contributions of DP1 (2.0-1.3 V) and DP2 (1.3-0.8 V) for MnSEDO and $\alpha-\mathrm{MnO}_{2}$ cathodes at different rates. 
Figures 3.2e-f illustrate the extraordinary long-term cycling stability of MnS-EDO. The MnSEDO and $\mathrm{MnO}_{2}$ cathodes were pre-activated at $1 \mathrm{C}$ for 10 cycles and then cycled at high rates of 5 and $10 \mathrm{C}$. MnS-EDO cathodes demonstrate an obvious activation process with the apparently increased specific discharge capacities followed by the stabilization of capacities during the initial 10 cycles at $1 \mathrm{C}$. This corresponds to the in situ electrochemical activation process for transformation of MnS to MnS-EDO in the early cycles. Then, the activated MnS-EDO cathode maintains a high capacity of $174 \mathrm{mAh} \mathrm{g}^{-1}$ after extra 1000 cycles at $5 \mathrm{C}$, corresponding to $82.8 \%$ of capacity retention. Even at $10 \mathrm{C}$, the activated MnS-EDO is still capable of affording a remarkable capacity of $104 \mathrm{mAh} \mathrm{g}^{-1}$ after extra 4000 cycles. The Coulombic efficiencies of MnSEDO are close to $100 \%$ at 5 and $10 \mathrm{C}$. By comparison, $\mathrm{MnO}_{2}$ only shows a much lower capacity of 86 and $75 \mathrm{mAh} \mathrm{g}^{-1}$ after cycling at 5 and $10 \mathrm{C}$, respectively. The exceptional rate performance and cycling durability of MnS-EDO stand out among variously reported ZIB cathodes. The in situ activation strategy to electrochemically oxidize manganese sulfide can promote the electrochemical performance of commercial $\mathrm{MnS}$ bulks beyond that of nanostructured $\mathrm{MnO}_{2}$, demonstrating phenomenal potentials for mass production of cost-effective and high-performance cathodes for aqueous rechargeable ZIBs.

\subsubsection{Reaction mechanism}

To understand the underlying reasons for the enhanced electrochemical performance of MnSEDO cathode and mechanisms for discharge and charge processes, the electrochemical insights into the ECSA, capacity contributions, kinetics and controlled galvanostatic and potentiostatic discharge and charge behaviors of cathodes were systematically investigated.

First, a systematic account of the ECSA is essential for correlating the aggregate electrochemical performance of an electrode to the intrinsic properties of the active materials, which has been widely studied for electrocatalysts [3, 74], but mostly overlooked for ZIB cathode materials. Even though only a few recent works reported the use of double-layer capacitance (DLC) measurements in aqueous ZIB electrolytes to estimate the ECSA values of manganese oxide [29], the pronounced convoluting ion transfer reactions at the oxide cathode/electrolyte interfaces such as corrosion, intercalation and specific adsorption have been found to introduce additional contribution to specific capacitances of electrodes especially loaded with porous nanostructured metal oxides, leading to unreliable DLC comparison [84]. Therefore, we adopted an established 
and reliable methodology of DLC measurement (Figures 3.4) in polar aprotic acetonitrile electrolyte (see Supporting Information (SI)) to estimate the ECSA values of MnS-EDO and $\mathrm{MnO}_{2}$ cathodes for fair comparison of their exposed active site densities [84-86] Figure 3.4a-c shows that the double-layer capacitance $\left(\mathrm{C}_{\mathrm{dl}}\right)$ of pristine $\mathrm{MnS}$ electrode without activation is much lower $\left(2.4 \mathrm{mF} \mathrm{cm}^{-2}\right)$ than that of the pristine $\mathrm{MnO}_{2}$ electrode $\left(6.1 \mathrm{mF} \mathrm{cm}^{-2}\right)$. However, after the first charge activation, the $\mathrm{C}_{\mathrm{dl}}$ of the formed MnS-EDO electrode is significantly increased to $15.2 \mathrm{mF}$ $\mathrm{cm}^{-2}$ (Figure 3.5a), which is more than twice larger than that of $\mathrm{MnO}_{2}\left(6.8 \mathrm{mF} \mathrm{cm}{ }^{-2}\right)$ under the similar conditions. After 15 cycles of $\mathrm{GCD}$, the $\mathrm{C}_{\mathrm{dl}}$ of $\mathrm{MnS}-\mathrm{EDO}$ at the charged state further increases to $24.2 \mathrm{mF} \mathrm{cm}{ }^{-2}$, significantly larger than that of $\mathrm{MnO}_{2}$. Clearly, the in situ electrochemical activation of $\mathrm{MnS}$ can substantially enhance the density of exposed active sites accounting for larger ECSA than that of $\mathrm{MnO}_{2}$ counterpart (Figure 3.4d-i), because the surface roughening, microstructure reconstruction and amorphization during the electrochemical activation enable the exposure of more active sites[72, 74, 76], which will be explained in the following discussion. 

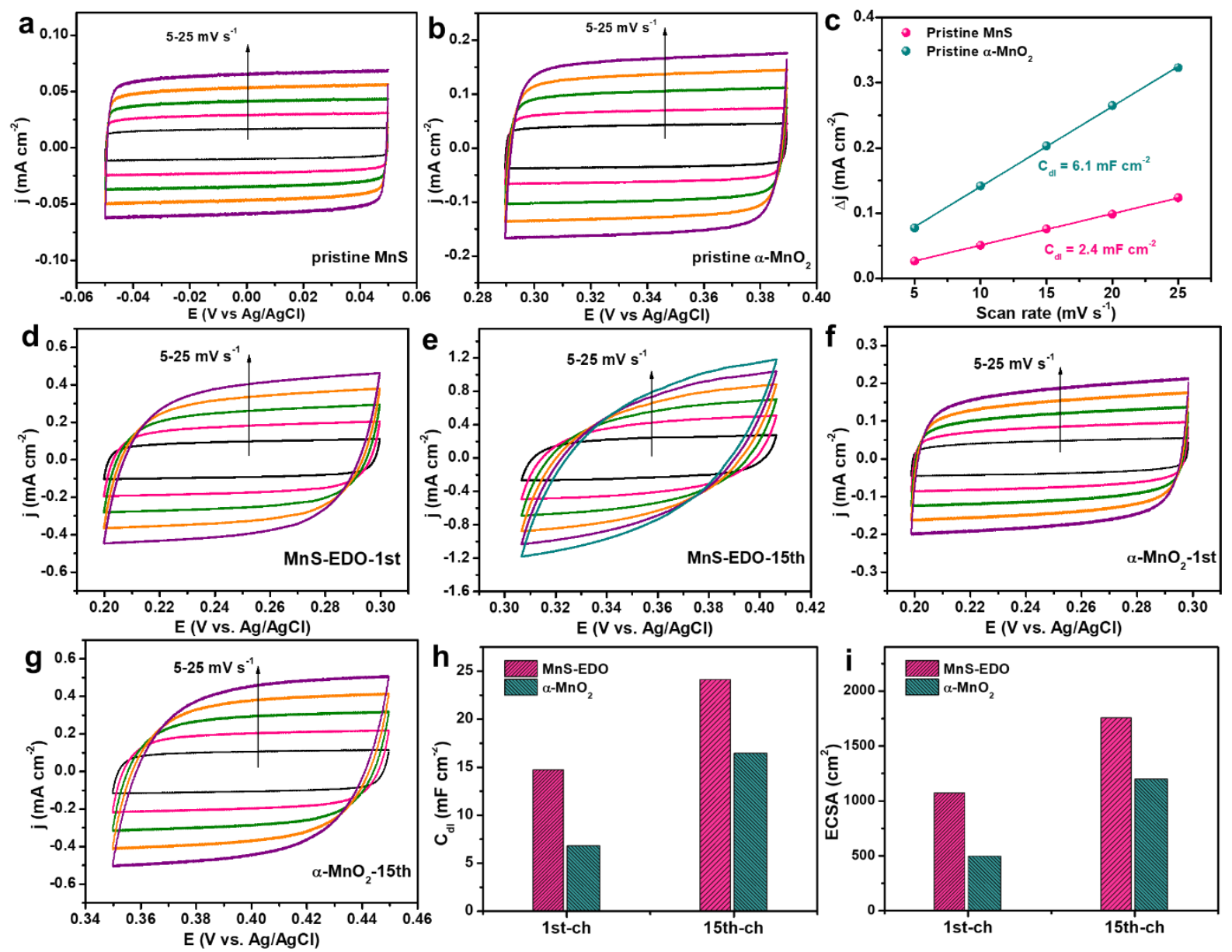

Figure 3. 4 Electrochemically active surface area (ECSA) measurements. (a) and (b) CV curves of pristine $\mathrm{MnS}$ and $\alpha-\mathrm{MnO}_{2}$ electrodes, respectively, at various scan rates ranging from 5 to 25 $\mathrm{mV} \mathrm{s}^{-1}$ in $\mathrm{CH}_{3} \mathrm{CN}$ with $0.15 \mathrm{M}$ TBA-PF . (c) The linear fitting of $\Delta \mathrm{j}$ (difference between anodic and cathodic current densities) versus scan rate for ECSA estimations of pristine $\mathrm{MnS}$ and $\alpha-\mathrm{MnO}_{2}$ electrodes. $\mathrm{CV}$ curves of $\mathrm{MnS}-\mathrm{EDO}$ and $\alpha-\mathrm{MnO}_{2}$ cathodes after $1^{\text {st }}(\mathrm{d}, \mathrm{f})$ and $15^{\text {th }}(\mathrm{e}, \mathrm{g})$ charge processes, respectively. (h) and (i) Quantitative comparison of double-layer capacitance and calculated ECSA results, respectively.

Figure 3.5b illustrates the $\mathrm{CV}$ curves of $\mathrm{MnS}-\mathrm{EDO}$ in $2 \mathrm{M} \mathrm{ZnSO}_{4}$ and $0.1 \mathrm{M} \mathrm{MnSO}_{4}$ at different sweep rates. Two pairs of redox peaks become intensified as the sweep rate rises. The relationship between the peak current $(i)$ and sweep rate $(v)$ follows an equation of $i=a v^{b}$ or expression $\log i=b \log v+\log a$, where the constants of $a$ and $b$ represent the empirical parameters[79] (see details in SI). The calculated $b$ values for all redox peaks of $\mathrm{MnS}$-EDO (Figure 3.5c) and $\mathrm{MnO}_{2}$ (Figure 3.6a-c) are close to 0.5 , demonstrating that the electrochemical reactions in both $\mathrm{MnS}$ and 
$\alpha-\mathrm{MnO}_{2}$ cathodes are primarily controlled by solid-state ionic diffusion processes [5, 79]. The deconvolution of capacitive contribution from the total capacity of MnS-EDO (Figure 3.5d) reveals that the capacitive contribution percentage slightly increases from 24.6 to $49.4 \%$ with the increase of sweep rate from 0.1 to $1 \mathrm{mV} \mathrm{s}^{-1}$, which is close to that of $\alpha-\mathrm{MnO}_{2}$ cathode. This confirmed the predominated diffusion-controlled kinetics of both $\mathrm{MnS}-\mathrm{EDO}$ and $\alpha-\mathrm{MnO}_{2}$ cathodes $[50,80,87]$.
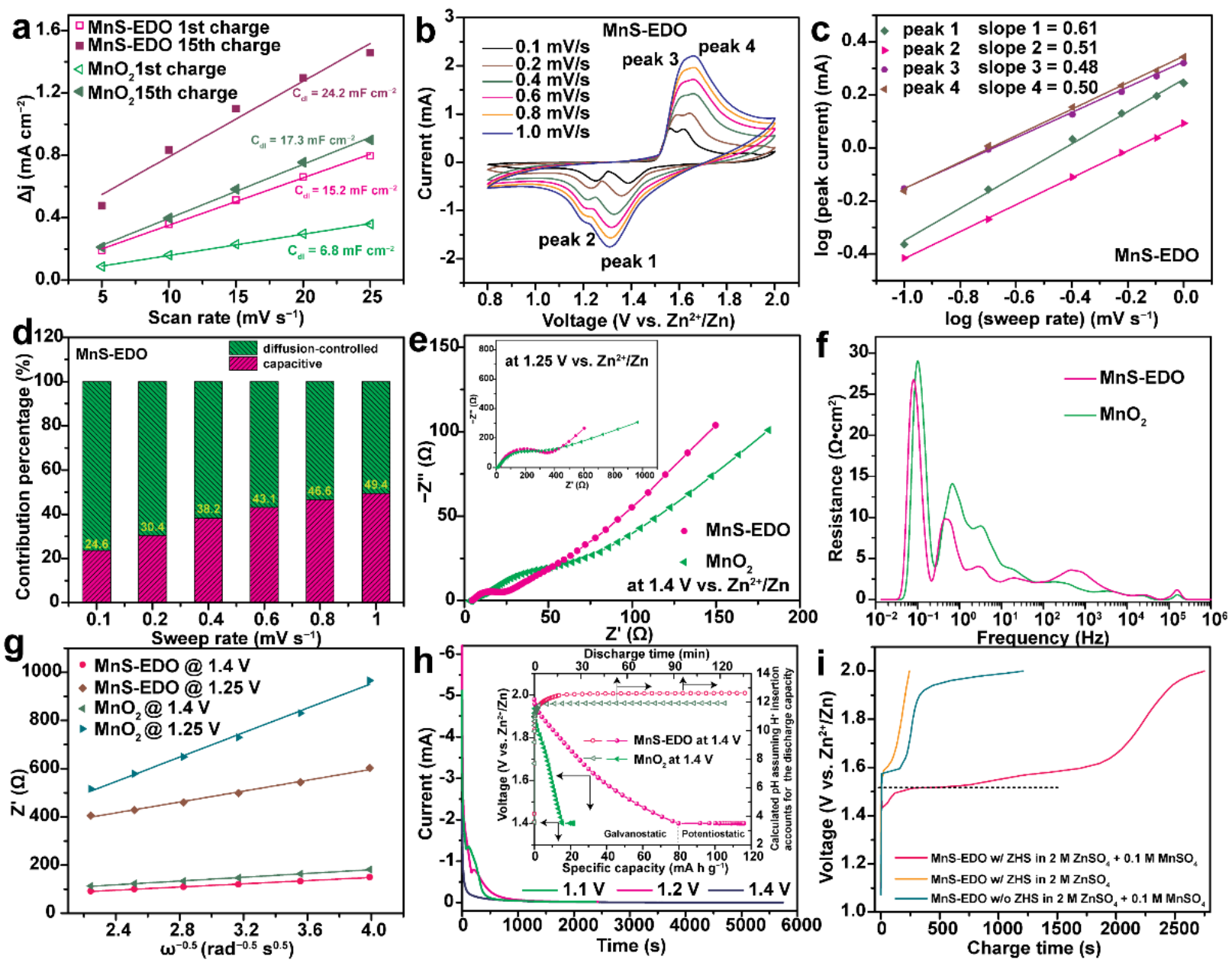

Figure 3. 5 (a) The linear fitting of $\Delta \mathrm{j}$ (difference between anodic and cathodic current densities) versus scan rate for ECSA estimations of fully charged $\mathrm{MnS}-\mathrm{EDO}$ and $\mathrm{MnO}_{2}$ electrodes after given GCD cycles. (b) CV curves of MnS-EDO cathode at various sweep rates in $2 \mathrm{M} \mathrm{ZnSO}_{4}$ and $0.1 \mathrm{M}$ $\mathrm{MnSO}_{4}$. (c) Plots of $\log$ (peak current) versus $\log$ (sweep rate) for MnS-EDO at various peaks derived from (b). (d) The percentage of capacitive contributions for MnS-EDO at various sweep rates. (e) Nyquist plots of $\mathrm{MnS}-\mathrm{EDO}$ and $\mathrm{MnO}_{2}$ cathodes at the discharge depth of 1.40 and 1.25 V (inset). (f) DRT analysis of EIS spectra of $\mathrm{MnS}-\mathrm{EDO}$ and $\mathrm{MnO}_{2}$ cathodes. (g) Plots of Z' versus 
$\omega^{-0.5}$ of $\mathrm{MnS}-\mathrm{EDO}$ and $\mathrm{MnO}_{2}$ cathodes in the low frequency Warburg impedance region of (e). (h) The time-dependent current of fully charged MnS-EDO electrodes under potentiostatic discharge at 1.1, 1.2 and $1.4 \mathrm{~V}$. The inset of (h) shows the discharge profiles of MnS-EDO (filled magenta circle) and $\mathrm{MnO}_{2}$ (filled green triangle) cathodes discharging galvanostatically from 2.0 to $1.4 \mathrm{~V}$ at $1 \mathrm{C}$ and then kept at $1.4 \mathrm{~V}$ for potentiostatic discharge for $2 \mathrm{~h}$ (left and bottom scale axes) and the theoretical electrolyte $\mathrm{pH}$ changes of cells with MnS-EDO (empty pink circle) and $\mathrm{MnO}_{2}$ (empty olive triangle) cathodes as a function of discharge time assuming that only the proton insertion reaction accounts for their discharge capacities at $\geq 1.4 \mathrm{~V}$. (i) The galvanostatic charge curves of fully discharged MnS-EDO cathodes under different conditions at $1 \mathrm{C}$.

The electrochemical reaction kinetics of $\mathrm{MnS}-\mathrm{EDO}$ and $\mathrm{MnO}_{2}$ were further investigated by the electrochemical impedance spectroscopy (EIS). Figure 3.5e illustrates their Nyquist plots recorded at two selected discharge platforms of 1.4 (DP1) and $1.25 \mathrm{~V}$ (DP2), composed of a small depressed semicircle at high frequency and a relatively large depressed semicircle at mid-to-low frequency together with an inclined Warburg line at lower frequency. The EIS data were fitted using an equivalent circuit (Figure 3.6d). The mid-to-low frequency semicircle is related to the charge transfer resistance $\left(R_{c t}\right)$ associated with the desolvation/solvation of ions and ion intercalation/deintercalation to/from the active particle surface[88]. MnS-EDO shows smaller $\mathrm{R}_{\mathrm{ct}}$ than $\mathrm{MnO}_{2}$ at both discharge platforms, indicating the accelerated charge transfer kinetics of electrochemical reactions in MnS-EDO. The distribution of relaxation time (DRT) analyses (Figure 3.5f) of EIS results further unequivocally confirm that MnS-EDO possesses smaller charge transfer resistance due to its smaller peak area than that of $\mathrm{MnO}_{2}$. Moreover, the Warburg factor $\sigma$ calculated from the Warburg line in lower frequency range (Figure 3.5g) is summarized (Table 3.1), manifesting that $\mathrm{MnS}$-EDO has a much lower $\sigma$ than $\mathrm{MnO}_{2}$. The lower $\sigma$ suggests a faster ion diffusion process[48, 80]. The apparent ion diffusion coefficient (D) is calculated. MnSEDO shows 1.4-fold and 5.1-fold increase in D value compared to $\mathrm{MnO}_{2}$ at 1.4 and $1.25 \mathrm{~V}$, respectively. Abundant exposed electrochemically active sites of MnS-EDO can offer larger electrolyte/electrode interfacial contact areas and enhance charge transfer and diffusion kinetics through shortening the diffusion pathway for ion and electron transport [56-58], contributing to improved electrochemical reactivity for ZIBs. 

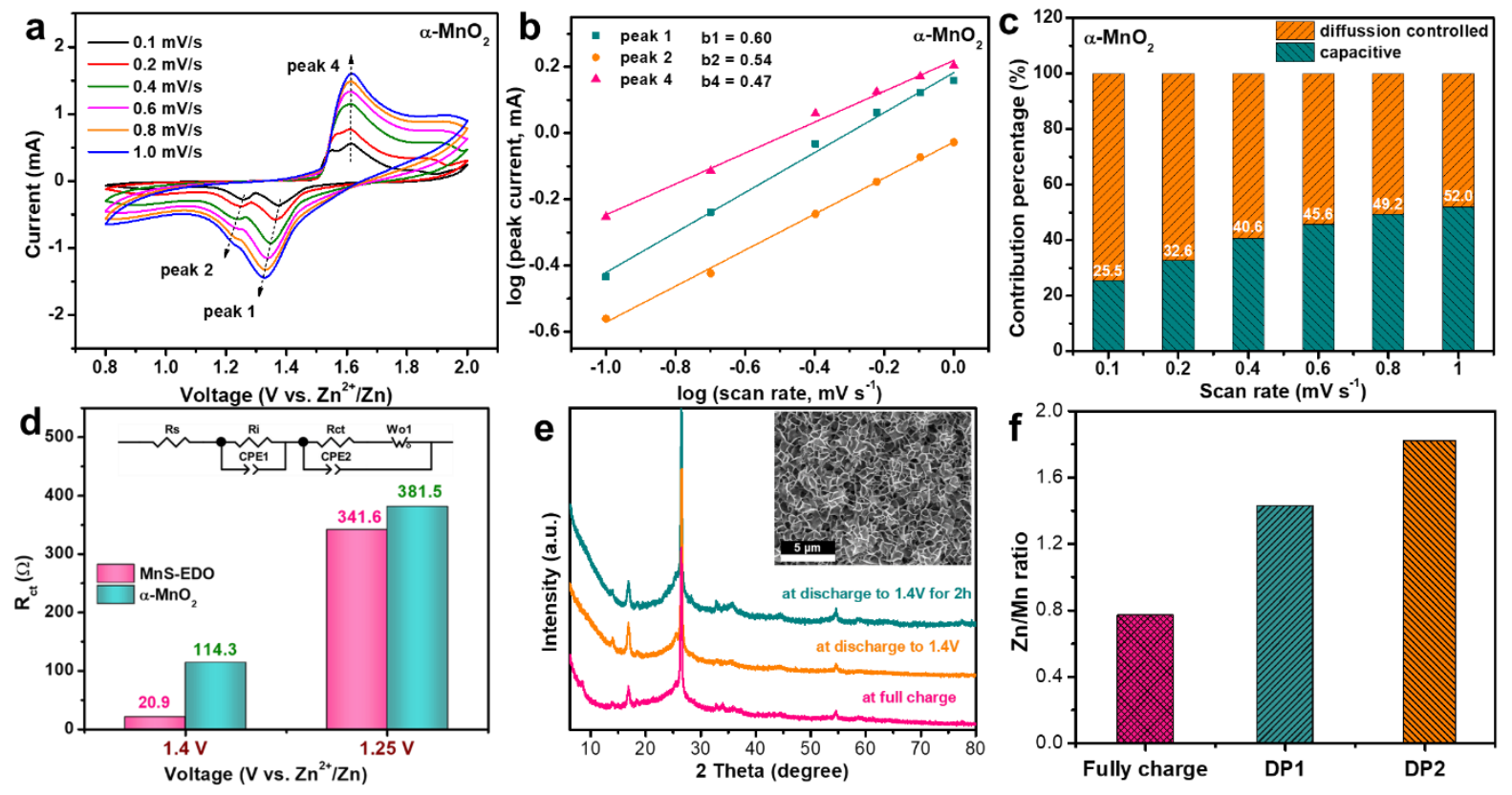

Figure 3. 6 (a) CV curves of $\alpha-\mathrm{MnO}_{2}$ cathode at various scan rates. (b) Plots of $\log$ i versus $\log \mathrm{v}$ at specific peak currents. (c) The percentage of capacitive contributions for $\alpha-\mathrm{MnO}_{2}$ cathode at various sweep rates. (d) Comparison of charge transfer resistance $\left(\mathrm{R}_{\mathrm{ct}}\right)$ values of $\mathrm{MnS}$-EDO and $\alpha-\mathrm{MnO}_{2}$ cathodes. Inset is the equivalent circuit used for EIS data fitting. (e) XRD and SEM images of MnS-EDO cathode after galvanostatically discharging from 2.0 to $1.4 \mathrm{~V}$ at $1 \mathrm{C}$ and then kept at $1.4 \mathrm{~V}$ for potentiostatic discharge of $2 \mathrm{~h}$. (f) EDX results of the atomic ratios of $\mathrm{Zn} / \mathrm{Mn}$ for MnS-EDO cathodes at different charge/discharge states: fully charged state, end of DP1 and end of DP2.

Additionally, the electrochemical discharge mechanisms of the $\mathrm{Zn} / \mathrm{MnO}_{2} \mathrm{ZIBs}$ with $\mathrm{ZnSO}_{4}$ based electrolytes still remain elusive. Although various mechanisms have been proposed [60], none of them can satisfactorily explain all experimental results. A commonly reported mechanism is the insertion of $\mathrm{H}^{+}$at the higher voltage platform and subsequent $\mathrm{Zn}^{2+}$ intercalation at the lower voltage platform based on the presence of two redox reactions and co-existence of $\mathrm{H}^{+}$and $\mathrm{Zn}^{2+}$ and the discrepancy of reaction kinetics at two discharge platforms [48, 51]. The GCD profiles of MnS-EDO and $\mathrm{MnO}_{2}$ cathodes in this work also demonstrate distinct DP1 and DP2 connected with a clear inflection or dip point (Figures 3.3e and 3.2b). As the current density increases from 150 to $300 \mathrm{~mA} \mathrm{~g}^{-1}$, their DP1 is almost overlapped, while their DP2 shows larger capacity fading. Actually, the established cathodic reduction mechanism of $\mathrm{MnO}_{2}$ in basic electrolytes for alkaline 
$\mathrm{Zn} / \mathrm{MnO}_{2}$ batteries also showed similar two-stage galvanostatic discharge profiles with continuously decreased DP1 and flat DP2, where there was a dip on the recorded curve at the end of DP1 and the high current density curtailed DP2 but influenced DP1 little [89-90]. In the 1960s, Kozawa et al. proved that a homogeneous solid-state insertion reaction (e.g., $\mathrm{H}_{\mathrm{x}} \mathrm{MnO}_{2}$ ) via an electron-proton mechanism accounts for the first sloping discharge step DP1, while the second relatively flat discharge step DP2 originates from a heterogeneous reduction process in the presence of both $\mathrm{MnOOH}$ and $\mathrm{Mn}(\mathrm{OH})_{2}$ involving reduction of dissolved $\mathrm{Mn}^{3+}$ to $\mathrm{Mn}^{2+}$ ions in the alkaline electrolyte through a dissolution-reduction-precipitation mechanism [89-91].These mechanisms have been substantiated by both the theoretical thermodynamic calculations and recent experimental results from others [92-94]. Due to the similarity of discharge profiles for our cathodes in mildly acidic electrolytes with those of alkaline $\mathrm{Zn} / \mathrm{MnO}_{2}$ batteries, we hypothesize the analogous discharge mechanisms. The fully charged MnS-EDO cathodes were discharged at different constant voltages including 1.4, 1.2 and 1.1 V. Figure 3.5h displays the current changes of MnS-EDO during the potentiostatic discharge, demonstrating that the current variation at $1.4 \mathrm{~V}$ (DP1) is subtle, while sharp current changes with apparent peaks are observed at 1.2 (DP2) and $1.1 \mathrm{~V}$. This indicates that a homogeneous reaction takes place at DP1 and a heterogeneous reaction occurs at DP2, consistent with a recent mechanistic study of $\mathrm{Zn} / \mathrm{MnO}_{2}$ batteries [60].

Table 3. 1 The Warburg factor $\sigma$ values for $\mathrm{MnS}-\mathrm{EDO}$ and $\alpha-\mathrm{MnO}_{2}$ cathodes based on EIS results.

\begin{tabular}{ccc}
\hline Cathode & $\sigma @ 1.4 \mathrm{~V}$ & $\sigma @ 1.25 \mathrm{~V}$ \\
\hline $\mathrm{MnS}-\mathrm{EDO}$ & 33.04 & 113.02 \\
$\alpha-\mathrm{MnO}_{2}$ & 39.17 & 253.96 \\
\hline
\end{tabular}

Table 3. 2 Theoretical calculations assuming that only a pure proton intercalation accounts for the observed discharge capacity at DP1.

\begin{tabular}{lll}
\hline \multicolumn{1}{c}{ Cathode } & MnS-EDO & $\alpha-\mathrm{MnO}_{2}$ \\
\hline Theoretical $\mathrm{pH}$ after galvanostatic discharge & & 11.93 \\
from 2.0 to $1.4 \mathrm{~V}$ at $1 \mathrm{C}$ and then & 12.63 & \\
potentiostatic discharge $1.4 \mathrm{~V}$ for $2 \mathrm{~h}$ & & $1.41 \times 10^{-5} \mathrm{mAh} \mathrm{g}^{-1}$ \\
\hline Theoretically calculated specific discharge & $1.49 \times 10^{-5} \mathrm{mAh} \mathrm{g}^{-1}$ & \\
capacity to enable the pH to rise to 5.74 & & \\
\hline
\end{tabular}


To investigate whether the insertion of $\mathrm{H}^{+}$is the primary reaction at DP1, the MnS-EDO and $\mathrm{MnO}_{2}$ cathodes were firstly discharged at the constant current of $1 \mathrm{C}$ to $1.4 \mathrm{~V}$ and then maintained at this voltage for $2 \mathrm{~h}$. Within this scenario, MnS-EDO delivers the specific discharge capacity of $116 \mathrm{mAh} \mathrm{g}{ }^{-1}$, more than 5 times higher than that of $\mathrm{MnO}_{2}$, indicating substantially higher $\mathrm{Mn}$ utilization of MnS-EDO (Figure 3.5h inset). The proton intercalation into the cathode should increase the electrolyte $\mathrm{pH}$. The theoretical $\mathrm{pH}$ change is calculated on the basis of the number of intercalated $\mathrm{H}^{+}$by using a reported method and assuming that only the proton intercalation reaction accounts for the observed discharge capacity (Table 3.2) [65]. The calculated $\mathrm{pH}$ values for both MnS-EDS and $\mathrm{MnO}_{2}$ are found to soar to 11 within 1 min and reach around 12 in the end of constant-voltage discharge (Figure 3.5h inset), consistent with a previous report [65]. Such a high $\mathrm{pH}$ is far beyond the threshold value of 5.74 that triggers $\mathrm{ZHS}$ precipitation[45, 65]. In other words, the $\mathrm{MnS}$-EDS and $\mathrm{MnO}_{2}$ cathodes are predicted to deliver merely $1.5 \times 10^{-5} \mathrm{mAh} \mathrm{g}^{-1}$ to raise the $\mathrm{pH}$ over 5.74. Therefore, ZHS precipitates are expected on these discharged cathodes if proton intercalation occurs at DP1. Nevertheless, the ex situ $\mathrm{pH}$ measurements before and after the discharge demonstrate that the $\mathrm{pH}$ slightly increased from initial 3.6 to 4.6 and no ZHS precipitates were found in MnS-EDO (Figure 3.6e) in the end of potentiostatic discharge, which excludes the proton insertion as a major reaction at DP1. No new phase formed during the homogeneous ion insertion (Figure 3.6e). The EDX result (Figure 3.6f) confirms higher $\mathrm{Zn} / \mathrm{Mn}$ atomic ratios in the cathode after discharging at $1.4 \mathrm{~V}$ compared to the starting fully charged counterpart, suggesting that the intercalation of $\mathrm{Zn}^{2+}$ ions is likely the primary reaction at DP1. These results corroborate that the homogeneous zinc ion insertion reaction occurs at DP1 for MnS-EDO. When MnS-EDO is galvanostatically discharged to $\mathrm{DP} 2$, new $\mathrm{MnOOH}$ phase appears and ZHS precipitates are formed simultaneously as discussed in the next section, indicating a heterogeneous reaction involving proton intercalation occurs at DP2. Furthermore, most of reports believe that the subsequent charge process only involves the extraction of the intercalated $\mathrm{Zn}^{2+}$ and $\mathrm{H}^{+}$in the fully discharged $\mathrm{MnO}_{\mathrm{x}}$ cathode and produces $\mathrm{MnO}_{2}[48,51,80]$. Here, we found that the reaction between ZHS precipitates and $\mathrm{Mn}^{2+}$ also takes place in the charge process $[60,68]$. The discharged MnS-EDO cathode covered with ZHS flakes was further charged in $\mathrm{ZnSO}_{4}$ electrolyte with or without $\mathrm{MnSO}_{4}$. Meanwhile, the discharged MnS-EDO with ZHS removed was charged in $2 \mathrm{M}$ $\mathrm{ZnSO}_{4}$ and $0.1 \mathrm{M} \mathrm{MnSO}_{4}$. The different charge curves (Figure 3.5i) under these conditions 
demonstrate that the charge plateau at $c a$. 1.5-1.6 V likely corresponds to the reaction between ZHS and $\mathrm{Mn}^{2+}$, consistent with recent reports [60, 68].
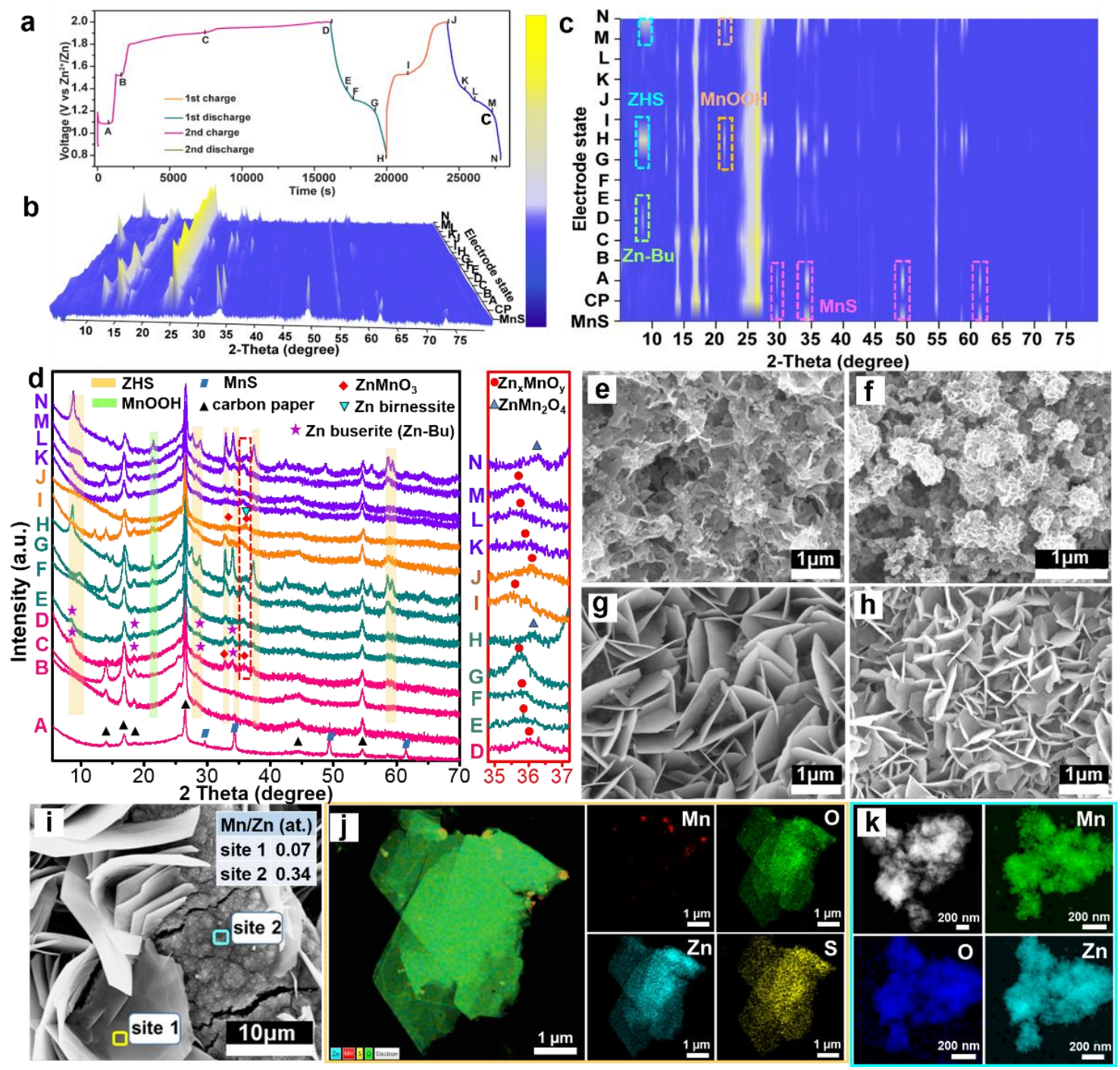

Figure 3. 7 Structural and morphological evolution of MnS-EDO. (a) The GCD curve of the first two cycles with selected states where cathodes were ex situ characterized. (b) and (c) The corresponding XRD evolution and patterns (d) of MnS-EDO at different states indicated in (a). (eh) SEM images at selected cathode states of B, C, D and F, respectively. (i) SEM image of MnSEDO at fully discharge state with selected regions for EDX analysis. HAADF-STEM images and elemental maps for fully discharged MnS-EDO corresponding to site $1(\mathrm{j})$ and $2(\mathrm{k})$.

To further unravel the electrochemical reaction mechanism of MnD-EDO in ZIBs, the structural and morphological evolutions of the cathodes at different states of charge/discharge (Figure 3.7a) during cycles were systematically investigated. The phase changes of the cathodes during the 
initial two GCD cycles were explored by ex situ XRD (Figure 3.7b-d). In the first charge oxidation, the pristine $\mathrm{MnS}$ phase quickly disappears and is completely transformed to $\mathrm{Zn}$ buserite ( $\mathrm{Zn}-\mathrm{Bu}$ ) [67], cubic and hexagonal $\mathrm{ZnMnO}_{3}\left(\mathrm{c}-\mathrm{ZnMnO}_{3}\right.$, JCPDS 19-1461; h- $\mathrm{ZnMnO}_{3}$, JCPDS 28-1468) with broadened peaks and low crystallinity. The original MnS particles become shortened and are gradually converted to interconnected nanosheets (Figure 3.7e), agglomerated nanosheets (Figure 3.7f) and eventually transformed to microsized flakes forming percolating microstructure and masking nanosheets aggregated clusters (Figure 3.7g).

In the subsequent discharge, no new phase is found in the DP1 stage $(\mathrm{D} \rightarrow \mathrm{E} \rightarrow \mathrm{F})$ except that the peak at $36.1^{\circ}$ shifts toward lower $2 \theta$ direction corresponding to the expansion of MnS-EDO interlayer spacing due to $\mathrm{Zn}^{2+}$ intercalation and the $\mathrm{Zn}-\mathrm{Bu}$ peak at $8.5^{\circ}$ becomes significantly broadened. The $\mathrm{Zn} / \mathrm{Mn}$ ratio is increased and microsized flakes are well maintained during DP1 (Figures 3.7h). These results demonstrate the homogeneous $\mathrm{Zn}^{2+}$ intercalation reaction at DP1. Previous reports have found that the uniform insertion of $\mathrm{Zn}^{2+}$ into layered crystalline $\mathrm{Zn}-\mathrm{Mn}-\mathrm{O}$ framework is a homogeneous reaction and may not induce severe structure collapse [60, 80, 87]. Here, the $\mathrm{Zn}-\mathrm{Mn}-\mathrm{O}$ composite framework including $\mathrm{Zn}$ busertie and $\mathrm{ZnMnO}_{3}$ generated from the electrochemical charge activation of $\mathrm{MnS}$ may provide a stable crystallographic architecture for intercalation and deintercalation of $\mathrm{Zn}^{2+}$. To examine the stability of $\mathrm{MnS}$-EDO for accommodating $\mathrm{Zn}^{2+}$ at DP1, the cell was cycled in a voltage window of 2.0-1.3 V. Even after 600 cycles, MnS-EDO still retains a stable discharge capacity of $76 \mathrm{mAh} \mathrm{g}^{-1}$ (Figure 3.8a-d). Neither $\mathrm{MnOOH}$ nor ZHS is found at $1.3 \mathrm{~V}$ and microstructure is maintained, indicating the high stability of $\mathrm{MnS}$-EDO during the homogeneous $\mathrm{Zn}^{2+}$ intercalation/deintercalation reaction and no $\mathrm{H}^{+}$ insertion occurs at DP1. In contrast, the capacity of $\mathrm{MnO}_{2}$ rapidly declines to less than $20 \mathrm{mAh} \mathrm{g}^{-}$ 1 (Figure 3.8e-h). The superior stability of MnS-EDO at DP1 is ascribed to its remarkable tolerance against the homogeneous $\mathrm{Zn}^{2+}$ insertion/extraction into/out of flakes/nanosheets, which not only minimizes the structure collapse caused by crystallographic transformation but also obviates the formation of irreversible phase. When MnS-EDO is discharged to the DP2 stage $(\mathrm{F} \rightarrow \mathrm{H})$, new phases such as $\mathrm{MnOOH}(\mathrm{JCPDS} 88-0648)$ and $\mathrm{Zn}_{4} \mathrm{SO}_{4}(\mathrm{OH})_{6} \cdot \mathrm{xH}_{2} \mathrm{O}(\mathrm{ZHS}$, JCPDS 44-0673; 39-0689) are observed (Figures 3.7b-d), suggesting the $\mathrm{H}^{+}$insertion occurs at DP2. Additionally, the typical peak at $36.1^{\circ}$ continues to shift towards lower $2 \theta$ owing to the $\mathrm{Zn}^{2+}$ insertion into $\mathrm{Zn}_{\mathrm{x}} \mathrm{MnO}_{\mathrm{y}}$ and $\mathrm{ZnMn}_{2} \mathrm{O}_{4}$ (JCPDS 24-1133) forms in the end of discharge due to phase segregation. During DP2, the original microsize flakes $(\sim 1.0 \mu \mathrm{m})$ disappear, while many larger 
hexagonal plates $(15-20 \mu \mathrm{m})$ appear and fluffy nanosheets are visible underneath (Figures 3.7i). There is few $\mathrm{Mn}$ in the large plate with $\mathrm{Zn} / \mathrm{S}$ ratio of 4.0, whereas a higher $\mathrm{Mn} / \mathrm{Zn}$ ratio is detected in the nanosheet region, suggesting that the plates and fluffy nanosheets are ZHS and Znintercalated manganese oxide phase $\left(\mathrm{Zn}_{\mathrm{x}} \mathrm{MnO}_{\mathrm{y}}\right)$, respectively. The HAADF-STEM and EDX mapping results (Figure 3.7j) demonstrate abundant and uniform distribution of $\mathrm{Zn}, \mathrm{S}$ and $\mathrm{O}$ over the plate with sparsely scattered Mn signal, corroborating the plates are ZHS which minor fragmented $\mathrm{Zn}_{\mathrm{x}} \mathrm{MnO}_{\mathrm{y}}$ nanosheets adhere to. Figure 3.7k illustrates the homogeneous distribution of $\mathrm{Zn}, \mathrm{Mn}$ and $\mathrm{O}$ within agglomerated nanosheets. Therefore, the co-insertion of $\mathrm{H}^{+}$and $\mathrm{Zn}^{2+}$ accompanied with recrystallization of ZHS plates and complex crystallographic phase transformation from $\mathrm{Zn}$ buserite and $\mathrm{ZnMnO}_{3}$ to $\mathrm{Zn}_{\mathrm{x}} \mathrm{MnO}_{\mathrm{y}}$ takes place at DP2. The EDX analysis (Figure 3.6f) shows the $\mathrm{Zn} / \mathrm{Mn}$ ratio grows continuously $(\mathrm{D} \rightarrow \mathrm{H})$. All the experimental results substantiate a hybrid discharge mechanism involving homogenous $\mathrm{Zn}^{2+}$ intercalation at DP1 and subsequent heterogeneous reactions of insertion of both $\mathrm{H}^{+}$and $\mathrm{Zn}^{2+}$ at DP2.
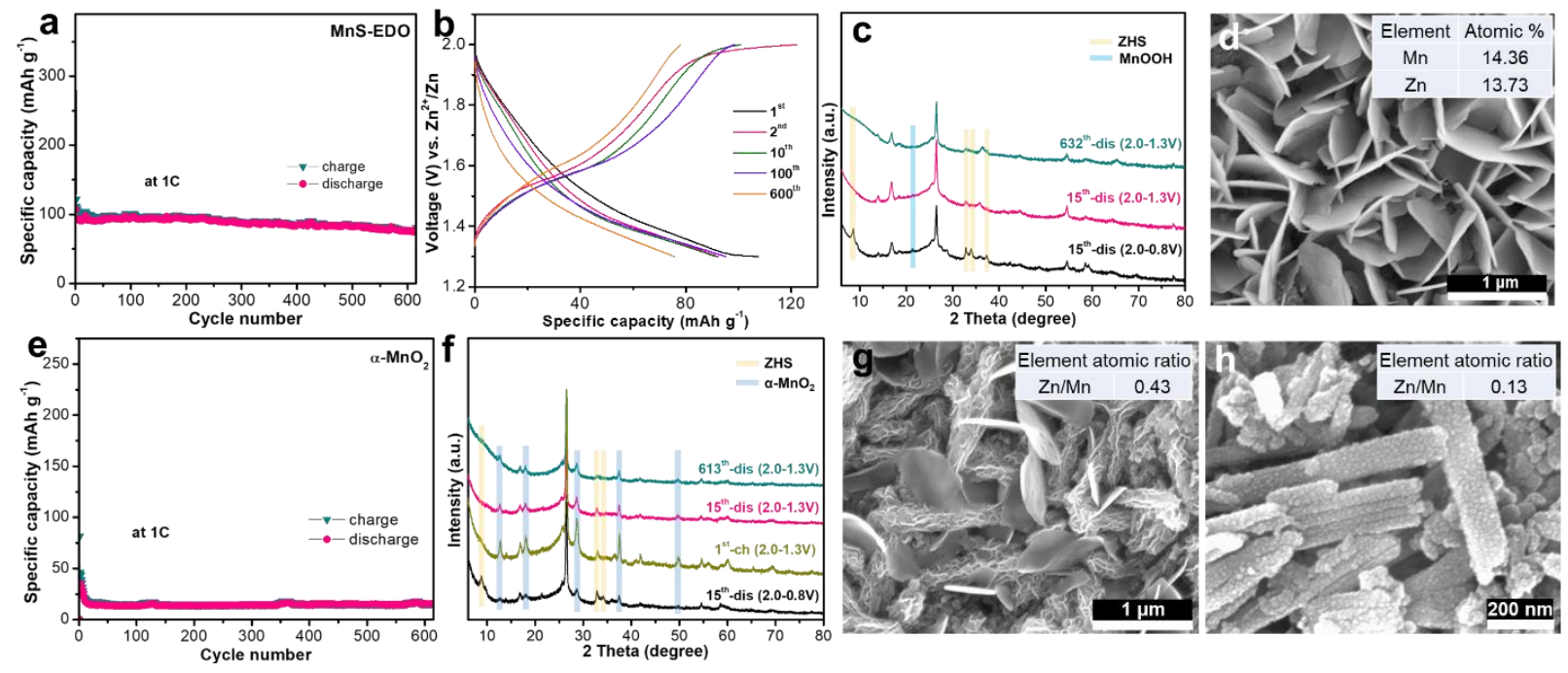

Figure 3. 8 Investigation of cycling stability of the MnS-EDO (a-d) and $\alpha-\mathrm{MnO}_{2}(\mathrm{e}-\mathrm{h})$ cathodes in the potential window of 2.0 -1.3 V (DP1). For MnS-EDO cathode: (a) Cycling performance at 1 C. (b) GCD curves of $1^{\text {st }}, 2^{\text {nd }}, 10^{\text {th }}, 100^{\text {th }}$ and $600^{\text {th }}$ cycles. (c) XRD patterns at different cycle states. (d) SEM image at discharged state $(1.3 \mathrm{~V})$. Inset of (d) is the corresponding EDX result of the element atomic percentage. For $\alpha-\mathrm{MnO}_{2}$ cathode: (a) Cycling performance at $1 \mathrm{C}$. (b) XRD patterns at different cycle states. (c) SEM image of $\mathrm{MnO}_{2}$ at the $1^{\text {st }}$ fully charged state $(2.0 \mathrm{~V})$. (d) SEM image of the $\mathrm{MnO}_{2}$ cathode at the $613^{\text {th }}$ discharged state $(1.3 \mathrm{~V})$. Insets of (c) and (d) are the corresponding EDX results, respectively. 
In the following charge process $(\mathrm{H} \rightarrow \mathrm{J})$, ZHS and $\mathrm{MnOOH}$ disappear in the XRD patterns and large ZHS plates progressively vanish (Figures 3.9a, b). In contrast to microsized flakes of the first charged MnS-EDO (Figure 3.7g), the second fully charged cathode consists of abundant hydrangea-shaped clusters with interconnected petal-like nanosheets and a few flakes (Figure 3.9b) with low-crystallinity possible phases of $\mathrm{ZnMnO}_{3}$ and $\mathrm{Zn}$ birnessite phases (e.g., $\mathrm{ZnMn}_{3} \mathrm{O}_{7} \cdot 3 \mathrm{H}_{2} \mathrm{O}$ ) lacking apparent characteristic peak of $\mathrm{Zn}$ buserite at $8.5^{\circ}$. The disappearance of ZHS plates in the charge process is likely attributed to its decomposition/dissolution caused by local $\mathrm{pH}$ decrease arising from $\mathrm{H}^{+}$extraction and the reaction of $\mathrm{ZHS}$ with $\mathrm{Mn}^{2+}$ in the electrolyte to form low-crystallinity layered products $[45,60,65]$. In the second discharge process $(\mathrm{J} \rightarrow \mathrm{N})$, peak shift and appearance of $\mathrm{MnOOH}$, ZHS plates and aggregated $\mathrm{Zn}_{\mathrm{x}} \mathrm{MnO}_{\mathrm{y}}$ nanosheets are observed akin to those in the first discharge process (Figure 3.9c).

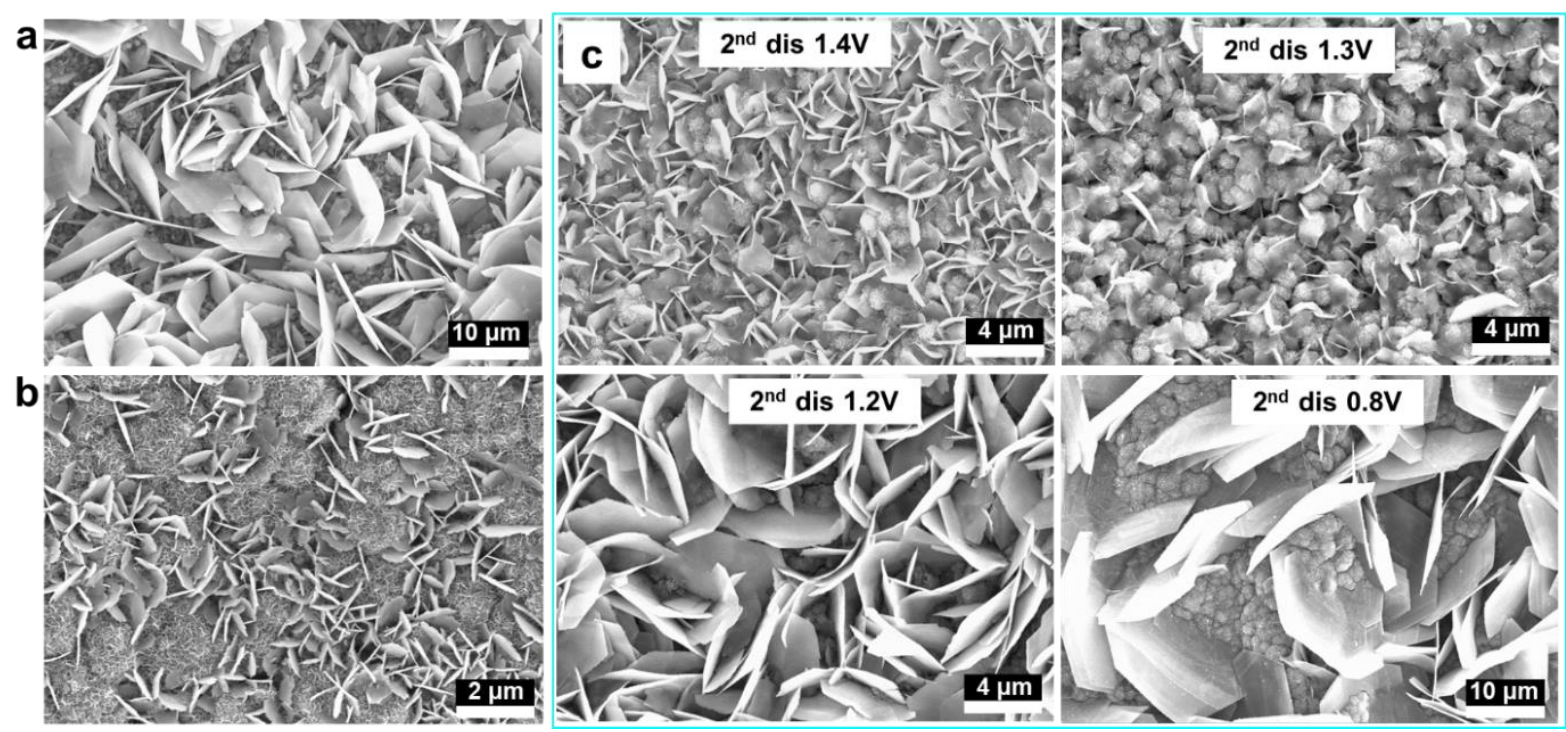

Figure 3. 9 SEM image of MnS-EDO cathode (a) at the selected state I of the second charge process (point I, marked in Figure 7a), (b) at the second fully charged state (point J, marked in Figure 7a), and (c) at selected states $\mathrm{K}, \mathrm{L}, \mathrm{M}$ and $\mathrm{N}(1.4,1.3,1.2$ and $0.8 \mathrm{~V}$, respectively) of the second discharge process, as shown in Figure 7a,

Note that it is challenging to exactly distinguish the intermediate products by XRD due to the low crystallinity and overlapping diffraction peaks of phyllomanganates as well as the complex spontaneous intergrowth or transformation during the battery resting and drying[59], leading to ambiguities. For instance, Mn-free ZHS and zinc-containing phyllomanganates including buserite and birnessite with hydrated interlayer cations have been muddled when investigating the 
discharged products [15, 26, 42-46, 50], because both possess layered structure and overlapping XRD peaks with close d-spacing (e.g., $\sim 10 \AA$ for $\mathrm{Zn}$ buserite and $\mathrm{Zn}_{4} \mathrm{SO}_{4}(\mathrm{OH})_{6} \cdot 4 \mathrm{H}_{2} \mathrm{O}$ and $\sim 7 \AA$ for $\mathrm{Zn}$ birnessite and $\mathrm{Zn}_{4} \mathrm{SO}_{4}(\mathrm{OH})_{6} \cdot 0.5 \mathrm{H}_{2} \mathrm{O}$ ) depending on dehydration degree (Figures 3.10a-b). Likewise, hydrated zinc hydroxide triflate has an analogous structure to zinc buserite (Figure 3.10c). Therefore, rigorous characterization techniques (e.g., local EDX) should be complemented with XRD to differentiate the phases of discharged/charged products. In this study, layered zinc buserite flakes were found in the first charged state [67], while ZHS plates were observed in the end of discharge.
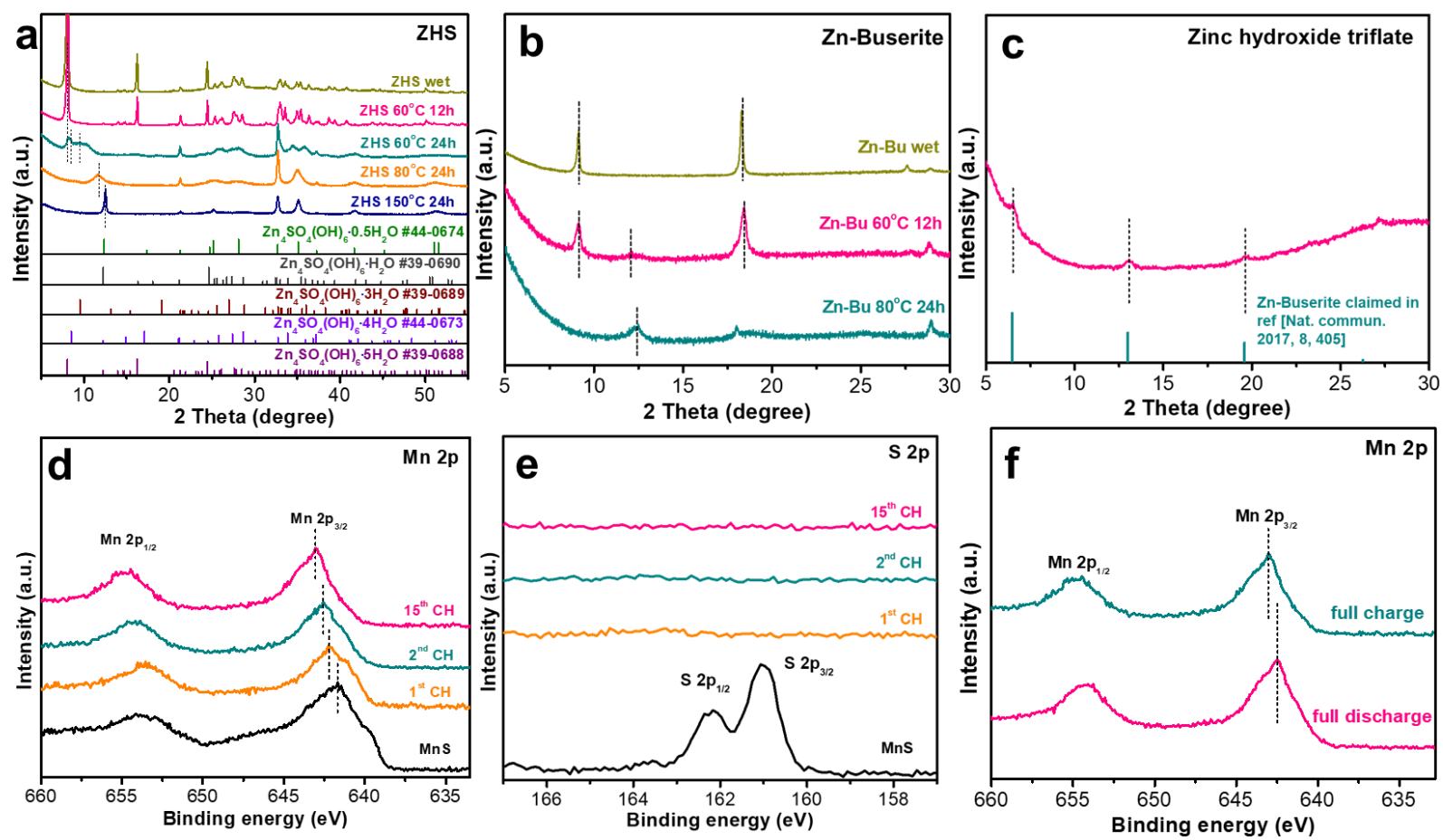

Figure 3. 10 XRD patterns of the synthesized (a) ZHS, (b) zinc buserite and (c) zinc hydroxide triflate samples under different drying conditions. XPS spectra of (d) Mn 2p and (e) S 2p for pristine $\mathrm{MnS}$ and cycled MnS-EDO cathodes at fully charged states. (f) Mn 2p XPS spectra of MnS-EDO cathodes at fully charged and discharged states.

The chemical compositions of electrodes were examined by XPS. The $\mathrm{S}^{2-} 2 \mathrm{p}$ peaks of MnSEDO vanish after the first charge activation and Mn $2 p$ peaks shift towards higher binding energy (Figure 3.10d, e), manifesting the $\mathrm{Mn}(\mathrm{II})$ in pristine $\mathrm{MnS}$ is gradually oxidized to higher valence accompanied with the leaching of $\mathrm{S}$ component in the initial cycles to form MnS-EDO [74, 76]. As the thick ZHS plates obscured the Mn XPS signal, the discharged MnS-EDO was rinsed with 
acetic acid to dissolve them and expose the underneath $\mathrm{Zn}_{\mathrm{x}} \mathrm{MnO}_{\mathrm{y}}$ nanosheets. The SEM, XRD and EDX results collectively confirm the removal of ZHS [45], and intercalated $\mathrm{Zn}$ is present in the discharge product, although the $\mathrm{Zn} / \mathrm{Mn}$ ratio is significantly reduced due to the extraction of $\mathrm{Zn}$ during acid rinsing compared to that without treatment [95]. The shift of $\mathrm{Mn} 2 \mathrm{p}$ peak towards lower binding energy verifies reduced $\mathrm{Mn}$ valence upon discharging (Figure 3.10f). The morphology and structure of MnS-EDO were examined after long-term GCD cycles.
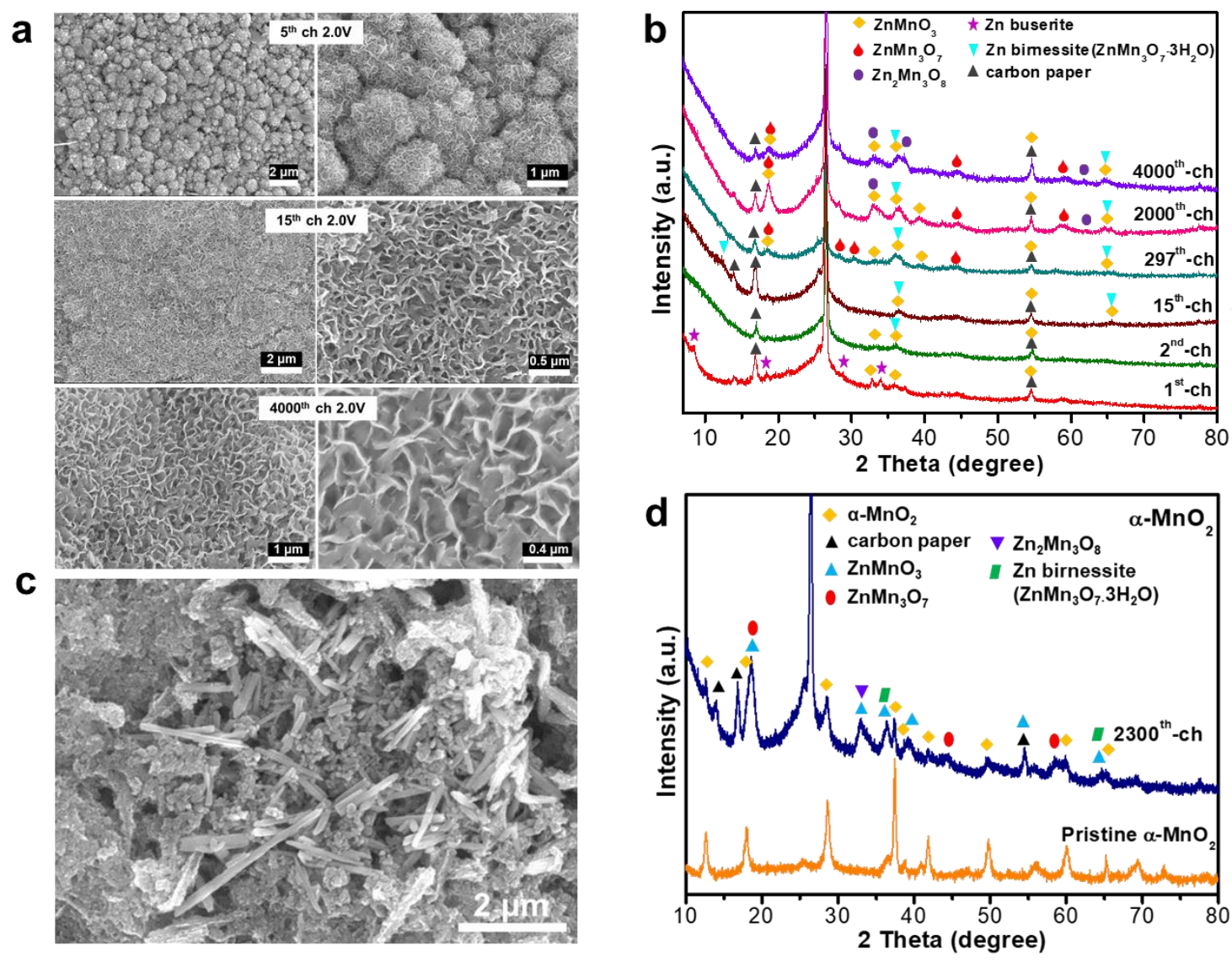

Figure 3. 11 (a) SEM and (b) XRD phase evolution of MnS-EDO cathode at fully charged states upon long-term cycling. (c) SEM images and (d) XRD pattern of $\mathrm{MnO}_{2}$ cathode at fully charged state $(2.0 \mathrm{~V})$ after 2300 cycles at $10 \mathrm{C}$.

The charged MnS-EDO after 5 and 15 cycles turns from agglomerated nanosheets to uniformly distributed nanosheets, the latter of which are conserved even after 4000 cycles (Figures 3.11a). Some new phases such as $\mathrm{ZnMn}_{3} \mathrm{O}_{7} \cdot 3 \mathrm{H}_{2} \mathrm{O}, \mathrm{ZnMn}_{3} \mathrm{O}_{7}$, and $\mathrm{Zn}_{2} \mathrm{Mn}_{3} \mathrm{O}_{8}$ are observed in the charged MnS-EDO upon long-term cycles (Figure 3.11b), which are likely produced by the reactions between ZHS and $\mathrm{Mn}^{2+}$ and intergrowth of multiple $\mathrm{Zn}-\mathrm{Mn}-\mathrm{O}$ composites [60]. It is tentatively 
hypothesized that the electrolyte species (e.g., $\mathrm{H}^{+}, \mathrm{OH}^{-}, \mathrm{Mn}^{2+}, \mathrm{Zn}^{2+}$ and $\mathrm{H}_{2} \mathrm{O}$ ) are involved in these complex reactions during the continuous charge and discharge cycles [60], in terms of formation of ZHS, phyllomanganates and $\mathrm{ZnMnO}_{3}$ phases and intergrowth of various intermediate $\mathrm{Zn}-\mathrm{Mn}$ $\mathrm{O}$ phases. The $\mathrm{Zn} / \mathrm{MnS}$-EDO battery chemistry demonstrates dynamic and complex reaction mechanisms upon long-term cycles, which will be systematically investigated by using the combination of the electrolyte composition analysis, in operando techniques, computation, phase and Pourbaix diagrams.

\subsubsection{Mechanistic discussion}

This work demonstrates an in situ electrochemical oxidation activation approach to converting intrinsically inactive $\mathrm{MnS}$ into high-performance MnS-EDO cathodes through oxidatively leaching sacrificial sulfide. The high capacity, remarkable rate capability and exceptional cyclability of MnS-EDO are attributed to the following factors. First, the desulfurization, microstructural reconstruction and amorphization during the electrochemical oxidation process will produce unusual metastable phyllomanganates and $\mathrm{ZnMnO}_{3}$ phases composed of turbostratic stacking of fragmented layers with abundant defects, edges, long-range disordering and vacancies as evidenced in previous studies [61, 63, 96-99], leading to significant XRD peak broadening and low crystallinity of charged MnS-EDO (Figure 3.7d). The HRTEM images (Figures 3.12a-b) demonstrate the ultrafine crystalline domains of cubic and hexagonal $\mathrm{ZnMnO}_{3}$ with different lattice orientation mixed in amorphous moieties in the fully charged MnS-EDO. Especially, cubic $\mathrm{ZnMnO}_{3}$ has been reported as an exotic defective cubic spinel with cationic vacancies [97-99]. Although metastable phyllomanganates are not visible in HRTEM as they are subject to decomposition upon high-energy electron irradiation, the aforementioned XRD and SEM results confirm their presence (Figures 3.4, 3.11a,b). Phyllomanganates containing $\mathrm{Zn}$ in the marine nodules have been verified to possess abundant vacancies, defects and incoherence (e.g., layer curling and stacking faults) [60-64].The STEM-HAADF and EDX mapping results clearly show the turbostratic stacking of curling layers with homogeneous Mn, Zn and O distribution (Figures 3.12c-f). The electron energy loss spectroscopy (EELS) results demonstrate the $\mathrm{Mn}_{2,3}$ and $\mathrm{O} \mathrm{K}$ edges of charged MnS-EDO and pristine $\mathrm{MnO}_{2}$ (Figures 3.12g,h). In contrast with bare $\mathrm{MnO}_{2}$, the shift of $\mathrm{Mn} \mathrm{L}_{2,3}$ towards lower energy loss, increased energy difference $\Delta \mathrm{E}\left(\mathrm{L}_{2}-\mathrm{L}_{3}\right)$ and intensity ratio of $\mathrm{L}_{3} / \mathrm{L}_{2}$ and suppressed $\mathrm{O} \mathrm{K}$ edge pre-peaks observed in MnS-EDO substantiate the presence 
of abundant vacancies in MnS-EDO (Table 3.3) [29, 53, 67]. The EPR spectra (Figure 3.12i) reveal the peak at $\mathrm{g}=2.013$ with hyperfine patterns in MnS-EDO indicating the existence of $\mathrm{Mn}$ vacancies [100-102], in sharp contrast with the smooth curve of $\mathrm{MnO}_{2}$. The defects of MnS-EDO are largely produced in the first charge, as there is only minor change in the STEM-HAADF EDX mapping and EELS spectrum of Mn L2,3 for MnS-EDO after 15 GCD cycles at charge state (Figures 3.13e-f). These defective features synergistically have positive effects on the following electrochemical and structural properties.
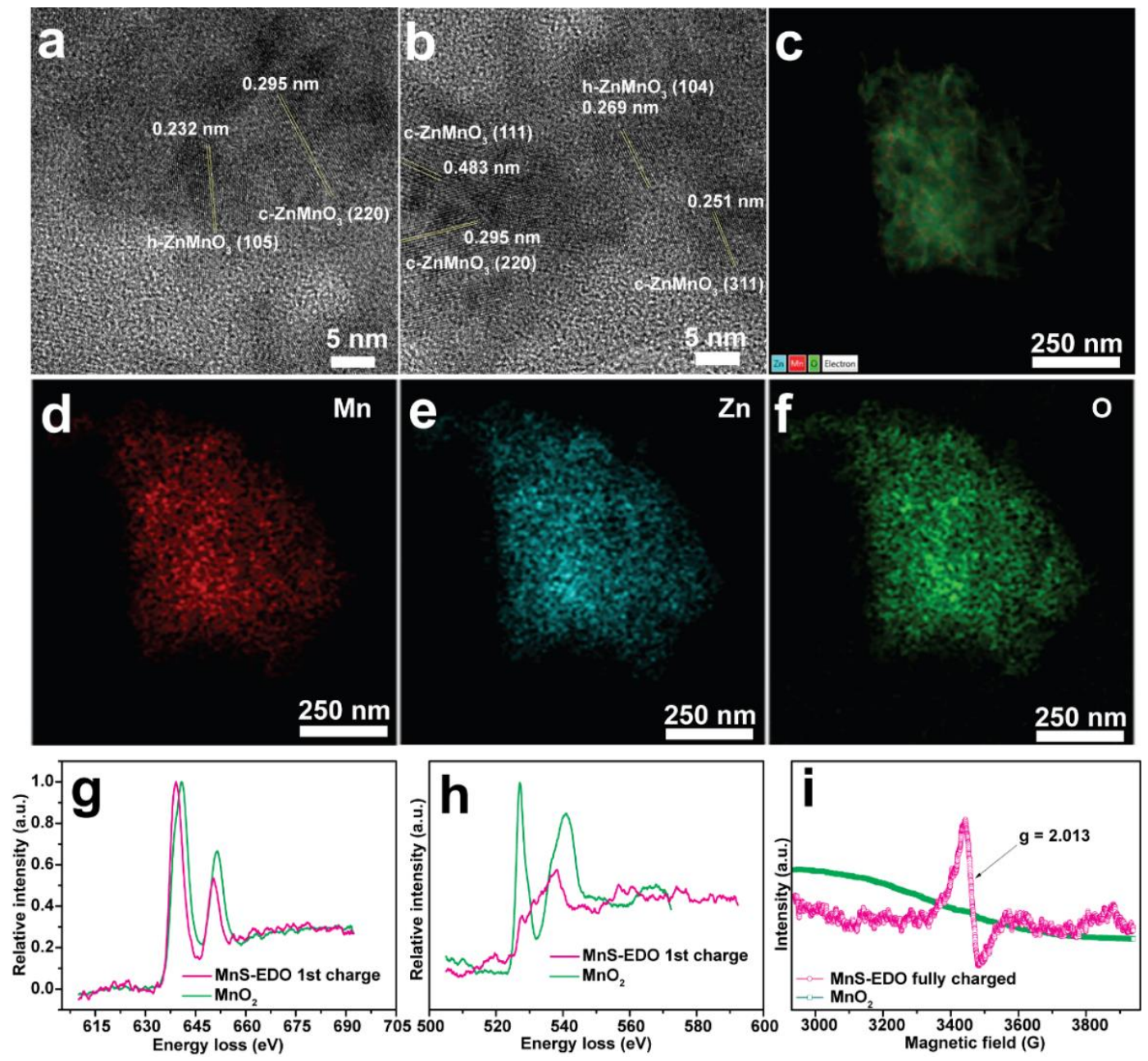

Figure 3. 12 (a) and (b) HRTEM images and (c) the superimposition image of HAADF-STEM and EDX mapping for MnS-EDO after $1^{\text {st }}$ charge with elemental maps of (d) Mn, (e) Zn and (f) O. EELS spectra of (g) Mn L2,3 edges and (h) O K-edges for MnS-EDO after $1^{\text {st }}$ charge and pristine $\mathrm{MnO}_{2}$. (i) EPR spectra of fully charged $\mathrm{MnS}-\mathrm{EDO}$ and pristine $\mathrm{MnO}_{2}$. 
Table 3. 3 Comparison of EELS spectra of $\mathrm{Mn} \mathrm{L}_{2,3}$ edges for $\mathrm{MnS}$-EDO after $1^{\text {st }}$ charge and pristine $\mathrm{MnO}_{2}$.

\begin{tabular}{lllllll}
\hline Material & $\begin{array}{l}\mathrm{E}\left(\mathrm{Mn}-\mathrm{L}_{3}\right) \\
(\mathrm{eV})\end{array}$ & $\begin{array}{l}\mathrm{E} \\
(\mathrm{eV})\end{array}$ & $\begin{array}{l}\left(\mathrm{Mn}-\mathrm{L}_{2}\right) \\
(\mathrm{eV})\end{array}$ & $\mathrm{I}\left(\mathrm{Mn}-\mathrm{L}_{3}\right)$ & $\mathrm{I}\left(\mathrm{Mn}-\mathrm{L}_{2}\right)$ & $\begin{array}{l}\mathrm{I}\left(\mathrm{Mn}-\mathrm{L}_{3}\right) \\
/ \mathrm{I}\left(\mathrm{Mn}-\mathrm{L}_{2}\right)\end{array}$ \\
\hline $\begin{array}{l}\mathrm{MnS}-\mathrm{EDO} \text { after } \\
1^{\text {st }} \text { charge }\end{array}$ & 639.175 & 650.325 & 11.15 & 1.0 & 0.53538 & 1.868 \\
\hline Pristine $\mathrm{MnO}_{2}$ & 640.775 & 651.475 & 10.70 & 1.0 & 0.66658 & 1.500 \\
\hline
\end{tabular}

Second, MnS-EDO exhibits larger ECSA and higher density of highly accessible exposed active sites (Figures 3.4 and 3.5a), in that there are numerous interconnected flakes, nanosheets, fragmented layers and lattice defects in MnS-EDO which can serve as active intercalation sites $[29,47,52-53,84,95]$. The abundant exposed active sites can facilitate infiltration of the electrolyte into the porous percolating structure of cathode, promote the ionic mass transfer, provide abundant electrode/electrolyte contact interfaces and hence result in high electrochemical reactivity and utilization of active Mn redox center [29, 56-59]. Third, MnS-EDO has a larger ionic diffusion coefficient for fast ion diffusion kinetics and accelerated charge transfer (Figures 3.5eg and 3.6d). The porous nanosheets and highly accessible active sites can shorten the diffusion pathway for ionic and electronic transport [56-58]. Meanwhile, the vacancies and defects can enhance the intrinsic ionic diffusion kinetics by providing open channels and microstructural voids, adjusting delocalized electron cloud state and weakening the electrostatic interactions between the guest ions and host framework [29, 47, 54-55]. Fourth, the interlayer Zn and Mn ions and crystal water pillar in the zinc phyllomanganates of MnS-EDO together with rich vacancies and defects may reduce the energy barrier of $\mathrm{Zn}^{2+}$ migration by lowering desolvation energy penalty at the cathode-electrolyte interface and shielding the electrostatic interaction between the intercalated $\mathrm{Zn}^{2+}$ and the host [15-16, 19], leading to its promoted charge transfer [88]. Last but not least, the 2D lamellar structure of nanosheets in MnS-EDO with low crystallinity is well maintained after long-term cycles (Figures 3.11a,b), indicating the extraordinary mechanical robustness. Steric effects such as local distortions in the nanosheets around vacancies can relieve electrochemical strains through slippage at domain boundaries during cycling $[52,103]$. The pre-pillared species, amorphous domains and layered nanostructure in the low-crystallinity MnS-EDO can provide interlayer elasticity, buffer volume changes and stabilize the electrode structure, benefiting the reversibility and cycling stability $[15,19,80]$. It is worth noting that it is still unclear why the 
thermodynamically metastable defective phases of $\mathrm{ZnMnO}_{3}$ and $\mathrm{Zn}$ phyllomanganates in $\mathrm{MnS}$ EDO are maintained after long-term redox cycles. Previous geochemical and mineralogical studies confirm that the existence of $\mathrm{Zn}^{2+}$ adsorbed on the surface at vacancy sites in $\mathrm{Zn}$ phyllomanganates can interrupt layer stacking along c axis (i.e., turbostratic stacking), repel interlayer Mn(III) rendering vacancy sites, curtail the transformation from defective layered to less-defective tunneled structures and thus stabilize the defective phyllomanganate phases against long-term electrochemical redox cycles in the neutral electrolyte [63-64, 104]. In contrast to the lamellar structure of nanosheets and defective phases in cycled MnS-EDO, crystalline tunnelled $\alpha-\mathrm{MnO}_{2}$ nanowires with higher structural order and few defects are still retained after long-term cycles (Figure 3.11c,d), although some agglomerations of layers and only a few defective phases are observed likely due to the similar electrochemical activation. The defective $\mathrm{Mn}_{0.61} \square_{0.39} \mathrm{O}$ was previously reported to be formed through the electrochemical oxidation induced Mn dissolution from $\mathrm{MnO}$ precursor [47]. In this study, the use of $\mathrm{MnS}$ (displacement of oxygen in $\mathrm{MnO} / \mathrm{MnO}_{2}$ with sulfur) seems more efficient to generate defective phases, as the desulfurization, microstructural reconstruction and amorphization during the in situ electrochemical oxidation/activation of $\mathrm{MnS}$ precursor produce low-crystallinity manganese oxide phases $\left(\mathrm{ZnMnO}_{3}\right.$ and $\mathrm{Zn}$ phyllomanganates) with a higher density of defects. Furthermore, the purposely fabricated cation and oxygen vancancies in various reported $\mathrm{MnO}_{\mathrm{x}}$ cathodes for $\mathrm{ZIBs}$ have been found to enhance the capacities and cycling stability up to thousands of cycles, although it has been not explicitly identified whether those vacancies are perserved after long-term cycles [29, 47, $52-55,74,76]$. This warrants future investigation on the mechanistic understanding. To confirm the positive effects of in situ generated defects of MnS-EDO on the electrochemical performance for ZIB, MnS precursor was also charged in $\mathrm{KOH}$. The EELS spectra manifest that the MnS-EDO charged in $\mathrm{KOH}$ contains fewer vacancies (Figure 3.13f). The resulting MnS-EDO consists of interconnected nanosheets of highly crystalline $\mathrm{K}^{+}$-inserted $\delta-\mathrm{MnO}_{2}$ with higher ordering and fewer defects and delivers lower capacity and poor cycling stability (Figure 3.13a,d), suggesting the crucial role of defects in enhancing the electrochemical reactivity and stability. 

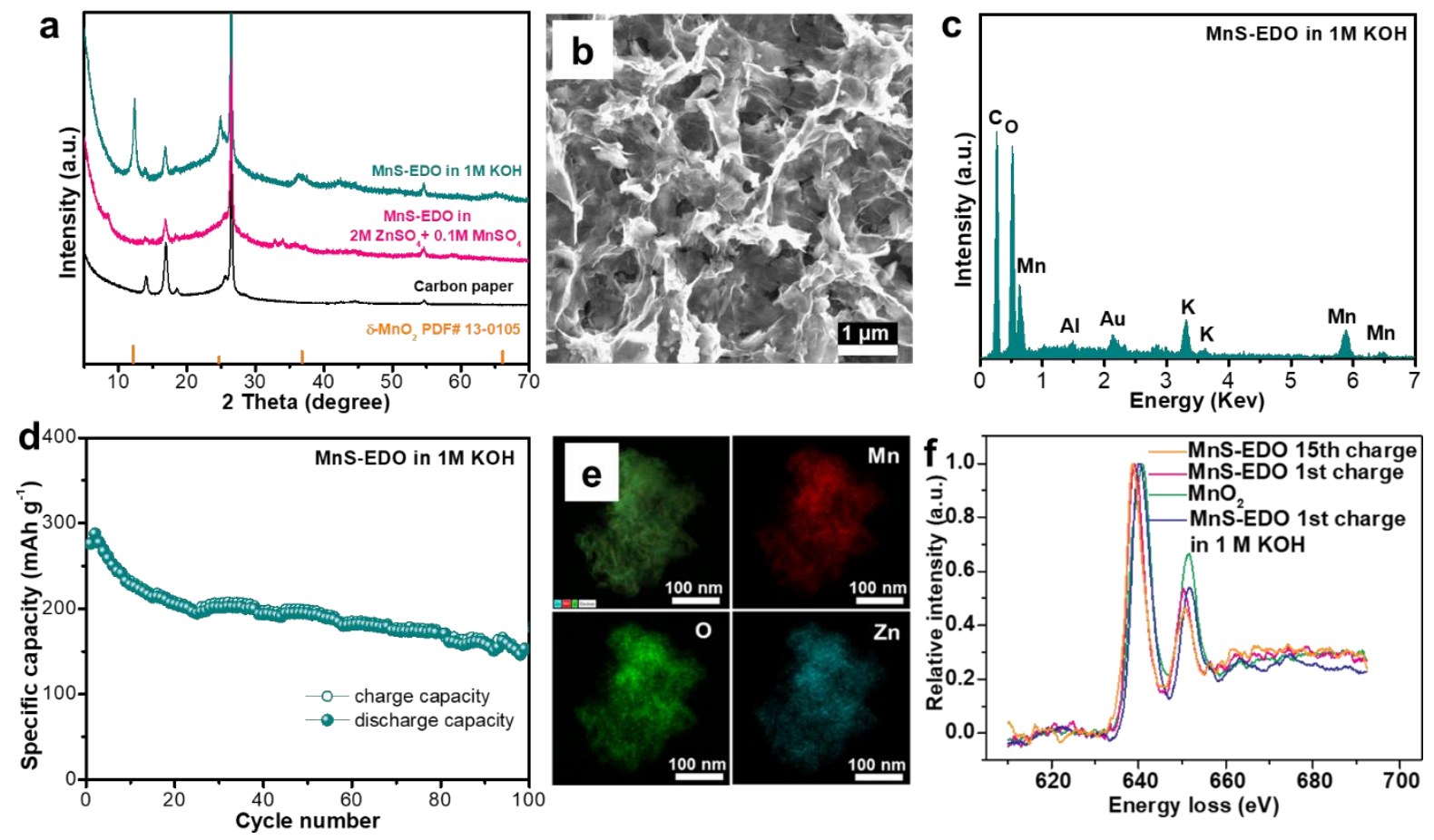

Figure 3. 13 (a) XRD pattern of MnS-EDO after $1^{\text {st }}$ electrochemical charge in $1 \mathrm{M} \mathrm{KOH}$ solution in comparison with that of MnS-EDO after $1^{\text {st }}$ electrochemical charge in the electrolyte of $2 \mathrm{M}$ $\mathrm{ZnSO}_{4}$ and $0.1 \mathrm{M} \mathrm{MnSO}_{4}$. (b) SEM image and (c) EDX spectrum of MnS-EDO after $1^{\text {st }}$ electrochemical charge in $1 \mathrm{M} \mathrm{KOH}$ solution. (d) Cycling performance of MnS-EDO charged in $1 \mathrm{M} \mathrm{KOH}$ for the ZIB at $1 \mathrm{C}$ consisting of the $\mathrm{Zn}$ anode, new cathode and electrolyte of $2 \mathrm{M} \mathrm{ZnSO}_{4}$ and $0.1 \mathrm{M} \mathrm{MnSO}_{4}$. (e) The image of HAADF-STEM and EDX mapping for MnS-EDO after 15 GCD cycles at the charge state with elemental maps of Mn, Zn and O. (f) EELS spectra of Mn $\mathrm{L}_{2,3}$ edges for MnS-EDO after 1 and $15 \mathrm{GCD}$ cycles at the charge state in coin cells with $2 \mathrm{M} \mathrm{ZnSO}_{4}$ and $0.1 \mathrm{M} \mathrm{MnSO}_{4}$ electrolyte or after $1^{\text {st }}$ charge in $1 \mathrm{M} \mathrm{KOH}$ solution and pristine $\mathrm{MnO}_{2}$.

\subsection{Conclusion}

In conclusion, this work reports an in situ electrochemical activation approach to oxidizing $\mathrm{MnS}$ into highly active MnS-EDO, which unlocks its potential as a high-performance cathode for ZIBs. The activated MnS-EDO cathode contains turbostratic stacking of fragmented layers with abundant defects and long-range disordering induced by the electrochemical oxidation and leaching of sacrificial sulfide and thus demonstrates large ECSA, high electrochemical reactivity, 
fast ion diffusion kinetics, small charge transfer resistance and exceptional cycling stability. The MnS-EDO cathode exhibits a high specific capacity of $335.7 \mathrm{mAh} \mathrm{g}^{-1}$ with nearly $100 \%$ capacity retention after 100 cycles at $1 \mathrm{C}$, and outstanding rate capability and long-term stability for 4000 cycles at $10 \mathrm{C}$. The underlying electrochemical insights are systematically anatomized. Various reported charge storage mechanisms are summarized and a unique hybrid discharge mechanism is proposed involving homogenous $\mathrm{Zn}^{2+}$ intercalation at $\sim 1.4 \mathrm{~V}$ and subsequent heterogeneous reactions of insertion of both $\mathrm{H}^{+}$and $\mathrm{Zn}^{2+}$ at $\sim 1.25 \mathrm{~V}$ for MnS-EDO. The ambiguities among $\mathrm{Zn}$ buserite, birnessite and ZHS are clarified. This work opens up a new paradigm for simple, scalable and low-cost fabrication of highly active and stable zinc manganese oxide cathodes and sheds light on mechanistic understanding of manganese oxide -based cathodes for ZIBs. There are still challenges to precisely resolve the crystallographic structures of turbostratic phyllomanganates in the cathodes and dynamic structure changes due to their long-range disordering and complex polymorph diversity. To address those challenges, the future investigations may gain inspiration from knowledge of mineralogy and geochemistry [62-64, 104].

\section{References}

[1] T.M. Gür, Energy Environ. Sci. 11 (2018) 2696-2767.

[2] W. Li, N. Jiang, B. Hu, X. Liu, F. Song, G. Han, T.J. Jordan, T.B. Hanson, T.L. Liu, Y. Sun, Chem 4 (2018) 637-649.

[3] W. Li, X. Gao, D. Xiong, F. Wei, W.-G. Song, J. Xu, L. Liu, Adv. Energy Mater. 7 (2017) 1602579.

[4] H. Jia, Z. Wang, B. Tawiah, Y. Wang, C.-Y. Chan, B. Fei, F. Pan, Nano Energy 70 (2020) 104523.

[5] L. Hu, F. Wang, M.S. Balogun, Y. Tong, J. Mater. Sci. Technol. (2019)

[6] J. Zhang, C. Zhang, W. Li, Q. Guo, H. Gao, Y. You, Y. Li, Z. Cui, K.-C. Jiang, H. Long, D. Zhang, S. Xin, ACS Appl. Mater. Interfaces 10 (2018) 5543-5550.

[7] Z. Zeng, W. Li, Q. Wang, X. Liu, Adv. Sci. 6 (2019) 1900711.

[8] W. Li, Y.-X. Yin, S. Xin, W.-G. Song, Y.-G. Guo, Energy Environ. Sci. 5 (2012) 8007-8013.

[9] X. Li, G. Wu, X. Liu, W. Li, M. Li, Nano Energy 31 (2017) 1-8.

[10] S. Song, W. Li, Y.-P. Deng, Y. Ruan, Y. Zhang, X. Qin, Z. Chen, Nano Energy 67 (2020) 104208. 
[11] H. Li, L. Ma, C. Han, Z. Wang, Z. Liu, Z. Tang, C. Zhi, Nano Energy 62 (2019) 550-587.

[12] G. Fang, J. Zhou, A. Pan, S. Liang, ACS Energy Lett. 3 (2018) 2480-2501.

[13] M. Song, H. Tan, D. Chao, H.J. Fan, Adv. Funct. Mater. 28 (2018) 1802564.

[14] Y. Li, J. Fu, C. Zhong, T. Wu, Z. Chen, W. Hu, K. Amine, J. Lu, Adv. Energy Mater. 9 (2019) 1802605.

[15] K. W. Nam, H. Kim, J. H. Choi, J. W. Choi, Energy Environ. Sci. 12 (2019) 1999-2009.

[16] D. Kundu, S. Hosseini Vajargah, L. Wan, B. Adams, D. Prendergast, L. F. Nazar, Energy Environ. Sci. 11 (2018) 881-892.

[17] B. Tang, L. Shan, S. Liang, J. Zhou, Energy Environ. Sci. 12 (2019) 3288-3304.

[18] L. Zhang, L. Chen, X. Zhou, Z. Liu, Adv. Energy Mater. 5 (2015) 1400930.

[19] D. Kundu, B. D. Adams, V. Duffort, S. H. Vajargah, L. F. Nazar, Nat. Energy 1 (2016) 16119.

[20] P. He, M. Yan, G. Zhang, R. Sun, L. Chen, Q. An, L. Mai, Adv. Energy Mater. 7 (2017) 1601920.

[21] F. Wang, E. Hu, W. Sun, T. Gao, X. Ji, X. Fan, F. Han, X.-Q. Yang, K. Xu, C. Wang, Energy Environ. Sci. 11 (2018) 3168-3175.

[22] Y. Yang, Y. Tang, S. Liang, Z. Wu, G. Fang, X. Cao, C. Wang, T. Lin, A. Pan, J. Zhou, Nano Energy 61 (2019) 617-625.

[23] Y. Li, Z. Huang, P. K. Kalambate, Y. Zhong, Z. Huang, M. Xie, Y. Shen, Y. Huang, Nano Energy 60 (2019) 752-759.

[24] B. Tang, G. Fang, J. Zhou, L. Wang, Y. Lei, C. Wang, T. Lin, Y. Tang, S. Liang, Nano Energy 51 (2018) 579-587.

[25] H. Pan, Y. Shao, P. Yan, Y. Cheng, K. S. Han, Z. Nie, C. Wang, J. Yang, X. Li, P. Bhattacharya, K. T. Mueller, J. Liu, Nat. Energy 1 (2016) 16039.

[26] B. Wu, G. Zhang, M. Yan, T. Xiong, P. He, L. He, X. Xu, L. Mai, Small 14 (2018) 1703850.

[27] N. Zhang, F. Cheng, J. Liu, L. Wang, X. Long, X. Liu, F. Li, J. Chen, Nat. Commun. 8 (2017) 405.

[28] J. Lee, J. B. Ju, W. I. Cho, B. W. Cho, S. H. Oh, Electrochim. Acta 112 (2013) 138-143.

[29] T. Xiong, Z. G. Yu, H. Wu, Y. Du, Q. Xie, J. Chen, Y.-W. Zhang, S. J. Pennycook, W. S. V. Lee, J. Xue, Adv. Energy Mater. 9 (2019) 1803815.

[30] Q. Zhao, W. Huang, Z. Luo, L. Liu, Y. Lu, Y. Li, L. Li, J. Hu, H. Ma, J. Chen, Sci. Adv. 4 (2018) eaao1761. 
[31] W. Liu, J. Hao, C. Xu, J. Mou, L. Dong, F. Jiang, Z. Kang, J. Wu, B. Jiang, F. Kang, Chem. Commun. 53 (2017) 6872-6874.

[32] L. Ma, S. Chen, H. Li, Z. Ruan, Z. Tang, Z. Liu, Z. Wang, Y. Huang, Z. Pei, J. A. Zapien, C. Zhi, Energy Environ. Sci. 11 (2018) 2521-2530.

[33] D. Wang, Y. Zhao, G. Liang, F. Mo, H. Li, Z. Huang, X. Li, T. Tang, B. Dong, C. Zhi, Nano Energy 71 (2020) 104583.

[34] K. Zhang, X. Han, Z. Hu, X. Zhang, Z. Tao, J. Chen, Chem. Soc. Rev. 44 (2015) 699-728.

[35] N. D. Ingale, J. W. Gallaway, M. Nyce, A. Couzis, S. Banerjee, J. Power Sources 276 (2015) 7-18.

[36] G. G. Yadav, X. Wei, J. W. Gallaway, Z. Chaudhry, A. Shin, J. Huang, R. Yakobov, M. Nyce, N. Vanderklaauw, S. Banerjee, Mater. Today Energy 6 (2017) 198-210.

[37] T. Yamamoto, T. Shoji, Inorg. Chim. Acta 117 (1986) L27-L28.

[38] T. Shoji, M. Hishinuma, T. Yamamoto, J. Appl. Electrochem. 18 (1988) 521-526.

[39] T. Shoji, T. Yamamoto, J. Electroanal. Chem. 362 (1993) 153-157.

[40] S. H. Kim, S. M. Oh, J. Power Sources 72 (1998) 150-158.

[41] C. Xu, B. Li, H. Du, F. Kang, Angew. Chem. Int. Ed. 51 (2012) 933-935.

[42] M. H. Alfaruqi, V. Mathew, J. Gim, S. Kim, J. Song, J. P. Baboo, S. H. Choi, J. Kim, Chem. Mater. 27 (2015) 3609-3620.

[43] B. Lee, C. S. Yoon, H. R. Lee, K. Y. Chung, B. W. Cho, S. H. Oh, Sci. Rep. 4 (2014) 6066.

[44] B. Lee, H. R. Lee, H. Kim, K. Y. Chung, B. W. Cho, S. H. Oh, Chem. Commun. 51 (2015) 9265-9268.

[45] B. Lee, H. R. Seo, H. R. Lee, C. S. Yoon, J. H. Kim, K. Y. Chung, B. W. Cho, S. H. Oh, ChemSusChem 9 (2016) 2948-2956.

[46] B. Jiang, C. Xu, C. Wu, L. Dong, J. Li, F. Kang, Electrochim. Acta 229 (2017) 422-428.

[47] C. Zhu, G. Fang, S. Liang, Z. Chen, Z. Wang, J. Ma, H. Wang, B. Tang, X. Zheng, J. Zhou, Energy Storage Mater. 24 (2020) 394-401.

[48] J. Huang, Z. Wang, M. Hou, X. Dong, Y. Liu, Y. Wang, Y. Xia, Nat. Commun. 9 (2018) 2906.

[49] Y. Zeng, X. Zhang, Y. Meng, M. Yu, J. Yi, Y. Wu, X. Lu, Y. Tong, Adv. Mater. 29 (2017) 1700274. 
[50] Y. Fu, Q. Wei, G. Zhang, X. Wang, J. Zhang, Y. Hu, D. Wang, L. Zuin, T. Zhou, Y. Wu, S. Sun, Adv. Energy Mater. 8 (2018) 1801445.

[51] W. Sun, F. Wang, S. Hou, C. Yang, X. Fan, Z. Ma, T. Gao, F. Han, R. Hu, M. Zhu, C. Wang, J. Am. Chem. Soc. 139 (2017) 9775-9778.

[52] N. Zhang, F. Cheng, Y. Liu, Q. Zhao, K. Lei, C. Chen, X. Liu, J. Chen, J. Am. Chem. Soc. 138 (2016) 12894-12901.

[53] S. Lian, C. Sun, W. Xu, W. Huo, Y. Luo, K. Zhao, G. Yao, W. Xu, Y. Zhang, Z. Li, K. Yu, H. Zhao, H. Cheng, J. Zhang, L. Mai, Nano Energy 62 (2019) 79-84.

[54] H. Zhang, J. Wang, Q. Liu, W. He, Z. Lai, X. Zhang, M. Yu, Y. Tong, X. Lu, Energy Storage Mater. 21 (2019) 154-161.

[55] G. Fang, C. Zhu, M. Chen, J. Zhou, B. Tang, X. Cao, X. Zheng, A. Pan, S. Liang, Adv. Funct. Mater. 29 (2019) 1808375.

[56] Y. Huang, H. Yang, T. Xiong, D. Adekoya, W. Qiu, Z. Wang, S. Zhang, M. S. Balogun, Energy Storage Mater. 25 (2020) 41-51.

[57] L. Hu, Y. Gao, T. Xiong, D. Adekoya, W. Qiu, H. Yang, M. S. Balogun, S. Zhang, A. Pan, Y. Li, Y. Tong, Nanoscale Horiz. 4 (2019) 1402-1410.

[58] D. Adekoya, H. Chen, H. Y. Hoh, T. Gould, M. S. J. T. Balogun, C. Lai, H. Zhao, S. Zhang, ACS Nano (2020) doi: 10.1021/acsnano.0c01395.

[59] Y. Li, S. Wang, J. R. Salvador, J. Wu, B. Liu, W. Yang, J. Yang, W. Zhang, J. Liu, J. Yang, Chem. Mater. 31 (2019) 2036-2047.

[60] Y. Huang, J. Mou, W. Liu, X. Wang, L. Dong, F. Kang, C. Xu, Nano-Micro Lett. 11 (2019) 49.

[61] K. L. Holland, J. R. Walker, Clays Clay Miner. 44 (1996) 744-748.

[62] H. S. Choi, S. J. Kim, J. J. Kim, Geosci. J. 8 (2004) 273-279.

[63] S. Zhao, Q. Wang, J. Sun, O. J. Borkiewicz, R. Huang, E. M. Saad, B. Fields, S. Chen, M. Zhu, Y. Tang, Chem. Geol. 493 (2018) 234-245.

[64] S. Grangeon, A. Manceau, J. Guilhermet, A.-C. Gaillot, M. Lanson, B. Lanson, Geochim. Cosmochim. Acta 85 (2012) 302-313.

[65] P. Oberholzer, E. Tervoort, A. Bouzid, A. Pasquarello, D. Kundu, ACS Appl. Mater. Interfaces 11 (2019) 674-682.

[66] A. Moezzi, M. B. Cortie, A. M. McDonagh, Dalton Trans. 42 (2013) 14432-14437. 
[67] M. Chamoun, W. R. Brant, C.-W. Tai, G. Karlsson, D. Noréus, Energy Storage Mater. 15 (2018) 351-360.

[68] S. Zhao, B. Han, D. Zhang, Q. Huang, L. Xiao, L. Chen, D. G. Ivey, Y. Deng, W. Wei, J. Mater. Chem. A 6 (2018) 5733-5739.

[69] Y. Zhu, Y. Matsumura, M. Velayutham, L. M. Foley, T. K. Hitchens, W. R. Wagner, Biomaterials 177 (2018) 98-112.

[70] M. Li, Q. He, Z. Li, Q. Li, Y. Zhang, J. Meng, X. Liu, S. Li, B. Wu, L. Chen, Z. Liu, W. Luo, C. Han, L. Mai, Adv. Energy Mater. 9 (2019) 1901469.

[71] D. Chao, W. Zhou, C. Ye, Q. Zhang, Y. Chen, L. Gu, K. Davey, S.-Z. Qiao, Angew. Chem. Int. Ed. 58 (2019) 7823-7828.

[72] W. Li, D. Xiong, X. Gao, L. Liu, Chem. Commun. 55 (2019) 8744-8763.

[73] G. K. Schweitzer, L. L. Pesterfield, The aqueous chemistry of the elements. Oxford University Press: 2010.

[74] W. Chen, H. Wang, Y. Li, Y. Liu, J. Sun, S. Lee, J.-S. Lee, Y. Cui, ACS Cent. Sci. 1 (2015) 244-251.

[75] O. Mabayoje, A. Shoola, B. R. Wygant, C. B. Mullins, ACS Energy Lett. 1 (2016) 195-201.

[76] W. Chen, Y. Liu, Y. Li, J. Sun, Y. Qiu, C. Liu, G. Zhou, Y. Cui, Nano Lett. 16 (2016) 75887596.

[77] D.-H. Liu, W.-H. Li, Y.-P. Zheng, Z. Cui, X. Yan, D.-S. Liu, J. Wang, Y. Zhang, H.-Y. Lü, F.-Y. Bai, J.-Z. Guo, X.-L. Wu, Adv. Mater. 30 (2018) 1706317.

[78] M. Chigane, M. Ishikawa, J. Electrochem. Soc. 147 (2000) 2246-2251.

[79] Y. Jin, L. Zou, L. Liu, M. H. Engelhard, R. L. Patel, Z. Nie, K. S. Han, Y. Shao, C. Wang, J. Zhu, H. Pan, J. Liu, Adv. Mater. 31 (2019) 1900567.

[80] J. Wang, J.-G. Wang, H. Liu, C. Wei, F. Kang, J. Mater. Chem. A 7 (2019) 13727-13735.

[81] P. Balaya, Energy Environ. Sci. 1 (2008) 645-654.

[82] Y. Wang, H. Li, P. He, E. Hosono, H. Zhou, Nanoscale 2 (2010) 1294-1305.

[83] P. Roy, S. K. Srivastava, J. Mater. Chem. A 3 (2015) 2454-2484.

[84] Y. Yoon, B. Yan, Y. Surendranath, J. Am. Chem. Soc. 140 (2018) 2397-2400.

[85] F. Song, W. Li, J. Yang, G. Han, T. Yan, X. Liu, Y. Rao, P. Liao, Z. Cao, Y. Sun, ACS Energy Lett. 4 (2019) 1594-1601.

[86] F. Song, W. Li, J. Yang, G. Han, P. Liao, Y. Sun, Nat. Commun. 9 (2018) 4531. 
[87] H. Ren, J. Zhao, L. Yang, Q. Liang, S. Madhavi, Q. Yan, Nano Res. 12 (2019) 1347-1353.

[88] R. Tatara, P. Karayaylali, Y. Yu, Y. Zhang, L. Giordano, F. Maglia, R. Jung, J. P. Schmidt, I. Lund, Y. Shao-Horn, J. Electrochem. Soc. 166 (2019) A5090-A5098.

[89] A. Kozawa, J. F. Yeager, J. Electrochem. Soc. 112 (1965) 959-963.

[90] A. Kozawa, R. A. Powers, J. Electrochem. Soc. 113 (1966) 870-878.

[91] A. Kozawa, J. F. Yeager, J. Electrochem. Soc. 115 (1968) 1003-1007.

[92] K. J. Vetter, J. Electrochem. Soc. 110 (1963) 597-605.

[93] R. Patrice, B. Gérand, J. B. Leriche, L. Seguin, E. Wang, R. Moses, K. Brandt, J. M. Tarascon, J. Electrochem. Soc. 148 (2001) A448-A455.

[94] A. M. Kannan, S. Bhavaraju, F. Prado, M. M. Raja, A. Manthiram, J. Electrochem. Soc. 149 (2002) A483-A492.

[95] J. C. Knight, S. Therese, A. Manthiram, J. Mater. Chem. A 3 (2015) 21077-21082.

[96] P. G. Perret, P. R. L. Malenfant, C. Bock, B. MacDougall, J. Electrochem. Soc. 159 (2012) A1554-A1561.

[97] J. D. Rall, S. Thota, J. Kumar, M. S. Seehra, Appl. Phys. Lett. 100 (2012) 252407.

[98] A. Minelli, P. Dolcet, S. Diodati, S. Gardonio, C. Innocenti, D. Badocco, S. Gialanella, P. Pastore, L. Pandolfo, A. Caneschi, A. Trapananti, S. Gross, J. Mater. Chem. C 5 (2017) 3359-3371. [99] J. Jaćimović, Z. Micković, R. Gaál, R. Smajda, C. Vâju, A. Sienkiewicz, L. Forró, A. Magrez, Solid State Commun. 151 (2011) 487-490.

[100] D. M. Marinova, R. R. Kukeva, E. N. Zhecheva, R. K. Stoyanova, Phys. Chem. Chem. Phys. 20 (2018) 12755-12766.

[101] C. Li, X. Hu, W. Tong, W. Yan, X. Lou, M. Shen, B. Hu, ACS Appl. Mater. Interfaces 9 (2017) 29829-29838.

[102] B. Song, M. Tang, E. Hu, O. J. Borkiewicz, K. M. Wiaderek, Y. Zhang, N. D. Phillip, X. Liu, Z. Shadike, C. Li, L. Song, Y.-Y. Hu, M. Chi, G. M. Veith, X.-Q. Yang, J. Liu, J. Nanda, K. Page, A. Huq, Chem. Mater. 31 (2019) 3756-3765.

[103] P. Gao, P. Metz, T. Hey, Y. Gong, D. Liu, D. D. Edwards, J. Y. Howe, R. Huang, S. T. Misture, Nat. Commun. 8 (2017) 14559.

[104] H. Jung, M. Taillefert, J. Sun, Q. Wang, O. J. Borkiewicz, P. Liu, L. Yang, S. Chen, H. Chen, Y. Tang, J. Am. Chem. Soc. 142 (2020) 2506-2513. 


\section{Chapter 4: Engineering Stable $\mathrm{Zn}-\mathrm{MnO}_{2}$ Batteries by Synergistic Stabilization Between the Carbon Nanofiber Core and Birnessite- $\mathrm{MnO}_{2}$ Nanosheets Shell}

\subsection{Introduction}

Mn-based cathodes still suffered from inferior cyclability, rapid capacity decay and poor rate capability for grid-scale energy storage. The commonly used tunnelled-type $\mathrm{MnO} 2$ generally undergoes complex crystallographic transformation to layered phase upon cycling accompanied with structure collapse and volumetric variation, thus leading to severe pulverization and capacity loss. [1-3] Therefore, $\delta-\mathrm{MnO}_{2}$, which intrinsically possesses layered frameworks, is particularly advantageous as a stable host candidate for ions intercalation with minimal "sacrificial capacity" caused by phase variation. [4-6] Nevertheless, the efficient utilization of inherent $\mathrm{MnO} 2$ capacity is far from expectation due to the self-aggregation of active materials. Moreover, the intrinsically low electrical conductivity of manganese oxides restrains fast electron transport, giving rise to the sluggish kinetics, poor rate capability and cycling stability, especially at high charge/discharge depth. [7-9]

To address these issues, integrating nanosized manganese oxides with highly conductive substrate matrices is especially demonstrated capable of inhibiting capacity decay and enhancing rate and cycling capability. As mentioned in the chapter 1, several strategies have been devoted to fabricating manganese oxides with a variety of conductive substrates for ZIBs. In particular, carbonaceous materials are promising conductive matrices due to their low cost, high electrical conductivity, highly accessible structures, and relatively robust electrochemical resistibility to mild electrolytes. However, the incorporation of $\mathrm{MnO}_{2}$ into substrates such as carbon nanotubes, nanofibers and graphite is usually carried out using time-consuming, expensive and complex fabrication processes. Especially, direct immobilization of manganese oxides onto common carbon substrates is plagued by their inherent hydrophobic surfaces. Consequently, pre-treatment of hydrophobic carbon using harsh oxidizing agents and acids (e.g. nitric acid, sulfuric acid, hydrogen peroxide, and hydrofluoric acid) under heating or plasma is essential to endow the carbon substrates with sufficient hydrophilicity towards aqueous ions and solutions for inducing growth 
of active manganese oxides.[10-12] These expensive, tedious and complicated procedures, harsh experimental conditions and potentials hazards of using strong acids and oxidants are a formidable obstacle to implement mass production of $\mathrm{MnO}_{2} /$ carbon composite cathodes. Therefore, it is highly desired to develop a facile and cost-effective way to realize the scalable production and application of Mn-based materials.

One-dimensional (1D) carbon nanofibers (CNFs) can provide efficient electron pathway and flexibility to alleviate the strain of volume variation, $[13,14]$ while thin $\delta-\mathrm{MnO}_{2}$ nanosheets may expose large electrochemically active surface areas. Given the complementary features of both components, a synergistic effect is envisioned on their combination. In this work, hierarchical core-shell structure of carbon nanofiber@ $\mathrm{MnO}_{2}\left(\mathrm{CNF} @ \mathrm{MnO}_{2}\right)$ was prepared via a simple, lowcost and scalable method combining the solid-grinding and wet-chemical reaction. Vertically aligned birnessite- $\mathrm{MnO}_{2}$ nanosheets were in situ grown on the surface of carbon nanofibers. The straightforward fabrication process and hierarchical core-shell $\mathrm{CNF}_{\mathrm{NnO}} \mathrm{Mn}_{2}$ structure design demonstrate several merits as follows. i) The surface reactivity of commercial CNFs can be readily improved for inducing the nucleation by grinding the mixture of $\mathrm{CNFs}$ and $\mathrm{KMnO}_{4}$ without additional acid pre-treatment, and then $\mathrm{MnO}_{2}$ nanosheets are in situ grown via a low-temperature and fast wet-chemical reaction. This one-pot approach offers a promising way to achieve the mass manufacturing of cathode materials for ZIBs. ii) The conductive CNFs enable fast electron transport to thin $\mathrm{MnO}_{2}$ nanosheets, boosting the charge transfer kinetics. iii) The vertically aligned ultrathin nanosheets structure of $\mathrm{MnO}_{2}$ sheath greatly enhances the contact area at electrode/electrolyte interfaces, shortens the ion diffusion paths for fast diffusion kinetics and thus promotes the overall utilization of active Mn centres and rate capability. iv) The interconnected hierarchical core-shell architecture with intimate contact between $\mathrm{CNFs}$ and $\mathrm{MnO}_{2}$ nanosheets can maintain the conductive network with minimized volume variation. The activated 1D CNFs serve as a core backbone and endow the entire skeleton with flexibility to accommodate the strain and layered $\mathrm{MnO}_{2}$ reduces structural collapse upon cycling, contributing to collaborative stability. The affinity between $\mathrm{MnO}_{2}$ nanosheets and CNFs restricts the aggregation and pulverization during repeated discharge and charge cycles.

\subsection{Materials and methods}


Synthesis of $\mathbf{C N F @ M n O}$ and pure $\delta$ - $\mathrm{MnO}_{2}$. Potassium permanganate $(\geq 99.0 \%$, SigmaAldrich), zinc sulfate hepahydrate ( $\geq 99.0 \%$, Alfa Aesar), manganese sulfate monohydrate $(99.0 \%$, Alfa Aesar), carbon nanofibers (Alfa Aesar) and hydrochloric acid solution (36.5-38.0 wt.\%, Alfa Aesar) were used as received without any further purification.

The CNF@ $\mathrm{MnO}_{2}$ composite was prepared via a facile and scalable wet-chemical reaction. Typically, $100 \mathrm{mg}$ of CNFs and given amount of $\mathrm{KMnO}_{4}$ were ground together in an agate mortar for around $20 \mathrm{~min}$. The mixed powder was added into $100 \mathrm{~mL}$ of deionized water and stirred until it was well dispersed. Then $0.5 \mathrm{~mL}$ of concentrated $\mathrm{H}_{2} \mathrm{SO}_{4}$ (98\%) was dropped into the above suspension with continuous stirring for $30 \mathrm{~min}$. Subsequently, the mixed solution was heated in an oil bath at $80{ }^{\circ} \mathrm{C}$ with stirring for $2 \mathrm{~h}$. After cooling to room temperature, the resulting precipitates were centrifuged and washed with deionized (DI) water and ethanol for several times followed by vacuum drying at $60^{\circ} \mathrm{C}$ for $12 \mathrm{~h}$. The obtained products were denoted as MOC-2, 5, 10, 15 and 20 based on the feeding weight ratio of $\mathrm{KMnO}_{4} / \mathrm{CNF}$ correspondingly. This synthetic method can readily offer a high yield (grams) of the product in one pot by increasing the amounts of precursors and using mechanical milling for scalable production. For comparison, a control sample of $\mathrm{MnO}_{2} / \mathrm{CNF}$ was prepared by a similar procedure described above without grinding $\mathrm{CNF}$ and $\mathrm{KMnO}_{4}$ together.

The pure $\delta-\mathrm{MnO}_{2}(\mathrm{MO})$ was synthesized by a hydrothermal method. Typically, $5.0 \mathrm{mmol}$ $\mathrm{KMnO}_{4}$ was added in $70 \mathrm{~mL}$ of deionized water with stirring until it was completely dissolved. Then, $1.75 \mathrm{~mL}$ of $\mathrm{HCl}(37 \%)$ was dropped into the above solution and continuously stirred for 30 min at room temperature. After that, the mixture solution was transferred into a $100 \mathrm{~mL}$ Teflonlined stainless-steel autoclave and heated at $100{ }^{\circ} \mathrm{C}$ for $6 \mathrm{~h}$. The resulting precipitates were collected by centrifugation and washed with DI water and ethanol, and then the MO sample was obtained after drying the solid products at $60^{\circ} \mathrm{C}$ for $12 \mathrm{~h}$.

Material characterization. The morphology and composition of materials were characterized using a scanning electron microscope (SEM, Hitachi S-4700) equipped with an energy dispersive $\mathrm{X}$-ray (EDX) spectroscopy. Transmission electron microscopy (TEM) and high-resolution TEM (HRTEM) were performed on a JEOL JEM-2100F microscope to further analyse the crystal and lattice structure. The phase structures of samples were characterized by the X-ray diffraction (XRD, PANalytical X'Pert Pro X-ray diffractometer) with $\mathrm{Cu} \mathrm{K \alpha}$ radiation at $45 \mathrm{kV}$ and $40 \mathrm{~mA}$, and 
Raman spectroscopy (Renishaw InVia, excited by $532 \mathrm{~nm}$ laser). The XRD patterns were indexed according to the Joint Committee on Powder Diffraction Standards (JCPDS) Powder Diffraction File (PDF) database. The surface chemical states were characterized by the X-ray photoelectron spectroscopy (XPS) using a Physical Electronics PHI 5000 Versa Probe spectrometer equipped with a monochromatic $\mathrm{Al} \mathrm{K \alpha}$ source. To estimate the content of each component in MOC composites, thermogravimetric analysis (TGA, SDT650 TA Instruments) was conducted under air atmosphere with a heating rate of $10{ }^{\circ} \mathrm{C} \mathrm{min}^{-1}$. To study the post-mortem phase and morphology of cathode, the coin cells were dissembled after cycling. The working electrodes were washed with DI water several times and then immersed in DI water for 10 min to remove electrolyte residues. After drying at $60{ }^{\circ} \mathrm{C}$ under vacuum, the electrodes were used for further characterization.

Electrochemical measurements. The Electrochemical performances of cathode materials were collected in CR2032 coin cells, which were assembled using either MOC or MO electrode as the cathode, Zn metal plate (Alfa Aesar) as the anode, nylon membrane (MILLPORE, GNWP) as the separator and 2.0 $\mathrm{M} \mathrm{ZnSO}_{4}$ with $0.1 \mathrm{M} \mathrm{MnSO}_{4}$ in water as the electrolyte. To prepare the cathode, active materials (MOC or MO, $70 \mathrm{wt} \%$ ) were mixed with carbon black (super P, $20 \mathrm{wt} \%$ ) and polyvinylidene fluoride (PVDF, $10 \mathrm{wt} \%$ ) in N-methylpyrrolidone solvent. Then the slurry was cast onto a carbon paper (Sigracet 39 AA, Fuel Cell Store) followed by drying in a vacuum oven at $60^{\circ} \mathrm{C}$. The mass loading of active material was around $1.5-2.0 \mathrm{mg} \mathrm{cm}^{-2}$. All electrochemical measurements of the coin cells were performed after $4 \mathrm{~h}$ aging at room temperature. The galvanostatic charge and discharge (GCD) measurements were conducted on a multichannel battery test equipment (Arbin BT2143 32CH) with a potential window of 1.0-1.85 V vs. $\mathrm{Zn}^{2+} / \mathrm{Zn}$. The specific capacity was normalized by the mass weight of the hydrated $\mathrm{MnO}_{2}$ component in $\mathrm{CNF} @ \mathrm{MnO}_{2}$ or $\delta-\mathrm{MnO}_{2}$. The cyclic voltammogram $(\mathrm{CV})$ curves and galvanostatic intermittence titration techniques (GITT) were tested in coin cells by electrochemical workstation (Bio-Logic, SP-300). Electrochemical impedance spectroscopy (EIS) measurements were performed on an electrochemical workstation (Gamry Interface 5000E) with $5 \mathrm{mV}$ amplitude in the frequency from 0.01 to $10^{5} \mathrm{~Hz}$.

\subsection{Morphology and structure characterizations of MOC}


The facile preparation process of MOC is depicted in Figure 4.1. In this work, the low-cost and conductive CNFs were employed as both the skeleton and sacrificial reductants for the $\mathrm{MnO}_{2}$ nanosheets. The hydrophilicity and reactivity of inherently hydrophobic CNFs can be easily enhanced by the grinding process with $\mathrm{KMnO}_{4}$ powder without harsh acidic refluxing pretreatment. After grinding treatment, $\mathrm{MnO}_{2}$ nanocrystalline nucleus are formed on CNFs surface through the redox reaction of $\mathrm{KMnO}_{4}$ and $\mathrm{C}\left(4 \mathrm{MnO}_{4}{ }^{-}+3 \mathrm{C}+\mathrm{H}_{2} \mathrm{O} \rightarrow 4 \mathrm{MnO}_{2}+\mathrm{CO}_{3}{ }^{2-}+2 \mathrm{HCO}_{3}{ }^{-}\right)$ at room temperature. After the wet-chemical reaction, $\mathrm{MnO}_{2}$ nanosheets grow in-situ on the CNF surface at $80{ }^{\circ} \mathrm{C}$, forming the hierarchical shell-core MOC structure. Compared to MOC, pure $\delta$ $\mathrm{MnO}_{2}(\mathrm{MO})$ nanosheets are synthesized via a hydrothermal way.
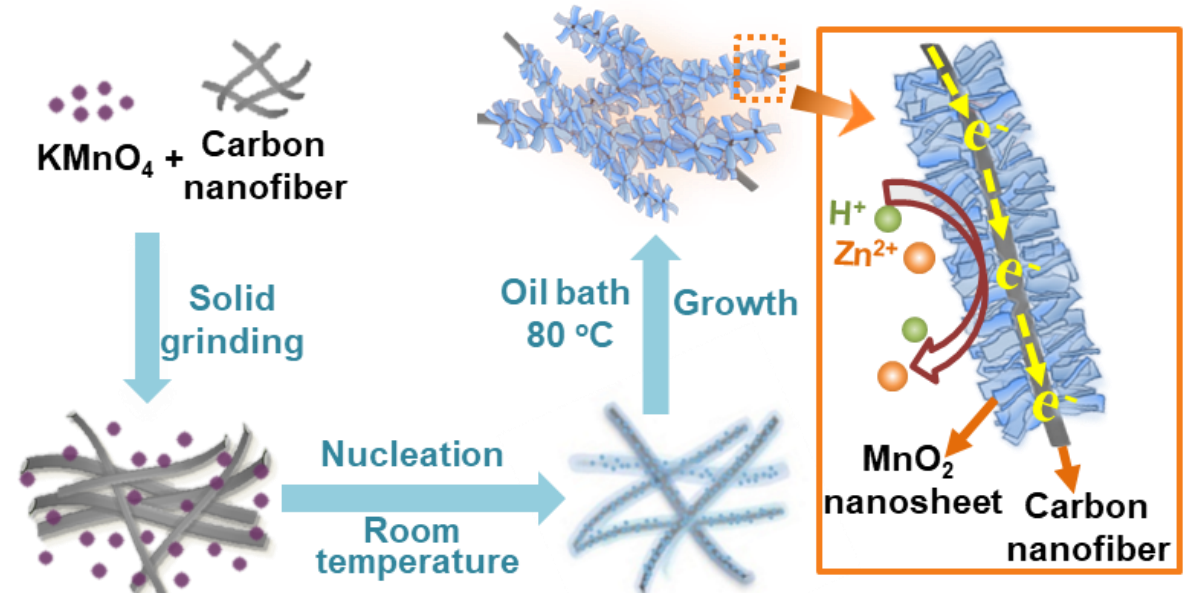

Figure 4. 1 Schematic diagram of the synthetic procedure of MOC.

The phase structures of as-prepared MOC composites and MO were characterized by XRD. As shown in Figure 4.2a, four main diffraction peaks of MOC and MO are indexed to the crystal planes of (001), (002), (11-1), and (114) in birnessite- $\mathrm{MnO}_{2}$ (JCPDS PDF\#13-0105).[15,16] Note that the characteristic peak of graphite at $26^{\circ}$ is also observed in MOC-2 and MOC-5 which were synthesized under relatively low feeding ratio of $\mathrm{KMnO}_{4} / \mathrm{CNF}$. The $\mathrm{MnO}_{2}$ diffraction peaks exhibit weak and board features, suggesting the low crystallinity of MOC-2 and MOC-5. With the increase of $\mathrm{KMnO}_{4}$ weight, characteristic graphite peak gradually vanishes, while the diffraction peak of $\mathrm{MnO} 2$ becomes sharper, indicating formation of highly crystalline $\mathrm{MnO}_{2}$. The crystalline structure of as-prepared materials was further investigated by Raman (Figure 4.2b). The bands at around 641 and $575 \mathrm{~cm}^{-1}$ can be assigned to $\mathrm{v} 1$ and $\mathrm{v}_{2}$ bands related to $\mathrm{Mn}-\mathrm{O}$ symmetric stretching vibration in $\mathrm{MnO}_{6}$ octahedral and $\mathrm{Mn}-\mathrm{O}$ stretching vibration in the basal plane of $\mathrm{MnO}_{6}$ layer, 
respectively, consistent with the reported Raman results of birnessite- $\mathrm{MnO}_{2}$.[17] In addition, characteristic D and G bands of CNFs are also observed in MOC-2, MOC-5 and MOC-10 but almost invisible in MOC-15 and MOC-20, because the thick coating layer of $\mathrm{MnO}_{2}$ on CNFs surface shields the signals of CNFs.
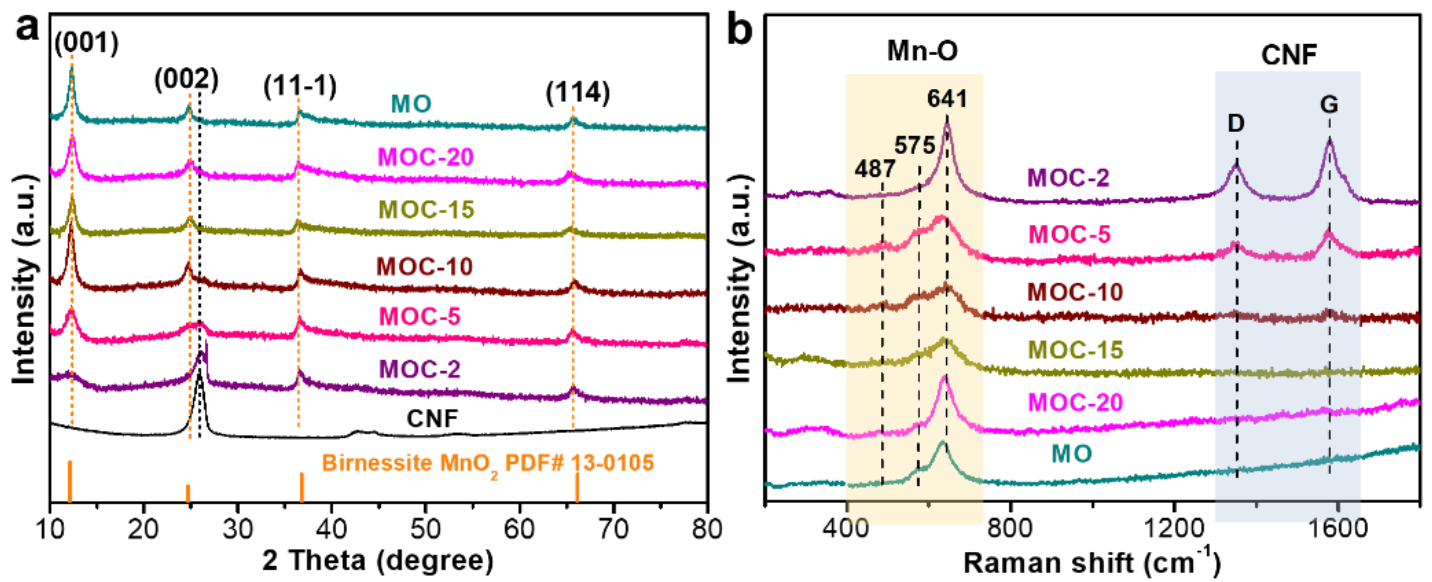

Figure 4. 2 XRD patterns (a) and Raman spectra (b) of as-prepared MOC composites and MO.

Morphologies of as-synthesized MOC composites were characterized by SEM (Figure 4.3). It is clearly observed that the MOC composite features the overall morphology of 1D hierarchical nanowire composed of vertically aligned nanosheet units with thickness of ca. 5-13 nm. Further, the core-sheath structure of MOC is obviously illustrated in the cross-section image (Figure 4.3c). As $\mathrm{KMnO}_{4}$ addition amount increases, the diameter of hierarchical nanowire rises from around 300 to $500 \mathrm{~nm}$, and meanwhile nanosheet units become denser and thicker. Taking the CNF diameter of 100-150 nm into consideration (Figure 4.31), the thickness of nanosheet covering the CNFs surface is around 200-400 nm. It is indicative of the controllable fabrication of $\mathrm{MnO}_{2}$ in mass loading and morphology. The core-sheath structure of MOC is further revealed by TEM images (Figure 4.3e, f). The surface of the CNF core (marked by a green circle in Figure 4.3g) is coated with ultrathin nanosheets. The high-resolution TEM (HRTEM) images exhibit the lattice fringes of $0.36 \mathrm{~nm}$ for ultrathin layers (Figure 4.3h) and $0.33 \mathrm{~nm}$ for 1D core component (Figure 4.3i) corresponding to the (002) lattice planes of birnessite- $\mathrm{MnO}_{2}$ and graphite, respectively. The TEM results confirm the integrated core-shell CNF@ $\mathrm{MnO}_{2}$ construction. Compared with MOC, micro-sized flowerlike MO assembled by aggregated nanosheets was obtained in the absence of CNFs (Figure 4.3j, k). Furthermore, in contrast to the hierarchical core-shell structure of MOC, the product synthesized in a similar wet-chemical reaction without solid-grinding treatment 
displays similar morphology to pristine CNFs and few nanosheets are formed on the smooth surface of CNFs (Figure 4.3m). This is due to the hydrophobic nature of pristine CNFs surface which leads to low wet-chemical reaction activity with $\mathrm{KMnO}_{4}$. As a result, pre-treatment of carbon with strong acids and oxidants and plasma is always adopted in previous reports.[10,11,18] Impressively, in this work, the reactivity of pristine CNFs towards effective growth of $\mathrm{MnO}_{2}$ can be easily achieved by a simple solid-grinding process. This facile and mass production of MOC also contributes the low-cost manufacturing of cathode materials for ZIBs.

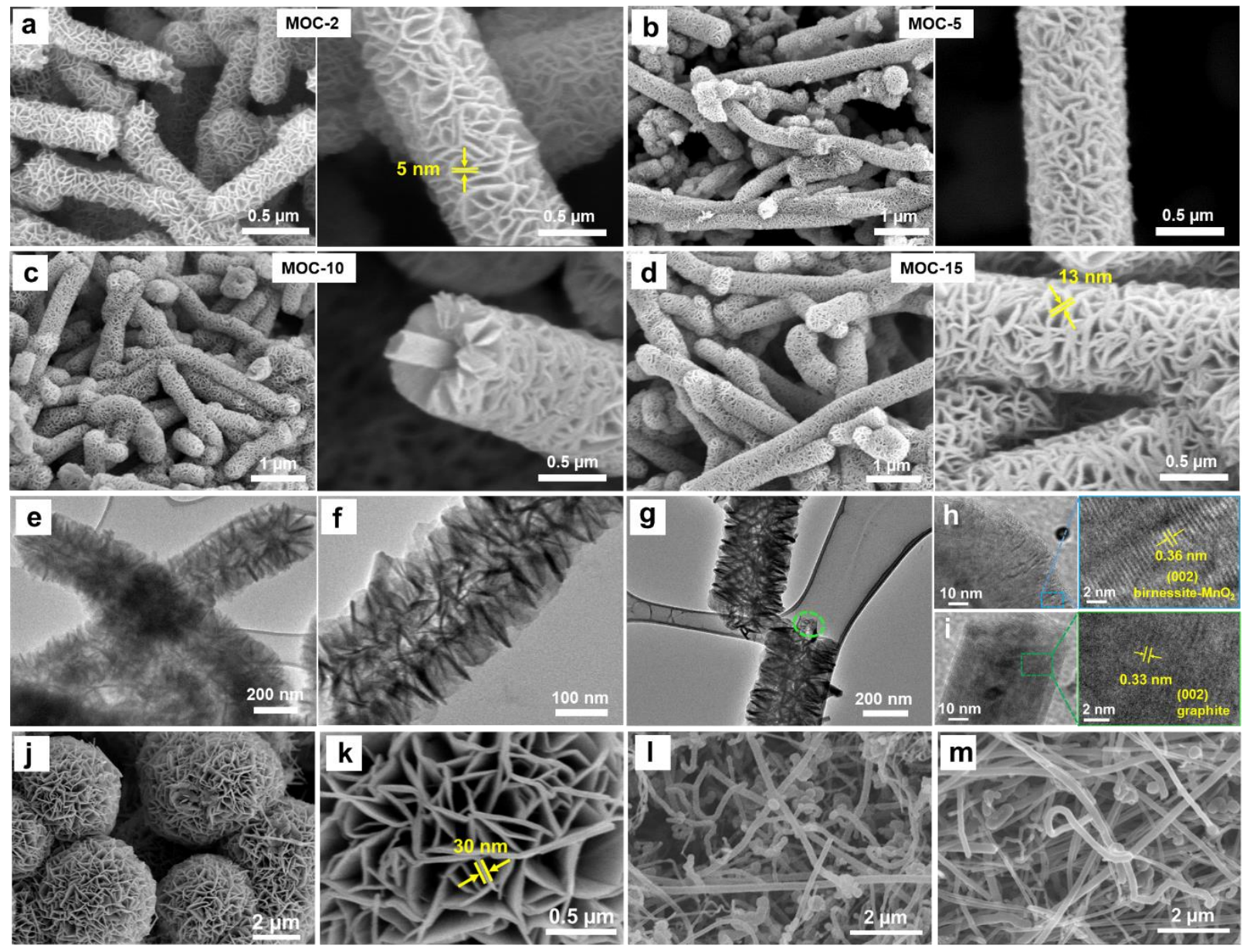

Figure 4. 3 SEM images of MOC-2 (a), MOC-5 (b), MOC-10 (c), MOC-15 (d) and TEM (e-g), $\operatorname{HRTEM}(\mathrm{h}, \mathrm{i})$ of MOC-5. SEM image of $(\mathrm{j}-\mathrm{k}) \delta-\mathrm{MnO}_{2}$ prepared via a hydrothermal method in the absence of CNFs, (l) pristine CNFs, and (m) the product prepared by the similar wet-chemical reaction without solid grinding pretreatment.

The XPS measurement was conducted to investigate the oxidation state of Mn in MOC-5. The existence of Mn, O and C element is observed in the survey scan XPS spectrum (Figure 4.4a). Mn 
$2 p$ spectrum (Figure 4.4b) shows the characteristic doublet peaks of Mn 2 $\mathrm{p}_{1 / 2}(654.3 \mathrm{eV})$ and $\mathrm{Mn}$ $2 \mathrm{p}_{3 / 2}(642.5 \mathrm{eV})$ with the energy separation of $11.8 \mathrm{eV}$ for $\mathrm{MnO}_{2}$.[19] The average oxidation state (AOS) of Mn can be determined by the energy separation of Mn $3 \mathrm{~s}$ doublet $\left(\Delta \mathrm{E}_{\mathrm{Mn} 3 \mathrm{~s}}\right)$ based on the equation of $\mathrm{AOS}=8.95-1.13 \Delta \mathrm{E}_{\mathrm{Mn} 3 \mathrm{~s}}(\mathrm{eV}) \cdot[20,21]$ The spin-energy separation of $4.67 \mathrm{eV}$ for $\mathrm{Mn} 3 \mathrm{~s}$ (Figure 4.4c) suggests the AOS of 3.68 for Mn in MOC-5. In addition, the core level O 1s spectrum can be used to further estimate Mn oxidation state.[22] As shown in Figure 4.4d, three peaks located at 530.1, 531.6 and 532.8 eV can be assigned to Mn-O-Mn (oxide), Mn-O-H (hydroxide) and $\mathrm{H}-\mathrm{O}-\mathrm{H}$ (water) bonds, respectively.[11] According to the area contribution of tetravalent MnO-Mn (86.5\%) and trivalent Mn-O-H (13.5\%) species, the AOS of Mn is estimated to be 3.86, close to the result from $\mathrm{Mn} 3 \mathrm{~s}$ calculation. The $\mathrm{AOS}$ of $\mathrm{Mn}$ between +3 and +4 in birnessite- $-\mathrm{MnO}_{2}$ can be compensated by the potassium ions generally intercalate between edge-shared $\mathrm{MnO}_{6}$ octahedra interlayers during wet-chemical synthesis.[11,23,24] The loading of $\mathrm{MnO}_{2}$ on the CNFs can be estimated from TGA measurements (Figure 4.4e).[11] The content of $\mathrm{MnO}_{2}$ rises with the increase of $\mathrm{KMnO}_{4}$ addition (Table 4.1). Additionally, the presence of crystal water (7.6-11.8\%) is confirmed in MOC, which can be assigned to the pre-inserted water molecules in the crystallographic interlayer of birnessite- $\mathrm{MnO}_{2}$. According to the average Mn oxidation state of 3.77, the molecular formula of active material in MOC composite can be denoted as $\mathrm{K}_{0.23} \mathrm{MnO}_{2} \cdot \mathrm{nH}_{2} \mathrm{O}(\mathrm{n}=0.37-0.65)$. The $\mathrm{K}^{+}$and crystal water can intrinsically stabilize the CNF@birnessite- $\mathrm{MnO}_{2}$ architecture, which is favourable for structural stability as cathode materials in aqueous ZIBs. [6,25] 

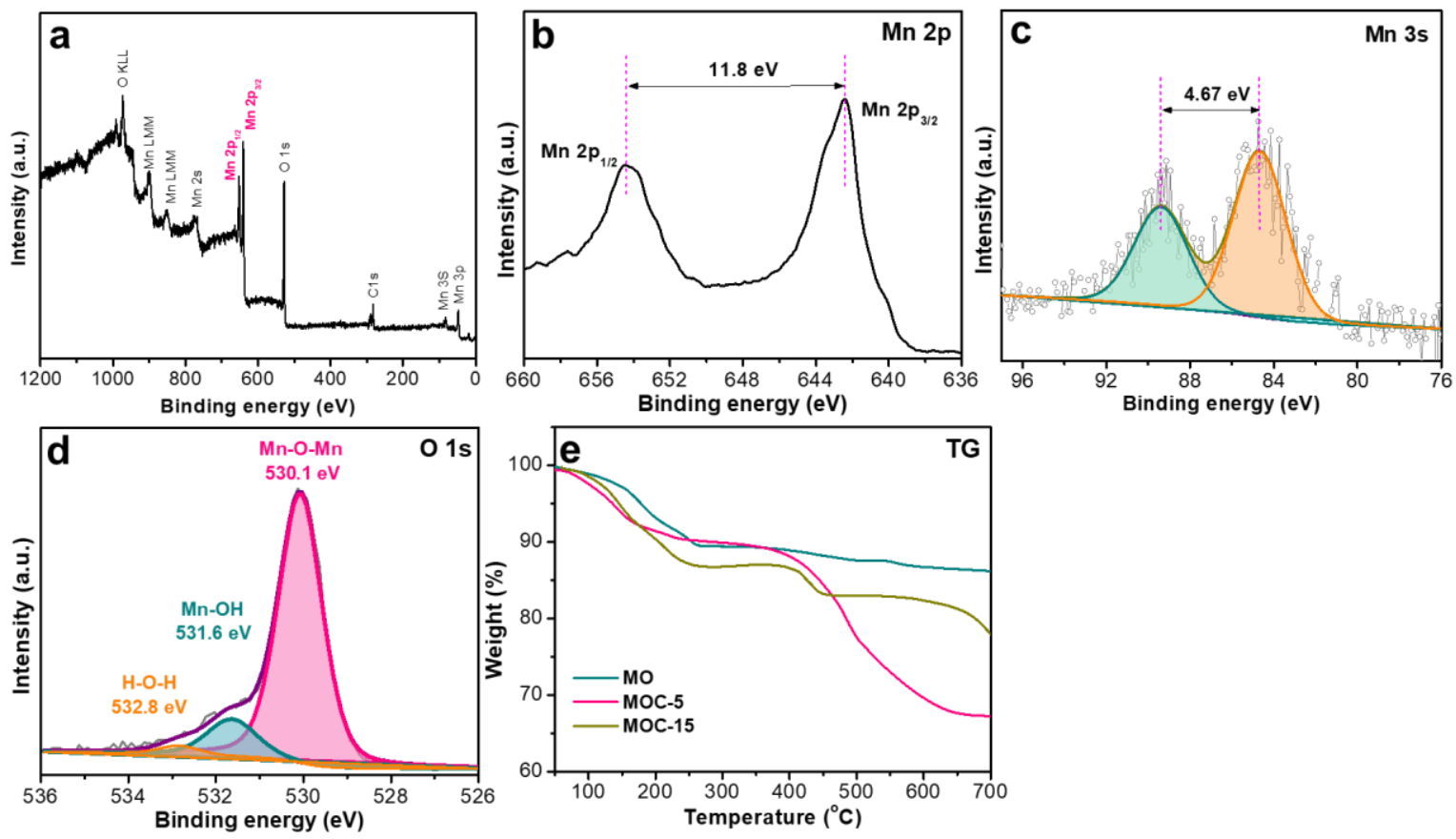

Figure 4. 4 XPS spectra of (a) survey spectrum (b) Mn 2p, (c) Mn 3s, (d) O 1s of MOC-5. (e) TG curves of the as-prepared MOC composites and MO.

\subsection{Electrochemical performance of MOC}

The electrochemical performances of MOC-5, MOC-15 and bare $\delta$-MnO2 (MO) cathodes for aqueous ZIBs were investigated by using $\mathrm{Zn}$ plate anodes and $2 \mathrm{M} \mathrm{ZnSO} 4$ and $0.1 \mathrm{M} \mathrm{MnSO} 4$ electrolyte in coin cells. Figure 4.5a shows the cyclic voltammogram (CV) curves of MOC-5 at a scan rate of $0.1 \mathrm{mV} \mathrm{s}-1$ between 1.0 and $1.85 \mathrm{~V}$. In the cathodic/anodic scans, CV curves are well overlapped, indicating good reversibility of MOC-5 cathode. Two characteristic redox peaks located at 1.24/1.55 V and 1.37/1.61 V are consistent with those of MOC-15 and MO control cathodes, evidencing that the MOC cathodes possess the similar redox reactions to MO cathode and the existence of CNFs does not significantly affect the electrochemical charge storage mechanism of $\delta-\mathrm{MnO}_{2} \cdot[26]$ 

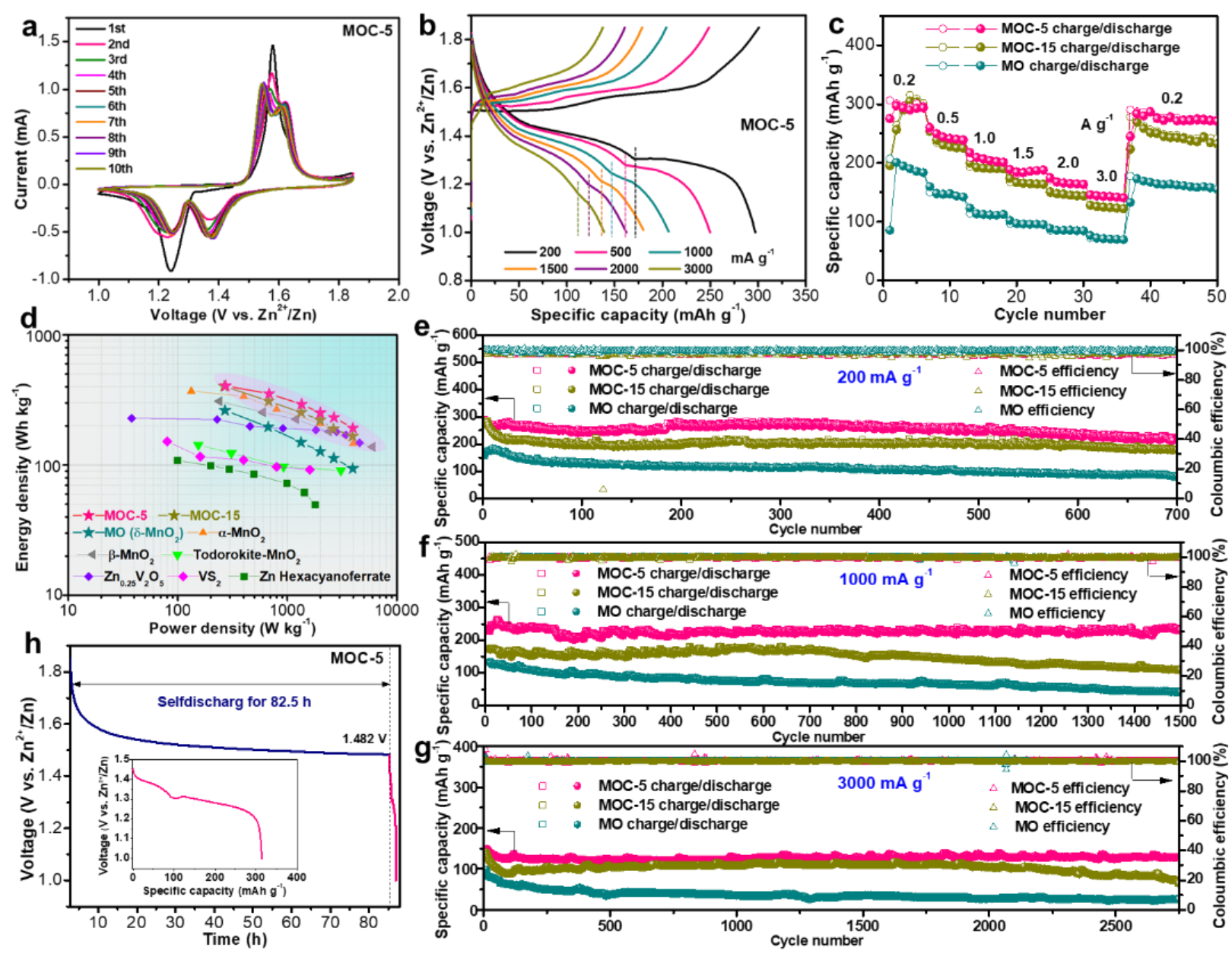

Figure 4. 5 The electrochemical performances of ZIBs with MOC-5, MOC-15 and MO cathodes, $\mathrm{Zn}$ anodes and aqueous electrolyte of $2 \mathrm{M} \mathrm{ZnSO}_{4}$ with $0.1 \mathrm{M} \mathrm{MnSO}_{4}$. (a) $\mathrm{CV}$ of MOC-5 cathode at a scan rate of $0.1 \mathrm{mV} \mathrm{s}^{-1}$. (b) GCD profiles of MOC-5 cathode at different current densities from 200 to $3000 \mathrm{~mA} \mathrm{~g}^{-1}$. (c) Rate performance at various current densities. (d) Ragone plot of MOC-5 and other reported cathodes. Cycling performance of MOC-5, MOC-15 and MO at (e) $200 \mathrm{~mA} \mathrm{~g}$ 1, (f) $1000 \mathrm{~mA} \mathrm{~g}^{-1}$ and (g) $3000 \mathrm{~mA} \mathrm{~g}^{-1}$. (h) Self-discharge curve and the following discharge profile (shown in the inset) of MOC-5 at $200 \mathrm{~mA} \mathrm{~g}^{-1}$.

The rate capabilities of MOC-5, MOC-15 and MO were evaluated at various current densities from 200 to $3000 \mathrm{~mA} \mathrm{~g}^{-1}$. Figure 4.5b exhibits the galvanostatic charge and discharge (GCD) curves of MOC-5 at various current densities. Two characteristic discharge plateaus at around 1.4 and $1.28 \mathrm{~V}$ can be clearly observed with an inflection point at $200 \mathrm{~mA} \mathrm{~g}^{-1}$. This feature is shown even at a high current density of $3000 \mathrm{~mA} \mathrm{~g}^{-1}$. However, the capacity contribution (Figure 4.6c) in the lower discharge plateau significantly decreases as the current rises, while the capacity 
contribution in the upper discharge plateau is retained relatively well. This phenomenon evidence that two discharge steps are different reaction-dominated processes, leading to distinct ratedependent kinetics. Two discharge plateaus with an inflection point are also observed in MOC-15 (Figure 4.6). In contrast to MOC composites, $\mathrm{MO}$ demonstrates an indiscernible inflection point at current densities higher than $1000 \mathrm{~mA} \mathrm{~g}^{-1}$ (Figure 4.6a, b), revealing enhanced reaction kinetics of MOC-5 and MOC-15 likely due to the facilitated electron transfer arising from conductive CNFs. Moreover, the MOC composite cathodes exhibit substantially lower polarization compared to $\mathrm{MO}$, further suggesting that the hierarchical core-shell structure integrating conductive CNFs with dispersed $\delta-\mathrm{MnO}_{2}$ nanosheets is able to effectively decrease electrochemical reaction energy barriers and promote kinetics for synergistic ionic and electronic transfer.[27] The MOC-15 cathode shows slightly higher polarization than MOC-5, which may be caused by the lower CNF content and thicker $\delta-\mathrm{MnO}_{2}$ nanosheet shealth of MOC-15. Figure 4.5c illustrates the specific capacities of MOC-5, MOC-15 and MO at various current densities. MOC-5 delivers discharge capacities of 297, 250,210, 188, 168 and $144 \mathrm{mAh} \mathrm{g}^{-1}$ at 200, 500, 1000, 1500, 2000 and 3000 $\mathrm{mA} \mathrm{g}^{-1}$, respectively. Additionally, when the current density returns from 3000 to $200 \mathrm{~mA} \mathrm{~g}^{-1}$, the reversible capacity of MOC-5 is recovered to $283 \mathrm{mAh} \mathrm{g}^{-1}$, suggesting a high-capacity retention of $95 \%$ of the initial value. MOC-15 exhibits capacities slightly lower than MOC-5 at the same current densities, however, the capacity of MOC-15 cannot be fully recovered when the current density returns to $200 \mathrm{~mA} \mathrm{~g}^{-1}$. In contrast to MOC composites, MO displays much lower capacities, owing to the poor conductivity and agglomerated structure of bare $\delta$-MnO2. The exceptional rate performance of MOC-5 is further reflected in the Ragone plot (Figure 4.5d). It delivers a high specific energy and powder density of $406 \mathrm{Wh} \mathrm{kg}^{-1}$ at $273 \mathrm{~W} \mathrm{~kg}^{-1}, 354 \mathrm{Wh} \mathrm{kg}^{-1}$ at $682 \mathrm{~W} \mathrm{~kg}^{-1}$, $293 \mathrm{Wh} \mathrm{kg}^{-1}$ at $1352 \mathrm{~W} \mathrm{~kg}^{-1}, 251 \mathrm{Wh} \mathrm{kg}^{-1}$ at $2001 \mathrm{~W} \mathrm{~kg}^{-1}, 232 \mathrm{Wh} \mathrm{kg}^{-1}$ at $2666 \mathrm{~W} \mathrm{~kg}^{-1}$, and 192 $\mathrm{Wh} \mathrm{kg}{ }^{-1}$ at $3970 \mathrm{~W} \mathrm{~kg}^{-1}$ based on the weight of active materials, which stands out among diverse reported cathode materials for aqueous $\mathrm{ZIBs}$, including $\mathrm{MnO}_{2}$ polymorphs,[1,28,29] vanadiumbased[30,31] and PBA-based cathodes.[32] 

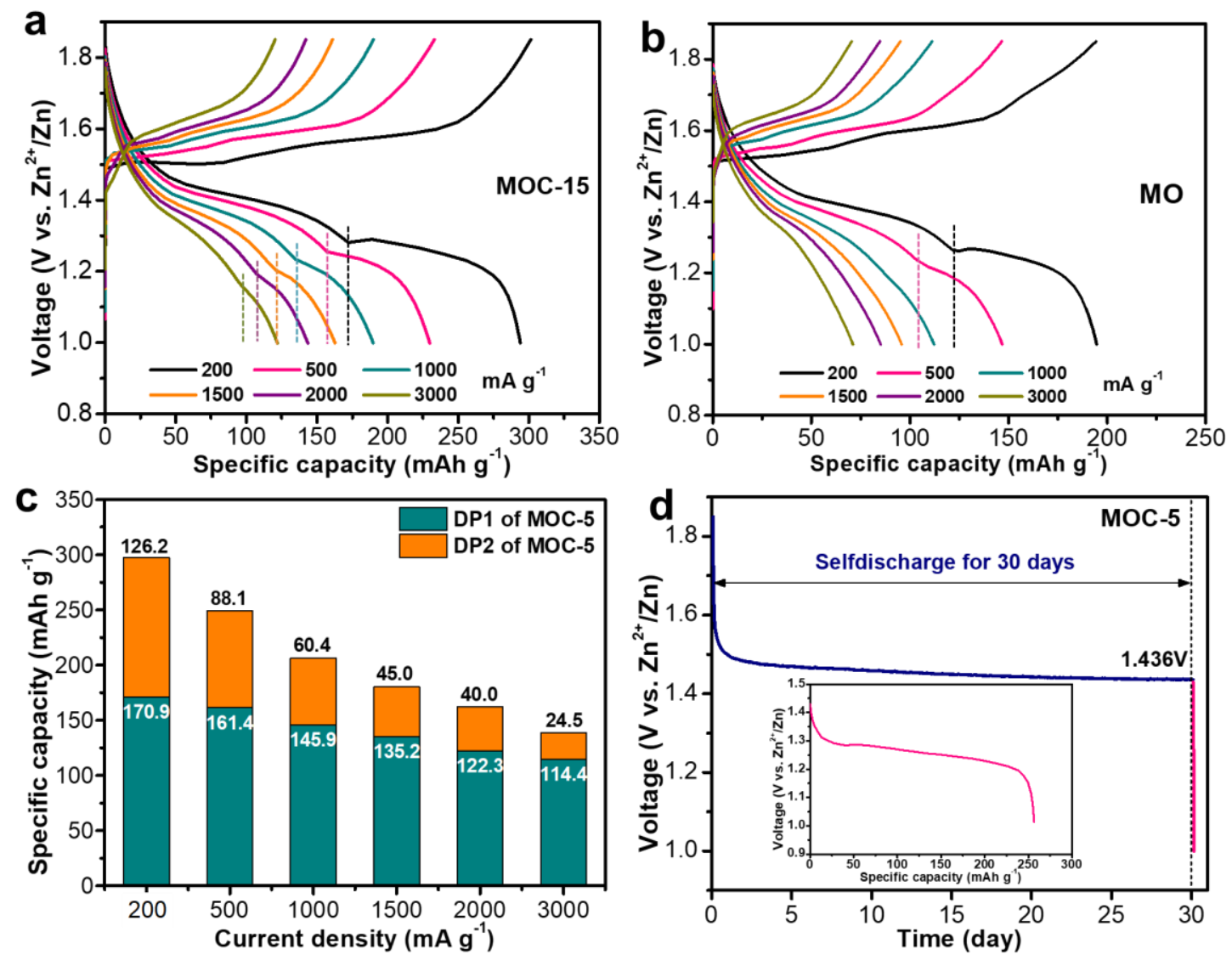

Figure 4. 6 GCD curves of MOC-15 (a) and MO (b) cathodes at various current densities. (c) The capacities of MOC-5 contributed by DP1 and DP2 at various current densities. (d) Long-term selfdischarge curve of MOC-5 and the following discharge profile at $200 \mathrm{~mA} \mathrm{~g}^{-1}$ (shown in the inset).

The exceptional long-term cycling stability of energy storage devices at a broad range of current densities is of vital importance to ensure the reliability and resiliency of electrical grids. Most of reports have focused on developing cathodes with enhanced cyclability of aqueous rechargeable ZIBs at high current densities.[1,16,33,34] Nevertheless, it still remains a formidable challenge to develop stable manganese oxide based cathodes under low and moderate current densities, as the long duration of discharge or charge at small current increases the possibility of undesired side reactions leading to irreversible products and capacity fade.[35] In this work, the long-term cycling stability of MOC-5, MOC-15 and MO cathodes were systematically investigated at low (200 mA $\left.\mathrm{g}^{-1}\right)$, moderate $\left(1000 \mathrm{~mA} \mathrm{~g}^{-1}\right)$ and high current densities $\left(3000 \mathrm{~mA} \mathrm{~g}^{-1}\right)$. At $200 \mathrm{~mA} \mathrm{~g}^{-1}$ (Figure 4.5e), MOC-5 shows stable reversible capacities and exhibits the maximum specific discharge capacity of $277 \mathrm{mAh} \mathrm{g}^{-1}$ with $\sim 100 \%$ Coulombic efficiency and little capacity decay $\left(0.08 \mathrm{mAh} \mathrm{g}^{-}\right.$ 
${ }^{1}$ per cycle) for 700 cycles. MOC-15 demonstrates slight capacity fade in the initial 30 cycles and then maintains a stable capacity of $178 \mathrm{mAh} \mathrm{g}^{-1}$ after 700 cycles. In contrast, MO displays a lower initial capacity (<200 mAh g-1) and continuous capacity decrease to $80 \mathrm{mAh} \mathrm{g}^{-1}$. At $1000 \mathrm{~mA} \mathrm{~g}^{-}$ ${ }^{1}$ (Figure 4.5f), MOC-5 delivers a high and extremely stable reversible capacity of around 232 $\mathrm{mAh} \mathrm{g}^{-1}$ for 1500 cycles with almost $100 \%$ capacity retention. MOC-15 exhibits an apparent capacity decline after keeping a stable capacity of $170 \mathrm{mAh} \mathrm{g}^{-1}$ for 720 cycles. Likewise, MO manifests significantly lower capacity $\left(<150 \mathrm{mAh} \mathrm{g}^{-1}\right)$ and persistents capacity decline to $42 \mathrm{mAh}$ $\mathrm{g}^{-1}$. At $3000 \mathrm{~mA} \mathrm{~g}^{-1}$ (Figure 4.5g), MOC-5 is capable of maintaining a remarkable and stable capacity of $130 \mathrm{mAh} \mathrm{g}^{-1}$ after 2750 cycles, whereas MOC-15 shows severe capacity deterioration after 2000 cycles and MO exhibits rapid decline to a negligible capacity. The rate and cycling performances of MOC-5 outperform those of many reported manganese oxide cathodes. The shelf life of ZIBs plays a critical role in their practical application and thus the self-discharge behaviour of MOC-5 was monitored after being charged to $1.85 \mathrm{~V}$. As depicted in Figure 4.5h, the open circuit voltage of battery is gradually decreased and then maintained at around $1.48 \mathrm{~V}$ after selfdischarging for $82.5 \mathrm{~h}$. A high capacity of over $300 \mathrm{mAh} \mathrm{g}^{-1}$ is still delivered in the following discharge process at $200 \mathrm{~mA} \mathrm{~g}^{-1}$ with negligible capacity loss. Even after the extremely long-term (30 days) self-discharging (Figure 4.6d), a capacity of $257 \mathrm{mAh} \mathrm{g}^{-1}$ is well preserved, demonstrating the great application potential of MOC-5 in ZIBs with long shelf life for grid energy storage.

\subsection{Reaction kinetics}

To understand the insights into the electrochemical performances of MOC and MO cathodes, the electrochemical reaction kinetics related to the two-stage discharge plateaus were investigated. Figure 6a illustrates the CV curves of MOC-5 cathode with two pairs of redox peaks at various scan rates from 0.1 to $1.0 \mathrm{mV} \mathrm{s}^{-1}$. The peak current (i) and scan rate (v) follow a relationship: logi $=\log \mathrm{a}+\mathrm{b} \log v$, where $\mathrm{a}$ and $\mathrm{b}$ are adjustable parameters. [36,37] The value of $\mathrm{b}$ generally varies in the range of 0.5-1.0 depending on the charge storage behaviour. The $b$ value of 0.5 implies that the charge storage is mainly controlled by a solid-state ion diffusion process, while the b value of 1.0 suggests the surface capacitive controlled charge storage process. [7,34] The b values of MOC5 cathode at four redox peaks are calculated as 0.72 (peak 1), 0.56 (peak 2), 0.65 (peak 3) and 0.68 (peak 4) (Figure 4.7b), demonstrating that its charge storage behaviour is related to both the 
diffusion-controlled process and capacitive effect. In addition, the capacitive contribution in the total capacity of MOC-5 gradually grows from 36 to $68.2 \%$ when the scan rate increases from 0.1 to $1 \mathrm{mV} \mathrm{s}^{-1}$ (Figure 4.7c). The similar $\mathrm{b}$ values and capacitive contribution percentages were obtained for MO counterpart (Figure 4.8a-c). Therefore, the diffusion-controlled process dominates the charge storage under low current densities, while the capacitive effect governs the electrochemical behaviour under high current densities for both MOC-5 and MO.[25,38] The solid-state diffusion kinetics of MOC-5 and MO cathodes in ZIBs were in-depth investigated by the galvanostatic intermittent titration technique (GITT). As depicted in Figure 4.7d, the overvoltage values for MOC-5 in both two discharge steps are much lower than those of MO (Figure 4.8d), which is related to the small charge transfer resistance and fast ion diffusion of MOC-5.[39] The calculated diffusion coefficient (D) further confirms the fast diffusion kinetics of MOC-5 (Figure 4.7e). The D values of MOC-5 are in a range of $10^{-7}-10^{-10} \mathrm{~cm}^{2} \mathrm{~s}^{-1}$ in DP1 and $10^{-11}-10^{-13} \mathrm{~cm}^{2} \mathrm{~s}^{-1}$ in DP2, which are one order of magnitude higher than those of MO $\left(10^{-8}-10^{-11}\right.$ $\mathrm{cm}^{2} \mathrm{~s}^{-1}$ in DP1 and $10^{-12}-10^{-14} \mathrm{~cm}^{2} \mathrm{~s}^{-1}$ in DP2). This result agrees with the superior rate capability of MOC-5. The ultrathin $\mathrm{MnO}_{2}$ nanosheets greatly enhance electrode/electrolyte interfacial areas and shorten the ion diffusion paths. Meanwhile, the conductive CNFs facilitate fast electron transport to lamellar $\mathrm{MnO}_{2}$. Both contribute to the exceptional kinetics synergistically. Moreover, the cliff fall of D value from DP1 to DP2 (almost two order of magnitude) is observed for both MOC-5 and MO consistent with the reported $\mathrm{MnO}_{2}$ cathodes, $[2,22,25,38]$ suggesting the different reaction mechanisms at DP1 and DP2. 

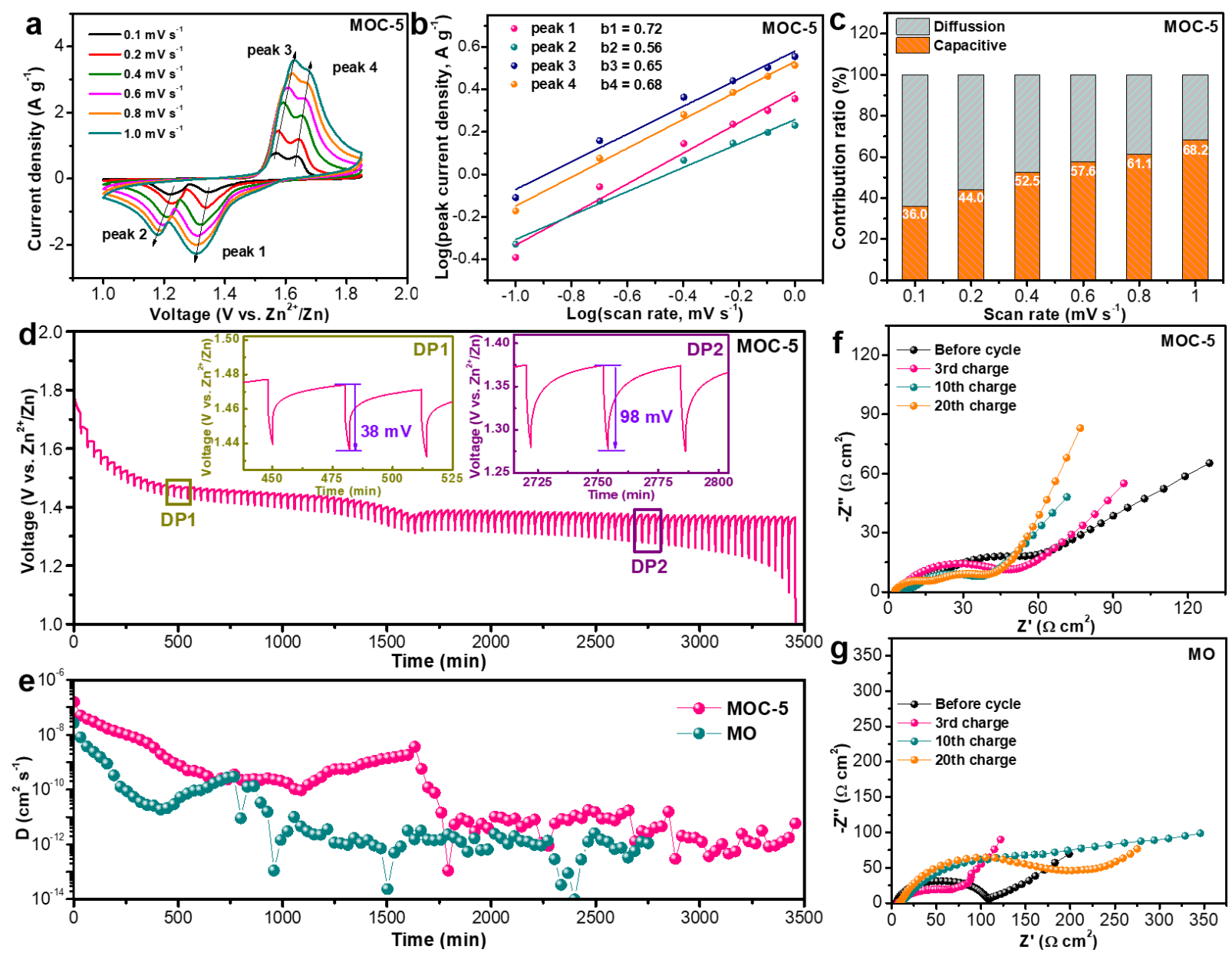

Figure 4. 7 (a) CV curves of MOC-5 cathode at various sweep rates in $2 \mathrm{M} \mathrm{ZnSO}_{4}$ and $0.1 \mathrm{M}$ $\mathrm{MnSO}_{4}$. (b) Plots of $\log$ (peak current density) versus $\log$ (sweep rate) for MOC-5 cathode at various peaks derived from (a). (c) The percentages of capacitive and diffusion contributions for MOC cathode at various sweep rates. (d) GITT profile of MOC-5 cathode. (e) Calculated ion diffusion coefficients of MOC-5 and MO based on the GITT results. Nyquist plots of MOC-5 (f) and MO cathodes (g) at fully charged states after given cycles.

The charge transfer resistances (Rct) of MOC-5 and MO cathodes are also compared. Electrochemical impedance spectroscopy (EIS) measured at different discharge/charge states provides dynamic information for electrode during charge storage processes. Figure 4.7f shows the Nyquist plots of MOC-5 before and after given cycles at fully charged states. The Rct value of MOC-5 significantly decreases after the activation process in the first 10 cycles compared to the initial state, and then gets stabilized. Meanwhile, the slope of Warburg line increases, suggesting the improved ion diffusion process. The facilitated infiltration of the electrolyte into the nanosheets 
effectively promotes the ionic transfer at the electrode/electrolyte interface and diffusion into the active $\mathrm{MnO} 2 .[40]$ In contrast, $\mathrm{MO}$ demonstrates a much higher $\mathrm{R}_{\mathrm{ct}}$ than MOC-5 at both the initial state and fully charged states of following cycles (Figure $\mathbf{4 . 7 g}$ ). The lower $\mathrm{R}_{\mathrm{ct}}$ values of MOC-5 substantiate that the coupling of vertically aligned birnessite- $\mathrm{MnO}_{2}$ nanosheets and conductive CNFs core can produce a synergistic effect in reducing the resistance of charge transfer and ionic diffusion.[41] To further disclose the variation of interfacial resistance associated to two discharge steps, the EIS analysis was also conducted at two discharge platforms of 1.4 and $1.25 \mathrm{~V}$ after 20 cycles (Figure $4.8 e, \mathbf{f})$. The $\mathrm{R}_{\mathrm{ct}}$ value shows negligible change from fully charged state $(1.85 \mathrm{~V})$ to DP1 $(1.4 \mathrm{~V})$, but substantially ascends as the discharge proceeds to DP2 (1.25 V). It reaches the maximum value at the fully discharged state $(1.0 \mathrm{~V})$. This phenomenon reveals that the discharging is dictated by different reactions, which includes a homogeneous $\mathrm{Zn}^{2+}$ intercalation reaction at DP1 and heterogeneous conversion reactions related to $\mathrm{H}^{+}, \mathrm{Zn}^{2+}, \mathrm{SO}_{4}{ }^{2-}, \mathrm{Mn}^{2+}$ and $\mathrm{MnO}_{2}$ at DP2.[42,43]
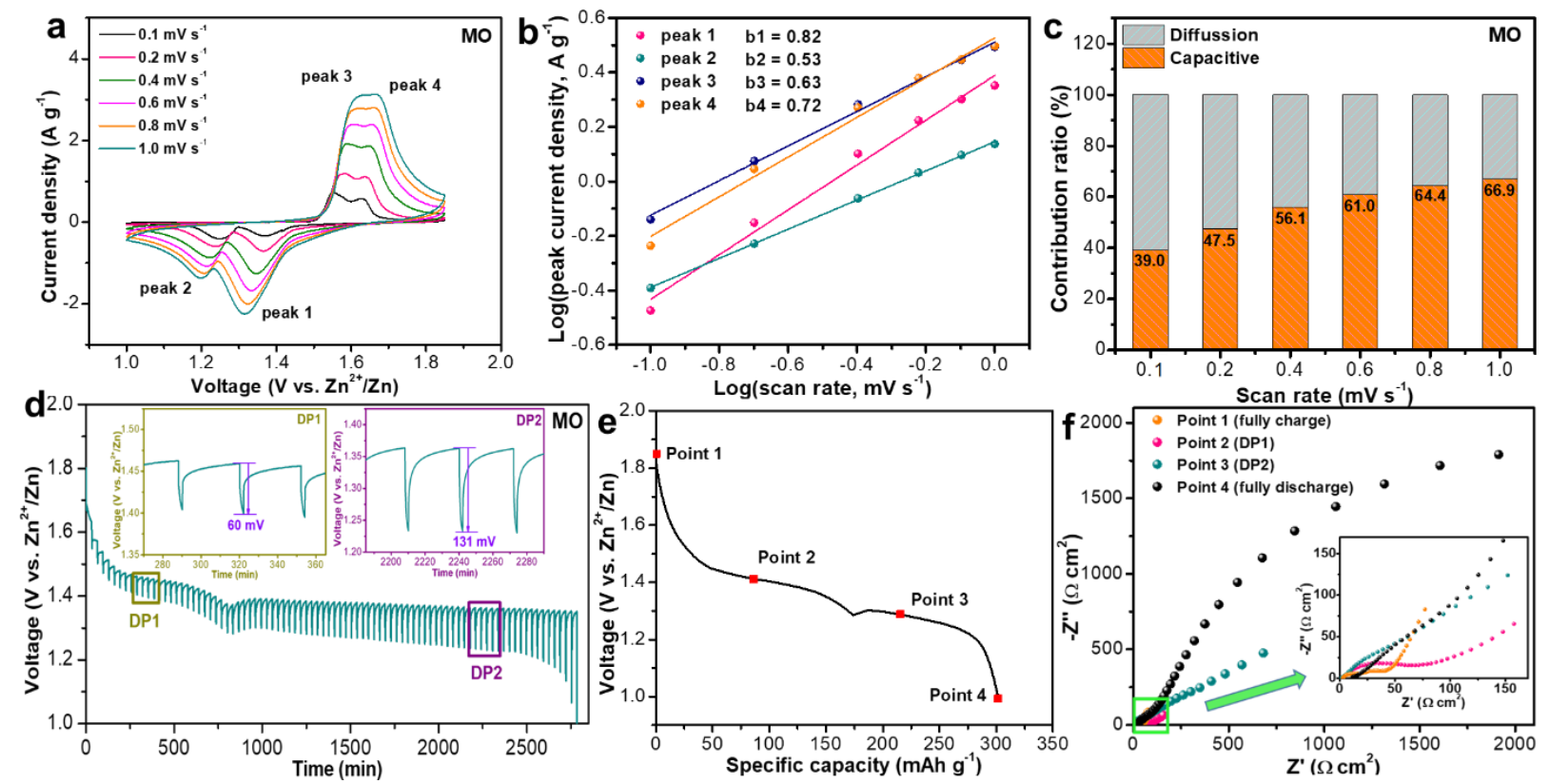

Figure 4. 8 (a) CV curves of MO cathode at various sweep rates in $2 \mathrm{M} \mathrm{ZnSO}_{4}$ and $0.1 \mathrm{M} \mathrm{MnSO}_{4}$. (b) Plots of $\log$ (peak current density) versus log (sweep rate) for MO cathode at various peaks derived from (a). (c) The percentages of capacitive and diffusion contributions for MO cathode at various sweep rates. (d) GITT curve of MO cathode during the discharge process. (e-f) Nyquist plots of MOC-5 at fully charged state, fully discharged state, first discharge platform (1.4 V) and second discharge $(1.25 \mathrm{~V})$. 
To further elucidate the reaction mechanism of MOC-5 cathode in ZIBs, the phase and morphology evolutions of MOC-5 at different discharge/charge states were systematically investigated by ex situ XRD and SEM. The stainless-steel (SS) meshes were employed instead of carbon papers as current collectors of MOC-5 for the ex-situ characterizations in the initial two cycles to avoid the ambiguity between the intermediates and carbon papers caused by their overlapped XRD patterns. Figure 4.9b shows the XRD evolution of MOC-5 cathode at selected states of initial two cycles (marked points in Figure 4.9a). When the discharge process initially reaches near inflection point (A), no significant change was observed in XRD peaks of $\delta-\mathrm{MnO}_{2}$ except for the intensity decrease, and the nanosheet structure of $\mathrm{MnO}_{2}$ is still maintained (Figure 4.9c). The EDX results shows high content of $\mathrm{Zn}$ in the nanosheet structure, suggesting the $\mathrm{Zn}^{2+}$ intercalation reaction at DP1. Intercalation chemistry offers the advantage of a topotactic reaction which minimizes structural change.[44] As the discharge proceeds to DP2 $(\mathrm{B} \rightarrow \mathrm{C})$, new phases of $\mathrm{Zn}_{4} \mathrm{SO}_{4}(\mathrm{OH})_{6} \cdot \mathrm{nH}_{2} \mathrm{O}$ (n=1-3, zinc hydroxide sulfate, ZHS, JCPDS: 39-0689) and MnOOH (JCPDS: 88-0648) were observed, implying that the $\mathrm{H}^{+}$conversion reaction occurs at DP2. As shown in SEM images (Figure 4.9d, e), the large flake structure grows continuously (10-20 $\mu \mathrm{m})$ and shields the underneath nanosheets. The EDX results (Figure 4.10a) further confirm the large flakes are ZHS, which possess negligible $\mathrm{Mn}$ and abundant $\mathrm{Zn}$ with $\mathrm{Zn} / \mathrm{S}$ ratio of 4.0. The higher $\mathrm{Mn} / \mathrm{Zn}$ ratio detected in the nanosheets region indicates the $\mathrm{Zn}$-intercalated manganese oxide phase $\left(\mathrm{Zn}_{\mathrm{x}} \mathrm{Mn}_{\mathrm{y}} \mathrm{O}_{\mathrm{z}}\right)$. 

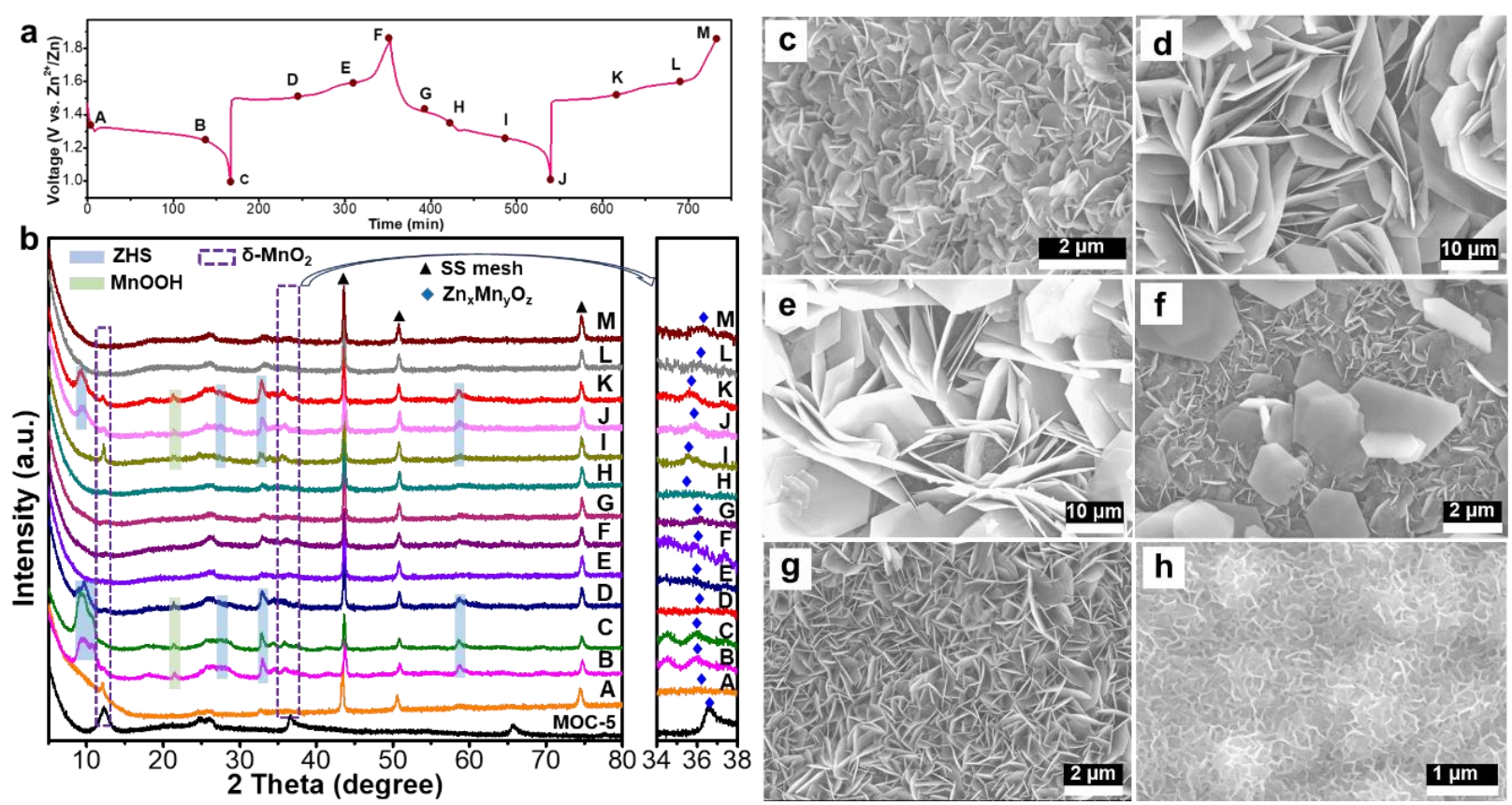

Figure 4. 9 Structural and morphological evolution of MOC-5. (a) The GCD curve of the first two cycles with selected states where cathodes were ex situ characterized. (b) The corresponding XRD evolution and patterns at different states indicated in (a). (c-h) SEM images collected at the selected states of A (c), B (d), C (e), D (f), E (g) and F (h).

In the following charge process $(\mathrm{D} \rightarrow \mathrm{F}), \mathrm{ZHS}$ and $\mathrm{MnOOH}$ disappear in the XRD patterns. The large ZHS flakes gradually diminish and nanosheet structures become visible (Figures 4.9f, g, h). The decomposition of ZHS is associated to the $\mathrm{pH}$ decrease of electrolyte induced by the $\mathrm{H}^{+}$ conversion reaction.[29] In the second discharge/charge process $(\mathrm{F} \rightarrow \mathrm{J} / \mathrm{J} \rightarrow \mathrm{M})$, the peak shifts towards lower $2 \theta$ degree at DP1 while recovers during the following charge process. ZHS and $\mathrm{MnOOH}$ phase form at DP2 and decompose subsequently (Figure 4.9b). These phenomena are consistent with the observations in the initial discharge and charge processes. The precipitation/decomposition of ZHS and $\mathrm{MnOOH}$ and recoverable peak shift of $\delta-\mathrm{MnO}_{2}$ demonstrate the good reversibility of MOC-5 cathode. The EDX analysis (Figure 4.10b, c) exhibits the $\mathrm{Zn} / \mathrm{Mn}$ ratio grows continuously $(\mathrm{H} \rightarrow \mathrm{J})$, suggesting the insertion of $\mathrm{Zn}^{2+}$ occurs at both DP1 and DP2. All these experimental results demonstrate a hybrid charge storage mechanism including a $\mathrm{Zn}^{2+}$ intercalation at DP1 and subsequent co-insertion of $\mathrm{H}^{+}$and $\mathrm{Zn}^{2+}$ at DP2. Note that no obvious crystal structure change of $\delta-\mathrm{MnO}_{2}$ was detected during the continuous discharge/charge process (Figure 4.9b). This indicates that the $\delta-\mathrm{MnO}_{2}$ phase in $\mathrm{MOC}-5$ has exceptional structural stability for intercalation of $\mathrm{Zn}^{2+}$ and $\mathrm{H}^{+}$without framework collapse and 
phase transition. This extraordinary stability is related to the flexibility of nanosheets and preinserted crystal water pillars in the interlayer of $\delta-\mathrm{MnO}_{2}$, which can buffer the lattice strains during the (de)intercalation.[6]

The structure and morphology characterization of MOC-5 after long-term cycling further discloses its extraordinary electrochemical stability. The $\mathrm{Zn}$-containing cubic $\mathrm{ZnMnO}_{3}$ phase (JCPDS: 19-1461) featuring ultrathin nanosheet morphology is formed after 750 cycles at $200 \mathrm{~mA}$ $\mathrm{g}^{-1}$ (Figures 4.11) and mainly serves as the active material for continuous charge storage. The cubic $\mathrm{ZnMnO}_{3}$ has been reported as an exotic defective cubic spinel with cationic vacancies. [45,46] This defective crystallographic structure and ultrathin nanosheet texture of $\mathrm{ZnMnO}_{3}$ render the excellent long-term cycling stability of MOC-5 cathode in ZIBs.

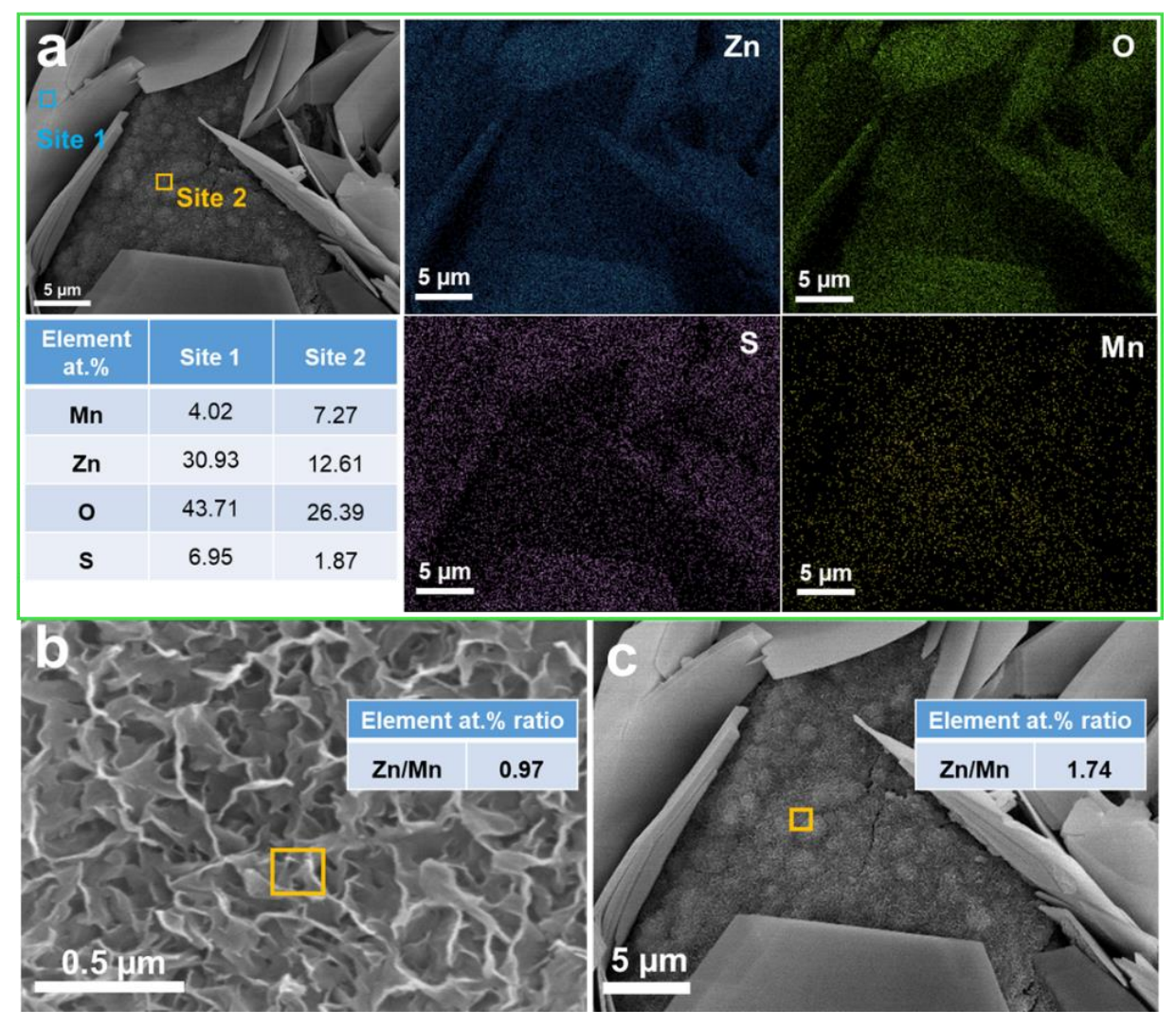

Figure 4. 10 (a) EDX elemental mappings of MOC-5 at fully discharged state. SEM images and EDX results of MOC-5 at point H (the end of DP1) (b) and point J (the end of DP2) (c) in Figure 9 a.

The high capacities, kinetics and extraordinary long-term cycling stability of MOC-5 should be attributed to the following aspects. First, the vertically aligned ultrathin $\delta-\mathrm{MnO}_{2}$ nanosheets and 
the hierarchical core-shell structure can significantly increase the contact areas between the active materials and electrolyte and reduce the ion diffusion length to facilitate the ionic transport at electrode/electrolyte interface and ionic diffusion, leading to high utilization of active Mn redox centers and rate performance, as validated by its high capacities and rate performance (Figure $\mathbf{4 . 5 c}$, d). Second, the conductive CNFs core accelerates the electron transport to $\mathrm{MnO}_{2}$ nanosheets coupled with their remarkable intrinsic ion diffusion properties, cooperatively boosting the charge transfer kinetics, which is corroborated by the prominent ion diffusion coefficients and low charge transfer resistance (Figure 4.6). Third, the optimal amount of pre-inserted crystal water in the interlayer of $\delta-\mathrm{MnO}_{2}$ nanosheets in MOC-5 acts as the pillar to stabilize the framework with interlayer stacking. It has also been found in the previous studies that the crystal water can effectively screen electrostatic interactions between guest cations and the host, provide interlayer elasticity and lower desolvation energy penalty at the interface of cathode and electrolyte. $[6,44,47,48]$ Last but not least, the intimate integration of CNFs core and $\mathrm{MnO}_{2}$ nanosheets sheath in this core-shell architecture plays a synergistic role in stabilizing a conductive network with minimized volume change. The 1D CNFs act as a backbone to homogeneously support the water pillared $\mathrm{MnO}_{2}$ nanosheets, which enhances the flexibility of the skeleton to buffer the strain and structural collapse upon cycling, demonstrating exceptional cycling stability in a broad range of current densities with reliability and resiliency (Figure 4.5).
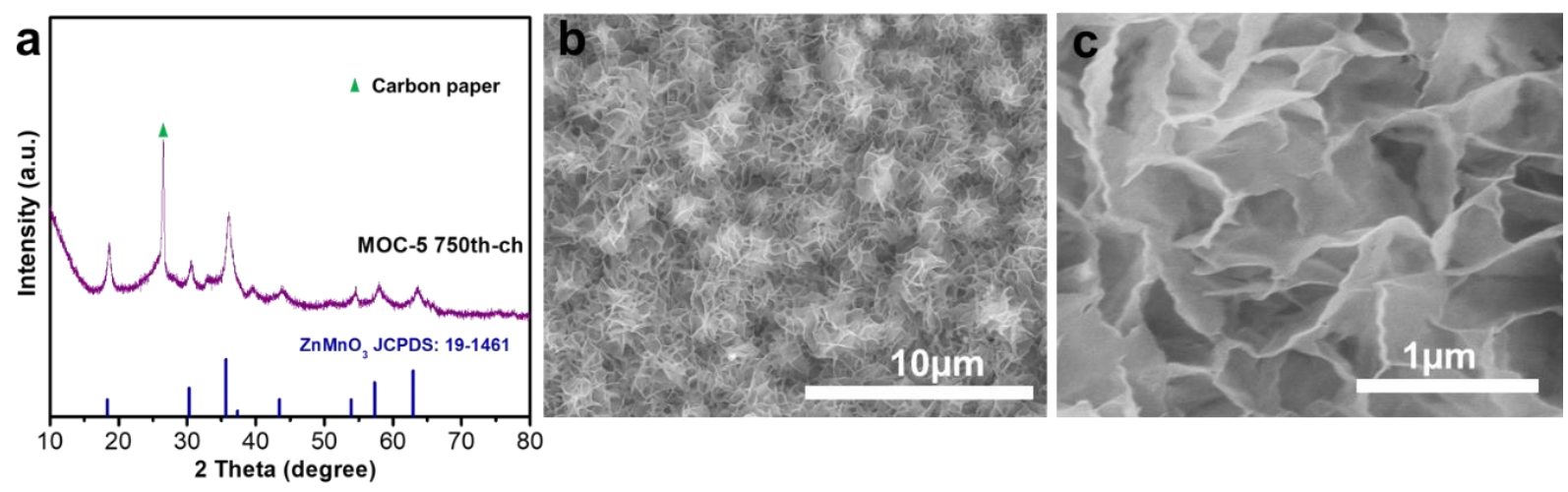

Figure 4. 11 (a) XRD and (b, c) SEM images of MOC-5 cathode at fully charged state after 750 cycles at a current density of $200 \mathrm{~mA} \mathrm{~g}^{-1}$.

\subsection{Conclusion}


In summary, we reported the rational design of hierarchical core-shell structure of $\mathrm{CNF} @ \mathrm{MnO}_{2}$ as the cathode for rechargeable aqueous ZIBs. The $\mathrm{CNF} @ \mathrm{MnO}_{2}$ architecture featuring in situ grown of vertically aligned birnessite- $\mathrm{MnO}_{2}$ nanosheets on the surface of carbon nanofibers was synthesized by a facile and scalable method combining solid-grinding and a wet-chemical reaction without the complicated pre-treatment with strongly oxidative acids. The $\mathrm{CNF} @ \mathrm{MnO}_{2}$ cathode delivers high-rate capability, long shelf life and the exceptional cycling stability in a broad range of current densities. A high capacity of $221 \mathrm{mAh} \mathrm{g}^{-1}$ was maintained after 700 cycles at $200 \mathrm{~mA}$

$\mathrm{g}^{-1}$. At a moderate current density of $1000 \mathrm{~mA} \mathrm{~g}^{-1}$, an extremely stable reversible capacity of 232 $\mathrm{mAh} \mathrm{g}^{-1}$ was retained for 1500 cycles. Even at a high current density of $3000 \mathrm{~mA} \mathrm{~g}^{-1}$, almost $100 \%$ capacity retention was still achieved after 2750 cycles. Such phenomenal electrochemical performance is likely attributed to the synergistic effect of CNF backbone and $\mathrm{MnO}_{2}$ shell on facilitating electronic and ionic transfer kinetics and structural stability along with the pillar role of crystal water in the interlayers. Considering the simplicity of fabrication, rational design of hierarchical core-shell architecture for synergism and exceptional electrochemical performance, the $\mathrm{CNF} @ \mathrm{MnO}_{2}$ will be a highly promising cathode candidate for low-cost and high-performance aqueous rechargeable ZIBs.

\section{References}

[1] N. Zhang, F. Cheng, J. Liu, L. Wang, X. Long, X. Liu, F. Li, J. Chen, Rechargeable aqueous zinc-manganese dioxide batteries with high energy and power densities, Nat. Commun. 8 (2017) 1-9.

[2] B. Lee, H.R. Lee, H. Kim, K.Y. Chung, B.W. Cho, S.H. Oh, Elucidating the intercalation mechanism of zinc ions into $\alpha-\mathrm{MnO}_{2}$ for rechargeable zinc batteries, Chem. Commun. 51 (2015) 9265-9268.

[3] M.H. Alfaruqi, V. Mathew, J. Gim, S. Kim, J. Song, J.P. Baboo, S.H. Choi, J. Kim, Electrochemically induced structural transformation in a $\gamma-\mathrm{MnO}_{2}$ cathode of a high capacity zincion battery system, Chem. Mater. 27 (2015) 3609-3620.

[4] M.H. Alfaruqi, J. Gim, S. Kim, J. Song, D.T. Pham, J. Jo, Z. Xiu, V. Mathew, J. Kim, A layered $\delta-\mathrm{MnO}_{2}$ nanoflake cathode with high zinc-storage capacities for eco-friendly battery applications, Electrochem. Commun. 60 (2015) 121-125. 
[5] Y. Jiang, D. Ba, Y. Li, J. Liu, Noninterference revealing of "layered to layered" zinc storage mechanism of $\delta-\mathrm{mno}_{2}$ toward neutral $\mathrm{Zn}-\mathrm{Mn}$ batteries with superior performance, Adv. Sci. (2020).

[6] K.W. Nam, H. Kim, J.H. Choi, J.W. Choi, Crystal water for high performance layered manganese oxide cathodes in aqueous rechargeable zinc batteries, Energy Environ. Sci. 12 (2019) 1999-2009.

[7] Y. Fu, Q. Wei, G. Zhang, X. Wang, J. Zhang, Y. Hu, D. Wang, L. Zuin, T. Zhou, Y. Wu, S. Sun, High-performance reversible aqueous $\mathrm{Zn}$-ion battery based on porous $\mathrm{MnO}_{\mathrm{x}}$ nanorods coated by MOF-derived n-doped carbon, Adv. Energy Mater. 8 (2018) 1-13.

[8] M.H. Alfaruqi, S. Islam, D.Y. Putro, V. Mathew, S. Kim, J. Jo, S. Kim, Y.K. Sun, K. Kim, J. Kim, Structural transformation and electrochemical study of layered $\mathrm{MnO}_{2}$ in rechargeable aqueous zinc-ion battery, Electrochim. Acta. 276 (2018) 1-11.

[9] X. Zhang, S. Wu, S. Deng, W. Wu, Y. Zeng, X. Xia, G. Pan, Y. Tong, X. Lu, 3D CNTs networks enable $\mathrm{MnO}_{2}$ cathodes with high capacity and superior rate capability for flexible rechargeable $\mathrm{Zn}-\mathrm{MnO}_{2}$ batteries, Small Methods. 1900525 (2019) 1-9.

[10] S.C. Sekhar, G. Nagaraju, S.M. Cha, J.S. Yu, Birnessite-type $\mathrm{MnO}_{2}$ nanosheet arrays with interwoven arrangements on vapor grown carbon fibers as hybrid nanocomposites for pseudocapacitors, Dalt. Trans. 45 (2016) 19322-19328.

[11] H. Xia, M. Lai, L. Lu, Nanoflaky $\mathrm{MnO}_{2} /$ carbon nanotube nanocomposites as anode materials for lithium-ion batteries, J. Mater. Chem. 20 (2010) 6896-6902.

[12] D. Xu, B. Li, C. Wei, Y.B. He, H. Du, X. Chu, X. Qin, Q.H. Yang, F. Kang, Preparation and characterization of $\mathrm{MnO}_{2} /$ acid-treated $\mathrm{CNT}$ nanocomposites for energy storage with zinc ions, Electrochim. Acta. 133 (2014) 254-261.

[13] X. Li, W. Li, M. Li, P. Cui, D. Chen, T. Gengenbach, L. Chu, H. Liu, G. Song, Glucoseassisted synthesis of the hierarchical $\mathrm{TiO}_{2}$ nanowire@ $\mathrm{MoS}_{2}$ nanosheet nanocomposite and its synergistic lithium storage performance, J. Mater. Chem. A. 3 (2015) 2762-2769.

[14] X. Li, G. Wu, X. Liu, W. Li, M. Li, Orderly integration of porous $\mathrm{TiO}_{2}(\mathrm{~B})$ nanosheets into bunchy hierarchical structure for high-rate and ultralong-lifespan lithium-ion batteries, Nano Energy. 31 (2017) 1-8. 
[15] J. Huang, Z. Wang, M. Hou, X. Dong, Y. Liu, Y. Wang, Y. Xia, Polyaniline-intercalated manganese dioxide nanolayers as a high-performance cathode material for an aqueous zinc-ion battery, Nat. Commun. 9 (2018) 1-8.

[16] T. Xiong, Z.G. Yu, H. Wu, Y. Du, Q. Xie, J. Chen, Y.W. Zhang, S.J. Pennycook, W.S.V. Lee, J. Xue, Defect engineering of oxygen-deficient manganese oxide to achieve high-performing aqueous zinc ion battery, Adv. Energy Mater. 9 (2019) 1-9.

[17] D. Chen, D. Ding, X. Li, G.H. Waller, X. Xiong, M.A. El-Sayed, M. Liu, Probing the charge storage mechanism of a pseudocapacitive $\mathrm{MnO}_{2}$ electrode using in operando raman spectroscopy, Chem. Mater. 27 (2015) 6608-6619.

[18] M. Yao, Z. Zeng, H. Zhang, J. Yan, X. Liu, Electrophoretic deposition of carbon nanofibers/silicon film with honeycomb structure as integrated anode electrode for lithium-ion batteries, Electrochim. Acta. 281 (2018) 312-322.

[19] Z. Lei, J. Zhang, X.S. Zhao, Ultrathin $\mathrm{MnO}_{2}$ nanofibers grown on graphitic carbon spheres as high-performance asymmetric supercapacitor electrodes, J. Mater. Chem. 22 (2012) 153-160.

[20] M. Sun, B. Lan, T. Lin, G. Cheng, F. Ye, L. Yu, X. Cheng, X. Zheng, Controlled synthesis of nanostructured manganese oxide: crystalline evolution and catalytic activities, CrystEngComm. 15 (2013) 7010-7018.

[21] W. Chen, G. Li, A. Pei, Y. Li, L. Liao, H. Wang, J. Wan, Z. Liang, G. Chen, H. Zhang, J. Wang, Y. Cui, A manganese-hydrogen battery with potential for grid-scale energy storage, Nat. Energy. 3 (2018) 428-435.

[22] J. Wang, J.G. Wang, H. Liu, C. Wei, F. Kang, Zinc ion stabilized $\mathrm{MnO}_{2}$ nanospheres for high capacity and long lifespan aqueous zinc-ion batteries, J. Mater. Chem. A. 7 (2019) 1372713735.

[23] A.S. Poyraz, J. Laughlin, Z. Zec, Improving the cycle life of cryptomelane type manganese dioxides in aqueous rechargeable zinc ion batteries: The effect of electrolyte concentration, Electrochim. Acta. 305 (2019) 423-432.

[24] J.G. Wang, Y. Yang, Z.H. Huang, F. Kang, A high-performance asymmetric supercapacitor based on carbon and carbon- $\mathrm{MnO}_{2}$ nanofiber electrodes, Carbon N. Y. 61 (2013) 190-199. 
[25] G. Fang, C. Zhu, M. Chen, J. Zhou, B. Tang, X. Cao, X. Zheng, A. Pan, S. Liang, Suppressing manganese dissolution in potassium manganate with rich oxygen defects engaged high-energy-density and durable aqueous zinc-ion battery, Adv. Funct. Mater. 29 (2019) 1-9.

[26] B. Wu, G. Zhang, M. Yan, T. Xiong, P. He, L. He, X. Xu, L. Mai, Graphene scroll-coated $\alpha-m_{2}$ nanowires as high-performance cathode materials for aqueous $\mathrm{Zn}$-ion battery, Small. 14 (2018) 1-8.

[27] M. Han, J. Huang, S. Liang, L. Shan, X. Xie, Z. Yi, Y. Wang, S. Guo, J. Zhou, Oxygen defects in $\beta-\mathrm{MnO}_{2}$ enabling high-performance rechargeable aqueous zinc/manganese dioxide battery, IScience. 23 (2020) 100797.

[28] J. Lee, J.B. Ju, W. Il Cho, B.W. Cho, S.H. Oh, Todorokite-type $\mathrm{MnO}_{2}$ as a zinc-ion intercalating material, Electrochim. Acta. 112 (2013) 138-143.

[29] H. Pan, Y. Shao, P. Yan, Y. Cheng, K.S. Han, Z. Nie, C. Wang, J. Yang, X. Li, P. Bhattacharya, K.T. Mueller, J. Liu, Reversible aqueous zinc/manganese oxide energy storage from conversion reactions, Nat. Energy. 1 (2016) 1-7.

[30] L. Shan, J. Zhou, M. Han, G. Fang, X. Cao, X. Wu, S. Liang, Reversible Zn-driven reduction displacement reaction in aqueous zinc-ion battery, J. Mater. Chem. A. 7 (2019) 73557359.

[31] P. He, M. Yan, G. Zhang, R. Sun, L. Chen, Q. An, L. Mai, Layered VS 2 nanosheet-based aqueous zn ion battery cathode, Adv. Energy Mater. 7 (2017) 2-6.

[32] L. Zhang, L. Chen, X. Zhou, Z. Liu, Towards high-voltage aqueous metal-ion batteries beyond 1.5 V: The zinc/zinc hexacyanoferrate system, Adv. Energy Mater. 5 (2015) 1-5.

[33] D. Wang, L. Wang, G. Liang, H. Li, Z. Liu, Z. Tang, J. Liang, C. Zhi, A Superior $\delta-\mathrm{MnO}_{2}$ cathode and a self-healing $\mathrm{Zn}-\delta-\mathrm{MnO}_{2}$ battery, ACS Nano. 13 (2019) 10643-10652.

[34] Y. Jin, L. Zou, L. Liu, M.H. Engelhard, R.L. Patel, Z. Nie, K.S. Han, Y. Shao, C. Wang, J. Zhu, H. Pan, J. Liu, Joint charge storage for high-rate aqueous zinc-manganese dioxide batteries, Adv. Mater. 31 (2019) 1-8.

[35] Y. Li, S. Wang, J.R. Salvador, J. Wu, B. Liu, W. Yang, J. Yang, W. Zhang, J. Liu, J. Yang, Reaction mechanisms for long-life rechargeable $\mathrm{Zn} / \mathrm{MnO}_{2}$ batteries, Chem. Mater. 31 (2019) 2036-2047. 
[36] T.C. Liu, W.G. Pell, B.E. Conway, S.L. Roberson, Behavior of molybdenum nitrides as materials for electrochemical capacitors comparison with ruthenium oxide, J. Electrochem. Soc. 145 (1998) 1882-1888.

[37] V. Augustyn, P. Simon, B. Dunn, Pseudocapacitive oxide materials for high-rate electrochemical energy storage, Energy Environ. Sci. 7 (2014) 1597-1614.

[38] S. Guo, S. Liang, B. Zhang, G. Fang, D. Ma, J. Zhou, Cathode interfacial layer formation via in situ electrochemically charging in aqueous zinc-ion battery, ACS Nano. 13 (2019) 1345613464.

[39] W. Sun, F. Wang, S. Hou, C. Yang, X. Fan, Z. Ma, T. Gao, F. Han, R. Hu, M. Zhu, C. Wang, $\mathrm{Zn} / \mathrm{MnO}_{2}$ battery chemistry with $\mathrm{H}^{+}$and $\mathrm{Zn}^{2+}$ Coinsertion, J. Am. Chem. Soc. 139 (2017) 9775-9778.

[40] N. Zhang, F. Cheng, Y. Liu, Q. Zhao, K. Lei, C. Chen, X. Liu, J. Chen, Cation-deficient spinel $\mathrm{ZnMn}_{2} \mathrm{O}_{4}$ cathode in $\mathrm{Zn}\left(\mathrm{CF}_{3} \mathrm{SO}_{3}\right)_{2}$ electrolyte for rechargeable aqueous $\mathrm{Zn}$-ion battery, $\mathrm{J}$. Am. Chem. Soc. 138 (2016) 12894-12901.

[41] Y. Liu, X. Chi, Q. Han, Y. Du, J. Huang, Y. Liu, J. Yang, $\alpha-\mathrm{MnO}_{2}$ nanofibers/carbon nanotubes hierarchically assembled microspheres: Approaching practical applications of highperformance aqueous Zn-ion batteries, J. Power Sources. 443 (2019) 1-8.

[42] H. Zhang, J. Wang, Q. Liu, W. He, Z. Lai, X. Zhang, M. Yu, Y. Tong, X. Lu, Extracting oxygen anions from $\mathrm{ZnMn}_{2} \mathrm{O}_{4}$ : Robust cathode for flexible all-solid-state $\mathrm{Zn}$-ion batteries, Energy Storage Mater. 21 (2019) 154-161.

[43] Y. Huang, J. Mou, W. Liu, X. Wang, L. Dong, F. Kang, C. Xu, Novel insights into energy storage mechanism of aqueous rechargeable $\mathrm{Zn} / \mathrm{MnO}_{2}$ batteries with participation of $\mathrm{Mn}^{2+}$, NanoMicro Lett. 11 (2019).

[44] D. Kundu, S. Hosseini Vajargah, L. Wan, B. Adams, D. Prendergast, L.F. Nazar, Aqueous: Vs. nonaqueous Zn-ion batteries: Consequences of the desolvation penalty at the interface, Energy Environ. Sci. 11 (2018) 881-892.

[45] A. Minelli, P. Dolcet, S. Diodati, S. Gardonio, C. Innocenti, D. Badocco, S. Gialanella, P. Pastore, L. Pandolfo, A. Caneschi, A. Trapananti, S. Gross, Pursuing the stabilisation of crystalline nanostructured magnetic manganites through a green low temperature hydrothermal synthesis, J. Mater. Chem. C. 5 (2017) 3359-3371. 
[46] X. Liu, C. Zhao, H. Zhang, Q. Shen, Facile synthesis of porous $\mathrm{ZnMnO}_{3}$ spherulites with a high lithium storage capability, Electrochim. Acta. 151 (2015) 56-62.

[47] M. Yan, P. He, Y. Chen, S. Wang, Q. Wei, K. Zhao, X. Xu, Q. An, Y. Shuang, Y. Shao, K.T. Mueller, L. Mai, J. Liu, J. Yang, Water-lubricated intercalation in $\mathrm{V}_{2} \mathrm{O}_{5} \cdot \mathrm{nH}_{2} \mathrm{O}$ for highcapacity and high-Rate aqueous rechargeable zinc batteries, Adv. Mater. 30 (2018) 1-6.

[48] K.W. Nam, S. Kim, S. Lee, M. Salama, I. Shterenberg, Y. Gofer, J.S. Kim, E. Yang, C.S. Park, J.S. Kim, S.S. Lee, W.S. Chang, S.G. Doo, Y.N. Jo, Y. Jung, D. Aurbach, J.W. Choi, The high performance of crystal water containing manganese birnessite cathodes for magnesium batteries, Nano Lett. 15 (2015) 4071-4079. 


\section{Chapter 5: Stabilizing Zn Plating/Stripping Electrochemistry by PVA Coating-induced Preferred Crystal Orientation}

\subsection{Introduction}

Aqueous $\mathrm{Zn}$-based batteries hold substantial promise for high energy and high safety energy storage applications owing to the intrinsic merits of $\mathrm{Zn}$ metal anodes, which have a high theoretical capacity ( $\left.820 \mathrm{mAh} \mathrm{g}^{-1}\right)$, suitable redox potential ( $-0.76 \mathrm{~V}$ vs. standard hydrogen electrode (SHE)), low cost, high abundance, and eco-friendliness. Recently, zinc ion batteries (ZIBs) with mild electrolytes have been intensively investigated as the potential candidates for large-scale energy storage applications.[1-4] Although the degradation of $\mathrm{Zn}$ anodes is less severe in mildly acidic electrolytes than traditional alkaline electrolytes, aqueous zinc salt-based electrolytes pose some common problems on $\mathrm{Zn}$ anodes, resulting in limited reversibility and poor stability and thus hindering the commercialization of high-energy density and cost-effective ZIBs. The limited Zn electrochemical reversibility are highly associated with the spontaneous side reactions occurring at the interfaces between $\mathrm{Zn}$ anodes and aqueous electrolytes, including dendrite growth, corrosion, competitive hydrogen evolution, and surface passivation.[5-7] The uneven Zn nucleation induces the dendrite growth on the electrode surface upon electrochemical deposition, which may penetrate a separator and give rise to short circuit. Meanwhile, the loose dendritic morphology with more exposed freshly deposited $\mathrm{Zn}$ exacerbates the surface corrosion, leading to a competitive hydrogen evolution reaction (HER) during Zn plating. The proton consumption in the undesired HER increases the local $\mathrm{pH}$ value and aggravates the passive byproduct formation on electrode surface, thereby reducing the reactivity of $\mathrm{Zn}$ anode. Both the HER and passive product formation/buildup at the cost of $\mathrm{H}_{2} \mathrm{O}$ consumption can cause the exhaustion of aqueous electrolytes and eventually lead to the cell failure.

Many efforts have been devoted to improving the reversibility and stability of $\mathrm{Zn}$ electrochemistry through stabilizing the interfacial reaction behaviors of $\mathrm{Zn}$ anodes, such as optimizing electrolyte formulations, tailoring novel $\mathrm{Zn}$ electrode structures, and electrode surface modification (i.e. constructing artificial surface coating or $\mathrm{Zn}$ alloying). $[6,8,9]$ However, it is still challenging to have a holistic approach to addressing all issues comprehensively. Regulating electrolyte composition using additives (polymers, brighteners, or surfactants) has been widely 
investigated to alleviate $\mathrm{Zn}$ dendrite formation and inhibit corrosion.[5,10-15] However, novel electrolytes with less toxicity, facile preparation, high efficiency, and low cost are still in high demand. Constructing three-dimensional (3D) structures of $\mathrm{Zn}$ on conductive host skeletons such as metal meshes, foams and carbon matrices has been reported to restrict $\mathrm{Zn}$ dendrite growth due to the uniform electric field distribution and reduced side reactions associated with shape change. [16-19] Notably, it is difficult to completely eliminate the dendrite growth by only using the 3D porous $\mathrm{Zn}$ anodes without the help of electrolyte additives for regulating $\mathrm{Zn}$ nucleation.[17,19] The increased electrochemically active surface areas of 3D $\mathrm{Zn}$ structures may also enhance the HER. Recently, surface modification of $\mathrm{Zn}$ with various coating layers has been reported to effectively inhibit dendrite growth through tuning current distribution and regulating electrolyte flux at the anode interface, including metal oxides,[20,21] polymer films,[22-24] and organicinorganic hybrid layers.[25] The strong adsorption ability of the organic materials is demonstrated beneficial for regulating the uniform $\mathrm{Zn}^{2+}$ distribution at the electrode/electrolyte interface and alleviating Zn dendrite formation.[26-28] Inspired by this, poly(vinyl alcohol) (PVA), an easily available polymer that features strong interaction with $\mathrm{Zn}^{2+}$, is anticipated favorable for stabilizing interfacial reactions of Zn plating/stripping.

Herein, we reported a durable and dendrite-free aqueous $\mathrm{Zn}$ anode enabled by PVA coating layer induced preferred crystal orientation. The strong interaction between PVA and $\mathrm{Zn}^{2+}$ ions rendered stabilized interfacial ion diffusion and homogeneous Zn nucleation. Benefiting from the protective effect of the PVA coating layer, the preferred Zn deposition along (002) basal plane and compact lamellar stacking on the electrode surface were achieved to inhibit dendrite growth and side reactions. Such smooth and dendrite-free $\mathrm{Zn}$ deposition ensured the superior electrochemical reversibility and exceptional long duration of the coated Zn anodes. Therefore, the PVA@Zn anodes exhibited ultralong cycle lifespan of thousands of hours at moderate current densities and durability under deep cycling capacities or high current densities as well as cyclability in $\mathrm{Zn} / \mathrm{V}_{2} \mathrm{O}_{5}$ full cells. This work demonstrated a simple coating method by using an easily available polymer of PVA and shed light on mechanistic understanding of the polymeric coating role for developing highly stable and cost-effective $\mathrm{Zn}$ anodes.

\subsection{Experimental section}




\subsubsection{Preparation of PVA-coated $\mathrm{Zn}$ anode}

Bare $\mathrm{Zn}$ foil (0.1 mm, Goodfellow) was polished using abrasive papers to remove the oxidation layer and cleaned with absolute ethanol under ultrasonication. These foils were used for PVA coating or control experiments. PVA solution was prepared by adding $0.2 \mathrm{~g}$ of PVA ( $\mathrm{Mw}=30,000-$ 70,000 , Sigma-Aldrich) into $2 \mathrm{~mL}$ of deionized water under stirring for $0.5 \mathrm{~h}$ at $80^{\circ} \mathrm{C}$ and then cooled to room temperature (RT) with continuous stirring for another $3 \mathrm{~h}$ to obtain a homogeneous solution. The solution was kept at RT overnight to remove bubbles. Subsequently, the PVA solution was casted on the surface of fresh $\mathrm{Zn}$ foil using a doctor blade method, followed by vacuum drying at $80^{\circ} \mathrm{C}$ overnight. The coated $\mathrm{Zn}$ foil was punched into discs with a diameter of $15 \mathrm{~mm}$. For comparison, the thickness of PVA film was adjusted by controlling doctor-blade thickness and PVA solution concentration. The obtained PVA coated $\mathrm{Zn}$ foils were denoted as PVA@Zn-1, 2, 3, and 4 based on the different thickness of PVA coating layers.

\subsubsection{Synthesis of $\mathrm{V}_{2} \mathrm{O}_{5}$ nanowire cathodes}

$\mathrm{V}_{2} \mathrm{O}_{5}$ nanowires were prepared by a simple hydrothermal method as cathodes for full cell test. Typically, $1 \mathrm{mmol} \mathrm{V}_{2} \mathrm{O}_{5}$ powder was dissolved in $25 \mathrm{~mL}$ of deionized water under magnetic stirring at RT. Then $2 \mathrm{~mL}$ of $\mathrm{H}_{2} \mathrm{O}_{2}(30$ wt. \%) were added in the above solution and kept continuously stirring for $1 \mathrm{~h}$ to form a transparent orange solution. The obtained solution was transferred into a $100 \mathrm{~mL}$ Teflon-lined stainless-steel autoclave and kept in an oven at $200{ }^{\circ} \mathrm{C}$ for $48 \mathrm{~h}$. After the autoclave had been cooled to RT, the precipitate was collected by centrifugation, washed with deionized water and ethanol for several times, and then dried at $80^{\circ} \mathrm{C}$ for overnight in a vacuum oven. Finally, the samples were annealed at $300{ }^{\circ} \mathrm{C}$ in a tube furnace (MTI OTF1200X-S) for $3 \mathrm{~h}$ in static air.

\subsubsection{Material characterization}

The morphology and composition of the samples were characterized by a scanning electron microscope (SEM, Hitachi S-4700) equipped with energy-dispersive X-ray (EDX) spectroscopy. The phase structure of samples was characterized using X'Pert Pro X-ray Diffraction (XRD, PANalytical, Almelo, Netherlands) with $\mathrm{Cu} \mathrm{K} \alpha$ radiation at $45 \mathrm{kV}$ and $40 \mathrm{~mA}$. The ${ }^{1} \mathrm{H}$ nuclear magnetic resonance (NMR) spectra of $0.7 \mathrm{~mL}$ solutions in $\mathrm{D} 2 \mathrm{O}$ were recorded on a $400 \mathrm{MHz}$ 
NMR spectrometer (Agilent, USA) using $5 \mathrm{~mm}$ tubes at $+25^{\circ} \mathrm{C}$. The $1 \mathrm{H}$ NMR spectra were referenced to the residual proton peaks (HDO) of $\mathrm{D}_{2} \mathrm{O}$ at $4.75 \mathrm{ppm}$.

\subsubsection{Electrochemical measurements}

Symmetrical Cells: The electrochemical performances of symmetrical and full cells were evaluated using CR2032-type coin cells on multichannel battery testing equipment (Arbin BT2143 $32 \mathrm{CH})$ at RT. The symmetrical cells were assembled using two bare or coated Zn plates separated by a glass microfiber separator (Whatman, $\mathrm{GF} / \mathrm{B}) \cdot \mathrm{Zn}\left(\mathrm{CF}_{3} \mathrm{SO}_{3}\right)_{2}$ aqueous solution $(2 \mathrm{M})$ was used as the electrolyte. For comparison, $2 \mathrm{M} \mathrm{Zn}\left(\mathrm{CF}_{3} \mathrm{SO}_{3}\right)_{2}$ electrolytes with $0.2,0.5$ and $1.0 \mathrm{wt} \%$ PVA electrolyte additive were also used to examine the effect of PVA on the Zn electrochemistry. The $\mathrm{Zn}$ plating/stripping test was performed at the current densities of $0.25-5 \mathrm{~mA} \mathrm{~cm}{ }^{-2}$ with the capacities of $0.25-1 \mathrm{mAh} \mathrm{cm}^{-2}$.

Half-cells: To evaluate the Coulombic efficiency of $\mathrm{Zn}$ plating/stripping, half cells were assembled using $\mathrm{Zn}$ foil as the counter electrode and bare or PVA-coated $\mathrm{Cu}$ foil as the working electrode with a glass microfiber separator in respective electrolytes. The cutoff voltage of halfcells was set as $1 \mathrm{~V}$ vs. $\mathrm{Zn} / \mathrm{Zn}^{2+}$ for plating/stripping at the current densities of $0.25-1 \mathrm{~mA} \mathrm{~cm}{ }^{-2}$.

$\mathrm{Zn} / \mathrm{V}_{2} \mathrm{O}_{5}$ full Cells: $\mathrm{V}_{2} \mathrm{O}_{5}$ cathodes were prepared from a mixture of $\mathrm{V}_{2} \mathrm{O}_{5}$, acetylene black and polyvinylidene fluoride (PVDF) in a mass ratio of 7:2:1. The slurry of mixture with NMP solvent was coated on a stainless steel mesh and dried at $60{ }^{\circ} \mathrm{C}$ for $12 \mathrm{~h}$ in a vacuum oven. Then the foil was cut into disks with a diameter of $10 \mathrm{~mm}$. The mass loading of active material is $\sim 1 \mathrm{mg} \mathrm{cm}^{-2}$. The $\mathrm{Zn} / \mathrm{V}_{2} \mathrm{O}_{5}$ cells were assembled similar to the symmetric cells except for replacing one $\mathrm{Zn}$ electrode with $\mathrm{V}_{2} \mathrm{O}_{5}$ cathode.

Linear polarization and chronoamperometry tests: Linear polarization experiments were performed in a three-electrode setup with a bare $\mathrm{Zn}$ foil or PVA coated $\mathrm{Zn}$ foil $(1 \mathrm{~cm} \times 1 \mathrm{~cm})$ as the working electrode, Ti sheet as the counter electrode, and saturated calomel electrode (SCE) as the reference electrode. The polarization curves were scanned in a potential window from -0.15 to $0.15 \mathrm{~V}$ vs. open circuit voltage $(\mathrm{OCV})$ at a scan rate of $0.2 \mathrm{mV} \mathrm{s}^{-1}$. Chronoamperometry tests were carried out in a three-electrode setup consisting of a Zn foil or PVA coated $\mathrm{Zn}$ foil $(1 \mathrm{~cm} \times 1$ $\mathrm{cm}$ ) as the working electrode, Pt wire as the counter electrode, and the SCE as the reference electrode. An overpotential of $-120 \mathrm{mV}$ vs. $\mathrm{Zn}^{2+/} \mathrm{Zn}$ was applied. 
Transparent cells and in situ optical microscope testing: The transparent symmetric cells with bare $\mathrm{Zn}$ and PVA coated $\mathrm{Zn}$ electrodes were assembled to in situ monitor the $\mathrm{Zn}$ plating/stripping process on different electrodes. The transparent cell consisted of glass slides and two Zn (or PVA coated Zn) strips. The glass slides were sealed using super glue to hold electrodes and a groove was reserved for adding electrolyte. The exposed area of each electrode in the electrolyte was controlled to $1 \mathrm{~cm} \times 0.5 \mathrm{~cm}$. The transparent cells were tested for galvanostatic $\mathrm{Zn}$ plating/stripping by an electrochemical workstation (Gamry Interface 5000E). The real-time observation of the plating/stripping processes on electrodes were recorded using digital microscope systems (Keyence VHX-7000 and Olympus DSX1000).

\subsection{Results and discussion}

\subsubsection{Electrochemical performance of symmetric batteries with PVA-coated Zn electrodes}

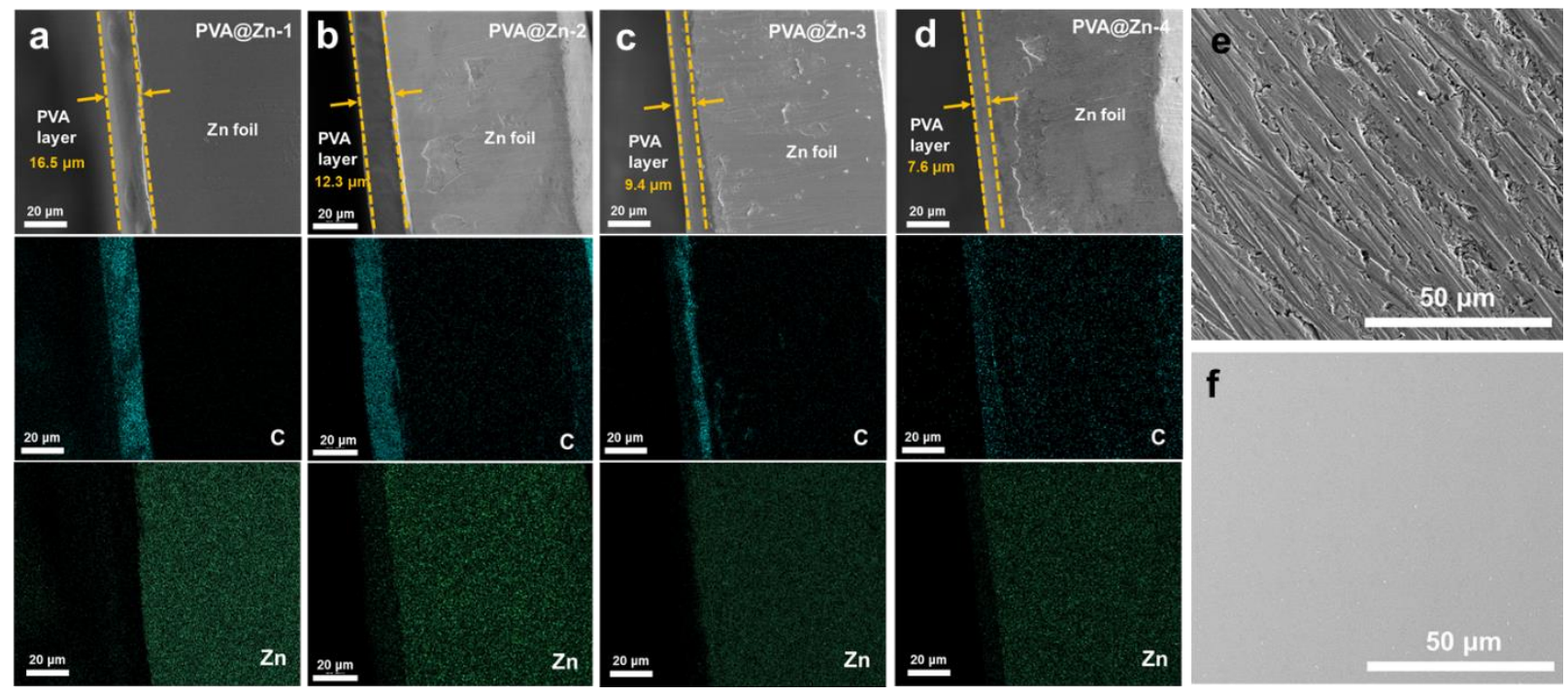

Figure 5. 1 a) Cross-sectional SEM images and corresponding EDX elemental maps of $\mathrm{C}$ and $\mathrm{Zn}$ for a)PVA@Zn-1, b)PVA@Zn-2, c) PVA@Zn-3, and d)PVA@Zn-4. Top view of SEM images of e) bare Zn foil and f) PVA@Zn-1.

The polished Zn foil was coated with PVA by a simple doctor-blade method. The thickness of PVA film was adjusted from 7.6 to $16.5 \mu \mathrm{m}$ by controlling doctor-blade conditions, as evidenced by EDX elemental maps of both Zn and C (Figure 5.1a-d). Compared with the rough surface of bare Zn electrode (Figure 5.1e), the PVA coated Zn electrode (PVA@Zn) showed a smooth and 
dense surface (Figure 5.1f). The PVA@Zn foil maintained the identical Zn crystallographic orientation as bare $\mathrm{Zn}$ foil (Figure 5.2a). With the presence of abundant intermolecular hydrogen bonds, $[29,30]$ the crosslinked PVA coating layer on $\mathrm{Zn}$ foil surface was stable in $\mathrm{Zn}(\mathrm{OTf})_{2}$ electrolyte (Figure 5.2b).
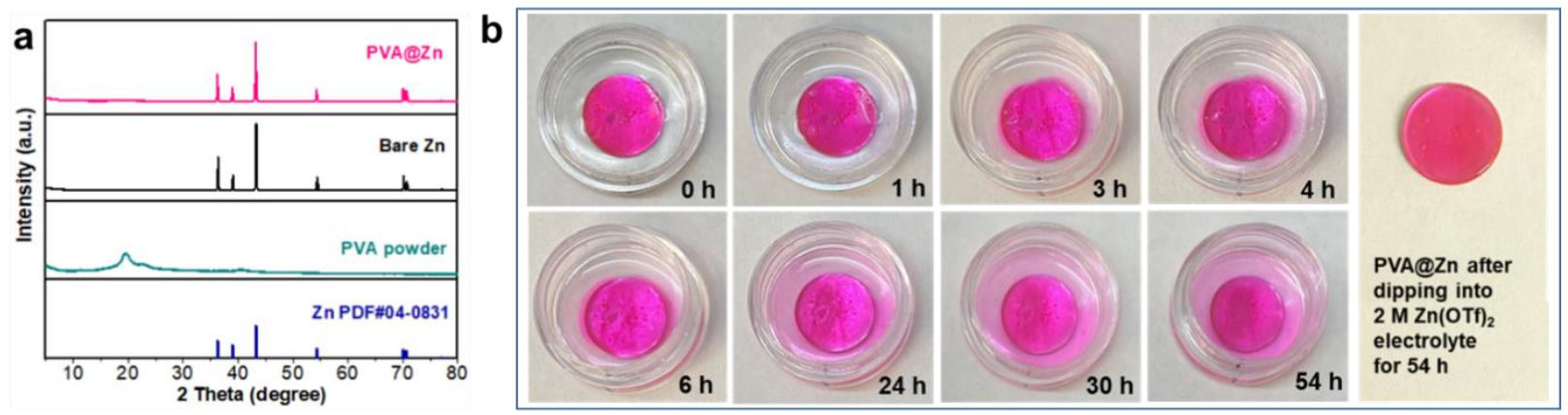

Figure 5. 2 a) X-ray diffraction (XRD) patterns of PVA powder, bare Zn foil and PVA@Zn foil. b) Photographs of the PVA@Zn electrode (pristine Zn foil coated by rhodamine B doped PVA solution for clarity) soaked into $2 \mathrm{M} \mathrm{Zn(OTf})_{2}$ electrolyte for different times.

Symmetric cells were assembled to evaluate the advantage of PVA film for stabilizing Zn plating/stripping behavior by galvanostatic charge-discharge cycling. At a current density of 0.25 $\mathrm{mA} \mathrm{cm}{ }^{-2}$ with a capacity of $0.25 \mathrm{mAh} \mathrm{cm}^{-2}$, the bare $\mathrm{Zn}$ electrodes showed limited stability for 136 h (Figure 5.3a). After that, an irreversible and sudden rise of polarization voltage appeared. In sharp contrast, the PVA@Zn electrodes delivered ultralong cycling stability and reversibility with lifespan up to 5000 h for PVA@Zn-1. Even with the thinnest PVA coating layer, PVA@Zn-4 demonstrated stability of over $900 \mathrm{~h}$. Similarly, a decent cycle life of over $2000 \mathrm{~h}$ was also observed for PVA@Zn-1 at $1 \mathrm{~mA} \mathrm{~cm}^{-2}$ with a capacity of $1 \mathrm{mAh} \mathrm{cm}^{-2}$ in contrast with the quick failure of bare Zn after $97 \mathrm{~h}$ (Figure 5.3b). Notably, the cycle lifespan of the PVA@Zn electrodes was proportional to the thickness of the PVA coating layer, whereas the overpotential of $\mathrm{Zn}$ plating/stripping was slightly increased with the thickness. It is proposed that the PVA coating layer with an adequate thickness can effectively prevent the freshly deposited $\mathrm{Zn}$ from direct contact with the excessive aqueous electrolyte, which reduces the possibility of severe undesired side reactions at the electrode/electrolyte interface, and thus enhances the reversibility of $\mathrm{Zn}$ plating/stripping.[31] The higher overpotential of the PVA@Zn electrodes compared to that of bare $\mathrm{Zn}$ is ascribed to the lower ionic conductivity in the coating polymer interface than that in the aqueous electrolyte. In the early cycling stage, the bare $\mathrm{Zn}$ surface is favorable for providing more 
active sites and high ion flux enabling lower overpotential. However, upon cycling, this can exacerbate the inhomogeneous deposition and other side reactions such as $\mathrm{Zn}$ corrosion and HER simultaneously, thus deteriorating the reversibility of $\mathrm{Zn}$.
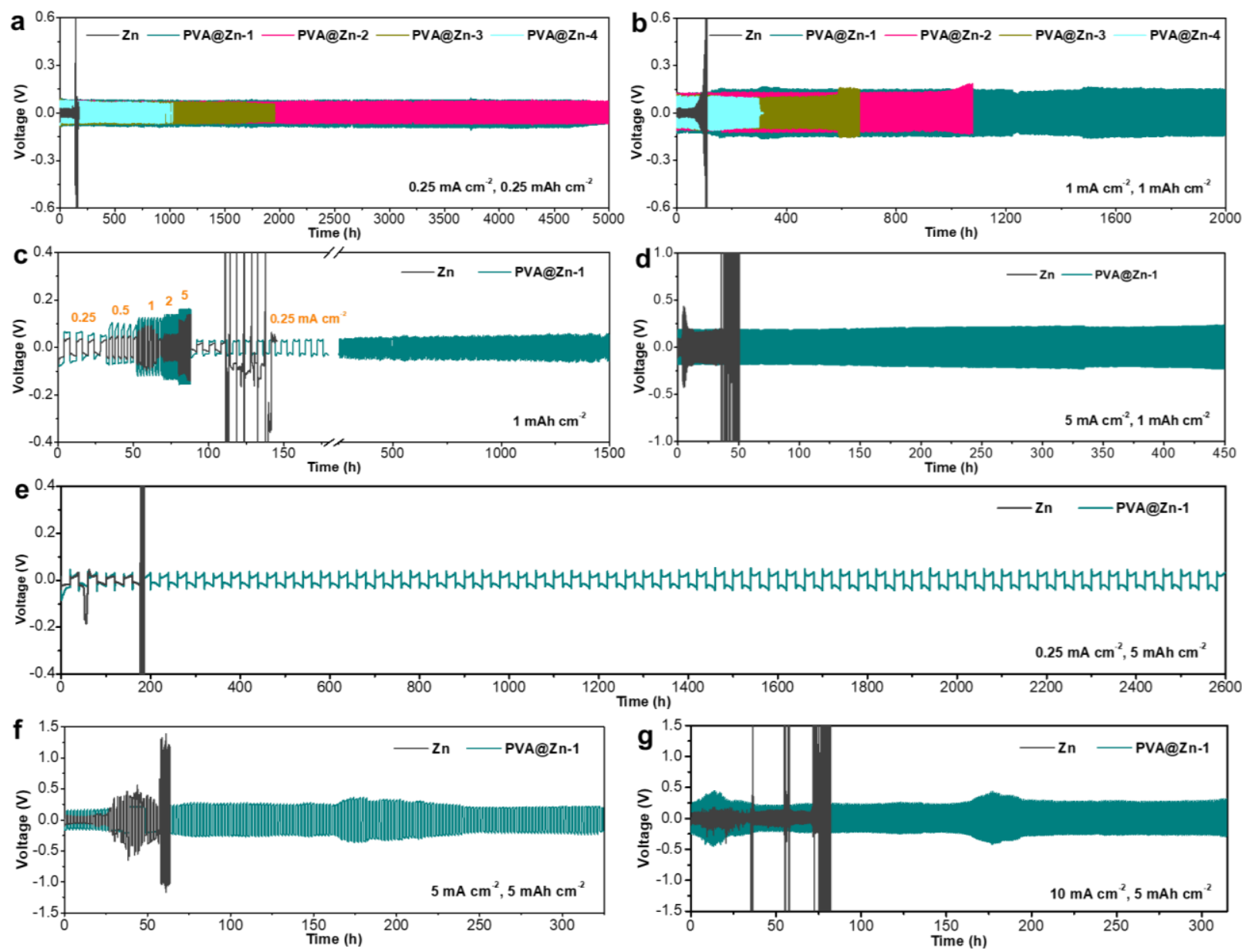

Figure 5. 3 Electrochemical performances of Zn and PVA@Zn electrodes in symmetric cells. Galvanostatic cycling of Zn electrodes and PVA@Zn electrodes with different thickness of PVA layer at a) $0.25 \mathrm{~mA} \mathrm{~cm}^{-2}$ for $0.25 \mathrm{mAh} \mathrm{cm}^{-2}$ and b) $1 \mathrm{~mA} \mathrm{~cm}^{-2}$ for $1 \mathrm{mAh} \mathrm{cm}^{-2}$. c) Rate performance of Zn and PVA@Zn electrodes at different current densities under a fixed capacity of $1 \mathrm{mAh} \mathrm{cm}^{-}$ ${ }^{2}$. d) Cycling performance of Zn and PVA@Zn electrodes at $5 \mathrm{~mA} \mathrm{~cm}{ }^{-2}$ for $1 \mathrm{mAh} \mathrm{cm}^{-2}$. Deep cycling stability of $\mathrm{Zn}$ and PVA@Zn electrodes at e) $0.25 \mathrm{~mA} \mathrm{~cm}{ }^{-2}$ with a plating/stripping capacity of $5 \mathrm{mAh} \mathrm{cm}^{-2}$, f) $5 \mathrm{~mA} \mathrm{~cm}^{-2}$ for $5 \mathrm{mAh} \mathrm{cm}^{-2}$, g) $10 \mathrm{~mA} \mathrm{~cm}^{-2}$ for $5 \mathrm{mAh} \mathrm{cm}^{-2}$.

Rate performance of the symmetric cells was evaluated at various current densities with a fixed capacity of $1 \mathrm{mAh} \mathrm{cm}^{-2}$ (Figure 5.3c). As the current density increased from $0.25,0.5,1,2$ to 5 mA cm-2, PVA@ Zn-1 electrode exhibited excellent rate capability with a reversible and stable 
voltage plateau as opposed to the largely fluctuated voltage profiles of bare $\mathrm{Zn}$. When the current density was recovered to $0.25 \mathrm{~mA} \mathrm{~cm}{ }^{-2}$, the PVA@Zn-1 electrode remained stable over $1500 \mathrm{~h}$, whereas the bare $\mathrm{Zn}$ failed after only 3 cycles. The cyclability at high current densities is of vital importance to ensure the applications with high power output requirements. The significantly enhanced Zn plating/stripping reversibility of PVA-coated Zn electrode was also observed at 5 $\mathrm{mA} \mathrm{cm} \mathrm{cm}^{-2}$ under $1 \mathrm{mAh} \mathrm{cm}^{-2}$ (Figure 5.3d). Furthermore, the advantage of PVA-coated $\mathrm{Zn}$ was examined under a large capacity of $5 \mathrm{mAh} \mathrm{cm}^{-2}$ (Figure 5.3e). At $0.25 \mathrm{~mA} \mathrm{~cm}^{-2}$ with a deep $\mathrm{Zn}$ plating/stripping of $20 \mathrm{~h}\left(5 \mathrm{mAh} \mathrm{cm} \mathrm{cm}^{-2}\right)$, PVA@Zn-1 electrode was stable over $2600 \mathrm{~h}$. Conversely, bare $\mathrm{Zn}$ electrode could only work for 4 cycles. Generally, the long duration of Zn plating might exacerbate the problem of dendrite growth and side reactions leading to cell failure. The high stability of voltage profiles over long-term deep cycling confirmed the superiority of the PVA coating layer for stabilizing Zn electrochemistry. Remarkably, at higher current densities of 5 and $10 \mathrm{~mA} \mathrm{~cm}^{-2}$ with a capacity of $5 \mathrm{mAh} \mathrm{cm}^{-2}$, PVA-coated $\mathrm{Zn}$ electrode still enabled durable $\mathrm{Zn}$ plating/stripping for more than $300 \mathrm{~h}$ (Figure 5.3f and 5.3g). The superior rate capability and long cycle life unequivocally evidenced the great protective effect of the PVA coating layer, which enabled high electrochemical reversibility with a steady ionic pathway for $\mathrm{Zn}^{2+}$ migration.[32] Compared with the previously reported $\mathrm{Zn}$ electrodes in $\mathrm{Zn}(\mathrm{OTf})_{2}$-based electrolytes (Table 5.1), PVA@Zn is considerably advantageous in long-term cycle life under a broad range of current densities and capacities.

Table 5. 1 Comparison of typical parameters and cycling performance of PVA@Zn symmetric cells in this work with those of reported $\mathrm{Zn}$ electrodes in $\mathrm{Zn}(\mathrm{OTf})_{2}$-based electrolytes.

\begin{tabular}{|c|c|c|c|c|c|c|}
\hline Strategy & Anode & Electrolyte & $\begin{array}{l}\text { Current } \\
\text { density } \\
\mathrm{mA} \mathrm{cm}\end{array}$ & 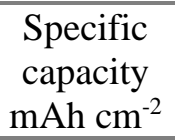 & $\begin{array}{c}\text { Cycle } \\
\text { time } \\
\mathrm{h}\end{array}$ & Reference \\
\hline \multirow{7}{*}{$\begin{array}{l}\text { Polymeric } \\
\text { coating }\end{array}$} & \multirow{6}{*}{ PVA@Zn } & \multirow{6}{*}{$2 \mathrm{M} \mathrm{Zn}(\mathrm{OTf})_{2}$} & 0.25 & 0.25 & 5000 & \multirow{6}{*}{ This work } \\
\hline & & & 0.25 & 5 & 2600 & \\
\hline & & & 1 & 1 & 2000 & \\
\hline & & & 5 & 1 & 450 & \\
\hline & & & 5 & 5 & 340 & \\
\hline & & & 10 & 5 & 320 & \\
\hline & & $1 \mathrm{M} \mathrm{Zn}\left((\mathrm{OTf})_{2}\right.$ & 0.2 & 0.2 & 1000 & \\
\hline
\end{tabular}




\begin{tabular}{|c|c|c|c|c|c|c|}
\hline \multirow{9}{*}{$\begin{array}{l}\text { Surface } \\
\text { coating }\end{array}$} & \multirow{2}{*}{$\begin{array}{l}\mathrm{Zn} @ \mathrm{ZnO} \\
\mathrm{HPA}\end{array}$} & \multirow[t]{2}{*}{$0.1 \mathrm{M} \mathrm{MnSO}_{4}$} & 1 & 1 & 400 & \multirow{2}{*}{$\begin{array}{l}\text { Adv. Funct. Mater., } \\
\text { 2020, 30, 2004210 }\end{array}$} \\
\hline & & & 5 & 2.5 & 100 & \\
\hline & $\mathrm{TiO}_{2} @ \mathrm{Zn}$ & $3 \mathrm{M} \mathrm{Zn}\left((\mathrm{OTf})_{2}\right.$ & 1 & 1 & 150 & $\begin{array}{c}\text { Adv. Mater. } \\
\text { Interfaces, } 2018,5, \\
1800848\end{array}$ \\
\hline & \multirow{3}{*}{$\mathrm{Al}_{2} \mathrm{O}_{3} @ \mathrm{Zn}$} & \multirow{3}{*}{$3 \mathrm{M} \mathrm{Zn}\left((\mathrm{OTf})_{2}\right.$} & 1 & 1 & 500 & \multirow{3}{*}{$\begin{array}{l}\text { J. Mater. Chem. A, } \\
\text { 2020,8, } 7836\end{array}$} \\
\hline & & & 2 & 1 & 50 & \\
\hline & & & 3 & 1 & 50 & \\
\hline & $\begin{array}{c}\text { CF@Zn@ } \\
\mathrm{C}\end{array}$ & $3 \mathrm{M} \mathrm{Zn}\left((\mathrm{OTf})_{2}\right.$ & 0.25 & 0.125 & 200 & $\begin{array}{l}\text { Adv. Funct. Mater., } \\
\text { 2021, 31, } 2008894\end{array}$ \\
\hline & \multirow{2}{*}{$\begin{array}{c}\mathrm{PAM} / \mathrm{PVP} \\
@ \mathrm{Zn}\end{array}$} & \multirow{2}{*}{$3 \mathrm{M} \mathrm{Zn}\left((\mathrm{OTf})_{2}\right.$} & 0.2 & 0.1 & 2220 & \multirow{2}{*}{$\begin{array}{l}\text { J. Mater. Chem. A., } \\
\text { 2020, 8, } 17725\end{array}$} \\
\hline & & & 1 & 0.5 & 600 & \\
\hline \multirow{7}{*}{$\begin{array}{l}\text { Structural } \\
\text { design }\end{array}$} & $\begin{array}{c}\mathrm{Zn} @ S S \\
\text { mesh }\end{array}$ & $3 \mathrm{M} \mathrm{Zn}\left((\mathrm{OTf})_{2}\right.$ & 2 & 1 & 300 & $\begin{array}{c}\text { Nano Energy, 2019, } \\
62,94\end{array}$ \\
\hline & \multirow{2}{*}{ Porous Zn } & \multirow{2}{*}{$2 \mathrm{M} \mathrm{Zn}\left((\mathrm{OTf})_{2}\right.$} & 0.5 & 0.1 & 1400 & \multirow{2}{*}{$\begin{array}{c}\text { Energy Storage } \\
\text { Mater., 2020, 30, } 104\end{array}$} \\
\hline & & & 5 & 10 & 200 & \\
\hline & \multirow{2}{*}{$\begin{array}{l}\mathrm{ZnAl} @ \mathrm{Cu}- \\
\text { mesh }\end{array}$} & \multirow{2}{*}{$3 \mathrm{M} \mathrm{Zn}\left((\mathrm{OTf})_{2}\right.$} & 0.5 & 0.25 & 240 & \multirow{2}{*}{$\begin{array}{c}\text { ACS Appl. Mater. } \\
\text { Interfaces, 2021, 13, } \\
28129\end{array}$} \\
\hline & & & 1 & 0.25 & 180 & \\
\hline & \multirow{2}{*}{ Zn paper } & \multirow{2}{*}{$2 \mathrm{M} \mathrm{Zn}\left((\mathrm{OTf})_{2}\right.$} & 1 & $\sim 0.167$ & 800 & \multirow{2}{*}{$\begin{array}{l}\text { Angew. Chem. Int. } \\
\text { Ed., 2021, 133, } 7289\end{array}$} \\
\hline & & & 10 & $\sim 1.67$ & 200 & \\
\hline \multirow{12}{*}{$\begin{array}{l}\text { Electrolyte } \\
\text { optimization }\end{array}$} & $\mathrm{Zn}$ foil & $3 \mathrm{M} \mathrm{Zn}\left((\mathrm{OTf})_{2}\right.$ & 0.1 & 0.1 & 400 & $\begin{array}{l}\text { J. Am. Chem. Soc., } \\
\text { 2016, 138, } 12894\end{array}$ \\
\hline & $\mathrm{Zn}$ foil & $\begin{array}{l}\mathrm{PVA} / 2 \mathrm{M} \\
\mathrm{Zn}\left((\mathrm{OTf})_{2}\right. \\
\text { hydrogel }\end{array}$ & 0.1 & 0.1 & 800 & $\begin{array}{l}\text { Angew. Chem. Int. } \\
\text { Ed., 2019, 131, } 4357\end{array}$ \\
\hline & \multirow{3}{*}{$\mathrm{Zn}$ foil } & \multirow{3}{*}{$\begin{array}{c}1 \mathrm{M} \mathrm{Zn}\left((\mathrm{OTf})_{2}\right. \\
+50 \mathrm{mM} \\
\text { dopamine } \\
(\mathrm{DA}) \text { additive }\end{array}$} & 1 & 1 & 1100 & \multirow{3}{*}{$\begin{array}{c}\text { Energy Environ. Sci., } \\
2021,14,5947\end{array}$} \\
\hline & & & 10 & 10 & 200 & \\
\hline & & & 30 & 30 & 75 & \\
\hline & \multirow{3}{*}{$\mathrm{Zn}$ foil } & \multirow{3}{*}{$\begin{array}{l}4 \mathrm{M} \mathrm{Zn}\left((\mathrm{OTf})_{2}\right. \\
+2 \mathrm{M} \mathrm{LiClO}_{4}\end{array}$} & 1 & 1 & 580 & \multirow{3}{*}{$\begin{array}{c}\text { Adv. Funct. Mater., } \\
\text { 2021, } 2103959\end{array}$} \\
\hline & & & 2 & 1 & 300 & \\
\hline & & & 5 & $\sim 0.83$ & 225 & \\
\hline & $\mathrm{Zn}$ foil & $\begin{array}{c}0.5 \mathrm{M} \\
\mathrm{Zn}\left((\mathrm{OTf})_{2} \text { in }\right. \\
\text { TEP: } \mathrm{H}_{2} \mathrm{O}(7: 3)\end{array}$ & 1 & 1 & 200 & $\begin{array}{l}\text { Angew. Chem. Int. } \\
\text { Ed., 2019, 58, } 2760\end{array}$ \\
\hline & \multirow{3}{*}{$\mathrm{Zn}$ foil } & \multirow{3}{*}{$\begin{array}{c}0.5 \mathrm{M} \\
\mathrm{Zn}\left((\mathrm{OTf})_{2} \text { in }\right. \\
\mathrm{TEP}(\mathrm{TEP} \text { as } \\
\text { solvent })\end{array}$} & 0.1 & 0.1 & 3000 & \multirow{3}{*}{$\begin{array}{l}\text { Angew. Chem. Int. } \\
\text { Ed., 2019, 58, } 2760\end{array}$} \\
\hline & & & 0.25 & 0.25 & 3000 & \\
\hline & & & 0.5 & 0.5 & 3000 & \\
\hline
\end{tabular}




\begin{tabular}{cccccc}
\cline { 3 - 4 } & & 0.8 & 0.8 & 600 & \\
\cline { 3 - 5 } & & 1 & 1 & 200 & \\
\cline { 3 - 5 } & 0.5 & 5 & 2000 & \\
\hline Zn foil & $\begin{array}{c}4 \mathrm{M} \text { Zn((OTf })_{2} \\
+0.5 \mathrm{M} \\
\mathrm{Me}_{3} \text { EtNOTF }\end{array}$ & 0.5 & 0.25 & 6000 & $\begin{array}{c}\text { Nat. Nanotechnol., } \\
2021,16,902\end{array}$ \\
\hline
\end{tabular}

PVA was also employed as an electrolyte additive owing to its water solubility. To further confirm the protective effect of PVA coating film on $\mathrm{Zn}$ stripping/plating reversibility, $\mathrm{Zn} / / \mathrm{Zn}$ symmetric cells with PVA-added electrolytes were tested as control samples. The bare $\mathrm{Zn}$ electrode in $2 \mathrm{M} \mathrm{Zn}\left(\mathrm{CF}_{3} \mathrm{SO}_{3}\right)_{2}$ electrolyte with different concentrations of PVA additive exhibited relatively good cycling stability under moderate testing conditions $\left(0.25 \mathrm{~mA} \mathrm{~cm}{ }^{-2}\right.$ for $0.25 \mathrm{mAh}$ $\mathrm{cm}^{-2}$ and $1 \mathrm{~mA} \mathrm{~cm}^{-2}$ for $1 \mathrm{mAh} \mathrm{cm}^{-2}$ ) (Figure 5.4a, b) and excellent rate capability (Figure 5.4c). However, the addition of dissolved PVA in the electrolyte cannot render satisfactory cycling stability of $\mathrm{Zn}$ under high current densities and/or large capacities $\left(5 \mathrm{~mA} \mathrm{~cm}{ }^{-2}\right.$ for $1 \mathrm{mAh} \mathrm{cm}^{-2}$ and $0.25-10 \mathrm{~mA} \mathrm{~cm}^{-2}$ for $5 \mathrm{mAh} \mathrm{cm}^{-2}$ ) (Figure 5.4d-f). This demonstrates that the PVA coating layer provides a superior stabilization effect for Zn electrodes to soluble PVA additive in the electrolyte.
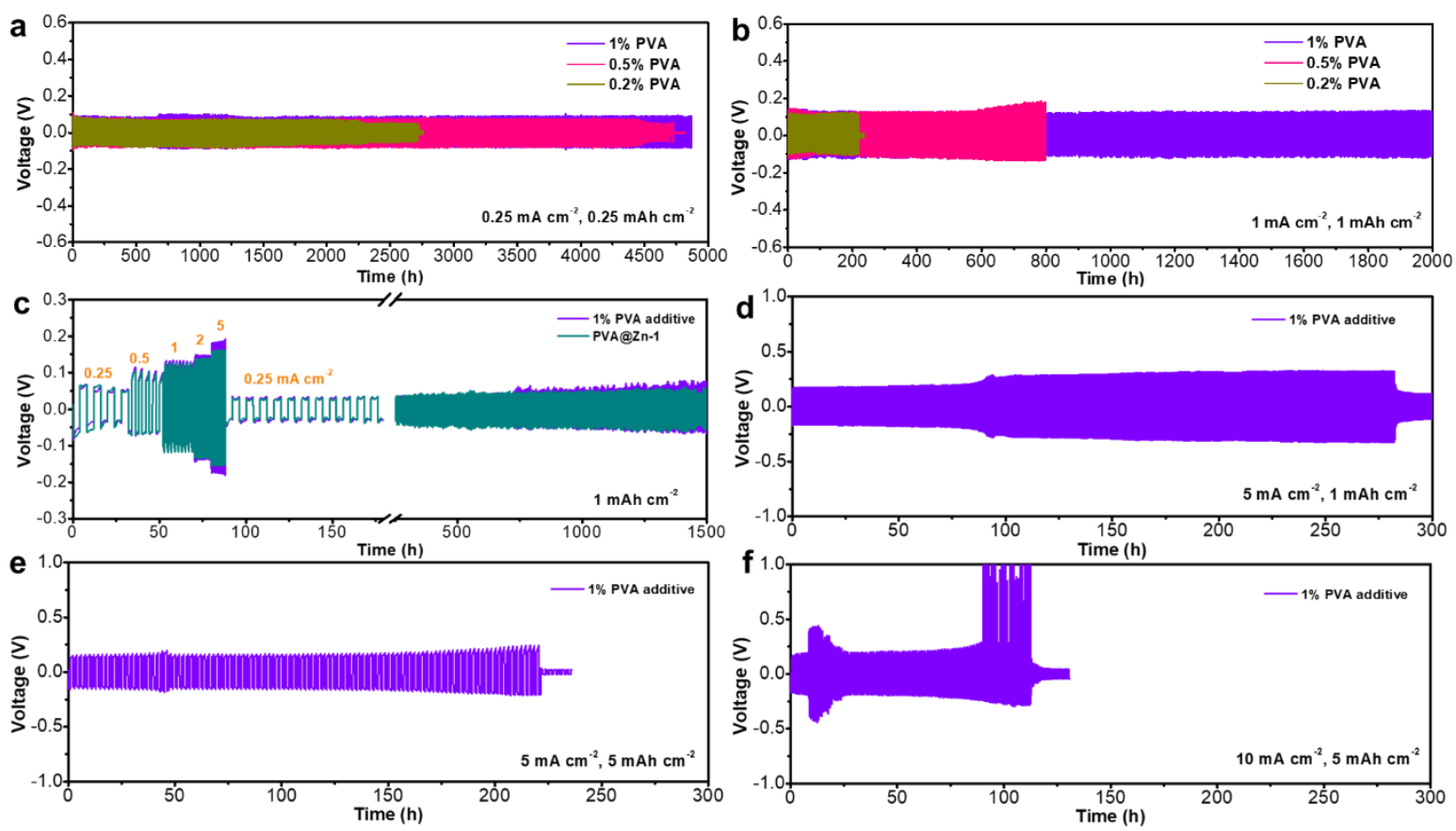

Figure 5. 4 Cycling performances of $\mathrm{Zn} / / \mathrm{Zn}$ symmetric cells in $2 \mathrm{M} \mathrm{Zn}\left(\mathrm{CF}_{3} \mathrm{SO}_{3}\right)_{2}$ electrolyte with $0.2,0.5$ and $1 \%$ PVA additive at a) $0.25 \mathrm{~mA} \mathrm{~cm}^{-2}$ for $0.25 \mathrm{mAh} \mathrm{cm}^{-2}$, and b) $1 \mathrm{~mA} \mathrm{~cm}^{-2}$ for $1 \mathrm{mAh}$ $\mathrm{cm}^{-2}$. c) Rate performance of symmetric cells of PVA@Zn electrodes in $2 \mathrm{M} \mathrm{Zn}\left(\mathrm{CF}_{3} \mathrm{SO}_{3}\right)_{2}$ 
electrolyte and bare $\mathrm{Zn}$ electrodes in $2 \mathrm{M} \mathrm{Zn}\left(\mathrm{CF}_{3} \mathrm{SO}_{3}\right)_{2}$ electrolyte with $1 \%$ PVA additive at current densities of $0.25-5 \mathrm{~mA} \mathrm{~cm}^{-2}$ with a fixed capacity of $1 \mathrm{mAh} \mathrm{cm}^{-2}$. Cycling performances of bare $\mathrm{Zn}$ electrodes in $2 \mathrm{M} \mathrm{Zn}\left(\mathrm{CF}_{3} \mathrm{SO}_{3}\right)_{2}$ electrolyte with $1 \%$ PVA additive at d) $5 \mathrm{~mA} \mathrm{~cm}{ }^{-2}$ for $1 \mathrm{mAh}$ $\mathrm{cm}^{-2}$, e) $5 \mathrm{~mA} \mathrm{~cm}^{-2}$ for $5 \mathrm{mAh} \mathrm{cm}^{-2}$, and f) $10 \mathrm{~mA} \mathrm{~cm}^{-2}$ for $5 \mathrm{mAh} \mathrm{cm}^{-2}$.

\subsubsection{Suppression of dendrite growth and side reactions by PVA coating induced preferential crystal growth}

To unravel the protective mechanism of PVA coating layer, postmortem characterization was carried out on the bare and PVA coated Zn anodes from the cycled symmetric cells. Three main issues associated with the interfacial reactions were explored, including HER, dendrite formation, and passive byproduct formation. First, the PVA coating effectively mitigated the gassing issue. The volume expansion of symmetric cells after galvanostatic cycling was assessed to reflect the extent of HER leading to $\mathrm{H}_{2}$ accumulation. The bare $\mathrm{Zn}$ symmetric cell after $100 \mathrm{~h}$ cycling exhibited apparent volume expansion with the cell thickness increased to $4.73 \mathrm{~mm}$ from $3.15 \mathrm{~mm}$

of the fresh cell (Figure 5.5a and 5.5c). The substantial $\mathrm{H}_{2}$ production in bare $\mathrm{Zn}$ coin cells caused a sudden increase of polarization voltage and cell failure in short cycles. In contrast, for the PVAcoated Zn electrodes, the shape of coin cell was well-maintained without obvious thickness change after cycling of $100 \mathrm{~h}$ (Figure 5.5b and 5.5d). Even after long-term cycling of $1080 \mathrm{~h}$, only a slight thickness increase was observed (Figure 5.5e), demonstrating a critical role of PVA coating layer in reducing $\mathrm{H}_{2}$ evolution rate. $[32,33]$ The capability of PVA in suppressing cell volume expansion was also found when PVA was used as electrolyte additive (Figure 5.6a and 5.6b). 

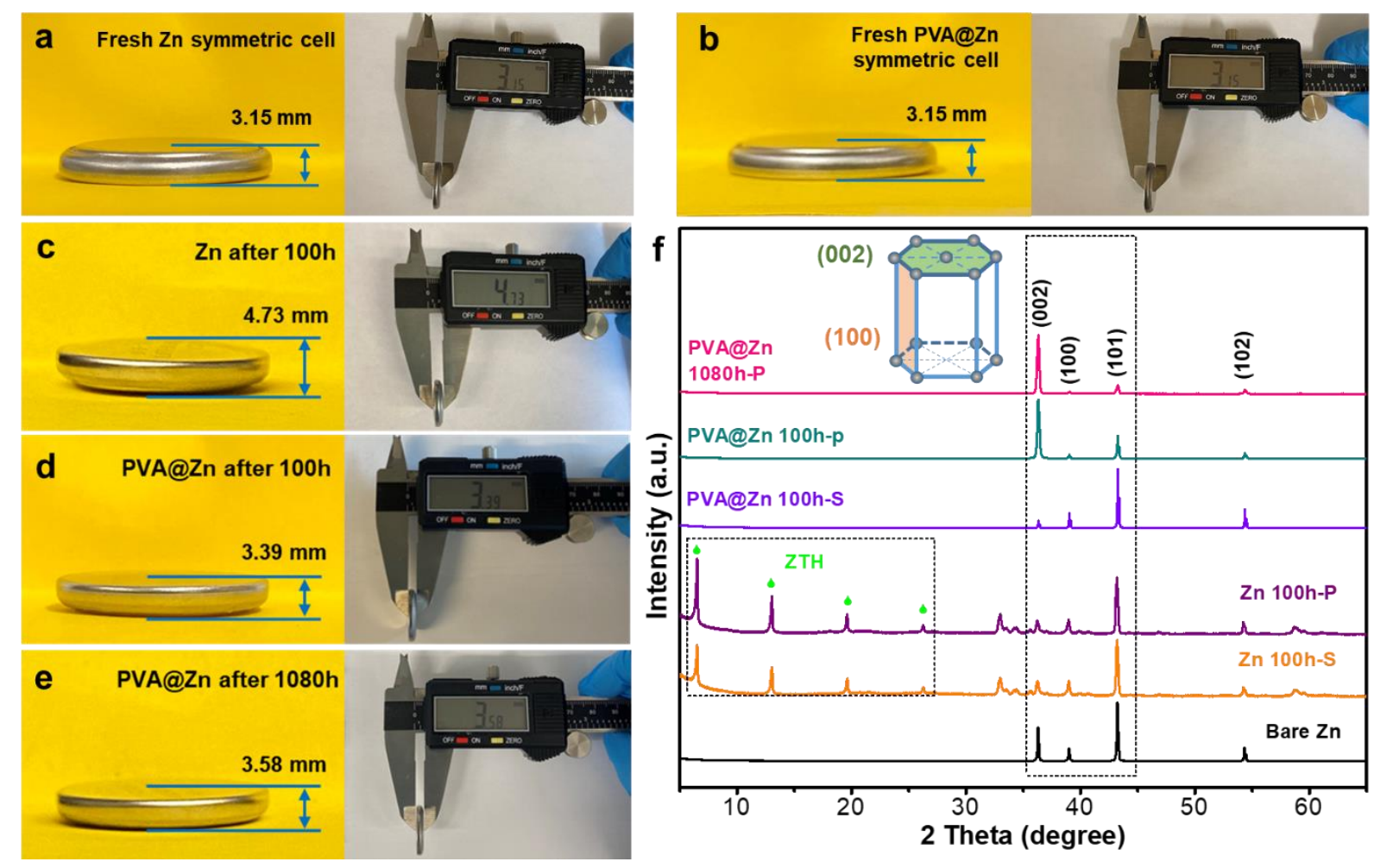

Figure 5. 5 Post-mortem characterization of Zn and PVA@Zn electrodes in symmetric cells after galvanostatic cycling at $1 \mathrm{~mA} \mathrm{~cm}{ }^{-2}$ for $1 \mathrm{mAh} \mathrm{cm}^{-2}$. Thickness measurement symmetric cells for a) bare Zn and b) PVA@Zn-1 right after assembly, c) bare Zn after 100 h, d) PVA@Zn-1 after 100 h, and e) PVA@Zn-1 after 1080 h. f) Corresponding XRD patterns of cycled Zn and PVA@Zn-1 electrodes at different plating and stripping states.

To further track the interfacial reactions associated with byproduct and dendrite formation, the phase and morphology of cycled electrodes were examined by XRD and SEM. As presented in $\mathrm{XRD}$ results (Figure 5.5f), in addition to metallic Zn phase, a large amount of zinc hydroxide triflate $\left(\mathrm{Zn}_{\mathrm{x}}(\mathrm{OTF})_{\mathrm{y}}(\mathrm{OH})_{2 \mathrm{x}-\mathrm{y}} \cdot \mathrm{H}_{2} \mathrm{O}\right)$ impurity phase was observed in cycled bare $\mathrm{Zn}$ electrode, which could hinder the electrons and ions transport at the electrode/electrolyte interface and influenced cycling stability.[12] Conversely, no impurity peaks appeared in cycled PVA@Zn electrode even after $1080 \mathrm{~h}$, confirming the ability of PVA protective layer to avoid surface passivation. 

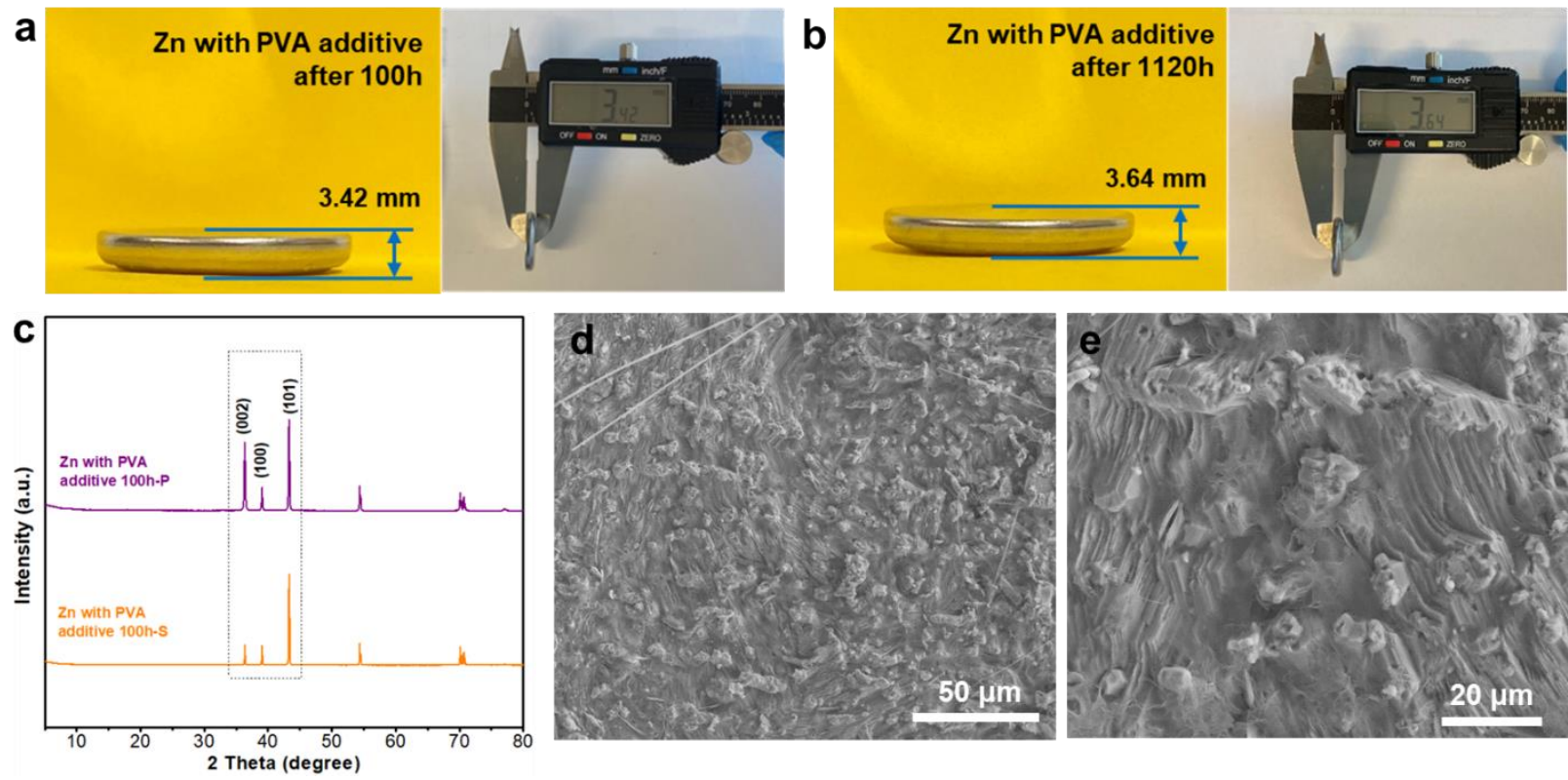

Figure 5. 6 Post-mortem characterization of Zn electrodes in symmetric cells in $2 \mathrm{M} \mathrm{Zn(OTf})_{2}$ electrolyte with $1 \%$ PVA additive after galvanostatic cycling at $1 \mathrm{~mA} \mathrm{~cm}$ cor $^{-2}$ foh cm m $^{-2}$. Volume expansion measurement of the $\mathrm{Zn}$ symmetric cells in $2 \mathrm{M} \mathrm{Zn}(\mathrm{OTf})_{2}$ electrolyte with $1 \%$ PVA cycled after a) $100 \mathrm{~h}$ and b) $1120 \mathrm{~h}$. c) XRD patterns of cycled Zn electrodes in symmetric

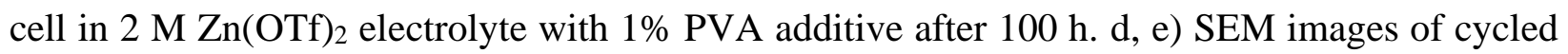
$\mathrm{Zn}$ electrode in $2 \mathrm{M} \mathrm{Zn(OTf})_{2}$ electrolyte with $1 \%$ PVA.

In addition, the XRD showed a significant difference in crystallographic orientation of deposited Zn on the cycled Zn and PVA@Zn electrodes. The (002) dominated orientation was observed on PVA@Zn electrode after plating, whereas the plated bare Zn electrode showed preferentially exposed (101) crystal facet similar to the pristine $\mathrm{Zn}$. The different preferentially exposed crystallographic orientation of deposited Zn on bare Zn and PVA@Zn verified the critical role of the PVA protective layer in inducing basal growth and stacking of $\mathrm{Zn}$ on the electrode surface to inhibit dendrite formation.[12,34-36] Notably, the preferential exposure of (002) over (101) plane was further increased as the cycle proceeded. The $(002)_{\mathrm{Zn}} /(101)_{\mathrm{Zn}}$ intensity ratio increased from 0.56 of pristine PVA@Zn sample to 2.55 and 6.49 for the electrodes after 100 and 1080 h cycling, respectively, indicating the enhanced role of PVA coating layer in continuously regulating deposition of $\mathrm{Zn}$ with preferentially exposed (002) plane orientation.[37] Therefore, it is hypothesized that PVA is favorable in homogenizing nucleation and inducing preferential $\mathrm{Zn}$ deposition along the (002) plane. Interestingly, after fully stripping the modified electrode, the 
dominance of (101) orientation for bare $\mathrm{Zn}$ was recovered. This might support the highly reversible Zn plating/stripping.
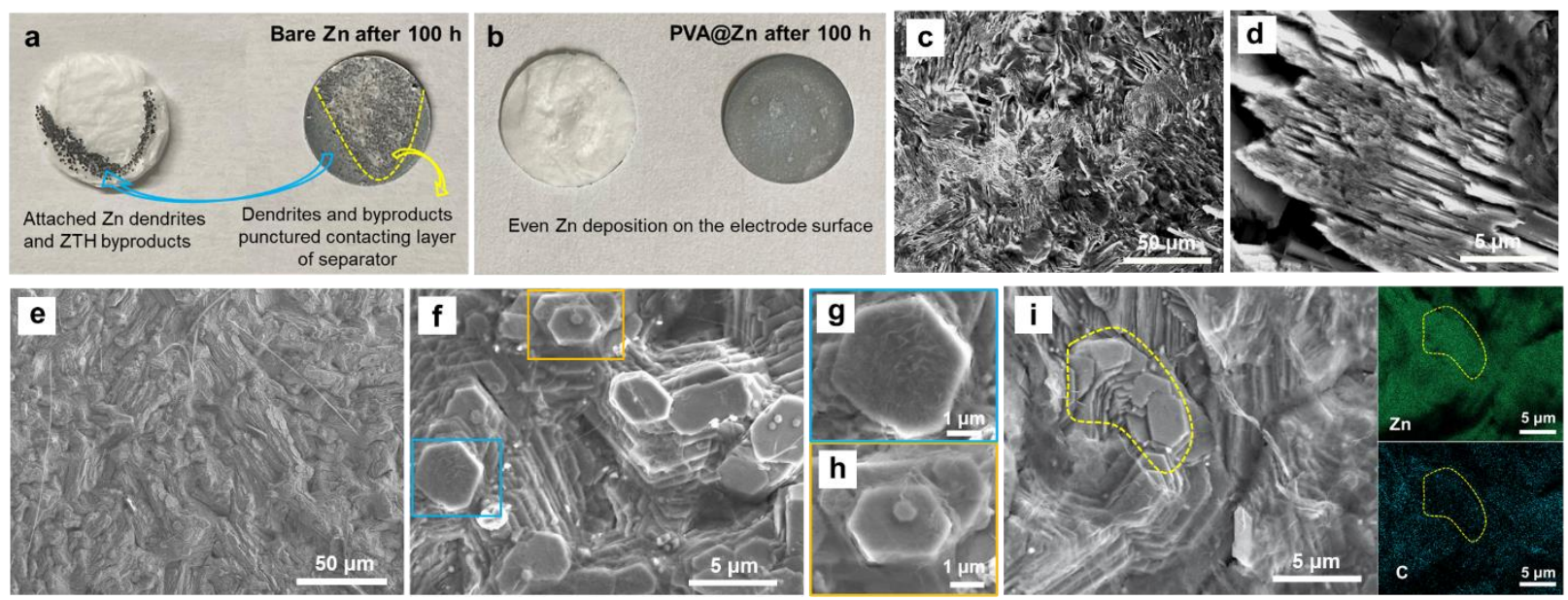

Figure 5. 7 Post-mortem morphology characterization of Zn and PVA@Zn electrodes in symmetric cells after galvanostatic cycling at $1 \mathrm{~mA} \mathrm{~cm}^{-2}$ for $1 \mathrm{mAh} \mathrm{cm}^{-2}$. Digital images of the separator and electrode disassembled from the symmetric cells for a) bare Zn and b) PVA@Zn cycled after 100 h. SEM images of c, d) Zn and e-i) PVA@Zn electrodes after 100 h. g) and h) High-magnification SEM images at the marked area in f). i) SEM image of PVA@Zn electrode after $100 \mathrm{~h}$ and corresponding EDX maps of $\mathrm{Zn}$ and $\mathrm{C}$ elements.

The SEM results of cycled electrodes also supported our hypothesis from XRD analysis. The intermingled byproducts and dendritic $\mathrm{Zn}$ deposition were observed on the cycled bare $\mathrm{Zn}$ electrode (Figure 5.7a, 5.7c, and 5.7d). The resultant sharp structure even pierced the contacting side of the separator with the $\mathrm{Zn}$ electrode (Figure 5.7a). Conversely, a much clean and even surface was obtained for the cycled PVA@Zn electrode (Figure 5.7b and 5.7e). More importantly, $\mathrm{Zn}$ deposits exhibited a hexagonal plate-like morphology with preferentially horizontal plates stacked into a lamellar structure (Figure 5.7f-i). This behavior was consistent with the $(002)_{\mathrm{Zn}}$ preferential deposition showed in the XRD results (Figure 5.5f), corroborating the role of PVA in regulating $\mathrm{Zn}$ deposition and inhabiting dendrite growth. In addition, a thin and almost transparent PVA layer with wrinkles can be observed on the surface of hexagonal Zn plates (Figure 5.7g and 5.7h). The presence of PVA coating layer was further evidenced by the EDX mapping (Figure 5.7i), in which both abundant $\mathrm{Zn}$ and $\mathrm{C}$ were evenly distributed in the PVA-covered area, whereas abundant $\mathrm{Zn}$ with few $\mathrm{C}$ was observed in an intentionally scratched area exposing stacked $\mathrm{Zn}$ plates. Notably, the preferential deposition of (002) plane-oriented Zn underneath thin PVA layer 
was still sustained after long-term cycling (Figure 5.8), demonstrating good stability of PVA layer during long-term $\mathrm{Zn}$ plating/stripping.
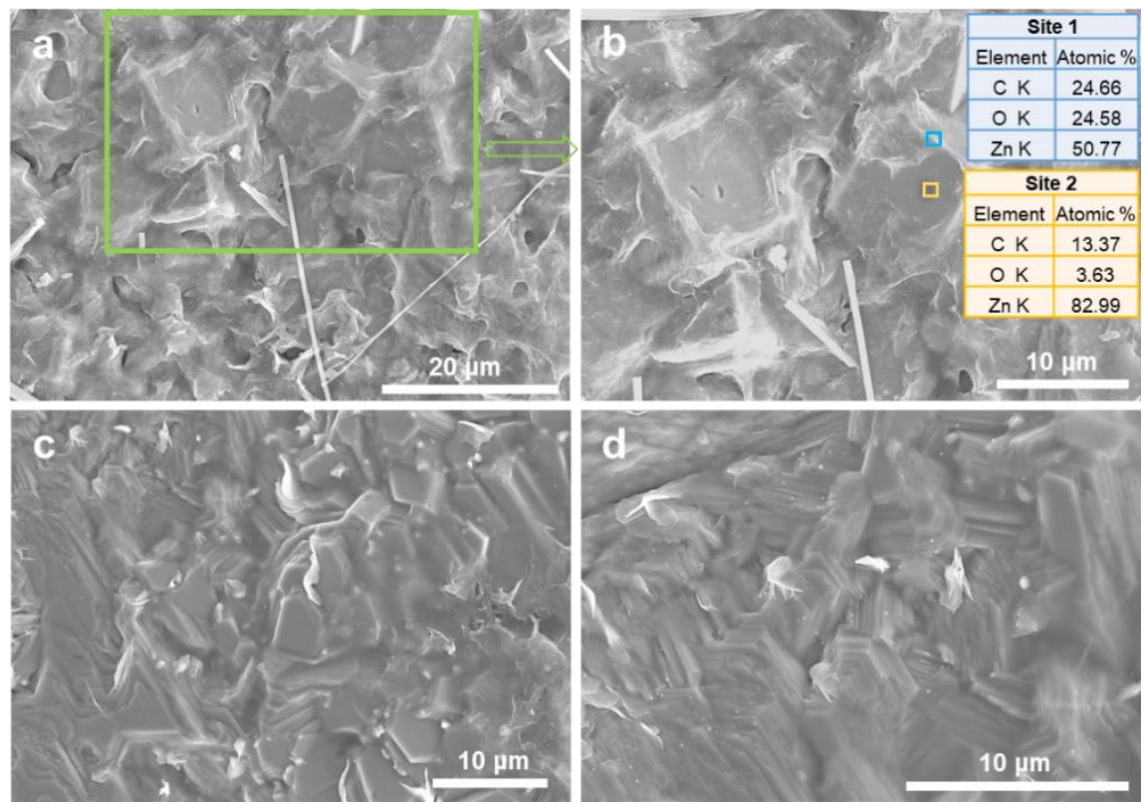

Figure 5.8 SEM images of PVA@Zn electrode after long-term cycling at $1 \mathrm{~mA} \mathrm{~cm}{ }^{-2}$ for $1 \mathrm{mAh}$ $\mathrm{cm}^{-2}$. Inset in (b) is the EDX results at different sites.

\subsubsection{In-situ observation of $\mathrm{Zn}$ plating/stripping}

To intuitively observe the influence of PVA on $\mathrm{Zn}$ deposition, transparent symmetric cells were assembled to in situ monitor Zn plating/stripping behavior on bare Zn and PVA @ Zn using an optical microscope (Figure 5.9). A current density of $2 \mathrm{~mA} \mathrm{~cm}$-2 was applied on the transparent cells with 20 min plating followed by 20 min stripping. As shown in Figure 5.10a, small nuclei and protrusions were clearly observed at the edge of the bare $\mathrm{Zn}$ electrode after 5 min platting, which rapidly evolved into $\mathrm{Zn}$ dendrites with further plating. Upon subsequent stripping, $\mathrm{Zn}$ corrosion occurred on the electrode topmost surface, while the deposited $\mathrm{Zn}$ dendrites remained on the edge over 20 min stripping, evidencing the uneven electrodeposition and poor reversibility on bare Zn electrode. In contrast, the PVA@Zn electrode exhibited homogeneous Zn plating/stripping behavior without forming dendritic morphology (Figure 5.10b). These results directly visualize the protective effect of PVA on $\mathrm{Zn}$ electrode in terms of homogenizing nucleation and suppressing $\mathrm{Zn}$ dendrite growth. In situ observation of platting/stripping on the uncoated $\mathrm{Zn}$ electrode in $\mathrm{Zn}(\mathrm{OTf})_{2}$ electrolyte with PVA additive was also conducted (Figure 
5.10c). The electrode displayed uniform deposition but uneven stripping, leading to small protrusions on the edge in the stripping process (15-20 min). Although some PVA molecules in electrolyte could be adsorbed on the electrode surface to homogenize interfacial reactions and regulate $\mathrm{Zn}$ deposition behavior to some extent, the deposited $\mathrm{Zn}$ did not show (002) plane dominated orientation unlike PVA@Zn (Figure 5.6c, d). Subsequently, the uneven stripping resulted in residual loose $\mathrm{Zn}$ deposits similar to "dead" Zn. This observation was consistent with the XRD and SEM results of cycled Zn electrodes in the electrolyte with PVA additive (Figure 5.6c-e), as well as its inferior cycling performance at high current densities (Figure 5.4).
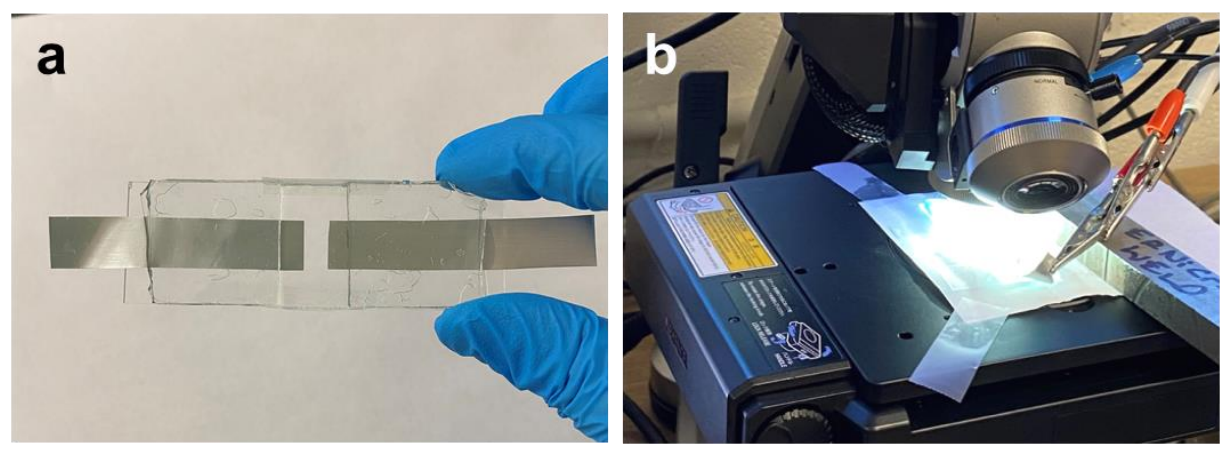

Figure 5. 9 a) Photograph of a home-made $\mathrm{Zn} / / \mathrm{Zn}$ transparent cell. b) Image of real-time monitoring of $\mathrm{Zn}$ plating/stripping behavior of $\mathrm{Zn}$ foil in a transparent symmetric cell using an optical microscopy system.
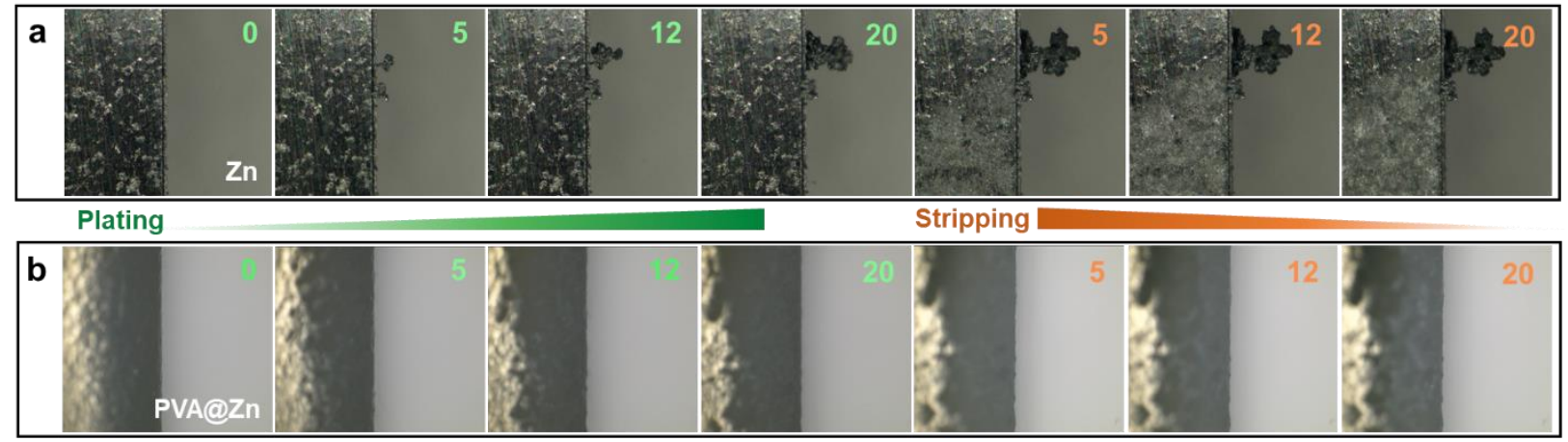

$$
\text { Plating }
$$
Stripping

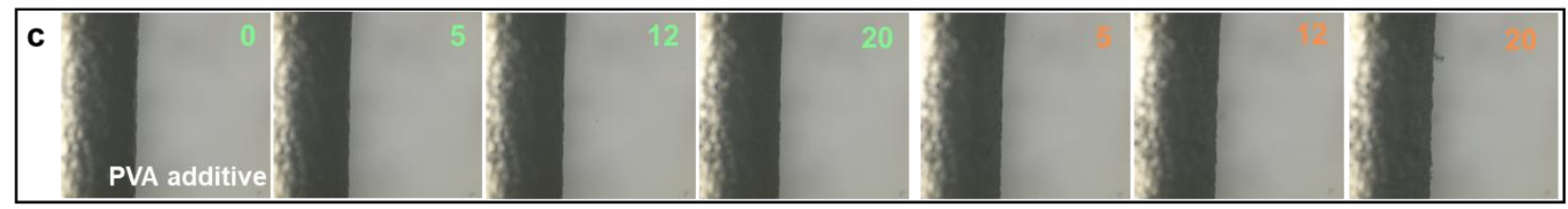

Figure 5. $10 \mathrm{In}$ situ optical microscope observation of $\mathrm{Zn}$ plating/stripping processes for a) $\mathrm{Zn}$ electrode and b) PVA@Zn electrode in symmetric transparent cells in $2 \mathrm{M} \mathrm{Zn}\left(\mathrm{CF}_{3} \mathrm{SO}_{3}\right)_{2}$ 
electrolytes, and c) $\mathrm{Zn}$ electrode in symmetric transparent cell in $2 \mathrm{M} \mathrm{Zn}\left(\mathrm{CF}_{3} \mathrm{SO}_{3}\right)_{2}$ electrolyte with PVA additive at $2 \mathrm{~mA} \mathrm{~cm}^{-2}$ for $20 \mathrm{~min}$.

\subsubsection{Zn Deposition mechanism of PVA@Zn electrodes}

The Coulombic efficiency (CE) of Zn plating/stripping was investigated in asymmetry cells of $\mathrm{Zn} / / \mathrm{Cu}$ and $\mathrm{Zn} / / \mathrm{PVA} @ \mathrm{Cu}$ to evaluate the effect of PVA on $\mathrm{Zn}$ electrochemistry reversibility (Figure 5.11 and 5.12). At $5 \mathrm{~mA} \mathrm{~cm}^{-2}$ with a capacity of $1 \mathrm{mAh} \mathrm{cm}^{-2}$ (Figure 5.11a), $\mathrm{Zn} / / \mathrm{Cu}$ cells obtained an average $\mathrm{CE}$ of $98.5 \%$ in first 310 cycles and then showed drastic $\mathrm{CE}$ fluctuation, while the $\mathrm{CE}$ of Zn//PVA@Cu quickly reached over 99\% and then was maintained steady over 700 cycles. Their CEs at a low current of $0.25 \mathrm{~mA} \mathrm{~cm}^{-2}$ with a capacity of $0.25 \mathrm{mAh} \mathrm{cm}$-2 were also tested (Figure 5.11b). Bare $\mathrm{Zn} / / \mathrm{Cu}$ cell showed poor performance with low $\mathrm{CE}$ in the first 50 cycles and significant $\mathrm{CE}$ fluctuation in the following cycles, indicating the unstable and uneven $\mathrm{Zn}$ reshaping on bare $\mathrm{Cu}$ foil.[32,38] The $\mathrm{CE}$ of $\mathrm{Zn} / / \mathrm{PVA} @ \mathrm{Cu}$ cell was significantly boosted, which increased in the initial 100 cycles and remained stable from 100 to 200 cycles with average values of $97.4 \%$ and $97.8 \%$, respectively. The poor $\mathrm{CE}$ of $\mathrm{Zn} / / \mathrm{Cu}$ cell is likely caused by dendritic deposition, HER, and irreversible byproduct formation. The significantly improved CE of Zn//PVA@Cu demonstrated the protective role of PVA layer in inhibiting side reactions and facilitating $\mathrm{Zn}$ plating/stripping reversibility (Figure 5.12). Figure 5.11c, d presented the corresponding voltage profiles. Compared with the rapidly deteriorated stripping capacity of Zn//Cu cell, Zn//PVA@Cu cell exhibited steady overpotentials upon long-term cycles, suggesting the uniform $\mathrm{Zn}$ nucleation and almost reversible plating/stripping on PVA coated $\mathrm{Cu}$. 

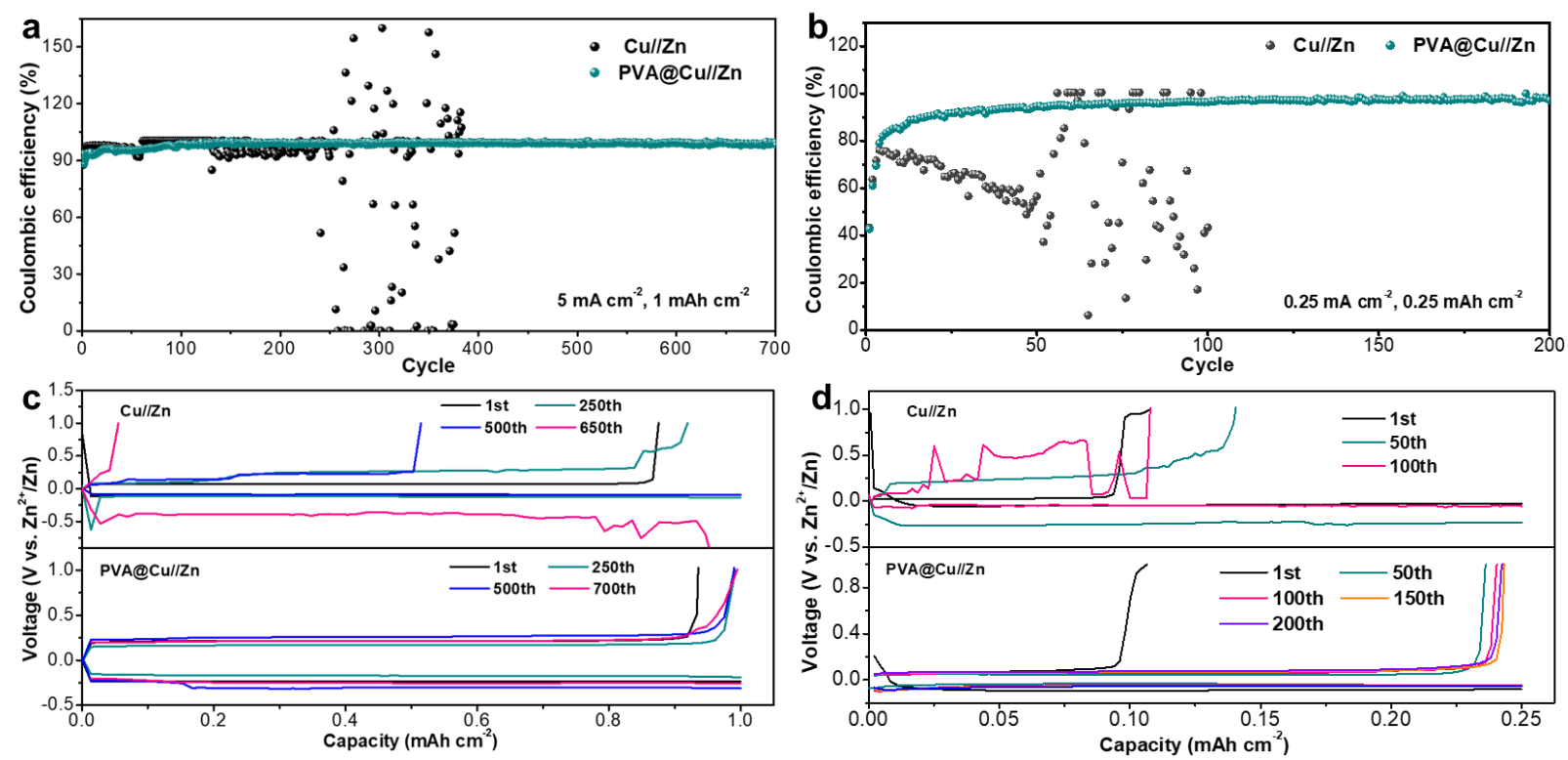

Figure 5. $11 \mathrm{CEs}$ and corresponding voltage profiles of the $\mathrm{Zn} / / \mathrm{Cu}$ and $\mathrm{Zn} / / \mathrm{PVA} @ \mathrm{Cu}$ cells at a, c) $5 \mathrm{~mA} \mathrm{~cm}$ for $1 \mathrm{mAh} \mathrm{cm}^{-2}, \mathrm{~b}, \mathrm{~d}$ ). e) $0.25 \mathrm{~mA} \mathrm{~cm}^{-2}$ for $0.25 \mathrm{mAh} \mathrm{cm}^{-2}$, respectively.
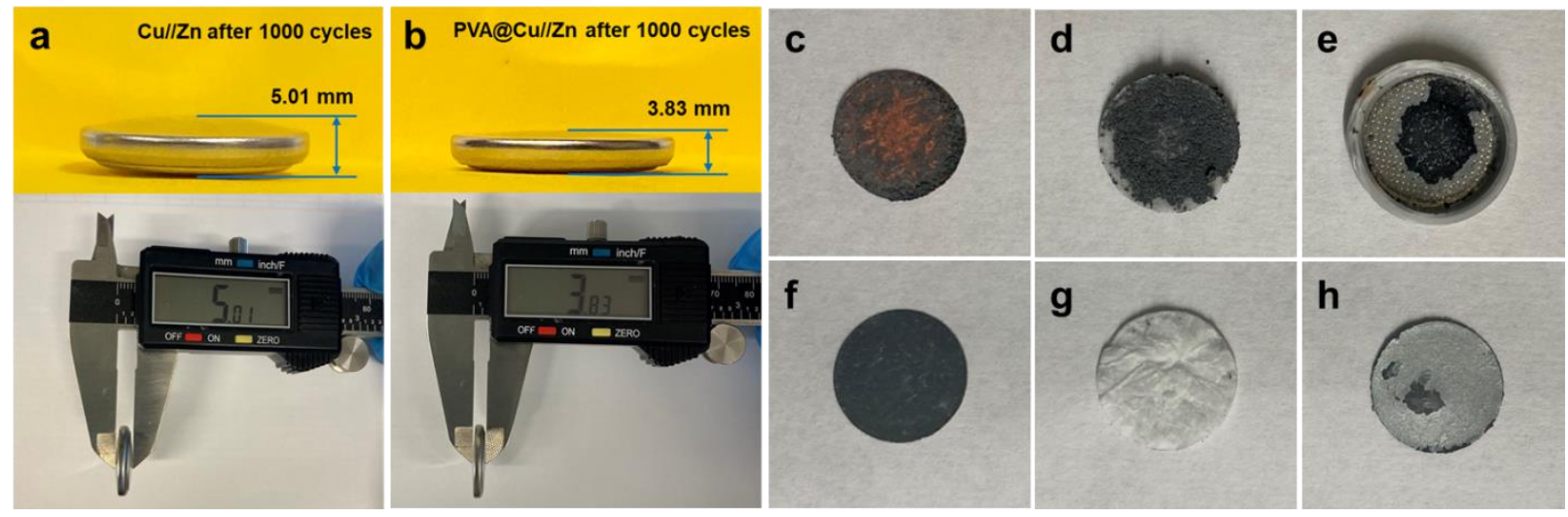

Figure 5. 12 Digital images of a) Zn//Cu and b) Zn//PVA@Cu cells after 1000 cycles at $5 \mathrm{~mA} \mathrm{~cm}$

2 for $1 \mathrm{mAh} \mathrm{cm}^{-2}$ and their volume expansion measurements. Digital images of $\mathrm{Cu}$ electrodes, separators and Zn electrodes disassembled from the c, d, e) Zn//Cu and f, g, h) Zn//PVA@Cu cells after 1000 cycles.

Linear polarization experiments were performed to further examine the effect of PVA on $\mathrm{Zn}$ corrosion behavior (Figure 5.13a). Compared with the corrosion potential of $-0.928 \mathrm{~V}$ vs. saturated calomel electrode (SCE) for bare Zn electrode, the corrosion potentials of Zn electrode with PVA coating layer and PVA additive in electrolyte were positively shifted. This higher positive corrosion potential implied less tendency of the corrosion reaction. Additionally, the corrosion currents of $\mathrm{Zn}$ electrodes significantly decreased in the presence of PVA, suggesting the 
reduced corrosion rate.[13,20,23,39] These results demonstrated that the presence of PVA provided high electrochemical stability of the $\mathrm{Zn}$ electrode. The $\mathrm{Zn}$ deposition behavior was explored through chronoamperometry method (Figure 5.13b). The variation of current density versus time under a constant overpotential depicted the nucleation and surface change process.[40,41] The plating current density of bare Zn electrode kept increasing under an applied overpotential of $-120 \mathrm{mV}$, indicating a rampant $2 \mathrm{D}$ diffusion process and uncontrolled deposition.[32] With low nucleation energy of $\mathrm{Zn}$ on the bare electrode, $\mathrm{Zn}^{2+}$ ions laterally migrated along the electrode surface and were preferentially reduced at the energetically favorable sites, which easily induced a "tip effect" and dendrite growth. In contrast, the plating current density on PVA@Zn electrode quickly reached a stable and lower equilibrium value, suggesting the local reduction of $\mathrm{Zn}^{2+}$ ions with constrained lateral surface diffusion.[40] PVA coating layer increased the energy barrier for the lateral migration and nucleation of adsorbed $\mathrm{Zn}^{2+}$ ions, leading to homogenous $\mathrm{Zn}$ nucleation and further stable deposition along the preferred crystal orientation.[22]
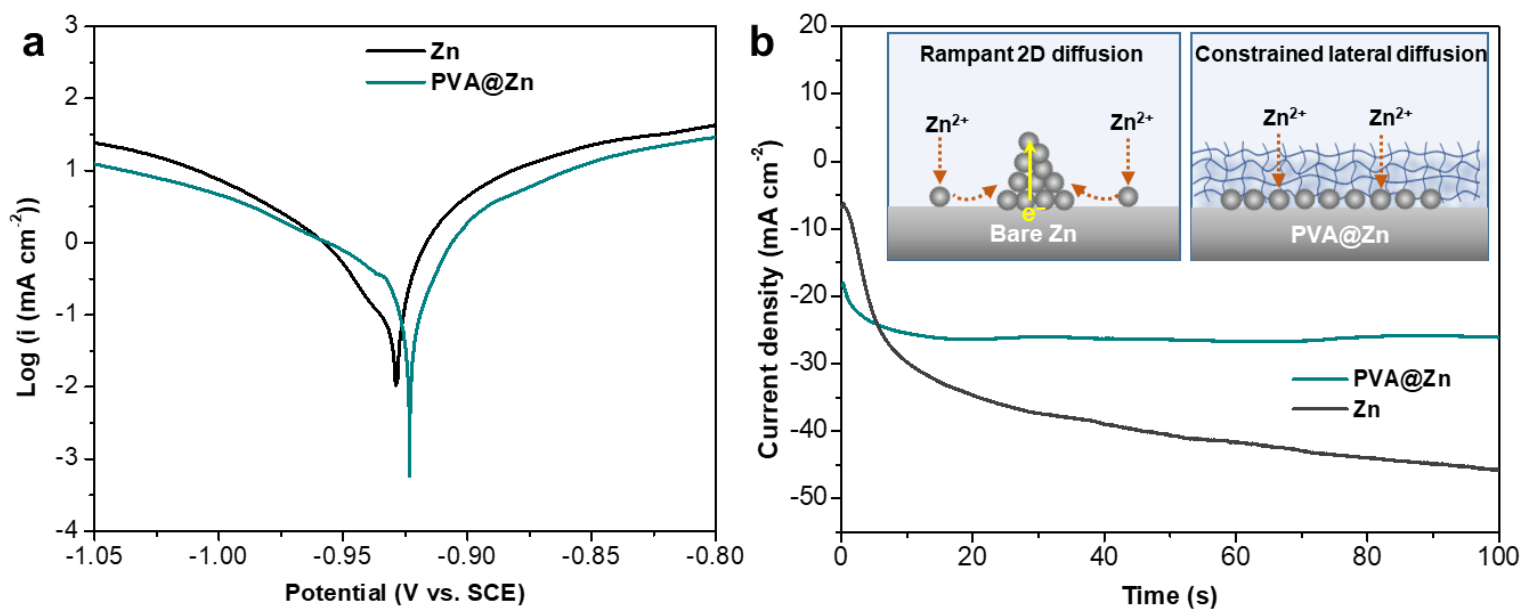

Figure 5. 13 Linear polarization curves of the bare $\mathrm{Zn}$ electrode in $2 \mathrm{M} \mathrm{Zn}\left(\mathrm{CF}_{3} \mathrm{SO}_{3}\right)_{2}$ electrolyte with and without PVA additive, and PVA@ $\mathrm{Zn}$ electrodes in $2 \mathrm{M} \mathrm{Zn}\left(\mathrm{CF}_{3} \mathrm{SO}_{3}\right)_{2}$ electrolyte at a scan rate of $0.2 \mathrm{mV} \mathrm{s}^{-1}$.

In order to further unravel the insights of PVA into regulating the interfacial reactions in aqueous $\mathrm{Zn}(\mathrm{OTf})_{2}$ electrolytes, the $1 \mathrm{H}$ NMR spectrum in $\mathrm{D}_{2} \mathrm{O}$ was utilized to elucidate the interactions between PVA molecules and $\mathrm{Zn}(\mathrm{OTf})_{2}$ electrolyte at the molecular level.[12] Figure 5.14a showed the overlaid ${ }^{1} \mathrm{H} N \mathrm{NR}$ spectra of $2 \mathrm{M} \mathrm{Zn}(\mathrm{OTf})_{2}, 1.0 \% \mathrm{PVA}$, and $2 \mathrm{M} \mathrm{Zn}(\mathrm{OTf})_{2}$ with 
$0.2 \%$ PVA, $0.5 \%$ PVA, and $1 \%$ PVA. The ${ }^{1} \mathrm{H}$ NMR spectra were referenced to the residual proton peak (HDO) of $\mathrm{D}_{2} \mathrm{O}$ at $4.75 \mathrm{ppm}$. The expanded spectral regions exhibited clearly shielding of the protons for the methylene (- $\left.\mathrm{CH}_{2}-\right)$ and methine (-CHOH-) groups in the presence of PVA (Figure 5.14b and 5.14c). The upfield chemical shifts after introducing PVA into the $2 \mathrm{M} \mathrm{Zn}(\mathrm{OTf})_{2}$ solution indicated increasing in electronic density around these groups. It could be ascribed to the interaction between PVA and $\mathrm{Zn}^{2+}$ ions which weakened the solvation sheath of $\mathrm{Zn}^{2+}$. PVA molecules might participate in the coordination structure of $\mathrm{Zn}^{2+}-\mathrm{H}_{2} \mathrm{O}-\mathrm{OTf}^{-}$to partially release the confined water molecules.[13,28,42,43] The interplay between $\mathrm{Zn}^{2+}$ and PVA was evidenced by the further shielding effect of methylene (- $\left.\mathrm{CH}_{2}-\right)$ and methine (-CHOH-) in the solution of $2 \mathrm{M}$ $\mathrm{Zn}(\mathrm{OTf})_{2}$ with $0.2 \%, 0.5 \%$, and $1.0 \%$ PVA, respectively.
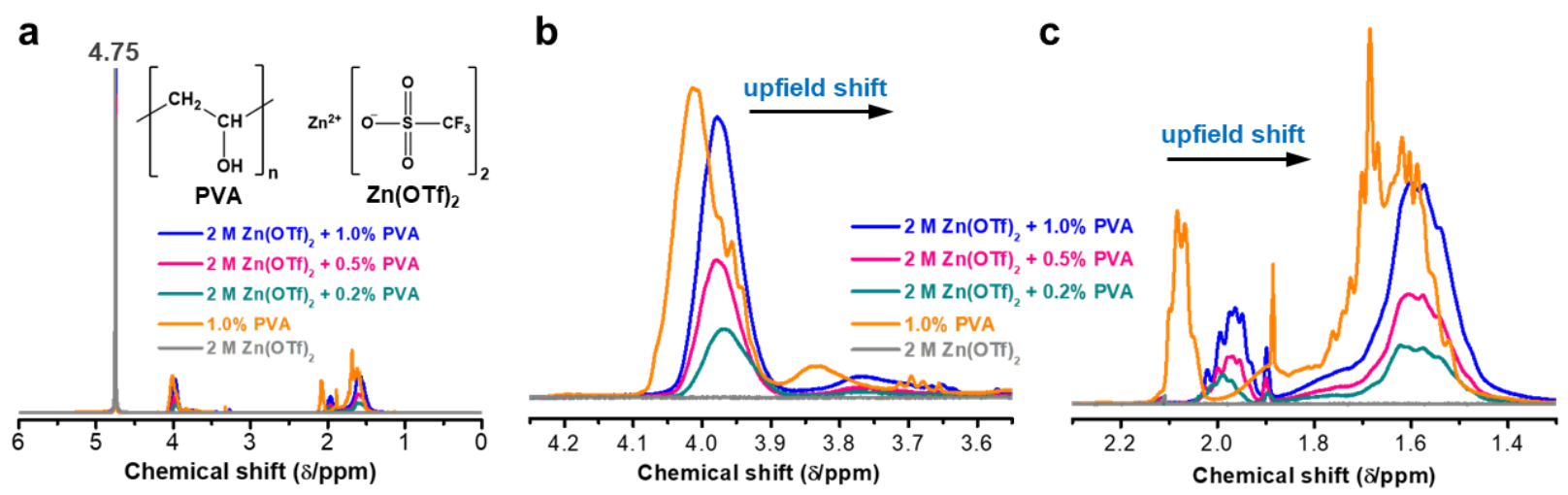

Figure 5. $14{ }^{1} \mathrm{H}$ NMR spectra of $2 \mathrm{M} \mathrm{Zn}(\mathrm{OTf})_{2}, 1.0 \%$ PVA, $2 \mathrm{M} \mathrm{Zn}(\mathrm{OTf})_{2}$ with $0.2 \%$ PVA, $0.5 \%$ PVA, and $1 \%$ PVA:

The PVA coating layer acts as an artificial electrode/electrolyte interface that ensures the stable interfacial reaction and smooth $\mathrm{Zn}$ deposition. The cross-linked PVA framework by abundant intermolecular hydrogen bonds can serve as a buffer layer to render a homogeneous and relatively sluggish diffusion of $\mathrm{Zn}^{2+}$ ions in the interfacial region. The stabilized interfacial $\mathrm{Zn}^{2+}$ ion diffusion may hinder the rapid dendrite growth caused by unregulated ion transport and thereby ensures homogeneous $\mathrm{Zn}$ nucleation and crystal growth with preferred orientation. Moreover, the strong binding affinity between $\mathrm{Zn}^{2+}$ and PVA affects the $\mathrm{Zn}^{2+}-\mathrm{H}_{2} \mathrm{O}-\mathrm{OTf}^{-}$coordination structure and leads to the increase of nucleation energy and nucleation overpotential, thereby inducing homogeneous $\mathrm{Zn}$ deposition.[15,27] Further, the coordinative interaction between PVA and $\mathrm{Zn}^{2+}$ facilitates the dissociation of $\mathrm{H}_{2} \mathrm{O}$ molecules from the $\mathrm{Zn}^{2+}-\mathrm{H}_{2} \mathrm{O}-\mathrm{OTf}^{-}$complex and the hydrogen bonding formation between $\mathrm{H}_{2} \mathrm{O}$ molecules in the bulk solution. The increase of hydrogen bonding 
weakens the water activity at the electrode/electrolyte interface, and thus alleviates the HER occurrence.[15]

Based on the abovementioned analyses and discussion, it can be hypothesized that the exceptional reversibility and stability of Zn plating/stripping electrochemistry on PVA@Zn electrode is mainly attributed to regulated interfacial ion diffusion, increased nucleation overpotential, and alleviated side reactions. The Zn deposition process on bare Zn and PVA@Zn electrodes is schematically depicted in Figure 5.15. At the beginning of plating, benefiting from the relatively low diffusivity of $\mathrm{Zn}^{2+}$ governed by the PVA coating layer, $\mathrm{Zn}^{2+}$ ions uniformly adsorb on the electrode surface and form a high density of nucleation sites. The stable nuclei preferentially form along the (002) basal plane due to the lower deposition energy.[8,27,37] Subsequently, the well-defined hexagonal Zn (002) plane aligned parallel to the electrode surface can be constructed. As the plating proceeds, the homoepitaxy growth of $\mathrm{Zn}$ deposition starts along both horizontal and vertical directions.[36] In addition to the continued growth of hexagonal plates to occupy the parallel electrode surface, new hexagonal nuclei attach on the freshly deposited $\mathrm{Zn}$ (002) surface, showing a growth trend of stacking into the lamellar structure (Figure 5.15a). This synergistically regulated epitaxial growth effectively inhibits the initial formation of dendrite tips, enabling a highly reversible dendrite-free $\mathrm{Zn}$ anode. The smooth and compact lamellar deposition combined with the adherent PVA protective layer would significantly alleviate the occurrence of side reactions such as corrosion and passivation, which guarantees the extraordinary cycle lifespan of PVA@Zn electrode.[8]

In sharp contrast to the stable deposition on PVA@Zn electrode, bare Zn electrode exhibits obvious dendrite formation, corrosion, and surface passivation in $\mathrm{Zn}(\mathrm{OTf})_{2}$ electrolyte (Figure 5.15b). The unregulated ion diffusion and low nucleation energy result in random and rampant $\mathrm{Zn}$ nucleation on the bare electrode surface. As the plating proceeds, lots of uneven deposits are subsequently generated and easily induce a "tip effect". $\mathrm{Zn}^{2+}$ ions preferentially accumulate on the protruding active sites, which accelerates the growth rate of the initial dendrite front. This behavior, in turn, aggravates the uneven electric field distribution and dendrite growth.[19,22] 

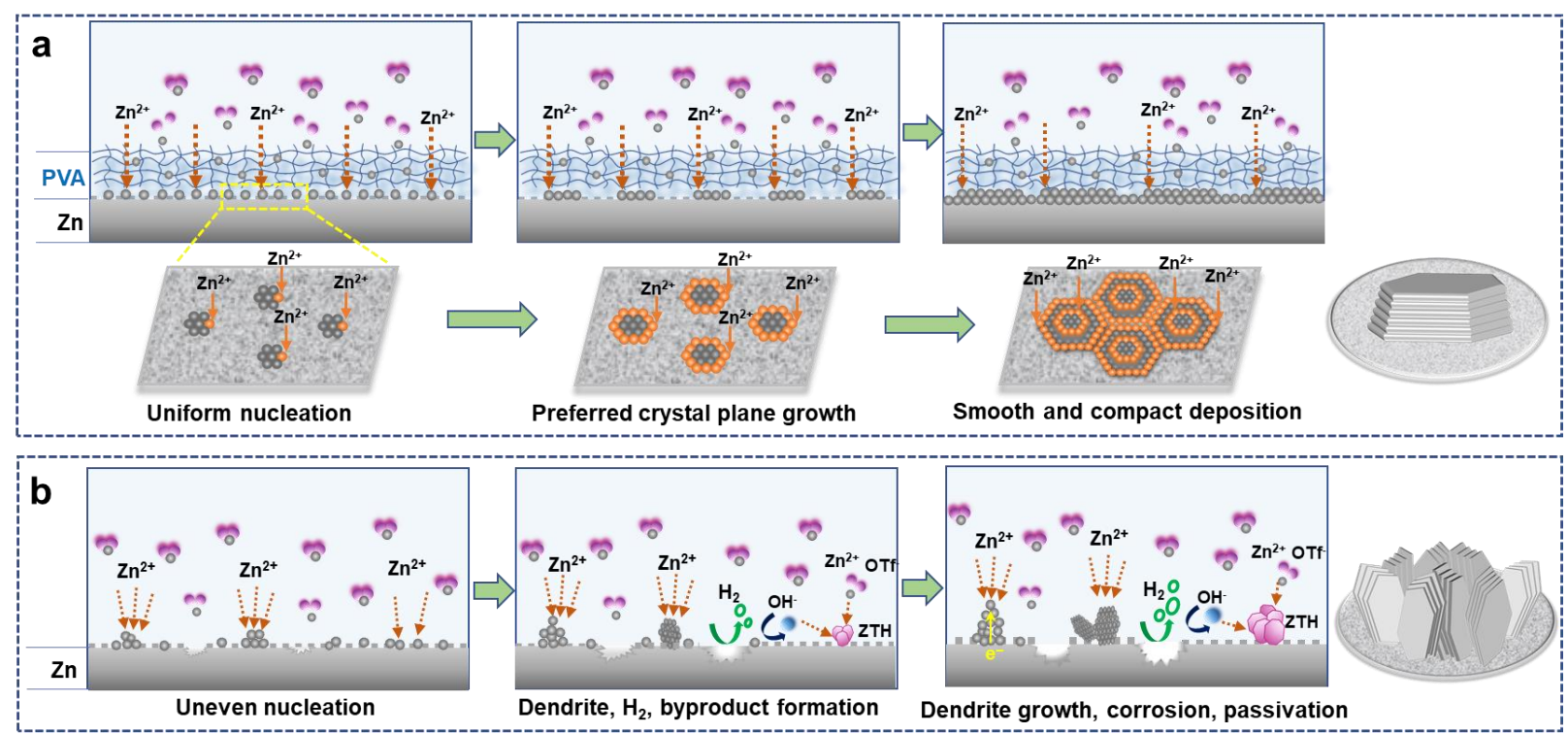

Figure 5. 15 Schematic illustration of the Zn deposition processes for a) PVA@Zn and b) bare Zn.

\subsubsection{Electrochemical performance of full batteries}

To further verify the advantages of PVA@ $\mathrm{Zn}$ anode in $\mathrm{Zn}$ ion batteries, the $\mathrm{V}_{2} \mathrm{O}_{5}$ cathode was coupled with the PVA@ $\mathrm{Zn}$ anode in $2 \mathrm{M} \mathrm{Zn(OTf})_{2}$ electrolyte to construct a full cell. The $\mathrm{V}_{2} \mathrm{O}_{5}$ nanowires were synthesized by a hydrothermal method and characterized (Figure 5.16a and 5.16b). Figure 5.16a compared the cyclic voltammogram $(\mathrm{CV})$ curves of the full cells with $\mathrm{Zn}$ andPVA@Zn anodes at $0.1 \mathrm{mV} \mathrm{s}^{-1}$. Both cells exhibited almost overlapped CV curves with two pairs of distinct redox peaks, indicating a negligible effect of PVA coating on the redox reaction of $\mathrm{V}_{2} \mathrm{O}_{5}$ cathode. The galvanostatic charge-discharge (GCD) curves of the PVA@Zn// $\mathrm{V}_{2} \mathrm{O}_{5}$ cell showed two sloping discharge plateaus at around $0.5-0.6$ and $0.9-1.0 \mathrm{~V}$, corresponding to the $\mathrm{Zn}^{2+}$ intercalation reactions in the $\mathrm{V}_{2} \mathrm{O}_{5}$ cathode as reported previously (Figure 5.16d).[44] The PVA@ $@ \mathrm{Zn} / / \mathrm{V}_{2} \mathrm{O}_{5}$ cell demonstrated superior rate capability at current densities increasing from 0.1 to $5.0 \mathrm{~A} \mathrm{~g}^{-1}$ (Figure 5.16e). Even at a high current density of $5 \mathrm{~A} \mathrm{~g}^{-1}$, this full cell demonstrated a large capacity of $\sim 190 \mathrm{mAh} \mathrm{g}^{-1}$. In contrast, the $\mathrm{Zn} / / \mathrm{V}_{2} \mathrm{O}_{5}$ cell showed inferior rate performance especially at high current densities (e.g., < $10 \mathrm{mAh} \mathrm{g}^{-1}$ at $5 \mathrm{~A} \mathrm{~g}^{-1}$ ). The PVA@ $\mathrm{Zn} / / \mathrm{V}_{2} \mathrm{O}_{5}$ cell exhibited remarkable long-term cycling stability (Figure 5d and S21). At $3 \mathrm{~A} \mathrm{~g}^{-1}, \mathrm{PVA} @ \mathrm{Zn} / / \mathrm{V}_{2} \mathrm{O}_{5}$ delivered a longer cycle lifespan and higher stability with nearly 80\% capacity retention after 500 cycles, whereas $\mathrm{Zn} / / \mathrm{V}_{2} \mathrm{O}_{5}$ showed merely $23 \%$ capacity retention (Figure 5.16f). Note that the $\mathrm{Zn} / / \mathrm{V}_{2} \mathrm{O}_{5}$ cells in electrolytes with and without PVA additive displayed almost same 
electrochemical performances (Figure 5.16e and 5.16f), implying that the PVA additive only could not effectively improve the full cell performance. The phase and morphology of $\mathrm{Zn}$ anodes in cycled full cells at $3 \mathrm{~A} \mathrm{~g}^{-1}$ after 500 cycles were also investigated. Like the cycled bare $\mathrm{Zn}$ electrodes in symmetric cells (Figure 5.7), sharp protuberances formed on the Zn anode surface, which pieced the separator surface (Figure 5.17a). Conversely, a clear and even surface was observed for the PVA@Zn anode (Figure 5.17b). The corresponding XRD and SEM results of cycled anodes further confirmed the formation of dendrites and zinc triflate hydroxide byproducts on bare Zn anode, whereas the cycledPVA@Zn anode was well maintained and covered by thin PVA layers with wrinkles (Figure 5.17d-f).
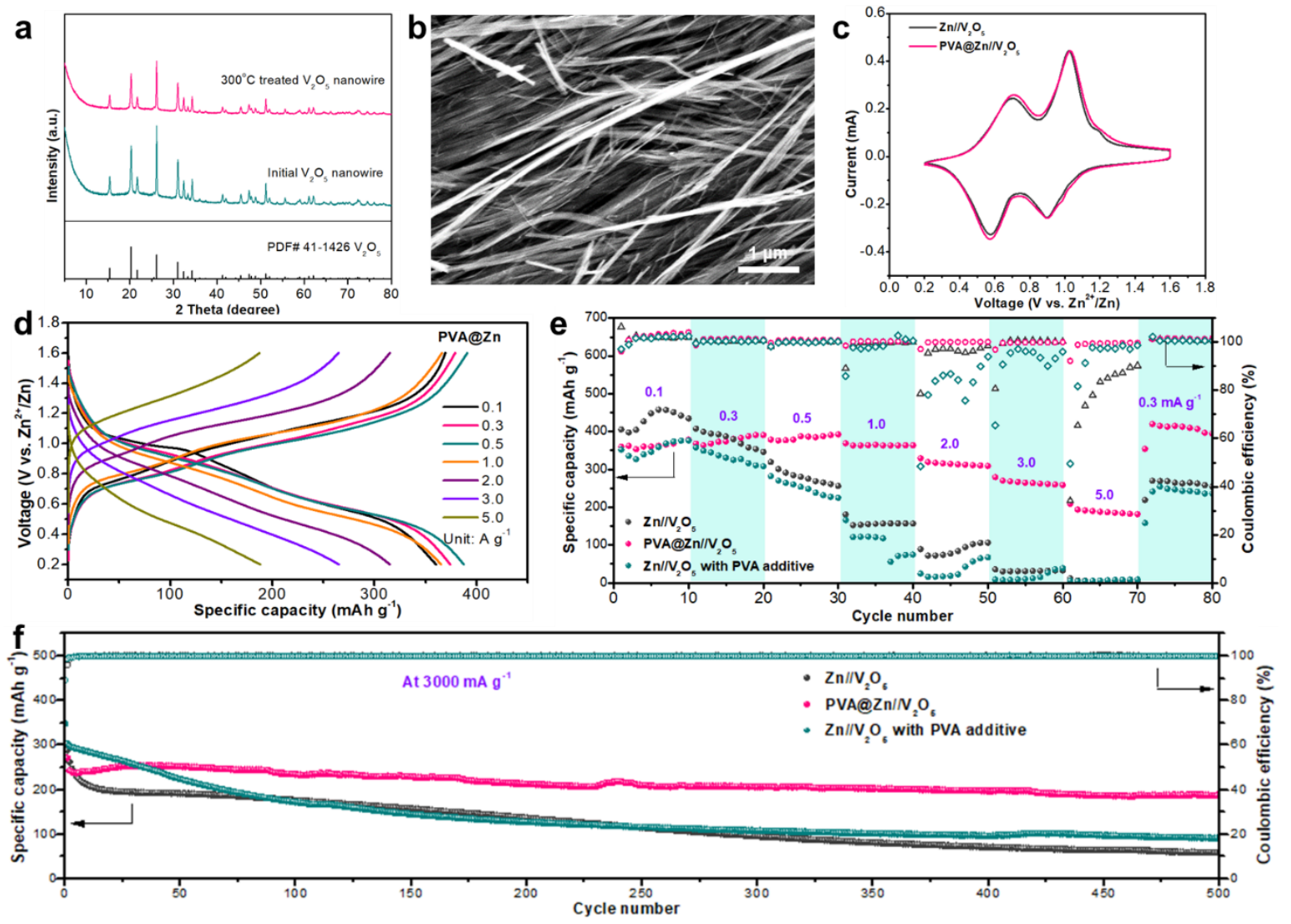

Figure 5. 16 a) XRD pattern and b) SEM image of synthesized $\mathrm{V}_{2} \mathrm{O}_{5}$ nanowires. c) CV curves of $\mathrm{Zn} / / \mathrm{V}_{2} \mathrm{O}_{5}$ and PVA@ $\mathrm{Zn} / / \mathrm{V}_{2} \mathrm{O}_{5}$ cells at $0.1 \mathrm{mV} \mathrm{s}^{-1}$. d) Voltage profiles of PVA@ $\mathrm{Zn} / / \mathrm{V}_{2} \mathrm{O}_{5}$ cell at different current densities. e) Rate capability and f) cycling performance of $\mathrm{Zn} / / \mathrm{V}_{2} \mathrm{O}_{5}$ and PVA@ $\mathrm{Zn} / / \mathrm{V}_{2} \mathrm{O}_{5}$ cells in $2 \mathrm{M} \mathrm{Zn}(\mathrm{OTf})_{2}$ electrolyte and $\mathrm{Zn} / / \mathrm{V}_{2} \mathrm{O}_{5}$ cell in $2 \mathrm{M} \mathrm{Zn}(\mathrm{OTf})_{2}$ electrolyte with $1 \%$ PVA cells at $3000 \mathrm{~mA} \mathrm{~g}^{-1}$. 


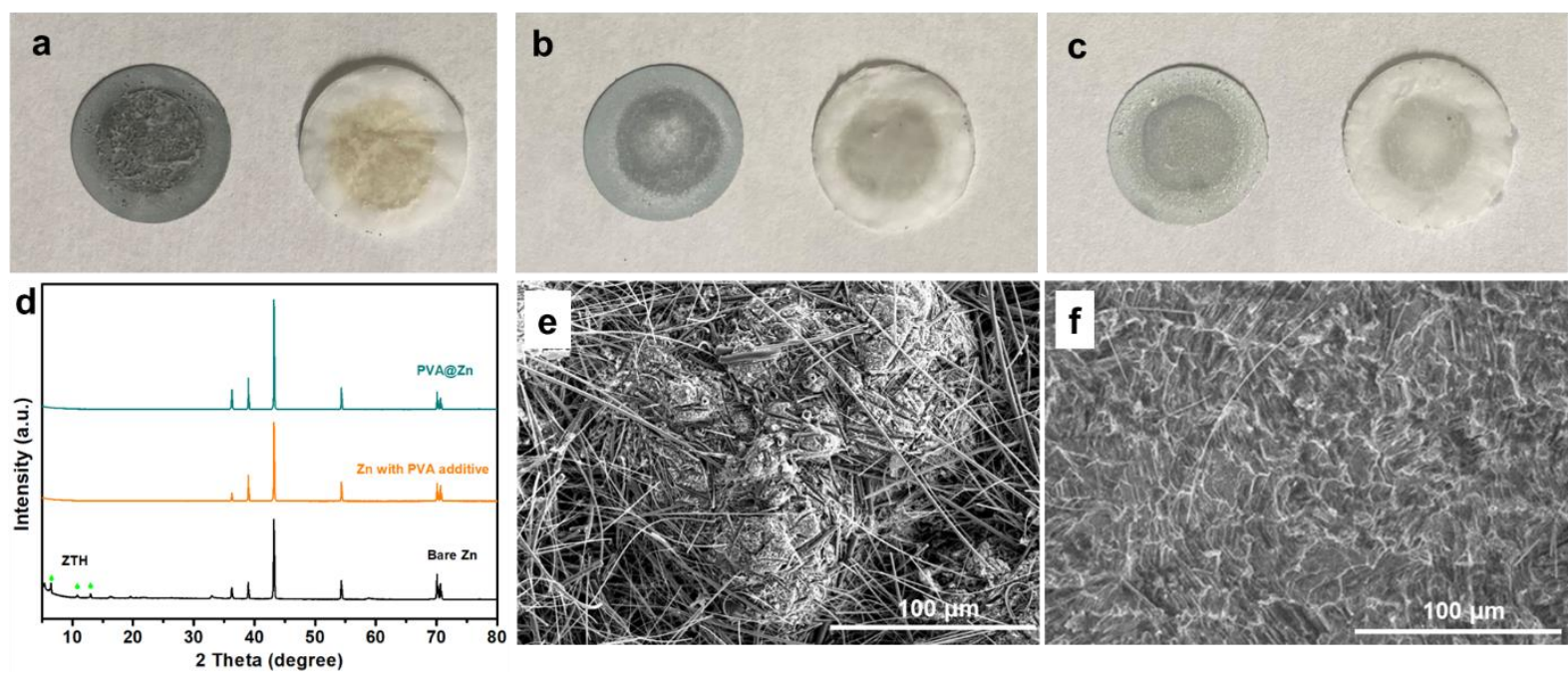

Figure 5. 17 Digital images of anodes and separators disassembled from the full cells after 500 cycles at $3 \mathrm{~A} \mathrm{~g}^{-1}$. a) $\mathrm{Zn} / / \mathrm{V}_{2} \mathrm{O}_{5}$ cell in $2 \mathrm{M} \mathrm{Zn}\left(\mathrm{CF}_{3} \mathrm{SO}_{3}\right)_{2}$ electrolyte. b) $\mathrm{Zn} / / \mathrm{V}_{2} \mathrm{O}_{5}$ cell in $2 \mathrm{M}$ $\mathrm{Zn}\left(\mathrm{CF}_{3} \mathrm{SO}_{3}\right)_{2}$ electrolyte with $1 \%$ PVA, c) PVA@ $\mathrm{Zn} / / \mathrm{V}_{2} \mathrm{O}_{5}$ cell in $2 \mathrm{M} \mathrm{Zn}\left(\mathrm{CF}_{3} \mathrm{SO}_{3}\right)_{2}$ electrolyte. d) Corresponding XRD patterns of the anodes from the cycled full cells. The full cells were stopped at discharged state, in which the anodes were maintained at the stripping state. SEM images of e) Zn and f)PVA@Zn anodes from the cycled full cells.

\subsection{Conclusion}

In summary, a highly stable and dendrite-free $\mathrm{Zn}$ anode was developed using a simple PVA coating method. The PVA@Zn anode exhibited a long-term cycling stability in symmetric cells over $5000 \mathrm{~h}$ at a current density of $0.25 \mathrm{~mA} \mathrm{~cm}^{-2}$ and a capacity of $0.25 \mathrm{mAh} \mathrm{cm}^{-2}$. Even under a deep cycling capacity of $5 \mathrm{mAh} \mathrm{cm}^{-2}$, the developed PVA@Zn anode exhibited superior durability of over $2600 \mathrm{~h}$ and even retained remarkable cycling stability at a high current density of $10 \mathrm{~mA}$ $\mathrm{cm}^{-2}$. The PVA coating layer induced the homogeneous $\mathrm{Zn}$ nucleation as well as epitaxial growth and stacking deposition with the preferentially exposed crystallographic orientation of $\mathrm{Zn}(002)$ planes. In addition, the interfacial side reactions of HER, corrosion, and surface passivation were also effectively suppressed by the PVA protective layer. The interaction between PVA and hydrated $\mathrm{Zn}^{2+}$ affects the $\mathrm{Zn}^{2+}-\mathrm{H}_{2} \mathrm{O}-\mathrm{OTf}^{-}$coordination structure and plays an important role. This study offers a straightforward way to stabilize Zn electrochemistry in mild aqueous electrolytes by using low-cost PVA as an artificial interface protective layer for high-performance aqueous rechargeable $\mathrm{Zn}$-ion batteries. 


\section{References}

[1] H. Pan, Y. Shao, P. Yan, Y. Cheng, K.S. Han, Z. Nie, C. Wang, J. Yang, X. Li, P. Bhattacharya, K.T. Mueller, J. Liu, Reversible aqueous zinc/manganese oxide energy storage from conversion reactions, Nat. Energy. 1 (2016) 16039.

[2] D. Kundu, B.D. Adams, V. Duffort, S.H. Vajargah, L.F. Nazar, A high-capacity and longlife aqueous rechargeable zinc battery using a metal oxide intercalation cathode, Nat. Energy. 1 (2016) 16119.

[3] X. Chen, W. Li, Y. Xu, Z. Zeng, H. Tian, M. Velayutham, W. Shi, W. Li, C. Wang, D. Reed, V. V Khramtsov, X. Li, X. Liu, Charging activation and desulfurization of MnS unlock the active sites and electrochemical reactivity for Zn-Ion batteries, Nano Energy. (2020) 104869.

[4] X. Chen, W. Li, Z. Zeng, D. Reed, X. Li, X. Liu, Engineering stable Zn-MnO 2 batteries by synergistic stabilization between the carbon nanofiber core and birnessite- $\mathrm{MnO}_{2}$ nanosheets shell, Chem. Eng. J. 405 (2021) 126969.

[5] M. Zhu, J. Hu, Q. Lu, H. Dong, D.D. Karnaushenko, C. Becker, D. Karnaushenko, Y. Li, H. Tang, Z. Qu, J. Ge, O.G. Schmidt, A patternable and in situ formed polymeric zinc blanket for a reversible zinc anode in a skin-mountable microbattery, Adv. Mater. 33 (2021) 2007497.

[6] J. Hao, X. Li, X. Zeng, D. Li, J. Mao, Z. Guo, Deeply understanding the Zn anode behaviour and corresponding improvement strategies in different aqueous Zn-based batteries, Energy Environ. Sci. 13 (2020) 3917-3949.

[7] C. Li, X. Xie, S. Liang, J. Zhou, Issues and future perspective on zinc metal anode for rechargeable aqueous zinc-ion batteries, Energy Environ. Mater. 3 (2020) 146-159.

[8] M. Zhou, S. Guo, J. Li, X. Luo, Z. Liu, T. Zhang, X. Cao, M. Long, B. Lu, A. Pan, G. Fang, J. Zhou, S. Liang, Surface-preferred crystal plane for a stable and reversible zinc anode, Adv. Mater. 33 (2021) 2100187.

[9] Z. Cao, P. Zhuang, X. Zhang, M. Ye, J. Shen, P.M. Ajayan, Strategies for dendrite-free anode in aqueous rechargeable zinc ion batteries, Adv. Energy Mater. 10 (2020) 2001599.

[10] A. Naveed, H. Yang, J. Yang, Y. Nuli, J. Wang, Highly reversible and rechargeable safe zn batteries based on a triethyl phosphate electrolyte, Angew. Chem. Int. Ed. 58 (2019) 27602764.

[11] W. Xu, K. Zhao, W. Huo, Y. Wang, G. Yao, X. Gu, H. Cheng, L. Mai, C. Hu, X. Wang, 
Diethyl ether as self-healing electrolyte additive enabled long-life rechargeable aqueous zinc ion batteries, Nano Energy. 62 (2019) 275-281.

[12] J. Hao, L. Yuan, C. Ye, D. Chao, K. Davey, Z. Guo, S.-Z. Qiao, Boosting zinc electrode reversibility in aqueous electrolytes by using low-cost antisolvents, Angew. Chem. Int. Ed. 60 (2021) 7366-7375.

[13] M. Yan, C. Xu, Y. Sun, H. Pan, H. Li, Manipulating Zn anode reactions through salt anion involving hydrogen bonding network in aqueous electrolytes with PEO additive, Nano Energy. 82 (2021) 105739.

[14] L. Cao, D. Li, E. Hu, J. Xu, T. Deng, L. Ma, Y. Wang, X.-Q. Yang, C. Wang, Solvation structure design for aqueous zn metal batteries, J. Am. Chem. Soc. 142 (2020) 21404-21409.

[15] R. Qin, Y. Wang, M. Zhang, Y. Wang, S. Ding, A. Song, H. Yi, L. Yang, Y. Song, Y. Cui, J. Liu, Z. Wang, S. Li, Q. Zhao, F. Pan, Tuning Zn ${ }^{2+}$ coordination environment to suppress dendrite formation for high-performance Zn-ion batteries, Nano Energy. 80 (2021) 105478.

[16] C. Li, X. Shi, S. Liang, X. Ma, M. Han, X. Wu, J. Zhou, Spatially homogeneous copper foam as surface dendrite-free host for zinc metal anode, Chem. Eng. J. 379 (2020) 122248.

[17] Q. Zhang, J. Luan, L. Fu, S. Wu, Y. Tang, X. Ji, H. Wang, The three-dimensional dendritefree zinc anode on a copper mesh with a zinc-oriented polyacrylamide electrolyte additive, Angew. Chem. Int. Ed. 58 (2019) 15841-15847.

[18] Y. Zeng, X. Zhang, R. Qin, X. Liu, P. Fang, D. Zheng, Y. Tong, X. Lu, Dendrite-free zinc deposition induced by multifunctional cnt frameworks for stable flexible $\mathrm{zn}$-ion batteries, Adv. Mater. 31 (2019) 1903675.

[19] A. Bayaguud, X. Luo, Y. Fu, C. Zhu, Cationic surfactant-type electrolyte additive enables three-dimensional dendrite-free zinc anode for stable zinc-ion batteries, ACS Energy Lett. 5 (2020) 3012-3020.

[20] P. Liang, J. Yi, X. Liu, K. Wu, Z. Wang, J. Cui, Y. Liu, Y. Wang, Y. Xia, J. Zhang, Highly reversible zn anode enabled by controllable formation of nucleation sites for Zn-based batteries, Adv. Funct. Mater. 30 (2020) 1908528.

[21] Q. Zhang, J. Luan, X. Huang, Q. Wang, D. Sun, Y. Tang, X. Ji, H. Wang, Revealing the role of crystal orientation of protective layers for stable zinc anode, Nat. Commun. 11 (2020) 3961.

[22] Y. Jiao, F. Li, X. Jin, Q. Lei, L. Li, L. Wang, T. Ye, E. He, J. Wang, H. Chen, J. Lu, R. Gao, 
Q. Li, C. Jiang, J. Li, G. He, M. Liao, H. Zhang, I.P. Parkin, H. Peng, Y. Zhang, Engineering polymer glue towards $90 \%$ zinc utilization for 1000 hours to make high-performance $\mathrm{Zn}$ ion batteries, Adv. Funct. Mater. (2021). https://doi.org/10.1002/adfm.202107652.

[23] Z. Cao, X. Zhu, D. Xu, P. Dong, M.O.L. Chee, X. Li, K. Zhu, M. Ye, J. Shen, Eliminating Zn dendrites by commercial cyanoacrylate adhesive for zinc ion battery, Energy Storage Mater. 36 (2021) 132-138.

[24] J. Hao, X. Li, S. Zhang, F. Yang, X. Zeng, S. Zhang, G. Bo, C. Wang, Z. Guo, Designing dendrite-free zinc anodes for advanced aqueous zinc batteries, Adv. Funct. Mater. 30 (2020) 2001263.

[25] Y. Cui, Q. Zhao, X. Wu, X. Chen, J. Yang, Y. Wang, R. Qin, S. Ding, Y. Song, J. Wu, K. Yang, Z. Wang, Z. Mei, Z. Song, H. Wu, Z. Jiang, G. Qian, L. Yang, F. Pan, An interfacebridged organic-inorganic layer that suppresses dendrite formation and side reactions for ultra-long-life aqueous zinc metal anodes, angew. Chem. Int. Ed. 59 (2020) 16594-16601.

[26] Q. Zhang, J. Luan, Y. Tang, X. Ji, H. Wang, Interfacial design of dendrite-free zinc anodes for aqueous zinc-ion batteries, Angew. Chem. Int. Ed. 59 (2020) 13180-13191.

[27] R. Feng, X. Chi, Q. Qiu, J. Wu, J. Huang, J. Liu, Y. Liu, Cyclic ether-water hybrid electrolyte-guided dendrite-free lamellar zinc deposition by tuning the solvation structure for high-performance aqueous zinc-ion batteries, ACS Appl. Mater. Interfaces. 13 (2021) 40638-40647.

[28] P. Sun, L. Ma, W. Zhou, M. Qiu, Z. Wang, D. Chao, W. Mai, Simultaneous regulation on solvation shell and electrode interface for dendrite-free $\mathrm{Zn}$ ion batteries achieved by a lowcost glucose additive, Angew. Chem. Int. Ed. 60 (2021) 18247-18255.

[29] Y. Guo, K. Zheng, P. Wan, A flexible stretchable hydrogel electrolyte for healable all-inone configured supercapacitors, Small. 14 (2018) 1704497.

[30] S. Huang, F. Wan, S. Bi, J. Zhu, Z. Niu, J. Chen, A self-healing integrated all-in-one zincion battery, Angew. Chem. Int. Ed. 58 (2019) 4313-4317.

[31] A.A. Assegie, J.-H. Cheng, L.-M. Kuo, W.-N. Su, B.-J. Hwang, Polyethylene oxide film coating enhances lithium cycling efficiency of an anode-free lithium-metal battery, Nanoscale. 10 (2018) 6125-6138.

[32] Z. Li, W. Deng, C. Li, W. Wang, Z. Zhou, Y. Li, X. Yuan, J. Hu, M. Zhang, J. Zhu, W. Tang, X. Wang, R. Li, Uniformizing the electric field distribution and ion migration during 
zinc plating/stripping via a binary polymer blend artificial interphase, J. Mater. Chem. A. 8 (2020) 17725-17731.

[33] Y. Jin, K.S. Han, Y. Shao, M.L. Sushko, J. Xiao, H. Pan, J. Liu, Stabilizing zinc anode reactions by polyethylene oxide polymer in mild aqueous electrolytes, Adv. Funct. Mater. 30 (2020) 2003932.

[34] X. Wang, J. Meng, X. Lin, Y. Yang, S. Zhou, Y. Wang, A. Pan, Stable Zinc Metal Anodes with Textured Crystal Faces and Functional Zinc Compound Coatings, Adv. Funct. Mater. (2021) 2106114. https://doi.org/10.1002/adfm.202106114.

[35] T. Foroozan, V. Yurkiv, S. Sharifi-Asl, R. Rojaee, F. Mashayek, R. Shahbazian-Yassar, Non-dendritic Zn electrodeposition enabled by zincophilic graphene substrates, ACS Appl. Mater. Interfaces. 11 (2019) 44077-44089.

[36] J. Zheng, Q. Zhao, T. Tang, J. Yin, C.D. Quilty, G.D. Renderos, X. Liu, Y. Deng, L. Wang, D.C. Bock, C. Jaye, D. Zhang, E.S. Takeuchi, K.J. Takeuchi, A.C. Marschilok, L.A. Archer, Reversible epitaxial electrodeposition of metals in battery anodes, Science. 366 (2019) 645648.

[37] D. Yuan, J. Zhao, H. Ren, Y. Chen, R. Chua, E.T.J. Jie, Y. Cai, E. Edison, W. Manalastas Jr., M.W. Wong, M. Srinivasan, Anion texturing towards dendrite-free zn anode for aqueous rechargeable batteries, Angew. Chem. Int. Ed. 60 (2021) 7213-7219.

[38] S. Zhou, Y. Wang, H. Lu, Y. Zhang, C. Fu, I. Usman, Z. Liu, M. Feng, G. Fang, X. Cao, S. Liang, A. Pan, Anti-corrosive and Zn-ion-regulating composite interlayer enabling long-life zn metal anodes, Adv. Funct. Mater. (2021) https://doi.org/10.1002/adfm.202104361.

[39] J. Huang, X. Chi, Y. Du, Q. Qiu, Y. Liu, Ultrastable zinc anodes enabled by antidehydration ionic liquid polymer electrolyte for aqueous Zn batteries, ACS Appl. Mater. Interfaces. 13 (2021) 4008-4016.

[40] Z. Zhao, J. Zhao, Z. Hu, J. Li, J. Li, Y. Zhang, C. Wang, G. Cui, Long-life and deeply rechargeable aqueous $\mathrm{Zn}$ anodes enabled by a multifunctional brightener-inspired interphase, Energy Environ. Sci. 12 (2019) 1938-1949.

[41] J.C. Ballesteros, P. Díaz-Arista, Y. Meas, R. Ortega, G. Trejo, Zinc electrodeposition in the presence of polyethylene glycol 20000, Electrochim. Acta. 52 (2007) 3686-3696.

[42] N. Chang, T. Li, R. Li, S. Wang, Y. Yin, H. Zhang, X. Li, An aqueous hybrid electrolyte for low-temperature zinc-based energy storage devices, Energy Environ. Sci. 13 (2020) 
3527-3535.

[43] Y. Dong, L. Miao, G. Ma, S. Di, Y. Wang, L. Wang, J. Xu, N. Zhang, Non-concentrated aqueous electrolytes with organic solvent additives for stable zinc batteries, Chem. Sci. 12 (2021) 5843-5852.

[44] Y. Li, Z. Huang, P.K. Kalambate, Y. Zhong, Z. Huang, M. Xie, Y. Shen, Y. Huang, $\mathrm{V}_{2} \mathrm{O}_{5}$ nanopaper as a cathode material with high capacity and long cycle life for rechargeable aqueous zinc-ion battery, Nano Energy. 60 (2019) 752-759. 


\section{Chapter 6: Conclusions}

The rechargeable aqueous ZIBs in mildly acidic electrolytes have emerged as promising largescale energy storage systems owing to their low cost, high safety, and environmental benignity. However, the existing aqueous ZIBs are far from satisfying the requirements of practical applications. Significant challenges hindering the further development of ZIBs come from the limited utilization and poor cycling stability of cathodes and limited reversibility of $\mathrm{Zn}$ anodes associated with dendrite growth, corrosion, and passivation. In this doctoral thesis, recent progress on the aqueous rechargeable ZIBs with mildly acidic electrolytes has been comprehensively reviewed, which includes the efficient modification of cathode materials, in-depth understanding of the reported charge storage mechanisms, electrolyte optimization, and $\mathrm{Zn}$ metal anode protection. Regarding the main issues of ZIBs, this research work covered both the cathode and anode to comprehensively improve the electrochemical performance of ZIBs (Figure 6.1).

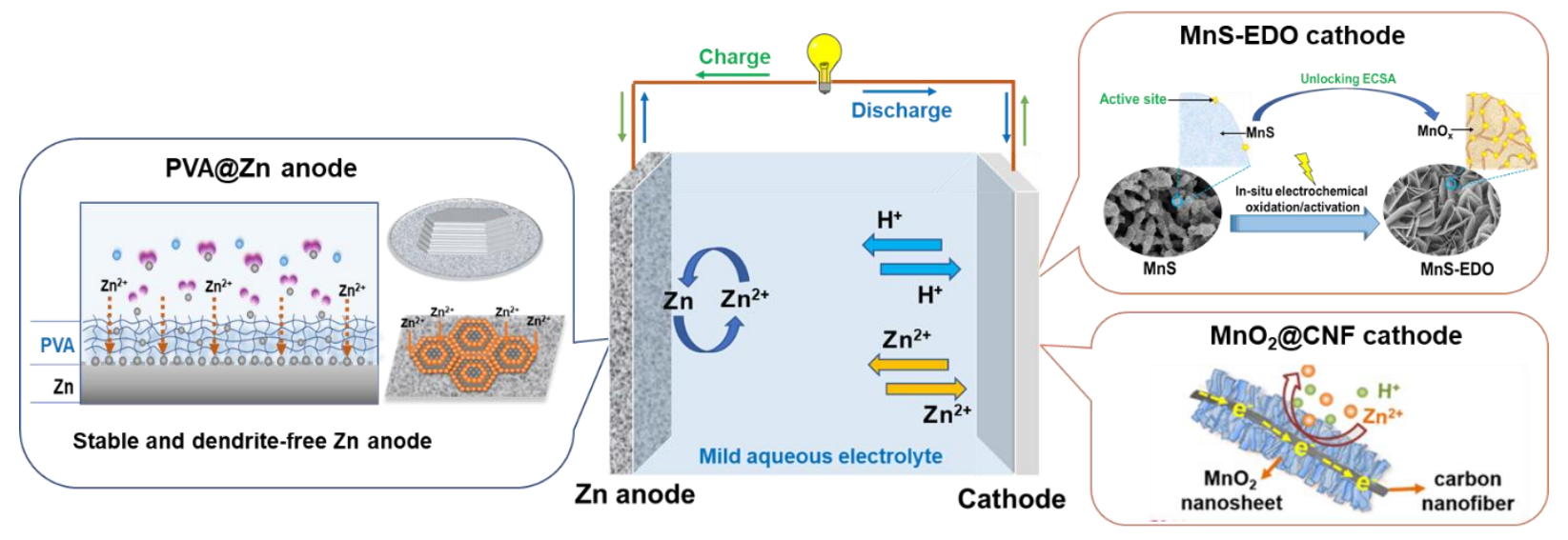

Figure 6. 1 Schematic summary of the dissertation work that covers the study on both the anode and the cathode of aqueous rechargeable ZIBs.

In the first case of cathode, an in situ electrochemical activation approach was adopted to oxidize MnS into highly active MnS-EDO, unlocking its potential as high-performance cathodes for ZIBs. Featuring fragmented layers with abundant defects, MnS-EDO enabled large ECSA, high electrochemical reactivity, fast ion diffusion kinetics, accelerated charge transfer and exceptional structural robustness during cycling compared to $\alpha-\mathrm{MnO}_{2}$. Consequently, $\mathrm{MnS}-\mathrm{EDO}$ exhibited a specific capacity of $335.7 \mathrm{mAh} \mathrm{g}^{-1}$ with $\sim 100 \%$ capacity retention after 100 cycles at $0.3 \mathrm{~A} \mathrm{~g}^{-1}$, outstanding rate capability and long-term stability retaining $104 \mathrm{mAh} \mathrm{g}^{-1}$ after 4000 
cycles at $3 \mathrm{~A} \mathrm{~g} \mathrm{~g}^{-1}$. Remarkably, this work elucidated the underlying electrochemical insights and a hybrid discharge mechanism involving homogeneous $\mathrm{Zn}^{2+}$ intercalation at $\sim 1.4 \mathrm{~V}$ and subsequent heterogeneous reactions of insertion of both $\mathrm{H}^{+}$and $\mathrm{Zn}^{2+}$ at $\sim 1.25 \mathrm{~V}$. Moreover, the ambiguities among $\mathrm{Zn}$ buserite, birnessite and zinc hydroxide sulfate were clarified.

In the second case of cathode, the hierarchical core-shell $\mathrm{CNF} @ \mathrm{MnO}_{2}$ nanowires were synthesized by using a facile, controllable and scalable approach combining simple grinding and low-temperature wet-chemical reaction. A synergistic effect was demonstrated for the $\mathrm{CNF} @ \mathrm{MnO}_{2}$ cathode, in which the conductive CNF backbone significantly boosted the electron transfer kinetics, while ultrathin $\mathrm{MnO}_{2}$ nanosheets provided large electrode/electrolyte interfacial contact areas and facilitated the ionic diffusion. Additionally, the intimate contact between CNFs and $\mathrm{MnO}_{2}$ synergistically rendered an interconnected network with high electronic and ionic conductivity and flexibility to minimize structural collapse and strain of volume variation upon cycling. The favorable synergistic effect ensured the high capacity, long shelf life, enhanced rate capability and extraordinary cycling stability of $\mathrm{CNF} @ \mathrm{MnO}_{2}$. It delivered a high capacity of 221 $\mathrm{mAh} \mathrm{g}^{-1}$ after 700 cycles at $200 \mathrm{~mA} \mathrm{~g}^{-1}$. Even at $3000 \mathrm{~mA} \mathrm{~g}^{-1}$, it still maintained $130 \mathrm{mAh} \mathrm{g}^{-1}$ after 2750 cycles without obvious capacity decay. Featuring the exceptional electrochemical performance, rational design for synergy and low-cost manufacturing, the developed CNF@ $\mathrm{MnO}_{2}$ cathode is promising for cost-efficient and high-performance ZIBs.

With respect to Zn anode, a thin polyvinyl alcohol (PVA) coating layer on Zn anode has enabled dendrite-free, long-life aqueous $\mathrm{Zn}$ batteries by effectively regulating the interfacial ion diffusion and inducing the homogeneous $\mathrm{Zn}$ nucleation and deposition of stacked plates with preferentially crystallographic orientation along (002)Zn planes. The PVA@Zn anode achieved ultralong cycle lifespan of thousands of hours at 0.25 and $1 \mathrm{~mA} \mathrm{~cm}^{-2}$. The coated anodes also demonstrated outstanding durability under a deep cycling capacity $\left(5 \mathrm{mAh} \mathrm{cm}{ }^{-2}\right)$, high current density $(10 \mathrm{~mA}$ $\mathrm{cm}^{-2}$ ) and long duration conditions. The superior cyclability of PVA@Zn anode was also demonstrated in PVA@ $\mathrm{Zn} / / \mathrm{V}_{2} \mathrm{O}_{5}$ full cells. This work provided a facile polymer coating approach to stabilizing Zn electrochemistry. The insights of PVA induced epitaxial deposition of Zn with preferred crystal orientation and interfacial regulation shed light on the future development of highly stable $\mathrm{Zn}$ anodes. 


\section{Chapter 7: Challenges and Perspectives}

In this doctoral thesis, we provide a broad overview of the recent advances on aqueous ZIBs with mild electrolyte. Although substantial progress has been achieved in aqueous ZIB during the past decade, yet the state-of-the-art aqueous ZIB technology is still far from satisfactory for the further large-scale applications. There is still much scope for the further development of highperformance ZIBs. In view of this, we here offer our candid viewpoints regarding the challenges and perspectives concerning the future development of ZIBs towards practical application according to the following aspects.

Controversial electrochemical reaction mechanisms. The electrochemical reactions associated with charge storage mechanisms of ZIBs remain debating, especially for the manganese-based cathodes. To date, the charge storage mechanisms of mild aqueous ZIBs have evolved from pure $\mathrm{Zn}^{2+}$ intercalation to $\mathrm{H}^{+}$related conversion reaction, mixed $\mathrm{Zn}^{2+} / \mathrm{H}^{+}$co-intercalation and the recently reported dissolution/deposition mechanism. The lack of rigorous characterization techniques might lead to ambiguities in the understanding of reaction mechanisms, which brings about the misleading design of electrode material towards high-performance ZIBs. Therefore, an in-depth mechanistic understanding with the assistance of rigorous protocols and multiple advanced characterization technologies is urgently required. Further, a combination of diverse experimental approaches with the simulation and theoretical calculations is highly needed to provide a comprehensive insight into the energy storage mechanism of aqueous ZIBs. These investigations not only enable a thorough understanding of the electrochemical determinants of the battery performance but also guide the strategies for optimized electrode construction and cell design.

Cathode engineering for efficient transport kinetics. It remains a challenge to develop advanced cathode materials that possess both high capacity and exceptional structural stability upon long-term cycling. It requires more efforts to clearly understand the effectiveness of structural engineering strategies for cathode material modification. The rational design of cathode architecture with efficient transport kinetics inside the electrode is critical for cathode performance optimization. The reduced transport length and enriched transport pathway in nanostructured electrode material benefit for enhancing charge accessibility and achieving high power/energy 
density. 3D printing technology has been reported as a promising method to fabricate 3D electrodes, which enables controlled fabrication of electrode with predesigned microstructure and optimized surface area for maximum active material utilization. This technology may develop 3D electrode architectures with high mass loading that still possess efficient ion diffusion to ensure capacitive performance without sacrificing gravimetric and volumetric capacities, which holds exceptional potential for future industrial application of ZIBs.

Towards highly reversible $\mathrm{Zn}$ anode. The electrochemical property of zinc anode is still far from the requirements of practical applications, especially for the high-energy density and costeffective ZIBs. On the one hand, Zn anodes with mild electrolytes are still challenged by common issues associated with the aqueous solution, such as dendrite growth, corrosion, low CE, and surface passivation. Many strategies have been developed to improve $\mathrm{Zn}$ anode reversibility, including electrolyte optimization, tailoring $\mathrm{Zn}$ electrode structures (high surface area, constructing 3D electrode), and electrode surface modification (surface coating, Zn alloying). On the other hand, most reported ZIBs directly use commercial Zn plate as the $\mathrm{Zn}$ anode, the highly excessive $\mathrm{Zn}$ might compensate for negative effects from the metallic $\mathrm{Zn}$ anode on the overall battery performance. Regarding the practical applications that aim to construct high energy density ZIBs, the weight and volume $\mathrm{Zn}$ anode must be taken into consideration.

In-depth understanding of electrolytes compatibility. In many reported ZIBs which consisted of a $\mathrm{Zn}$ metal anode and prepared cathode, the full cell electrochemical performance has been demonstrated that highly related to the applied electrolyte. The fundamental investigations on the relationship between electrolytes (with key parameters, such as zinc salts, additives, solvents, and $\mathrm{pH}$ ) and electrochemical performance are still in their infancy. Therefore, an in-depth understanding of electrolyte compatibility is of great importance for future development of highperformance ZIBs. The electrode/electrolyte interfaces at both the cathode side and anode side should be taken into consideration for electrolyte adjustment. In addition to developing highcapacity electrode materials, electrolyte regulation provides another effective approach to improving the battery energy density. 